\title{
Shrinkage and strength characterizations of concrete containing supplementary cementing materials
}

Aniruddha Chatterjee

West Virginia University

Follow this and additional works at: https://researchrepository.wvu.edu/etd

\section{Recommended Citation}

Chatterjee, Aniruddha, "Shrinkage and strength characterizations of concrete containing supplementary cementing materials" (2004). Graduate Theses, Dissertations, and Problem Reports. 1879.

https://researchrepository.wvu.edu/etd/1879

This Thesis is protected by copyright and/or related rights. It has been brought to you by the The Research Repository @ WVU with permission from the rights-holder(s). You are free to use this Thesis in any way that is permitted by the copyright and related rights legislation that applies to your use. For other uses you must obtain permission from the rights-holder(s) directly, unless additional rights are indicated by a Creative Commons license in the record and/ or on the work itself. This Thesis has been accepted for inclusion in WVU Graduate Theses, Dissertations, and Problem Reports collection by an authorized administrator of The Research Repository @ WVU. For more information, please contact researchrepository@mail.wvu.edu. 


\title{
Shrinkage and Strength Characterizations of Concrete Containing Supplementary Cementing Materials
}

\author{
Aniruddha Chatterjee \\ Thesis submitted to the College of Engineering and Mineral Resources \\ at West Virginia University \\ in partial fulfillment of the requirements \\ for the degree of \\ Master of Science
in \\ Civil Engineering \\ Indrajit Ray, Ph.D., Chair \\ Julio. F. Davalos, Ph.D., Co-Chair \\ Xingbo Liu, Ph.D.
}

Department of Civil and Environmental Engineering

Morgantown, West Virginia

2004

Keywords: HPC, C-S-H gel, Shrinkage, Strength, Model, ACI

Copyright 2004 Aniruddha Chatterjee 


\section{ABSTRACT \\ Shrinkage and Strength Characterizations of Concrete Containing Supplementary Cementing Materials}

\section{Aniruddha Chatterjee}

High Performance Concrete (HPC) is being implemented in many civil engineering structures to improve durability and long-term performance. HPC often includes supplementary cementing materials such as slag, fly ash and silica fume. But inclusion of these materials to concrete changes the fresh as well as hardened concrete properties. Considerable differences in drying shrinkage strains and compressive strengths are observed in HPC containing supplementary cementing material from normal concrete (without any supplementary cementing material). The differences in these properties occur due to different kinetics of hydration and hydrated structures resulting from replacement of cement by supplementary cementing material. As a consequence, the quantity and microstructure of the calcium silicate hydrate gel (C-S-H gel / the principal component of hydrated cement paste) for HPC containing supplementary cementing material differs significantly from that of normal concrete. This limits the application to HPC of standard prediction equations for shrinkage and strength of normal concrete.

Therefore in this study a novel technique has been used to estimate the C-S-H gel for cement pastes containing supplementary cementing material in varying replacement proportions and combinations. Both binary and ternary mixtures have been included in the study. This data is used to establish gel-time relationship of all the combinations. Based on these results, the present ACI equation which is currently based on concrete without supplementary cementing material, was modified to propose a new equation for each group of HPC. The proposed model is calibrated with the experimental results of concrete made with similar supplementary cementing material and water-cementitious material ratio. The shrinkage and strength data generated in a separate research on HPC to be used for WVDOH bridge decks and other published data have been compared with the proposed model.

Results show that shrinkage for both binary and ternary mixtures at early age ( 0 to 40 days of drying) depends on C-S-H gel formation, whereas at later age (up to 90 days), the shrinkage depends on replacement levels of supplementary cementing materials. For strength, however, C-S-H gel is the only influencing factor throughout 90 days.

Keywords: HPC, C-S-H gel, Shrinkage, Strength, Model, ACI 


\section{Acknowledgement}

I would like to take the opportunity to express my sincere gratitude to my advisor Dr. Julio F. Davalos who provided me with the opportunity to work on this interesting project. I was fortunate to have him as my teacher and advisor. His brilliant ideas, support and encouragement are among the many valuable things that I have come across during my two years of M.S. program at West Virginia University.

My sincere appreciation and respect goes to Dr. Indrajit Ray, who provided the research topic and invaluable advices all along the project. His excellent knowledge on Concrete Technology was important for every step of this project. Through continuous encouragement, support, advice and valuable suggestions for writing the thesis he had made my task easier. I was extremely fortunate to have Dr. Davalos and Dr. Ray as my advisors.

I would like to convey my sincere thanks to Dr. Xingbo Liu who served as the member of my committee and provided me with valuable technical suggestions.

Also I would like to thank Dayong Fan, Zhiguo Gong for helping me in the laboratory with concreting and associated tasks. My sincere appreciation goes to David Turner and Doug Cutlip for the technical help they have provided me in the concrete laboratory.

I gratefully acknowledge the financial support provided by West Virginia Department of Transportation - Division of Highways. I also acknowledge Arrow Concrete Company, Master Builders Inc. and other suppliers for generously supplying the materials.

I would like to dedicate this work to my wife Abanti. Without her continuous support and help it would have been hard to finish this work. 


\section{Table of Contents}

Abstract

Acknowledgement

ii

Table of Contents

iii

List of Tables

iv

List of Figures

Chapter 1 Introduction

1.1 Research Background

1.2 Global Research Objective

1.3 Present Research Plan and Task

1.4 Thesis Organization

Chapter 2 Background and Literature Review

2.1 Overview of Concrete Microstructure 4

$\begin{array}{ll}2.2 \text { Shrinkage } & 12\end{array}$

2.3 Synthesis from Literature Review 38

$\begin{array}{lll}2.4 & \text { Research Significance } & 39\end{array}$

$\begin{array}{llr}\text { Chapter } 3 \quad \text { Materials } & 40\end{array}$

$\begin{array}{llr}3.1 \text { Cement } & 40\end{array}$

$\begin{array}{ll}3.2 & \text { Coarse Aggregate }\end{array}$

3.3 Fine Aggregate 41

3.4 Supplementary Cementing Materials $\quad 42$

3.5 Chemical Admixture 43

$\begin{array}{lll}3.6 & \text { Water } & 44\end{array}$

3.7 Mixture Proportioning 44

3.8 Mixing Procedure $\quad 45$

3.9 Curing 46

$\begin{array}{lll}\text { Chapter } 4 \quad \text { Estimation of C-S-H gel } & 47\end{array}$

$\begin{array}{lll}4.1 & \text { Introduction } & 47\end{array}$

4.2 Method of Estimation 47

4.3 Theory for C-S-H Estimation $\quad 50$

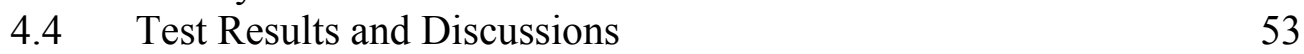

$\begin{array}{lll}4.5 & \text { Summary of Discussions } & 60\end{array}$

$\begin{array}{lll}\text { Chapter } 5 & \text { Shrinkage and Prediction Equation } & 62\end{array}$

5.1 Introduction $\quad 62$

$\begin{array}{lll}5.2 & \text { Test Procedure } & 62\end{array}$

5.3 Comparison of Models with Shrinkage Data 63 
5.4 Proposed Model 67

5.5 Testing the Model with Data from Other Sources 82

$\begin{array}{lll}\text { Chapter } 6 & \text { Compressive Strength } & 89\end{array}$

6.1 Introduction 89

6.2 Compressive Strength Measurement 89

6.3 ACI Prediction Equation for Compressive Strength 89

6.4 Test Results and Discussions 90

6.5 Proposed Model 96

6.6 Validation of the Proposed Model 106

$\begin{array}{lll}\text { Chapter } 7 & \text { Conclusions } & 109\end{array}$

7.1 C-S-H gel Estimation 109

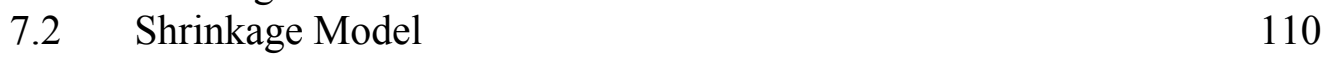

7.3 Compressive Strength Model 111

$\begin{array}{ll}\text { Bilbliography } & 112\end{array}$

$\begin{array}{ll}\text { Appendix A: Shrinkage Data for Different Mixtures } & 119\end{array}$

Appendix B: C-S-H gel Formation (semi-log plot) 120

Appendix C: Results of C-S-H gel Estimation 132

Appendix D: Compressive Strength of Various Mixtures for 90 Days 133 


\section{List of Tables}

Table 2.1 - Correction for $\gamma_{c p}$

Table 2.2 - Correction factors for average thickness of method of members less than $150 \mathrm{~mm} 22$

Table 2.3 - Coefficients in equation (2.58) 33

Table 2.4 - Coefficients in equation (2.61) 34

Table 2.5 - Calibration of the time function for different models for ACI, CEB, B3 and GL 37

Table 2.6 - Calibration of the ultimate shrinkage strains for different time functions 37

Table 2.7 - Modification of CEB time function 38

Table 3.1 - Physical properties of type I portland cement used $\quad 40$

Table 3.2 - Compound compositions of portland cement 40

Table 3.3 - Properties of coarse aggregates $\quad 41$

Table 3.4 - Sieve analysis result $\quad 41$

Table 3.5- Properties of fine aggregate $\quad 42$

Table 3.6 - Sieve analysis of sand $\quad 42$

Table 3.7- Properties of slag 43

Table 3.8- Mixture proportioning 45

Table 4.1 - Typical calculation for C-S-H gel estimation 53

Table 5.1 - Coefficient of Variation of different models with respect to drying shrinkage data control concrete $\quad 64$

Table 5.2 - Coefficient of Variation of different models with respect to drying shrinkage data for $\begin{array}{ll}15 \% \text { fly ash concrete } & 65\end{array}$

Table 5.3 - Table for A \& B $\quad 71$

Table 5.4 - Coefficient of variation of the test data with the proposed model 88

Table 6.1 - Co-efficient for the proposed model 97

Table 6.2 - Comparison of the ACI model and the proposed model for compressive strength 105

Table 6.3 - Comparison of the ACI model and the proposed model on data obtained from other source

108 


\section{List of Figures}

Fig 2.1- Powers Model for C-S-H

Fig 2.2 - Feldman-Sereda Model $\quad 8$

Fig 2.3 - Munich Model $\quad 8$

Fig 2.4 - Tokyo Model 9

Fig 2.5 - J-T Model $\quad 10$

Fig 2.6 - Jennings Model (Courtesy: Jennings 2000) 11

Fig. 4.1- D-drying in progress 48

Fig. 4.2 - Constant relative humidity chamber 49

Fig 4.3 - Humidity controller 49

Fig 4.4 - A four place of decimal balance used for weight measurement placed within the RH chamber $\quad 50$

Fig 4.5 - D-dried samples kept within the RH chamber for water adsorption 50

Fig 4.6 - (a) Before D-drying microstructure of C-S-H gel (b) after D-drying microstructure of C$\mathrm{S}-\mathrm{H}$ gel (c) microstructure of $\mathrm{C}-\mathrm{S}-\mathrm{H}$ gel at $11 \% \mathrm{RH}$ with water entering interlayer spaces and monolayer water adsorbed (d) microstructure of C-S-H gel at a $\mathrm{RH}>11 \% \mathrm{RH}$ (with multilayer adsorption) and amount of water adsorbed is proportional to $\mathrm{RH}$ in the range $11 \%-50 \% \mathrm{RH} \quad 52$ Fig. 4.7 - (a) Formation of C-S-H gel up to 90 days for different amount of replacement by slag (b) formation of C-S-H gel up to 90 days for different amount of replacement by fly ash $\quad 54$ Fig. 4.8 - (a) Formation of C-S-H gel up to 90 days for different amount of replacement by silica fume (b) formation of C-S-H gel up to 90 days for different amount of replacement by slag $25 \%$ + silica fume $5 \%$

Fig. 4.9 - (a) Formation of C-S-H gel up to 90 days for different amount of replacement by slag $25 \%+$ silica fume $10 \%$ (b) formation of C-S-H gel up to 90 days for different amount of replacement by slag 35\% + silica fume 5\% 55

Fig. 4.10 - (a) Formation of C-S-H gel up to 90 days for different amount of replacement by slag $35 \%+$ silica fume $10 \%$ (b) formation of C-S-H gel up to 90 days for different amount of replacement by slag $35 \%+$ silica fume $15 \%$

Fig. 4.11 - (a) Formation of C-S-H gel up to 90 days for different amount of replacement by slag $45 \%+$ silica fume $10 \%$ (b) formation of C-S-H gel up to 90 days for different amount of replacement by fly ash $15 \%+$ silica fume $15 \%$ 
Fig. 4.12 - (a) Formation of C-S-H gel up to 90 days for different amount of replacement by fly ash $25 \%+$ silica fume $5 \%$ (b) formation of C-S-H gel up to 90 days for different amount of replacement by fly ash $25 \%+$ silica fume $10 \%$

Fig. 4.13 - (a) Formation of C-S-H gel up to 90 days for different amount of replacement by fly ash $35 \%+$ silica fume $5 \%$ (b) formation of C-S-H gel up to 90 days for different amount of replacement by fly ash $35 \%+$ silica fume $10 \%$

Fig. 4.14 - (a) Formation of C-S-H gel up to 90 days for different amount of replacement by fly ash $35 \%+$ silica fume $15 \%$ (b) formation of C-S-H gel up to 90 days for different amount of replacement by slag $25 \%+$ fly ash $15 \%$

Fig 4.15 - Formation of C-S-H gel up to 90 days for different amount of replacement by slag $35 \%$

+ fly ash $15 \%$

Fig 5.1 - Free shrinkage test in progress 63

Fig 5.2 - Storage of shrinkage specimens 63

Fig 5.3 -Environmental chamber

Fig. 5.4 - Comparison of few models with obtained test results for drying shrinkage for control concrete with $\mathrm{w} / \mathrm{cm}=0.4$ and $0 \%$ replacement

Fig. 5.5 - Comparison of few models with obtained test results for drying shrinkage for control concrete with $\mathrm{w} / \mathrm{cm}=0.4$ and $15 \%$ fly ash replacement 65

Fig. 5.6 - (a) Residual plot of the ACI model (b) Residual plot of the CEB model 66

Fig. 5.7 - (a) Residual plot of the Huo et al. model (b) Residual plot of the GL model 66 Fig. 5.8 - Typical C-S-H formation for cement paste with $0 \%$ replacement plotted in log scale (best fit) equation

Fig. 5.9 - Comparison of the proposed model and few common prediction models with shrinkage data for normal concrete $(0 \%$ replacement)

Fig. 5.10 - Comparison of the proposed model and few prediction models with shrinkage data for concrete containing $25 \%$ slag by mass

Fig. 5.11 - Comparison of the proposed model and common prediction models with shrinkage data for concrete containing (a) 35\% slag by mass (b) $45 \%$ slag by mass

Fig. 5.12 - Comparison of the proposed model and common prediction models with shrinkage data for concrete containing (a) $15 \%$ fly ash by mass (b) $25 \%$ fly ash by mass

Fig. 5.13-Comparison of the proposed model and common prediction models with shrinkage data for concrete containing (a) $35 \%$ fly ash by mass (b) $5 \%$ silica fume by mass

Fig. 5.14- Comparison of the proposed model and common prediction models with shrinkage data for concrete containing (a) $10 \%$ silica fume by mass (b) $15 \%$ silica fume by mass 78 
Fig. 5.15- Comparison of the proposed model and common prediction models with shrinkage data for concrete containing (a) $25 \%$ slag $+5 \%$ silica fume by mass (b) $25 \%$ slag $+10 \%$ silica fume by mass

Fig. 5.16- Comparison of the proposed model and6 common prediction models with shrinkage data for concrete containing (a) $35 \%$ slag $+5 \%$ silica fume by mass (b) $35 \%$ slag $+10 \%$ silica fume by mass

Fig. 5.17- Comparison of the proposed model and common prediction models with shrinkage data for concrete containing (a) $35 \%$ slag $+15 \%$ silica fume by mass (b) $45 \%$ slag $+5 \%$ silica fume by mass

Fig. 5.18- Comparison of the proposed model and common prediction models with shrinkage data for concrete containing (a) $15 \%$ fly ash $+5 \%$ silica fume by mass (b) $25 \%$ fly ash $+5 \%$ silica fume by mass

Fig. 5.19- Comparison of the proposed model and few common prediction models with shrinkage data for concrete containing (a) $25 \%$ fly ash $+10 \%$ silica fume by mass (b) $35 \%$ fly ash $+5 \%$ silica fume by mass

Fig. 5.20- Comparison of the proposed model and common prediction models with shrinkage data for concrete containing (a) $35 \%$ fly ash $+10 \%$ silica fume by mass (b) $35 \%$ fly ash $+5 \%$ silica fume by mass

Fig. 5.21- Comparison of the proposed model and common prediction models with shrinkage data for concrete containing (a) $25 \%$ slag $+15 \%$ fly ash by mass (b) $35 \%$ slag $+15 \%$ fly ash by mass

Fig. 5.22- Residual plot of the proposed model

Fig. 5.23 - Comparison of the model with data obtained for mixtures in a separate research for WVDOH by Gong, 2004 (a) fly ash 20\% + silica Fume 5\% concrete (b) slag 30\% + silica fume $5 \%$ concrete

Fig. 5.24 - Residuals of the proposed model for the data obtained by Gong et al. 2004

Fig. 5.25 - Comparison of the model with data obtained for mixtures in research for WVDOH by Zhang, 2001 (a) fly ash $20 \%+$ silica fume $5 \%$ concrete (b) fly ash $15 \%+$ silica fume $5 \%$ concrete

Fig. 5.26 - Comparison of the model with data obtained for mixtures in research for WVDOH by Zhang, 2001 (a) fly ash 25\% + silica fume 5\% concrete (b) slag 25\% + silica fume 5\%

Fig. 5.27 - Comparison of the model with data obtained for mixtures in research for WVDOH by Zhang, 2001 (a) Slag 30\% + silica fume 5\% concrete (b) slag 35\% + silica fume 5\% concrete 
Fig. 5.28 - Residuals of the proposed model for the data obtained by Zhang, 2001

Fig. 5.29 - Comparison of the model with data obtained in research for WVDOH by Morris, 2002

(a) fly ash $20 \%+$ silica Fume 5\% concrete (b) corresponding residuals

Fig. 5.30 - Comparison of the model with data obtained for mixtures in research for VDOT by Mokarem, 2002 at Virginia Tech. (a) slag 40\% + silica Fume 5\% concrete (b) silica Fume 7\% concrete

Fig. 5.31 - Comparison of the model with data obtained for mixtures in research for VDOT by Mokare 2002 at Virginia Tech. (a) fly ash $20 \%+$ silica fume 5\% concrete

Fig. 5.33 - Residuals of the proposed model for the data obtained by Mokarem, 2002

Fig 6.1 - (a) Compressive strength of concretes with different slag replacements (b) C-S-H gel formation in slag replaced cement pastes

Fig 6.2 - (a) Compressive strength of concretes with different fly ash replacements (b) C-S-H gel formation for fly ash replaced cement pastes

Fig 6.3 - (a) Compressive strength of concretes with different silica fume replacements (b) C-S-H gel formation for silica fume replaced cement pastes

Fig 6.4 - (a) Compressive strength of concretes with different slag and silica fume replacements (b) C-S-H gel formation for slag and silica fume replaced cement pastes

Fig 6.5 - (a) Compressive strength of concretes with different slag and silica fume replacements (b) C-S-H gel formation for slag and silica fume replaced cement pastes

Fig 6.6 - (a) Compressive strength of concretes with different fly ash and silica fume replacements (b) C-S-H gel formation for fly ash and silica fume replaced cement pastes

Fig 6.7 - (a) Compressive strength of concretes with different fly ash and silica fume replacements (b) C-S-H gel formation for fly ash and silica fume replaced cement pastes

Fig 6.8 (a) Compressive strength of concretes with different slag and fly ash replacements (b) CS-H gel formation for slag and fly ash replaced cement pastes

Fig - 6.9 Gel-Strength relationship

Fig 6.10 - Comparison of ACI model and proposed model for compressive strength for normal concrete

Fig 6.11 - Comparison of ACI model and proposed model for compressive strength (a) slag 25\% by mass (b) slag $35 \%$ by mass

Fig 6.12 - Comparison of ACI model and proposed model for compressive strength (a) slag 45\% by mass (b) fly ash $15 \%$ by mass

Fig 6.13 - Comparison of ACI model and proposed model for compressive strength (a) fly ash $25 \%$ by mass (b) fly ash $35 \%$ by mass 
Fig 6.14 - Comparison of ACI model and proposed model for compressive strength (a) silica fume $5 \%$ by mass (b) silica fume $10 \%$ by mass

Fig 6.15 - Comparison of ACI model and proposed model for compressive strength (a) silica fume $10 \%$ by mass (b) ) slag $25 \%+$ silica fume $5 \%$ by mass

Fig 6.16 - Comparison of ACI model and proposed model for compressive strength (a) slag 25\% + silica fume $10 \%$ by mass (b) slag $35 \%+$ silica fume $5 \%$ by mass

Fig. 6.17 - Comparison of ACI model and proposed model for compressive strength (a) slag 35\% + silica fume $10 \%$ by mass (b) slag $35 \%$ + silica fume $15 \%$ by mass

Fig 6.18 - Comparison of ACI model and proposed model for compressive strength (a) slag 45\% + silica fume $5 \%$ by mass (b) fly ash $15 \%+$ silica fume $5 \%$

Fig 6.19 - Comparison of ACI model and proposed model for compressive strength (a) fly ash $15 \%+$ silica fume $5 \%$ (b) fly ash $15 \%+$ silica fume $5 \%$

Fig 6.20 - Comparison of ACI model and proposed model for compressive strength (a) fly ash $15 \%+$ silica fume $5 \%$ (b) fly ash $15 \%+$ silica fume $5 \%$

Fig 6.21 - Comparison of ACI model and proposed model for compressive strength (a) fly ash $15 \%+$ silica fume $5 \%$ (b) slag $25 \%+$ fly ash $15 \%$

Fig 6.22 - Comparison of ACI model and proposed model for compressive strength (a) slag 35\% + fly ash $15 \%$

Figure 6.23 - (a) Residual plot for ACI equation for compressive strength with data obtained from laboratory (b) residual plot for proposed model for compressive strength with data obtained from laboratory

Fig. 6.24 - Comparison of the ACI and the proposed model with data obtained from Neville (1996) for fly ash $25 \%$ concrete (b) for silica fume $10 \%$ concrete (c) for slag $40 \%+$ silica Fume $10 \%$ concrete

Fig. 6.25 - Comparison of the ACI and the Proposed model with data obtained in a current project of WVDOH at WVU (a) for fly ash $25 \%$ + silica fume $10 \%$ concrete (b) for slag $30 \%+$ silica fume $10 \%$ concrete

Fig. 6.26 - Residuals of the ACI model and the proposed models with respect to the data obtained from Neville (1996) and Gong et al. (2004) 


\section{Chapter 1}

\section{Introduction}

\subsection{Research Background}

Concrete is the most predominant construction material. The reasons behind its popularity can be observed from its durability, versatility and economy. In U.S. about 260 million cubic meters (340 million cubic yards) of ready mixed concrete is used each year. Concrete is being used everywhere starting from highways, pavements, bridges, parking garages to high rise buildings dams, homes, floors and numerous other applications. High performance concrete (HPC) as mentioned by ACI (Russell 1999) "is a type of concrete that meets special combinations of performance and uniform requirements that cannot always be achieved routinely using conventional constituents and normal mixing, placing and practices". High performance concrete is not limited to cement as the only cementing material. Quite often supplementary cementing material such as ground granulated blast furnace slag, fly ash, silica fume, metakaolin are used to enhance the durability and strength. They are used either as binary mixture (containing cement and one kind of supplementary cementing materials) or ternary mixture (containing cement and two kinds of supplementary cementing materials). Therefore it is extremely important to know the effect of supplementary cementing materials on fresh and hardened properties of concrete.

\subsection{Global Research Objective}

Several studies have been conducted by previous authors on the effect of supplementary cementing materials on concrete properties. Among the hardened concrete properties the compressive strength and drying shrinkage are considered very important in addition to creep, tensile strength and fracture properties. Compressive strength is generally the controlling factor for design but drying shrinkage is equally important for

its effect on durability and serviceability of structures. There exists different methods of 
estimating these properties (compressive strength and shrinkage) with respect to time but most of the relationships are established for normal concretes containing cement only. This present study will focus on the variation of compressive strength and shrinkage of HPC due to inclusion of supplementary cementing materials. It will check the validity of the commonly used prediction models of strength and shrinkage, and propose a new model which may be used for design purposes.

\subsection{Present Research Plan and Task}

To study the effects of supplementary cementing materials addition on shrinkage and compressive strength an investigation has been done on the reactivity of the supplementary cementing materials. The reactivity of supplementary cementing materials can be measured through the formation of C-S-H (Calcium Silicate Hydrate gel the main cementing component in concrete) gel. An estimation of C-S-H gel with respect to time can provide a reasonable estimate to their reactivity.

So $\mathrm{C}-\mathrm{S}-\mathrm{H}$ formation has been taken as the basis to describe the differences in concrete drying shrinkage and compressive strength of HPC containing supplementary cementing materials from that of ordinary concrete. In the global context the research significance can be outlined as -

1. To investigate the role of supplementary cementing materials on the strength and shrinkage properties

2. To study the reactivity of supplementary cementing materials both as ternary and binary mixtures

3. To investigate existing prediction models for drying shrinkage and their need for modification to include the effects of supplementary cementing materials

4. To develop prediction equation for shrinkage and strength which will include the effects due of supplementary cementing materials addition

5. Finally the equations can be used to predict long-tem shrinkage and strength of HPC mixtures prepared with various supplementary cementing materials 
The research plan can be outlined in the following way -

1. Review of literature on microstructure of concrete and its relation to shrinkage

2. Review on shrinkage and present prediction models

3. Estimation of reactivity of supplementary cementing materials in binary and ternary mixtures through estimation of C-S-H gel

4. Comparison of drying shrinkage and strength of different mixtures containing different proportion of supplementary cementing materials

5. Correlation of the results of C-S-H gel estimation and the measured shrinkage and strength for different mixtures qualitatively

6. Comparison of the existing models of shrinkage and strength prediction with the experimental results

7. Inclusion of the effect of C-S-H gel formation to the prediction models to come with a better prediction method for shrinkage of HPCs containing supplementary cementing materials

8. Suggestion of some aspect of durability from the results of C-S-H estimation and recommendations for further study

\subsection{Thesis Organization}

A description of concrete microstructure, drying shrinkage and the mechanisms behind it, shrinkage prediction models and effect of supplementary cementing materials on shrinkage has been included in chapter 2. Chapter 3 provides information on the materials and the mixture proportions used in the study. Chapter 4 outlines the method of estimation of C-S-H gel and discussion, on the results. Chapter 5 and 6 presents the development of prediction models for shrinkage and compressive strength, respectively from corresponding experimental data. Concluding remarks on the research have been furnished in chapter 7 . 


\section{Chapter 2 \\ Background and Literature review}

\subsection{Overview of Concrete Microstructure}

Concrete consists of hydrated cement paste (Hcp), coarse aggregate, fine aggregate, water and air voids. Hcp in turn consists of calcium silicate hydrate (C-S-H) gel, calcium hydroxide, monosulfates, ettringite, hydrated calcium aluminates and hydrated calcium alumino-ferrite formed from the different reactions encountered by the components of cement. Since shrinkage is mainly a paste property, each phase of the Hcp is discussed below with associated chemical reactions.

\subsubsection{Hydration of cement}

Cement mainly composes of $\mathrm{C}_{3} \mathrm{~S}, \mathrm{C}_{2} \mathrm{~S}, \mathrm{C}_{3} \mathrm{~A}$ and $C_{4} A F$. When cement comes in contact with water all these phases undergo some chemical reactions which are collectively called hydration reaction of cement and the product is referred as Hcp. The main chemical reactions are discussed below.

\subsubsection{Reactions for calcium silicates}

Both $\mathrm{C}_{3} \mathrm{~S}$ and $\mathrm{C}_{2} \mathrm{~S}$ react with water to form $\mathrm{C}-\mathrm{S}-\mathrm{H}$ gel and calcium hydroxide $(\mathrm{CH})$ through an exothermic reaction. The reaction of $\mathrm{C}_{3} \mathrm{~S}$ and $\mathrm{C}_{2} \mathrm{~S}$ can be classed into 5 stages- 1) period of rapid evolution of heat, 2) dormant period, 3) acceleration period. 4) slow down period and 5) steady state.

Reactions are shown below in cement chemistry shorthand notations followed universally:

$$
\begin{gathered}
2 \mathrm{C}_{3} \mathrm{~S}+6 \mathrm{H} \rightarrow \mathrm{C}_{3} \mathrm{~S}_{2} \mathrm{H}_{3}(\mathrm{C}-\mathrm{S}-\mathrm{H} \text { gel })+3 \mathrm{CH} \\
2 \mathrm{C}_{2} \mathrm{~S}+4 \mathrm{H} \rightarrow \mathrm{C}_{3} \mathrm{~S}_{2} \mathrm{H}_{3}(\mathrm{C}-\mathrm{S}-\mathrm{H} \text { gel })+\mathrm{CH}
\end{gathered}
$$


Both the above equations are similar stoichometrically, except $\mathrm{C}_{3} \mathrm{~S}$ produces more calcium hydroxide $(\mathrm{CH})$ than $\mathrm{C}_{2} \mathrm{~S}$ upon hydration. $\mathrm{C}-\mathrm{S}-\mathrm{H}$ gel is the main hydration product.

\subsubsection{Reactions for tricalcium aluminate}

$$
\mathrm{C}_{3} \mathrm{~A}+3 \mathrm{C} \overline{\mathrm{S}} \mathrm{H}_{2} \text { (gypsum) }+26 \mathrm{H} \rightarrow \mathrm{C}_{6} \mathrm{~A} \overline{\mathrm{S}} \mathrm{H}_{32} \text { (ettringite) }
$$

Ettringite is a stable compound only if there is ample supply of sulfate ions. If the sulfate ions are all consumed before all the $\mathrm{C}_{3} \mathrm{~A}$ have been hydrated then ettringite is transformed to more stable calcium monosulfate, as shown below.

$2 C_{3} A+C_{6} A \bar{S} H_{32}+4 H \rightarrow 3 C_{4} A \bar{S} H_{12}$ (calcium monosulfate)

Both of these hydration reactions are exothermic. The formation of ettringite slows down the hydration of $\mathrm{C}_{3} \mathrm{~A}$ by creating a diffusion barrier. This barrier is broken down during the conversion of ettringite to monosulfate and allows $\mathrm{C}_{3} \mathrm{~A}$ to react again.

If still some $\mathrm{C}_{3} \mathrm{~A}$ exists in the solution then it reacts with water vigorously to form $\mathrm{C}_{3} \mathrm{~A}_{6} \mathrm{H}_{6}$ or hydrogarnet. Reactions are as follows, $\mathrm{C}_{3} \mathrm{~A}+21 \mathrm{H} \rightarrow \mathrm{C}_{4} \mathrm{AH}_{13}+\mathrm{C}_{2} \mathrm{AH}_{8}$ $\mathrm{C}_{4} \mathrm{AH}_{13}+\mathrm{C}_{2} \mathrm{AH}_{8} \rightarrow 2 \mathrm{C}_{3} \mathrm{AH}_{6}$ (hydrogarnet) $+9 \mathrm{H}$

Gypsum is added to curb this violent reaction forming hydrogarnet which often produces flash set of cement.

\subsubsection{Reactions for ferrite phase}

The ferrite phase has a similar kind of reaction as the aluminate phase but the reaction is slower and produces less heat.

$$
\begin{aligned}
& C_{4} A F+3 C \bar{S} H_{2}+21 H \rightarrow C_{6}(A, F) \bar{S} H_{32}+(A, F) H_{3} \\
& C_{4} A F+C_{6}(A, F) \bar{S} H_{32}+7 H \rightarrow 3 C_{4}(A, F) \bar{S} H_{12}+(A, F) H_{3}
\end{aligned}
$$

\subsubsection{C-S-H gel}


C-S-H makes up about one half to two third of the volume of the Hcp and therefore it must dominate its behavior. During early hydration, $\mathrm{C}-\mathrm{S}-\mathrm{H}$ grows from the particles surfaces into the adjacent water filled spaces in the form of a low density arrangement and can be seen to have spiny appearance covering the $\mathrm{C}_{3} \mathrm{~S}$ grains. The spines do not grow after first few days (1-2days) (Young and Mindess 1981) and bulk of the additional C-S-H gel forms below the spines. This late product has a denser structure and is more resistant to physical change on drying. The early product sometimes referred as low-density C-S-H and the late one as high density C-S-H. It is the late product that provides most of the strength and with less $\mathrm{w} / \mathrm{cm}$ ratio the late product is more.

$\mathrm{C}-\mathrm{S}-\mathrm{H}$ gel is quite difficult to characterize in terms of atomic level structure because of its usual compositional flexibility and quasi amorphous structure. The composition which is mostly accepted is $\mathrm{C}_{3} \mathrm{~S}_{2} \mathrm{H}_{3}$ but this value is not even fixed even for C-S-H gel derived from pure $\mathrm{C}_{3} \mathrm{~S}$. Taylor (1950) showed a C: S ratio of 1 to 1.5 in the solid products with a low $\mathrm{CaO}$ concentration in the solution. This $\mathrm{C}-\mathrm{S}-\mathrm{H}$ with varying composition of C:S ratios C-S-H (I). Lea (1971) mentioned that the range of composition of this C-S-H (I) may extend down to minimum C: S ratio of even 0.8. X-ray pattern of C-S-H (I) closely resembles that of the crystalline tobermorite minerals. At $\mathrm{CaO}$ concentrations near saturation it has been seen that the $\mathrm{CaO}: \mathrm{SiO}_{2}$ ratio increases considerably and varies from 1.5 to 2 . Taylor (1950) also found that X-ray pattern of the solid products having a $\mathrm{C}: \mathrm{S}$ of 2 was different from $\mathrm{C}-\mathrm{S}-\mathrm{H}(\mathrm{I})$ or the later age $\mathrm{C}-\mathrm{S}-\mathrm{H}$ (high-density C-S-H). In view of variability of the C:S ratio due to different preparation methods of C-S-H the term C-S-H (II) is now taken to denote a semi-crystalline material with ratios from 1.5 to 2 and is the early age C-S-H(low-density). A stoichometric formula of $\mathrm{C}_{3.4} \mathrm{~S}_{2} \mathrm{H}_{3}$ will be used in the following section for $\mathrm{C}-\mathrm{S}-\mathrm{H}$ gel as used by Olson and Jennings (2000) and, Tennis and Jennings (2000).

\subsubsection{Models of C-S-H gel}

Different structures have been postulated. The most commonly discussed models for the microstructure can be divided into three kinds. The first one is the Munich model which is based on adsorption tests done by people like Feldman-Sereda (1968), Powers (1948). The second kind based on phase analysis by X-ray diffraction such as the Taylor 
Model (1986). The third is the Jennings-Johnson (1986) model developed from analysis of hydration process and then simulating it by computer techniques.

Powers and Brownyard (1948) proposed a model commonly known as Power Model supported by water adsorption test (Fig. 2.1). According to them C-S-H is made up of two or three layers of thin sheets which are bonded together by surface forces. The water between the layers is interlayer water and that on the surfaces are adsorbed water. The maximum average distance between the layers is $3 \mathrm{~nm}$ and the minimum average distance is $0.4 \mathrm{~nm}$. They postulated that if water between the layers is removed it would not reenter the layers. This irreversible water loss causes an irreversible shrinkage. According to their model $\mathrm{N}_{2}$ cannot enter all the pore spaces during $\mathrm{N}_{2}$ adsorption method and gives a lower estimation of C-S-H gel surface area compared to water adsorption.

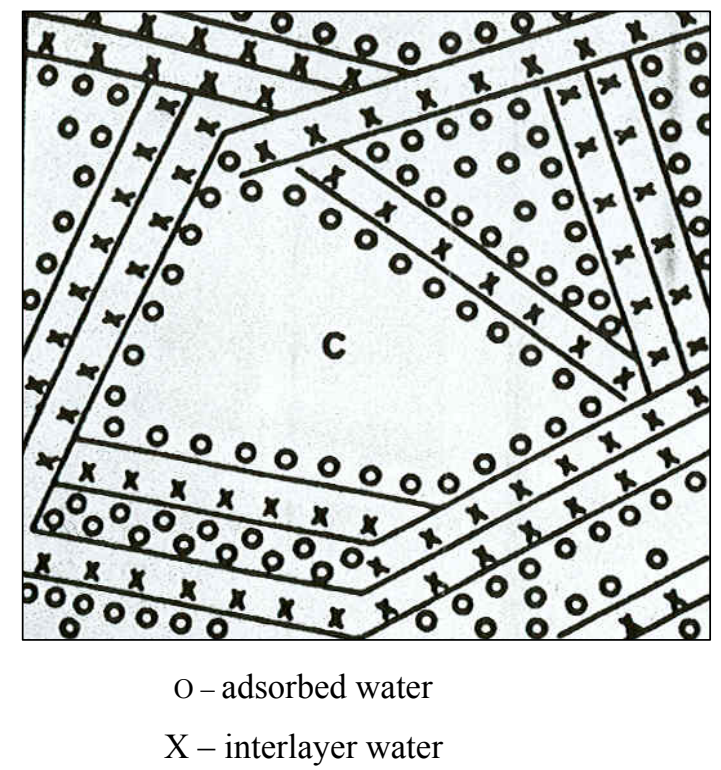

Fig 2.1 Powers Model for C-S-H (Courtesy: Powers 1948)

Feldman and Sereda (1968) put forward the idea that C-S-H is a completely irregular array of single layers (Fig. 2.2). Bonding between the layers is through solid-solid contacts. They also suggested that the interlayer water can move irreversibly in and out of the space. Since nitrogen cannot enter the interlayer space, nitrogen adsorption method gives the correct estimation of the specific surface area. According to them interlayer space should not be considered part of the surface. 


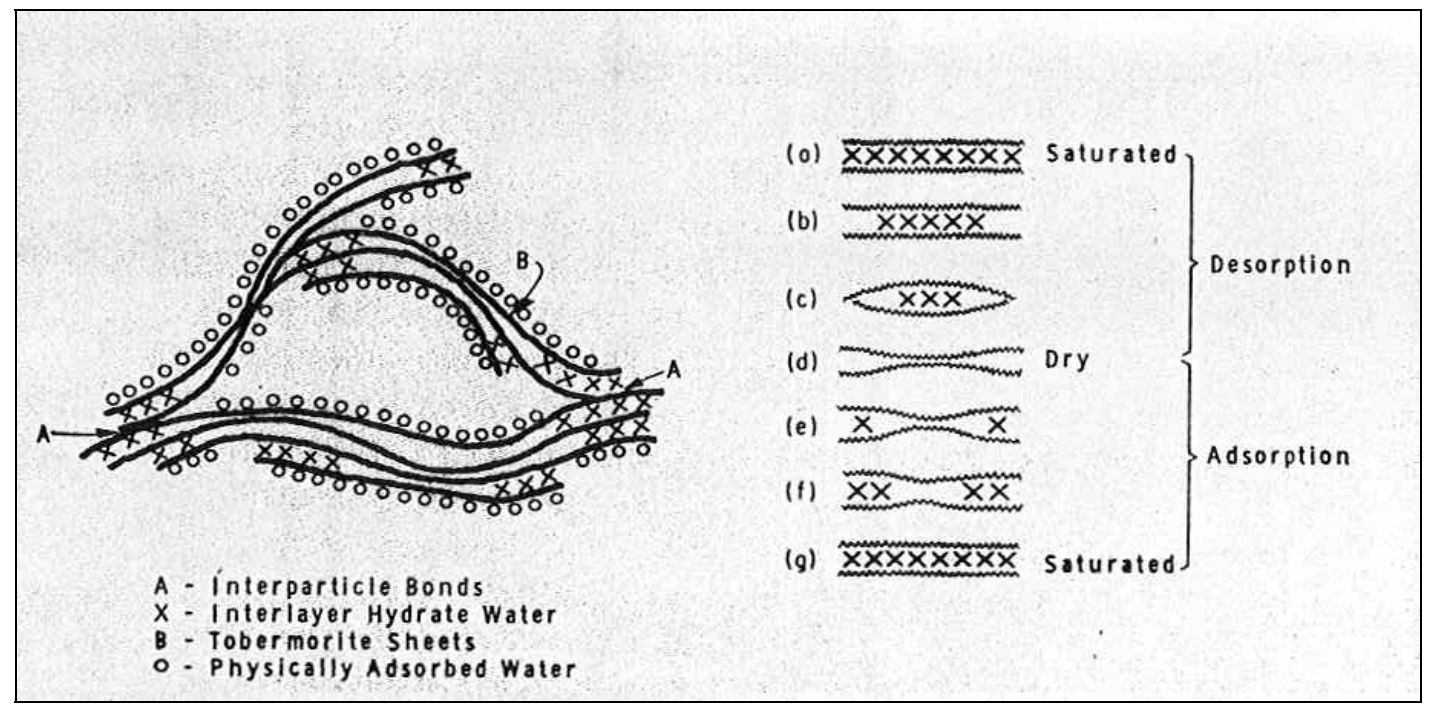

Fig 2.2 - Feldman-Sereda Model (Courtesy: Feldman and Sereda 1968)

Whittman (1968) described a model commonly known as the Munich model (Fig. 2.3). C-S-H has a three dimensional xerogel having a network of separate colloidal particles. The bonding of gel particles is achieved through the chemical bonds and van der Waals forces of attraction. The water movement between particles affects surface free energy at low humidity level and disjoining pressure at high humidity levels.

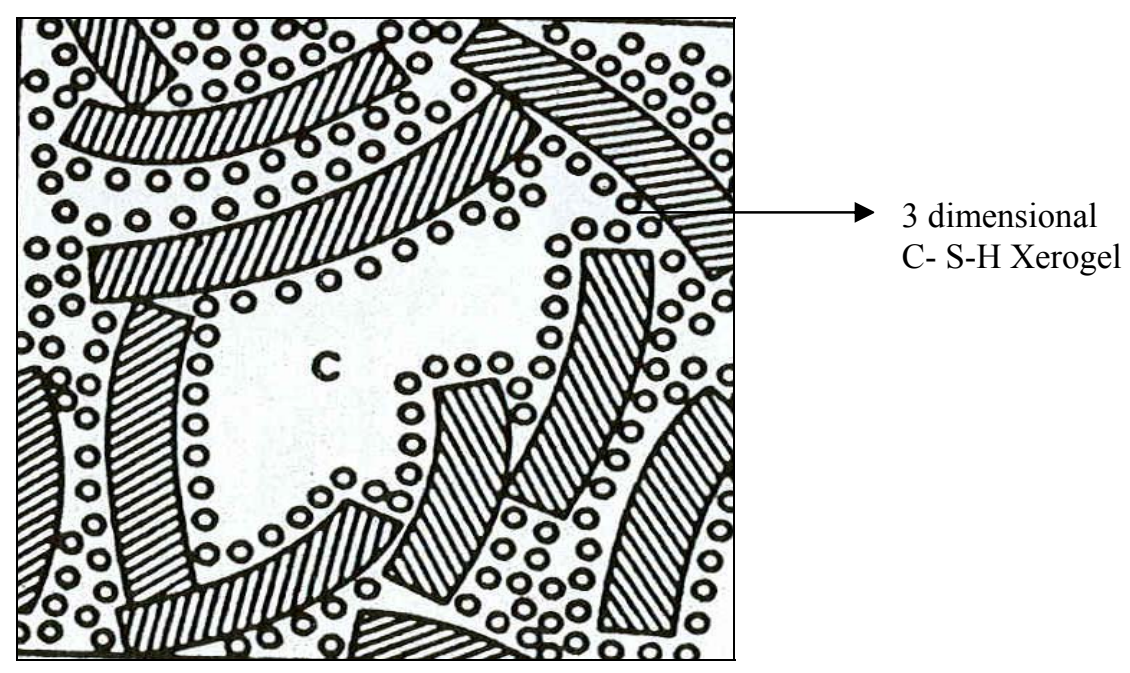

Fig 2.3 - Munich Model (Courtesy: Mindess and Young, 1981) 
Daimon et al. (1977) put forward the Tokyo (Fig. 2.4) model which is a combination of Power and the Feldman-Sereda model. It was proposed that the gel particles are composed of layers. There are two kinds of pores smaller intragel and wider intergel. The wider intragel pores can be observed in inner C-S-H. The intragel pores are classified as intercrystallite pore and intracrystallite pore. The intercrystallite pores can be thought of as the micropores in Power's model and the intercrystallite pores as the interlayer spaces in the Feldman-Sereda model. The pores between gel particles are capillary pores.
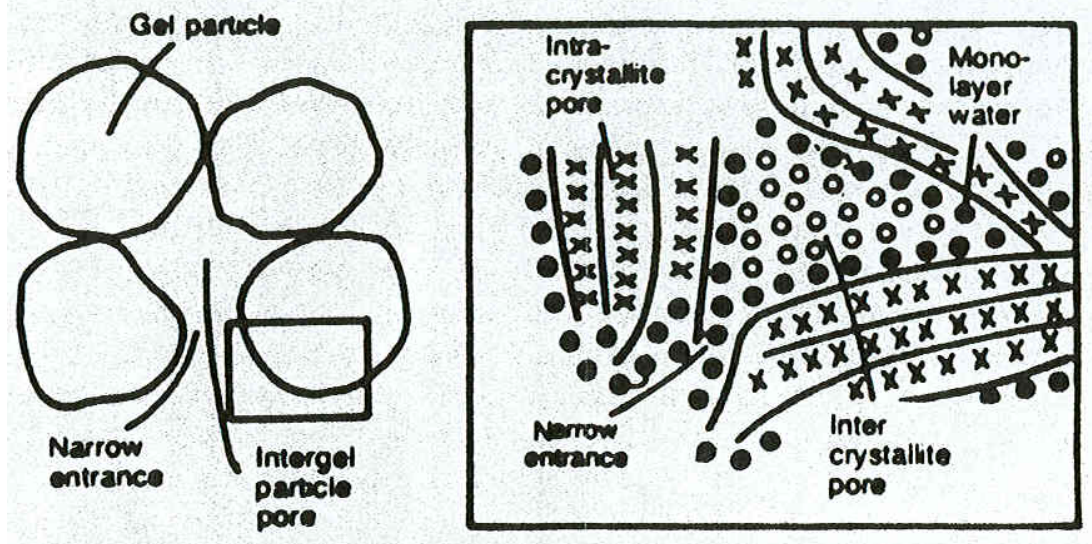

Fig 2.4 - Tokyo Model (Courtesy: Daimon et al. 1977)

Taylor (1986) in his model suggested that the C-S-H has a layered structure and most of the layers are structurally imperfect ones of jennite $\left(\mathrm{C}_{9} \mathrm{~S}_{6} \mathrm{H}_{11}\right)$ and a smaller proportion has a structure similar to a $1.4 \mathrm{~nm}$ tobermorite rather than $1.1 \mathrm{~nm}$ tobermorite. The first one is often termed as C-S-H (II) and the later one as C-S-H (I). Each layer of tobermorite is formed of a main layer and an interlayer with a total thickness of $1.4 \mathrm{~nm}$. The main layer is a sandwich in which a central part of empirical composition $\mathrm{CaO}_{2}$ is flanked by parallel rows of infinite chains of empirical formula $\mathrm{Si}_{3} \mathrm{O}_{9} \mathrm{H}$ and the interlayer consists of $\mathrm{H}_{2} \mathrm{O}$ molecules and additional $\mathrm{Ca}$ ions. On heating to $110^{\circ} \mathrm{C}$ or D-drying four molecules of $\mathrm{H}_{2} \mathrm{O}$ are lost and $1.1 \mathrm{~nm}$ tobermorite is formed. Jennite too has a similar kind of structure with a main layer and an interlayer. The combined thickness of the main 
layer and the interlayer is $1.05 \mathrm{~nm}$. On D-drying four molecules water is lost and the layer thickness comes down to $.87 \mathrm{~nm}$.

Jennings and Johnson (1986) developed a mathematical model which simulates the development of microstructure during the hydration of $\mathrm{C}_{3} \mathrm{~S}$. It has the potential for predicting microstructure and bulk properties resulting from a wide variety of hydration conditions. The simulation model is a large computer program with numerous subroutines and the core of the model consists of a data file containing numerical information about the size of the volume in which hydration occurs and about all the materials contained within the volume.

The J-T model by Tennis and Jennings (2000) considered two types of C-S-H, one with a lower density (LD) and the other with a higher density (HD) (Fig. 2.5). Their proposed HD and LD C-S-H could explain how higher surface areas (measured by $\mathrm{N}_{2}$ ) are associated with smaller volume of gel pores accessible to $\mathrm{N}_{2}$ and vice versa. Using this model it is possible to estimate the relative proportion of the two types of C-S-H gel which varies with the water cement ration and degree of hydration.

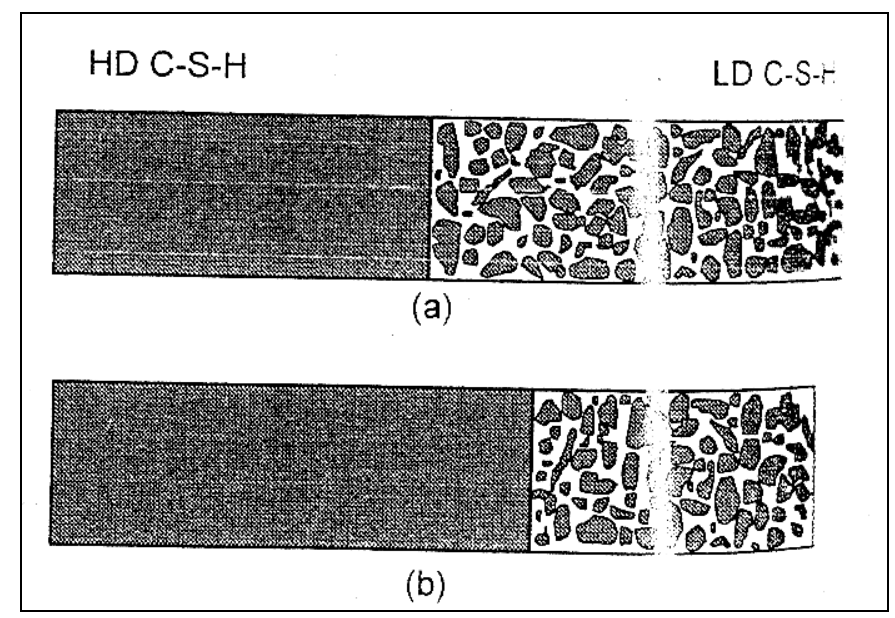

Fig 2.5 - J-T Model (Courtesy: Tennis and Jennings 1992)

Jennings (2000) postulated a structure for two types of C-S-H (Fig. 2.6) the lowdensity and high density type as mentioned in J-T model, 1992. According to him some basic building blocks of 1.1-1.2nm cluster together to form globules of 2.8-3.2nm. These globules then come together to form the two types of C-S-H gel. The low density C-S-H 
gel has a radius of $9 \mathrm{~nm}$ where as that of the high density cannot be estimated correctly. The structure is fractal and the model defines the size, density and packing efficiency of each of the mentioned structures. The principal advantage of this model is that it is quantitative at each scale.

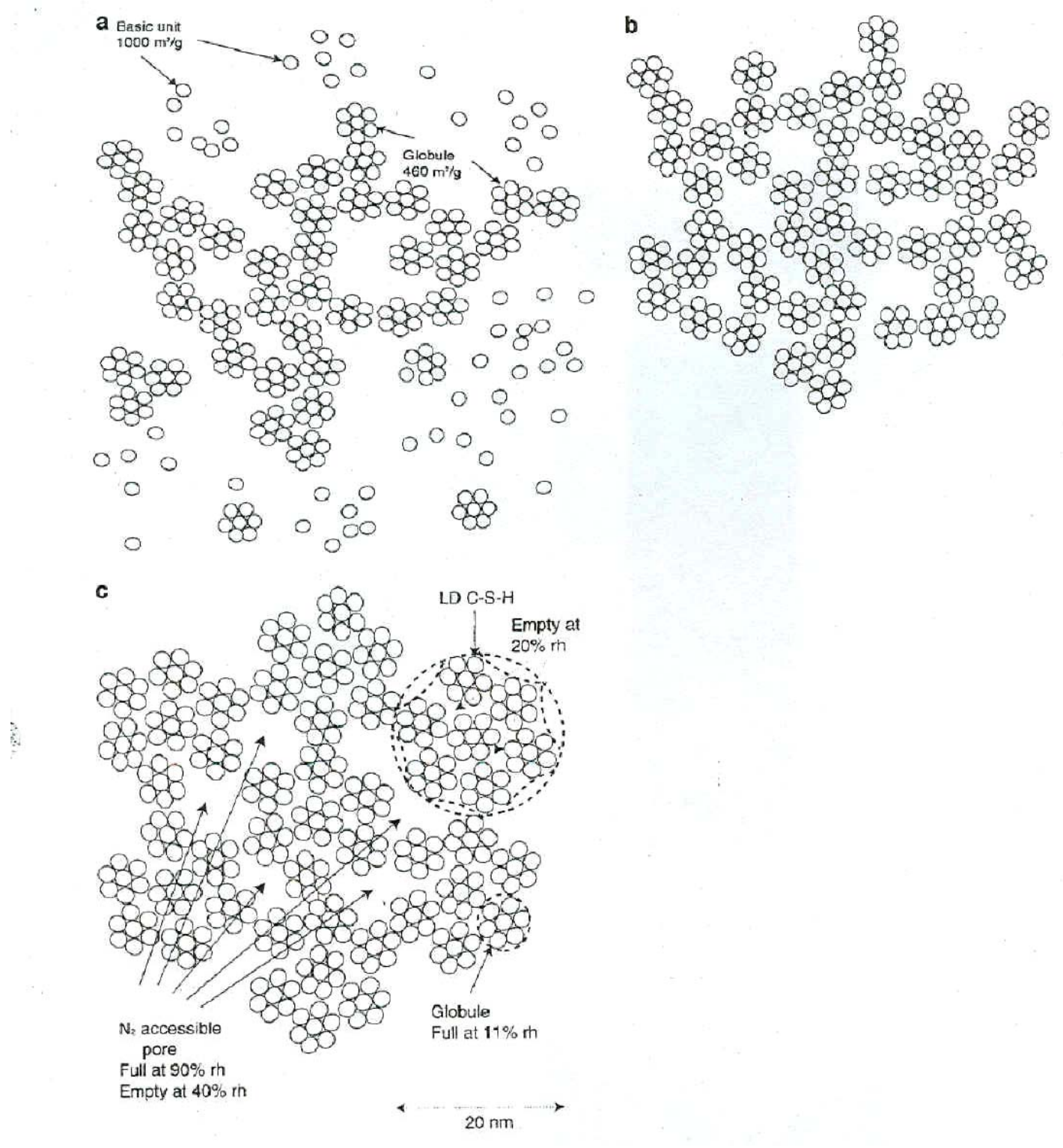

Fig 2.6 - Jennings Model (Courtesy: Jennings 2000)

\subsubsection{Calcium hydroxide (CH)}

Calcium hydroxide is an important product in cement hydration. Calcium hydroxide crystals occupy about $20-25 \%$ of the paste volume in cement pastes. Calcium 
hydroxide only grows where free space is available. During stage 3 hydration of $\mathrm{C}_{3} \mathrm{~S}$ many $\mathrm{CH}$ crystals nucleate and grow within capillary pore space. If the growth of $\mathrm{CH}$ is impeded by another $\mathrm{CH}$ crystal it may stop growing or may grow in another direction; if it finds unhydrated cement grain it might well grow around it.

Diamond (2004) mentioned from SEM studies that $\mathrm{CH}$ can be distinguished from C-S-H by a grey level slightly brighter than C-S-H gel. Despite having a good crystalline structure $\mathrm{CH}$ within cement appears as irregular masses of various sizes probably due to occlusion of hydrating cement grains. Morphology of $\mathrm{CH}$ is affected by admixtures and temperatures of hydration. The $\mathrm{CH}$ formed due to cement hydration reacts with the reactive silica in supplementary cementitious materials to form additional C-S-H and this reaction is often termed as pozzolanic reaction.

\subsubsection{Calcium sulfoaluminates}

The Calcium sulfoaluminates are relatively minor constituent of cement pastes occupying a $5-10 \%$ volume. Ettringite which forms due to the reaction of $\mathrm{C}_{3} \mathrm{~A}$ with gypsum is a stable compound only when there is ample presence of sulfate ions. If the sulfate ion concentration reduces then it reacts with remaining $\mathrm{C}_{3} \mathrm{~A}$ to form monosulfates and then monosulfates become more stable. Ettringite has a needle like structure which grows into the capillary spaces whereas monosulfates has a platy morphology. Much larger masses of ettringite can be found as secondary products in sulfate attacks.

\subsection{Shrinkage}

Shrinkage maybe defines as time dependent volumetric change of concrete due to loss of moisture from the surface or within the concrete, or due to the carbonation of Hcp. Types of Shrinkage:

1. Plastic Shrinkage

2. Autogenous Shrinkage

3. Drying Shrinkage

4. Carbonation Shrinkage 
Plastic Shrinkage: Shrinkage of concrete due to loss of water to the surroundings through evaporation while the concrete is in the plastic stage.

Autogenous Shrinkage: Shrinkage caused by loss internal of water from the capillary spaces of hardened concrete due to cement hydration.

Drying Shrinkage: Shrinkage of concrete caused by loss of water from the concrete to the unsaturated air through diffusion is called drying shrinkage.

Carbonation Shrinkage: Shrinkage caused by the dissolving of $\mathrm{Ca}(\mathrm{OH})_{2}$ while under a compressive stress and depositing of $\mathrm{CaCO}_{3}$ in spaces free from stress.

The current study is based on shrinkage of hardened concrete due to moisture loss internally or externally as HPC is particularly prone to these two shrinkages. Therefore the time dependent shrinkage due to drying and autogenous effect or self desiccation will be taken into account in the current research.

\subsubsection{Factors affecting drying and autogenous shrinkage}

Factors that affect the drying and autogenous shrinkage of concrete have been outlined below.

\subsubsection{Water-cementitious materials ratio}

For normal concrete, shrinkage becomes larger as the water to cementitous materials ratio $(\mathrm{w} / \mathrm{cm})$ becomes higher, since $\mathrm{w} / \mathrm{cm}$ determines the amount of evaporable water in the cement paste. Brooks (1989) showed that shrinkage of hydrated cement paste is directly proportional to $\mathrm{w} / \mathrm{cm}$ ratio between the values of 0.2 to 0.6 . Above the 0.6 $\mathrm{w} / \mathrm{cm}$ ratio water is evaporated without causing shrinkage. With constant $\mathrm{w} / \mathrm{cm}$ ratio, increase in cement content increases shrinkage due to greater paste volume. If workability is kept constant that means the water content is kept constant increase in cement content decreases shrinkage since effective $\mathrm{w} / \mathrm{cm}$ is reduced.

Smadi, Slate and Nilson (1987) compared the shrinkage of low strength (20-24 $\mathrm{MPa}$ ), medium strength (34-41 MPa) and high strength concrete (58-69 MPa). They found that long term drying shrinkage is greater for low strength concrete than for medium and high strength concrete. Higher $\mathrm{w} / \mathrm{cm}$ provides more space for water diffusion and moreover increase in water cement ratio reduces rigidity of the solid matrix 
and its capacity to resist deformation. High strength concretes having a low w/cm has a greater early age shrinkage this is probably due to the greater amount of paste content. In case of HPC using supplementary cementing materials (particularly silica fume) and low $\mathrm{w} / \mathrm{cm}(\leq 0.4)$ the shrinkage values are much higher, if the drying of concrete starts at very early stage (within 72 hours). This happens due to loss of moisture internally and subsequent self desiccation and additional shrinkage.

Aggregate present in concrete produces a restraining effect which reduces the amount of shrinkage. The ratio of shrinkage of concrete to that of neat cement paste depends on the aggregate content in the concrete. Pickett (1956) proposed a relation

$S_{c}=S_{p}(1-a)^{n}$

$\mathrm{S}_{\mathrm{c}}=$ Shrinkage of concrete

$\mathrm{S}_{\mathrm{p}}=$ Shrinkage of paste

$\mathrm{a}=$ aggregate content

$\mathrm{n}=\mathrm{n}$ has a value between 1.2 to 1.7

Hansen and Almudaiheem (1987) validated the estimation of the shrinkage of concrete from the shrinkage of neat cement paste having same $\mathrm{w} / \mathrm{cm}$ and the same degree of hydration by taking into consideration the aggregate content and the modulus of elasticity of the aggregate.

\subsubsection{Size and grading of aggregate}

The size and grading of aggregate do not influence the magnitude of shrinkage. Since use of larger size aggregates make the mix leaner, hence in a lower shrinkage.

\subsubsection{Aggregate modulus of elasticity}

More the aggregate modulus of elasticity more its restraining capacity hence the concretes have a lower shrinkage. If aggregates have a tendency to shrink the overall shrinkage of concrete is increases.

\subsubsection{Lightweight Aggregates}

Lightweight aggregates usually lead to higher shrinkage due to their low modulus of elasticity. 


\subsubsection{Cement properties}

Cement properties have little influence on shrinkage. Fineness of cement is a factor in the sense that the cement particles coarser than 75 micron hydrates very slowly hence cause a restraining effect. Cements deficient in gypsum exhibit considerably greater shrinkage. Bentz et al. (1999) mentioned fine cements increases hydration kinetics and produces more autogenous shrinkage.

\subsubsection{Supplementary cementing materials}

Inclusion of supplementary cementing materials increases shrinkage to a considerable extent. Brooks and Neville (1992) showed that often this increase is from 20 to 60 percent more than a concrete containing same amount of Ordinary Portland Cement and same $\mathrm{w} / \mathrm{cm}$.

ACI committee 226 reports that addition of silica fume less than $15 \%$ usually do not change the later age shrinkage with respect to normal concrete containing cement only. Higher percentage of silica fume has been found to change the later age shrinkage too. Incorporation of silica fume increases early age shrinkage. Hogan and Meusel (1981) found that later age shrinkage increases considerably with slag replacement. Dunstan (1984) and Symons and Fleming (1980) showed that increased fly ash slightly reduces shrinkage. Khatri, Sirivivatnanon and Gross (1995) investigated the effect of fly ash, silica fume and slag on shrinkage. Addition of silica fume increased early age shrinkage but reduces later age shrinkage. Whereas addition of slag with silica fume increases drying shrinkage and addition of fly ash to silica fume was found to increase drying shrinkage though the effect of variation of fly ash content from 15 to $25 \%$ was found not to have a significant difference.

Wee and Wong (2002) found addition of $65 \%$ slag increased early age shrinkage but they found not much difference in the later age value. On the other hand $10 \%$ silica fume reduced the amount of drying shrinkage when used with cement or both slag and cement. 


\subsubsection{Admixtures}

Neville (1996) reported that both water-reducing admixtures and superplasticizers (High range water reducing admixtures) increase shrinkage. Although WRA causes small increase in shrinkage 10 to $20 \%$ more shrinkage is observed due to addition of superplasticizers.

\subsubsection{Curing and storage conditions}

Prolonged moist curing delays the advent of shrinkage and it also reduces ultimate shrinkage of concrete. However for neat cement pastes greater the amount of hydrated paste lesser the amount of restraint. Hence a prolonged curing cause a higher amount of shrinkage in neat cement pastes.

\subsubsection{Relationship between shrinkage mechanisms and microstructure}

The loss of free water from the capillary spaces produces little or no shrinkage. Neville (1996) mentioned that change in the volume of unrestrained concrete is approximately equal to the loss of adsorbed water one molecule thick from the surface of all gel particles. The influence of gel particle size can be observed from the low shrinkage of coarse grained natural building stone and by the high shrinkage of fine grained shale. So it can be stated that the presence of different amount of gel particles in equal volume would cause different amount of shrinkage.

Three mechanisms can be identified as the main cause of shrinkage:

1. Variations of the surface free energy

2. Disjoining pressure or hindered adsorption in restricted spaces

3. Capillary condensation effects

\subsubsection{Variation of the surface free energy}

The free surface of a solid particle is under stress due to the asymmetrical attraction forces between atoms and molecules at this location. Hua, Acker and Ehrlacher (1995) and also Young et al. (1986) suggested that volume stability of highly divided 
solids such as C-S-H gel is extremely influenced by the water molecules adsorbed on the solid surface and intercrystalline spaces. Adsorbed water on the surface of a solid changes its surface energy.

Reversible change in free energy of a pure adsorbent from its initial state to the combining state, which can be given by Gibb's adsorption equation (Bissonnette et al., 2001)

$\Delta G=R T \int_{0}^{p} n \frac{d p}{p}$

where,

$\Delta G=$ surface free energy

$\mathrm{n}=$ number of moles adsorbate in a fixed mass of adsorbent

$\mathrm{R}=$ ideal gas constant

$\mathrm{T}=$ absolute temperature

$\mathrm{P}=$ vapor pressure of the adsorbent

It can also be written that

$\Delta G=\delta . \Delta \gamma$

Where $\delta=$ constant solid surface area

$\Delta \gamma=$ change in surface tension due to adsorption

Combining (2.2) and (2.3) -

$\Delta \gamma=-\frac{R T}{\delta} \int_{0}^{p} n \frac{d p}{p}$

$\Delta \gamma$ can be explained as the change in state of stress of the solid by the adsorbed water due to its interaction with the forces at the liquid/solid interface and effectively placing the solid in a state of compressive stress. A solid surface experiences maximum stress in vacuum while adsorption of water on cement gel particles reduces surface free energy and causing a net expansion. As a result the removal of adsorbed water causes the gel particles to contract.

Bangham (1939) (Bissonnette et al., 2001) suggested that change in length of a solid can be expressed as: 


$$
\frac{\Delta L}{L}=k_{1} \cdot \Delta \gamma
$$

where $\mathrm{k}_{1}$ is a material parameter and Young's modulus of a solid can be calculated as -

$$
Y=\rho \cdot \frac{\delta}{k_{1}}
$$

where $\rho=$ density of the solid

The effect of changes in surface free energy on shrinkage is considered to be a significant factor under low humidities but the removal of second or third layer of water does not affect the change in surface due to variation in relative humidities.

\subsubsection{Effect of disjoining pressure}

This mechanism assumes that hydrated cement paste is made of discrete particles separated by narrow spaces. At relative humidities above $0 \%$, the hydrated cement particles or C-S-H gel particles start adsorbing water. In locations where distances between particles are restricted adsorbed waters induce a pressure and cause an expansion. This pressure is termed disjoining pressure. Ferraris and Wittman (1987) and Derjaguin and Chuarev (1974) estimated different components of disjoining pressure. Hence loss of adsorbed water from cement particles causes contraction in the paste system. Ferraris and Wittman (1987) established that for hydrated cement paste, the volume change, due to disjoining pressure develops steadily in the range of RH between approximately $40 \%$ and $100 \%$.

\subsubsection{Capillary condensation effect}

As hydration proceeds in concrete the volume of product of hydration is greater than the volume of the reactants. This increase in volume is not sufficient to compensate the volume of water that has taken part in the reaction. As concrete starts to gain rigidity the excess volume is occupied by air and thus pores are formed. The pores in concrete have different size distribution. The pores which are greater than $10 \mathrm{~nm}$ are called capillary voids. Some of the capillaries remain filled with voids, some contain water with menisci and rest of them is empty. This can be explained by 
Kelvin's equation-

$p_{c}-p_{v}=\frac{R T}{M v} \ln \left(p_{v} / p_{0}\right)$

$p_{c}=$ capillary pressure

$\mathrm{v}=$ molar volume of the adsorbate

$p_{v}=$ equilibrium vapor pressure

$\mathrm{R}=$ ideal gas constant

$\mathrm{T}=$ absolute temperature

$\mathrm{m}=$ molar volume of the liquid (water)

and Laplace's equation -

$p_{c}-p_{v}=\frac{2 \sigma}{r}$

Combining (2.6) and (2.7)

$$
r=\frac{2 \sigma}{\frac{R T}{M v} \ln \left(p_{v} / p_{0}\right)}
$$

where

$\sigma=$ surface tension

$\mathrm{r}=$ radius of menisci

if $r_{p}$ is radius of the pore then we can assume $r=r_{p} \cos \theta$

As relative humidity within the concrete decreases the capillaries start to empty according to equation 2.8. Capillary force

Capillary pressure contributes to shrinkage of concrete till $40 \% \mathrm{RH}$.

Juenger and Jennings (2001) investigated the relationship between microstructure of C-S-H gel and drying shrinkage of cement paste. According to them reversible shrinkage is independent of surface area of C-S-H gel and depends mainly on the amount of capillary porosity, whereas the irreversible shrinkage is dependent on the morphology 
of C-S-H gel, presence of unhydrated paste and small pores. The proportion of two types of C-S-H gel present in the cement paste - LD C-S-H, HD C-S-H probably affects drying shrinkage since HD C-S-H is more resistant to shrinkage than the LD C-S-H. The LD CS-H shrinks reversibly whereas the HD C-S-H provide restraining effects, and the relative proportion of these two C-S-H varies with curing temperature and admixtures.

Other researchers such as Richardson (1999), Scherer (1999) and Taylor (1997) also mentioned that C-S-H gel plays the major part in drying shrinkage.

\subsubsection{Shrinkage models}

A number of models have been suggested to estimate the drying shrinkage of concrete by different authors over a period of time. The following section describes the existing models those are used and referenced by researchers.

\subsubsection{ACI 209R prediction equation:}

Following is the ACI prediction equation:

$$
\left(\varepsilon_{s h}\right)_{t}=\frac{t^{\alpha}}{f+t^{\alpha}}\left(\varepsilon_{s h}\right)_{u}
$$

$\alpha$ is within the values 9 to 1.3

$\mathrm{f}$ is within the values 20 to 130 days

$\left(\varepsilon_{s h}\right)_{u}$ is ultimate shrinkage with values between $415 \times 10^{-6}$ and $1070 \times 10^{-6}(\mathrm{~m} / \mathrm{m})$

$\mathrm{t}=$ time from end of initial curing

Based on normal weight, sand light weight and all light weight concretes using both moisture and steam curing the appropriate value of $\alpha$ and $\left(\varepsilon_{s h}\right)_{u}$ were determine as 1 and $780 \times 10^{-6} \mathrm{~m} / \mathrm{m}$ respectively. These values are presented by ACI $209 \mathrm{R}$.

Therefore the recommended equation for shrinkage under standard conditions is- 
$\left(\alpha_{s h}\right)_{t}=\frac{t}{35+t}\left(\varepsilon_{h}\right)_{u}$ for shrinkage after 7 days of moist cured concrete

$\left(\alpha_{s h}\right)_{t}=\frac{t}{55+t}\left(\varepsilon_{h}\right)_{u}$ for shrinkage after 1-3 days of steam cured concrete

$\mathrm{ACI}$ has also recommended different correction factors to ultimate shrinkage strain value when the conditions are different than the ones mentioned above.

Different corrections are described below:

1. Differential shrinkage: For shrinkage considered for other than 7 days for moist cured concrete and other than 1-3 days for steam cured concrete, the difference in equations 2.11 and 2.12 (as the case may be) is determined for any period starting after this time.

2. Initial moist curing: To determine shrinkage of concrete moist cured other than 7 days moist curing a $\gamma_{c p}$ factor is used. Table 2.1 shows $\gamma_{c p}$ factor corresponding to different moist curing duration.

Table 2.1 - Correction for $\gamma_{c p}$

\begin{tabular}{|c|c|}
\hline Moist curing duration, days & $\gamma_{c p}$ \\
\hline 1 & 1.2 \\
3 & 1.1 \\
7 & 1.0 \\
14 & .93 \\
28 & .86 \\
90 & .75 \\
\hline
\end{tabular}


3. Ambient relative humidity: If ambient relative humidity is greater than $40 \% \gamma_{\lambda}$ is used as a correction factor for ultimate shrinkage-

$$
\begin{aligned}
\gamma_{\lambda} & =1.4-.01 \lambda, \text { for } 40 \leq \lambda \leq 80 \\
& =3.0-.03 \lambda, \text { for } 80 \leq \lambda \leq 100
\end{aligned}
$$

Where, $\lambda=$ relative humidity in $\%$

For ambient humidity lower than $40 \%$ a value higher than 1 should be used for $\gamma_{\lambda}$

4. Correction for size and shape:

(a). Avg. thickness method correction $\left(\gamma_{h}\right)$

Table 2.2 shows the correction factors for members having average thickness less than $150 \mathrm{~mm}$

Table 2.2 - Correction factors for average thickness of method of members less than $150 \mathrm{~mm}$

\begin{tabular}{|c|c|}
\hline $\begin{array}{c}\text { Average thickness of } \\
\text { member }\end{array}$ & Shrinkage, $\gamma_{h}$ \\
\hline $\mathrm{mm}$ & $\leq 1 \mathrm{yr}$. \\
\hline 51 & 1.35 \\
\hline 76 & 1.25 \\
\hline 104 & 1.17 \\
\hline 127 & 1.08 \\
\hline
\end{tabular}

For average thickness of members greater than $150 \mathrm{~mm}$ and up to $300 \mathrm{~mm}$ to $375 \mathrm{~mm}$ the following equations are used for correction 
During the first year of drying:

Shrinkage $\gamma_{h}=1.23-.00015 \mathrm{~h}$

where $\mathrm{h}$ is the avg. thickness of the member in $\mathrm{mm}$

For ultimate values

Shrinkage $\gamma_{h}=1.17-.00114 \mathrm{~h}$

where $\mathrm{h}$ is the avg. thickness of the member in $\mathrm{mm}$

(b) Volume-surface ratio method $\left(\gamma_{v s}\right)$ (more accurate method)

Shrinkage $\gamma_{v s}=1.2 \exp (-.00472 \mathrm{v} / \mathrm{s})$

where, $\mathrm{v} / \mathrm{s}$ in $\mathrm{mm}$

In either method $\gamma_{s h}$ should be taken not less than 0.2. Also $\gamma_{s h}\left(\varepsilon_{s h}\right)_{u} \geq 100 \times 10^{-6}(\mathrm{~m} / \mathrm{m})$ is used if concrete is under seasonal wetting and drying cycles and $\gamma_{s h}\left(\varepsilon_{s h}\right)_{u} \geq 150 \times 10^{-6}$ $(\mathrm{m} / \mathrm{m})$, if concrete is under sustained drying condition.

5. Temperature other than $21^{\circ} \mathrm{C}$ :

This effect is usually considered to be less important than relative humidity since the operating range of most structures is small.

6. Correction factors for concrete composition:

(i) Slump:

Shrinkage $\gamma_{s}=0.89+.00161 \mathrm{~s}$

Where $\mathrm{s}$ is the observed slump in $\mathrm{mm}$.

(ii) Fine aggregate percentage:

For $\psi \leq 50$ percent 
Shrinkage $\gamma_{\psi}=0.30+0.14 \psi$

For $\psi>50$ percent

$$
\text { Shrinkage } \gamma_{\psi}=0.90+0.002 \psi
$$

$\psi$ is the ratio of the fine aggregate to total aggregate by weight expressed as percentage

(iii) Cement content:

Shrinkage $\gamma_{c}=0.75+.00061 \mathrm{c}$

where, $\mathrm{c}$ is cement content in $\mathrm{Kg} / \mathrm{m}^{3}$

(iv) Air content:

Shrinkage $\gamma_{\alpha}=.95+.008 \alpha$

where $\alpha$ is the air content in percent

7. Shrinkage ratio of concrete with equivalent paste quality:

Shrinkage strain is mainly a function of shrinkage characteristic of the cement paste and of the aggregate volume concentration.

$$
\frac{\left(\varepsilon_{s h}\right)_{u 1}}{\left(\varepsilon_{s h}\right)_{u 2}}=\frac{1-\left(v_{1}\right)^{1 / 3}}{1-\left(v_{2}\right)^{1 / 3}}
$$

where $\left(\varepsilon_{s h}\right)_{u 1} /\left(\varepsilon_{s h}\right)_{u 2}$ is the ratio of shrinkage strain of two mixes with different content of paste with equivalent paste quality and $\mathrm{v}_{1}$ and $\mathrm{v}_{2}$ are the total aggregate solid volumes per unit volume of concrete for each one of the mixes.

\subsubsection{CEB-FIP model 1990}

According to CEB-FIP (1990) total shrinkage or swelling strain $\varepsilon_{c s}\left(t, t_{s}\right)$ can be calculated from 
$\varepsilon_{c s}\left(t, t_{s}\right)=\varepsilon_{c s o} \beta_{s}\left(t-t_{s}\right)$

where,

$\varepsilon_{\text {cso }}$ is the notional shrinkage coefficient

$\beta_{s}$ is the coefficient to describe development of shrinkage with time

$t$ is the age of concrete (days)

$t_{s}$ is the age of concrete (days) at the beginning of shrinkage or swelling

$\varepsilon_{c s o}$ can be obtained from the following relationship-

$\varepsilon_{c s o}=\varepsilon_{s}\left(f_{c m}\right) \beta_{R H}$

with

$\varepsilon_{s}\left(f_{c m}\right)=\left[160+10 \beta_{s c}\left(9-f_{c m} / f_{c m o}\right)\right] \times 10^{-6}$ where,

$\mathrm{f}_{\mathrm{cm}}$ is the mean compressive strength of the concrete at the ages of 28 days (MPa)

$\mathrm{f}_{\mathrm{cmo}}=10 \mathrm{MPa}$

$\beta_{s c}$ is a coefficient which depends on the type of cement: $\beta_{s c}=4$ for slow hardening cements, $\beta_{s c}=5$ for normal or rapid hardening cements( $\mathrm{N}$ and $\mathrm{R}$ ); and $\beta_{s c}=8$ for rapid hardening high strength cement (RS).

$\beta_{R H}=-1.55 \beta_{\text {sRH }}$ for $40 \% \leq \mathrm{RH}<90 \%$

$\beta_{R H}=+.25$ for $\quad \mathrm{RH} \geq 99 \%$

where,

$$
\beta_{\text {sRH }}=1-\left(\frac{R H}{R H_{o}}\right)^{3}
$$


$\mathrm{RH}$ is the relative humidity of the ambient atmosphere (\%)

$\mathrm{RH}_{0}=100 \%$

The development of shrinkage with time is given by

$\beta_{s}\left(t-t_{s}\right)=\left[\frac{\left(t-t_{s}\right) / t_{1}}{350\left(h / h_{0}\right)^{2}+\left(t-t_{s}\right) / t_{1}}\right]^{0.5}$

where

$\mathrm{h}=\frac{2 A_{c}}{u}=$ notational size of member $(\mathrm{mm}), \mathrm{A}_{\mathrm{c}}$ is the cross-section and $\mathrm{u}$ is the perimeter of the member in contact with the atmosphere

$\mathrm{t}_{1}=1$ day

$\mathrm{h}_{0}=100 \mathrm{~mm}$

\subsubsection{Sakata model (1993)}

This model proposed a prediction equation for shrinkage by a statistical method on the basis of many experimental data. He proposed-

$$
\begin{aligned}
& \varepsilon_{\text {sh }}\left(t, t_{0}\right)=\varepsilon_{\text {sho }}\left[1-\exp \left\{-0.108\left(t-t_{0}\right)^{.56}\right]\right. \\
& \varepsilon_{\text {shoo }}=-60+78\{1-\exp (R H / 100)\}+38 \ln W-5\{\ln (v / s)\}^{2}+4\left(\ln t_{0}\right)
\end{aligned}
$$

where, $\varepsilon_{\text {sh }}\left(t, t_{0}\right)$ is predicted shrinkage $\left(\mathrm{x} 10^{-5}\right)$ and $\varepsilon_{\text {sho }}$ is ultimate shrinkage $\left(\mathrm{x} 10^{-5}\right)$.

\subsubsection{Bazant model (1996)}

He proposed a model which is known as B3 model. This model is described below-

Mean Shrinkage strain in the cross section: 
$\varepsilon_{\text {sh }}\left(t, t_{0}\right)=-\varepsilon_{\text {shoo }} k_{h} S(t)$

Time curve:

$S(t)=\tanh \left(\frac{t-t_{0}}{\tau_{s h}}\right)^{1 / 2}$

Humidity dependence:

$$
\begin{array}{rlrl}
\mathrm{k}_{\mathrm{h}} & =1-\mathrm{h}^{3} & & \text { for } \mathrm{h} \leq .98 \\
& =-0.2 & & \text { for } \mathrm{h}=1 \text { (swelling in water) } \\
& =\text { linear interpolation for } .98 \leq \mathrm{h} \leq 1
\end{array}
$$

Size dependence:

$$
\tau_{\text {sh }}=\mathrm{k}_{1}\left(\mathrm{k}_{\mathrm{s}} \mathrm{D}\right)^{2}
$$

where $\mathrm{D}=2 \mathrm{v} / \mathrm{s}=$ effective cross section thickness $\mathrm{k}_{\mathrm{s}}$ is the effective cross-section shape factor

$$
\begin{aligned}
\mathrm{k}_{\mathrm{S}} & =1.00 & & \text { for infinite slab } \\
& =1.15 & & \text { for infinite cylinder } \\
& =1.25 & & \text { for infinite square prism } \\
& =1.3 & & \text { for sphere } \\
& =1.55 & & \text { for a cube }
\end{aligned}
$$

time dependence of ultimate shrinkage-

$$
\varepsilon_{\text {shoo }}=\varepsilon_{\text {so }} \frac{E(7+600)}{E\left(t_{0}+\tau_{s h}\right)}
$$

typical values of $\varepsilon_{\text {shoo }}$ range from $300 \times 10^{-6}$ to $1100 \times 10^{-6}$

$$
\begin{aligned}
& \varepsilon_{s \infty}=\alpha_{1} \alpha_{2}\left[26 w^{2.1}\left(f_{c}^{\prime}\right)^{-.28}+270\right] \quad\left(\text { in } 10^{-6}\right) \\
& k_{1}=190.8 t_{0}^{-.28} f_{c}^{\prime} \quad \text { days } i^{-2} \\
& \alpha_{1}=1.0 \text { for Type I cement } \\
& =.85 \text { for Type II cement } \\
& =1.1 \text { for Type III cement }
\end{aligned}
$$

and $\alpha_{2}=.75$ for steam cured specimens 
$=1.0$ for $100 \% \mathrm{RH}$

$=1.2$ for specimens sealed during curing

\subsubsection{Gardner and Lockman model (2001)}

They proposed a design office procedure for calculating shrinkage. They used 28 day compressive strength and a factor $\mathrm{K}$ for accommodating different types of cement. Gardner and Lockman (2001) suggested by using different values of $\mathrm{K}$ it is also possible to include the effects of fly ash and slag. According to there model shrinkage can be estimated using the following equation-

$$
\begin{aligned}
& \varepsilon_{\text {sh }}=\varepsilon_{\text {shu }} \beta(h) \beta(t) \\
& \beta(h)=\left(1-1.18 h^{4}\right) \\
& \varepsilon_{\text {shu }}=1000 . K \cdot\left(\frac{30}{f_{\text {cm } 28}}\right)^{1 / 2} \cdot 10^{-6} \\
& \beta(t)=\left(\frac{t-t_{c}}{t-t_{c}+0.15 \cdot(V / S)^{2}}\right)^{0.5}
\end{aligned}
$$

where

$\mathrm{h}=$ humidity expressed as a decimal;

$\mathrm{t}=$ age of concrete, days;

$t_{c}=$ age drying commenced, end of moist curing, days;

$\mathrm{K}=1$ for Type I cement;

$\mathrm{K}=.70$ Type II cement

$\mathrm{K}=1.15$ Type III cement;

$\mathrm{V} / \mathrm{S}=$ volume-surface ratio, $\mathrm{mm}$;

$\mathrm{f}_{\mathrm{cm} 28}=$ concrete mean compressive strength at 28 days, $\mathrm{MPa}$

They also proposed a equation to predict the mean compressive strength at $t$ days.

$$
f_{c m t}=f_{c m 28} \frac{t^{3 / 4}}{a+b \cdot t^{3 / 4}}
$$


for

Type I cement concretes, $a=2.8$ and $b=0.77$

Type II cement concretes, $a=3.4$ and $b=0.72$

Type III cement concretes, $a=1.0$ and $b=0.92$

For blended cement concretes containing fly ash or slag, the measured concrete strengths should be used to determine which of the equations $(2.45 \mathrm{a}),(2.45 \mathrm{~b})$ or $(2.45 \mathrm{c})$ best represents the test results to determine the value of $\mathrm{K}$ to be used in the shrinkage prediction equation.

\subsubsection{Huo et.al model (2001)}

They found that ACI 209 equation for shrinkage prediction gives higher shrinkage values for HPC. Shrinkage strains of HPC at early ages develop faster than those of conventional concrete. They also found that the ultimate shrinkage strains of HPC are lower than those of conventional concrete. To accommodate two features of shrinkage strains of HPC, they proposed the following equation-

$\varepsilon_{s h}=\left(\varepsilon_{s h}\right)_{u} \frac{t}{K_{s}+t}$

where $\mathrm{K}_{\mathrm{s}}$ is an adjustment factor to reflect the rapidly developed shrinkage at an early age of concrete. To include the effect of compressive strength of the concretes, $\mathrm{K}_{\mathrm{s}}$ was expressed as function of 28 days compressive strength for concretes. $\mathrm{K}_{\mathrm{s}}$ is 35 for normal strength concretes, $\mathrm{f}_{\mathrm{c}}{ }^{\prime}=28 \mathrm{MPa}$ as in the ACI 209 equation and it is equal to 15 for $\mathrm{f}_{\mathrm{c}}{ }^{\prime}=$ $83 \mathrm{MPa}$ based on their test results.

$K_{s}=45-.3626 . f_{c}^{\prime}$ in $\mathrm{MPa}$

where $f_{c}^{\prime}=$ compressive strength of concrete at 28 days

They also proposed a correction factor $\gamma_{s t, s}$ other than ACI 209R equation correction factors to consider the lower ultimate shrinkage strains of HPC. The strength adjustment factor $\gamma_{s t, s}$ is a linear function of compressive strengths of concrete.

$\gamma_{s t, s}=1.20-.0073 f_{c}^{\prime} \leq 1, \mathrm{f}_{\mathrm{c}}^{\prime}$ in $\mathrm{MPa}$

They developed this formula from measured data and $\gamma_{s t, s}=1$ when $\mathrm{f}_{\mathrm{c}}{ }^{\prime}=28 \mathrm{MPa}$. 


\subsubsection{Gardner and Zhao Model (1993)}

They proposed the following equation for early-age concrete strength development:

$$
f_{c m t}^{\prime}=f_{c m 28}^{\prime} \frac{t^{3 / 4}}{a+b t^{3 / 4}}
$$

for

Type I cement concretes $a=2.8$ and $b=0.77$

Type II cement concretes $a=3.4$ and $b=0.72$

Type III cement concretes $a=1.0$ and $b=0.92$

Where $\mathrm{f}_{\mathrm{cmt}}^{\prime}=$ mean concrete strength at age $\mathrm{t}$ days

$\mathrm{f}_{\mathrm{cm} 28}^{\prime}=$ mean concrete strength at 28 days

They proposed the following equation to calculate the development of shrinkage with time-

$\varepsilon_{\text {sh }}=\varepsilon_{\text {shu }} \times \beta(h) \times \beta(t)$

$\varepsilon_{\text {shu }}=900 \times K \times\left(\frac{f_{c m 28}^{\prime}}{f_{c m t c}^{\prime}}\right)^{1 / 2} \times\left(\frac{25}{f_{c m 28}^{\prime}}\right)^{1 / 2} \times 10^{-6}$

$\beta(t)=\left[\frac{7.27+\ln \left(t-t_{c}\right)}{17.18}\right] \times\left(\frac{t-t_{c}}{t-t_{c}+0.125 \times(V / S)^{2}}\right)$

and

$\beta(h)=\left(1-h^{4}\right)$ for $\mathrm{h}<0.99$ 
$=-.20$ for $\mathrm{h}=1.00$ swelling only when concrete not stressed

where

$\mathrm{h}=$ humidity expressed as a decimal

$\mathrm{t}=$ age of concrete, days

$t_{c}=$ age drying commenced, days

$\mathrm{t}_{0}=$ age concrete loaded

$\mathrm{K}=1$ for Type I cement

$\mathrm{K}=0.70$ for Type II cement

$\mathrm{K}=1.33$ for Type III cement

$\mathrm{V} / \mathrm{S}=$ volume-surface ratio, $\mathrm{mm}$,

$\mathrm{f}_{\mathrm{cm} 28}^{\prime}=$ concrete mean compressive strength at 28 days, $\mathrm{MPa}$

$\hat{f}_{\text {cmtc }}=$ concrete mean compressive strength when drying commenced, MPa

$\mathrm{f}_{\text {cmto }}^{\prime}=$ concrete mean compressive strength when loading commenced, MPa

According to them when using blended fly-ash or slag cement concretes, the measured concretes should be used to determine which of equations (2.50a), $(2.50 \mathrm{~b})$ or $(2.50 \mathrm{c})$ best represents the result to determine the appropriate value of $\mathrm{K}$.

\subsubsection{Miyazawa and Tazawa model (2001)}

They described a prediction model for total shrinkage including autogenous shrinkage and drying shrinkage for high strength concretes $\left(f_{c}^{\prime}>80 \mathrm{MPa}\right)$.

Development of Autogenous Shrinkage with time

$$
\varepsilon_{c}(t)=\gamma \varepsilon_{c 0}(w / c) \beta_{a}(t)
$$


For $0.2 \leq w / c \leq 0.5: \quad \varepsilon_{c 0}(w / c)=3070 \exp \{-7.2(w / c)\}$

For $0.5<w / c: \quad \varepsilon_{c 0}(w / c)=80$

$\beta_{a}(t)=\left[1-\exp \left\{-a\left(t-t_{0}\right)^{b}\right\}\right] \quad$ (Table 2.3)

where,

$\varepsilon_{c}(t)$ : autogenous shrinkage of concrete at age $\mathrm{t}\left(\mathrm{\times} 10^{-6}\right)$

$\gamma:$ a coefficient to describe the effect of cement type ( $\gamma=1.0$ for OPC)

$\varepsilon_{c 0}(w / c)$ : the ultimate autogenous shrinkage

$\beta_{a}(t):$ a coefficient to describe the development of autogenous shrinkage with time $w / c:$ water-cement ratio

$\mathrm{a}$ and $\mathrm{b}$ : constants given in the following tables

$t$ : the age of concrete in day

$t_{0}$ : initial setting time in day

the effect of concrete temperature is taken into account by modifying the age $t$ and $t_{0}$

$t, t_{0}=\sum_{i=1}^{n} \Delta t_{i} \cdot \exp \left[13.65-\frac{4000}{273+T\left(\Delta t_{i}\right) / T_{0}}\right]$

where,

$\Delta t_{i}$ : the number of days where a temperature $\mathrm{T}\left({ }^{\circ} \mathrm{C}\right)$ prevails

$\mathrm{T}\left(\Delta t_{i}\right)$ : the temperature during the time period $\Delta t_{i}, \mathrm{~T}_{0}=1^{\circ} \mathrm{C}$ 
Table 2.3 - Coefficients in equation (2.58)

\begin{tabular}{|c|c|c|}
\hline $\mathbf{w} / \mathbf{c m}$ & $\mathbf{a}$ & $\mathbf{b}$ \\
\hline 0.2 & 1.2 & 0.4 \\
\hline 0.23 & 1.5 & 0.4 \\
\hline 0.3 & 0.6 & 0.5 \\
\hline 0.4 & 0.1 & 0.7 \\
\hline$\geq 0.5$ & .03 & 0.8 \\
\hline
\end{tabular}

Drying Shrinkage Prediction Model

$\varepsilon_{d}\left(t, t_{d}\right)=\varepsilon_{d 0}(R H) \beta_{d}(t)$

$\varepsilon_{d 0}(R H)=e \cdot\left[1-\exp \left\{\left(R H-R H_{0}\right) / 100\right\}\right]$

$\beta_{d}(t)=\left[\frac{\left(t-t_{d}\right) / t_{1}}{350\left(h / h_{0}\right)^{2}+\left(t-t_{d}\right) / t_{1}}\right]^{0.5}$

where,

$\varepsilon_{d}\left(t, t_{d}\right):$ drying shrinkage from age $t_{d}$ to $t\left(\times 10^{-6}\right)$

$\beta_{d}(t):$ a coefficient to describe the development of drying shrinkage with time

$\varepsilon_{d 0}(R H)$ : the ultimate drying shrinkage $\left(\times 10^{-6}\right)$

$t_{d}$ : the age of concrete at start of exposure to the atmosphere (days)

RH: the ambient relative humidity (\%) ( $40 \% \leq R H \leq 90 \%)$

$\mathrm{RH}_{0}$; specific relative humidity (\%) (Table 2.4) 
e: coefficients (Table 2.4)

$\mathrm{h}=2 \mathrm{~A}_{\mathrm{c}} \mathrm{u}$, where $\mathrm{A}_{\mathrm{c}}$ is the cross section and $\mathrm{u}$ is the perimeter of the member in contact with the atmosphere $(100 \mathrm{~mm} \leq h \leq 500 \mathrm{~mm})$

$\mathrm{h}_{0}=200 \mathrm{~mm}, \mathrm{t}_{1}=1$ day

The prediction model for total shrinkage assumes that autogenous shrinkage and drying shrinkage can be superimposed

$\varepsilon_{t}\left(t, t_{d}\right)=\varepsilon_{c}(t)+\varepsilon_{d}\left(t, t_{d}\right)$

Table 2.4 - Coefficients in equation (2.61)

\begin{tabular}{|c|c|c|}
\hline $\mathbf{w} / \mathbf{c m}$ & $\mathbf{R H}_{\mathbf{0}}$ & $\mathbf{e}$ \\
\hline 0.2 & 74.9 & 2200 \\
\hline 0.3 & 84.7 & 1800 \\
\hline 0.4 & 90.0 & 2000 \\
\hline 0.5 & 95.0 & 2200 \\
\hline 0.6 & 97.0 & 2200 \\
\hline
\end{tabular}

\subsubsection{Models by other authors}

Basma and Jawad (1995) developed a probabilistic model in which they took care of the uncertainties in the parameters that affect drying shrinkage. They defined the parameter $-R_{c p}=\left(\frac{\varepsilon_{c}}{\varepsilon_{p}}=\left(1-V_{a}\right)^{\beta}\right)$

Based on Pickett's (1956) model and that modified by Almudaiheem (1992)

Where $\varepsilon_{c} / \varepsilon_{p}$ is the ratio of the shrinkage of concrete to that of the paste, $\mathrm{V}_{\mathrm{a}}$ is the volume of aggregate and $\beta$ is a function of $v_{c}, v_{a}, E_{c}$ and $E_{a}$. They suggested a simplified model $\mathrm{R}_{\mathrm{cp}}=\varepsilon_{\mathrm{c}} / \varepsilon_{\mathrm{p}}=\left(.0541+.4 \alpha-.94 \mathrm{~V}_{\mathrm{a}}\right)$ 
Where $\alpha$ is a function of curing time in days, curing temperature in degree centigrade and the water cement ratio. They incorporated a probabilistic approach to determine the variation in $R_{c p}$ with the variation in temperature and volume of aggregate.

Bazant et al. (1987) described a statistical method to extrapolate short term shrinkage test data to obtain long term shrinkage values and their standard deviations. For predicting long term strains from short term tests best predictions are obtained when the shrinkage formula is fitted to test data using non-linear optimizations. After that linear regression in transformed variables can be used to obtain the confidence limits for long term predictions.

Hansen and Almudaiheem (1987) investigated the influence of major parameters on ultimate drying shrinkage of concrete. They used the relationship

$\epsilon_{\mathrm{c}}=\epsilon_{\mathrm{p}}\left(1-\mathrm{V}_{\mathrm{a}}\right)^{1.7}$

Where-

$\epsilon_{c}=$ ultimate shrinkage of concrete

$\epsilon_{\mathrm{p}}=$ ultimate shrinkage of paste

$\mathrm{V}_{\mathrm{a}}=$ relative aggregate content by overall volume of concrete

They found that concretes of 65 and 70 percent aggregate content by volume has significantly different ultimate drying shrinkage and with the decrease of modulus of elasticity of the aggregates the ultimate shrinkage values also increase. $\mathrm{RH}$ has a significant influence on mortar and paste shrinkage.

They also found that the ultimate shrinkage of concrete is independent of the volume and size of the specimen but has a significant effect on the early age shrinkage strains. They modified the shrinkage half time value $f$ in the typical time function of shrinkage -

$\epsilon_{\mathrm{s}}=\mathrm{t} /(\mathrm{f}+\mathrm{t}) \epsilon_{\mathrm{shu}}$

by $\mathrm{V} / \mathrm{S}$ ratio.

McDonald and Roper (1993) investigated the accuracy of different shrinkage prediction models using residual plotting. In the residual plotting method - if the prediction model underestimates or overestimates strain by a constant amount then the 
line joining the residual amounts will be parallel to the horizontal axis. A correction to the prediction method requires addition of constant residual to the prediction model. If the rate of strain is not well predicted then a hump or dip is observed in the residual plot. To improve the accuracy of the prediction adjustment in the rate factor is needed. As in most prediction techniques there is multiplication of different parameters. An inaccuracy in one of these parameters will make the residual plot move away from the horizontal axis. By observing the resultant residuals and using the appropriate corrections improvement to the models can be done.

Ojdrovic and Zarghamee (1996) proposed a method to determine the long term prediction of shrinkage through short tem tests. The Bp-KX and ACI models for shrinkage are of the form-

$\mathrm{s}(\mathrm{t})=\mathrm{ST}_{\mathrm{s}}(\mathrm{t})$

where $\mathrm{s}(\mathrm{t})=$ shrinkage strain at any time $\mathrm{t}$

$\mathrm{S}=$ ultimate shrinkage strain value

And $\mathrm{T}_{\mathrm{s}}(\mathrm{t})=$ time function

Dividing strain at any time $t_{1}$ by the corresponding value of the time function at $t_{1}$ gives the ultimate shrinkage value.

$\mathrm{S}=\mathrm{s}\left(\mathrm{t}_{1}\right) / \mathrm{T}_{\mathrm{s}}\left(\mathrm{t}_{1}\right)$

They found that using 28 days as $\mathrm{t}_{1}$ the results obtained are more accurate than predictions using either BP-KX model or ACI model.

Videla, Covarrubias and Masana (2004) modified different shrinkage models viz. ACI, CEB, B3 , GZ, GL and Sakata for concrete made in Chile with local materials. They found that almost all the models underestimate the drying shrinkage strain of concrete containing pozzolan cements. According to them GZ, GL and Sakata models give relatively good estimation for concretes containing ordinary portland cement where as the ACI, CEB and B3 models underestimate the strains. They calibrated the existing models and modified the CEB time function for the concretes used in Chile. 
Table 2.5 - Calibration of the time function for different models for ACI, CEB, B3 and GL

\begin{tabular}{|c|c|c|}
\hline Model and Functions & $\begin{array}{c}\text { Portland } \\
\text { Cement }\end{array}$ & $\begin{array}{c}\text { Portland } \\
\text { Pozzolan }\end{array}$ \\
\cline { 2 - 3 } & $\mathbf{K}_{\mathbf{c}}$ & $\mathbf{K}_{\mathbf{c}}$ \\
\hline ACI Model: $\left(\alpha_{s h}\right)_{t}=\frac{t}{K_{c} \times 35+t}\left(\varepsilon_{h}\right)_{u}$ & 0.86 & 0.65 \\
\hline CEB Model: $\beta_{s}\left(t-t_{s}\right)=\left[\frac{\left(t-t_{s}\right) / t_{1}}{K_{c} \times .0035 \times(2 V / S)^{2}+\left(t-t_{s}\right) / t_{1}}\right]^{0.5}$ & 1.70 & 1.24 \\
\hline B3 Model: $S(t)=\tanh \left(\frac{t-t_{0}}{K_{c} \times \tau_{s h}}\right)^{1 / 2}$ & 1.16 & 0.88 \\
\hline GL Model: $\beta(t)=\left(\frac{t-t_{c}}{t-t_{c}+K_{c} \times 0.15 .(V / S)^{2}}\right)^{0.5}$ & 1.59 & 1.16 \\
\hline
\end{tabular}

Table 2.6 - Calibration of the ultimate shrinkage strains for different time functions

\begin{tabular}{|c|c|c|}
\hline \multirow{2}{*}{ Models } & \multicolumn{2}{|c|}{ Cement Class } \\
\cline { 2 - 3 } & Portland & Portland Pozzolan \\
\cline { 2 - 3 } & $\mathbf{K}_{\mathbf{G}}$ & $\mathbf{K}_{\mathbf{G}}$ \\
\hline ACI & 1.59 & 1.67 \\
\hline CEB & 1.62 & 1.82 \\
\hline B3 & 1.3 & 1.42 \\
\hline GL & 1.06 & 1.17 \\
\hline
\end{tabular}

Where $\mathrm{K}_{\mathrm{G}}=$ modifies the ultimate shrinkage

Modification of CEB time function-

$f^{\prime}\left(t, t_{0}\right)=\left[\frac{\left(t-t_{0}\right)}{K_{c}(2 V / S)^{2}+\left(t-t_{0}\right)}\right]^{b}$ 
Table 2.7 - Modification of CEB time function

\begin{tabular}{|c|c|c|c|c|}
\hline \multirow{2}{*}{ Cement Type } & \multicolumn{2}{|c|}{ Modification Factor } & Correlation & $\begin{array}{c}\text { Standard } \\
\text { error, } \mathbf{~ m m} / \mathbf{m}\end{array}$ \\
\cline { 2 - 3 } & $\mathbf{K}_{\mathbf{c}}$ & Power b & Coefficient, $\%$ & 0.0354 \\
\hline $\begin{array}{c}\text { Portland } \\
\text { Pozzolan }\end{array}$ & 0.0193 & 0.9 & 98.99 & 0.0426 \\
\hline
\end{tabular}

\subsection{Synthesis from Literature Review}

From the detailed literature review, the following information can be summarized -

1. C-S-H gel has a large surface area and it has a layered structure with associated gel porosity.

2. Shrinkage is caused by the movement of water from pores or gel surface which is proportional to the ambient relative humidity.

3. Shrinkage is mainly governed by three types of mechanisms as follows -

(a) capillary tension at high humidity levels, (b) disjoining pressure at low humidities and (c)surface energy at low humidities.

4. C-S-H gel is the main contributing factor to shrinkage which is the mass that is prone to volume deformation and the other components such as aggregate, unhydrated paste and calcium hydroxide provides a restraining effects.

5. Due to addition of supplementary cementing materials in general early age shrinkage increases but the later age shrinkage decreases.

6. Several models exist for the prediction of shrinkage. However none of them considered the effects of supplementary cementing materials directly into their equations. Some models upgraded for HPC, considered the strength development as criterion for shrinkage and few of them suggested the use of cement type (Type II or III) to make it applicable for fly ash, slag or silica fume. But none of them introduce the effect of supplementary cementing materials directly in the formula. Similar observation was made for long-term prediction model for strength. 


\subsection{Research Significance}

Supplementary cementing materials are increasingly used in HPC preparations. The existing prediction models for shrinkage of HPC with binary and ternary admixture are not accurate enough. Similar problem exists for strength prediction equation by ACI. The current study will introduce the effects of supplementary materials (fly ash, slag and silica fume) in shrinkage and strength prediction equation, by incorporating rate of C-S-H gel formation. Results are based on typical commercial silica fume, local slag and fly ash and local aggregate can be used for predicting shrinkage and compressive strength for wide range of HPC mixtures. 


\section{Chapter 3}

\section{Materials and Mixture Proportioning}

\subsection{Cement}

Commercially available type I portland cement conforming to ASTM C 150 was used in this study. The basic physical properties and compound composition of the type I cement are presented in the following tables -

Table 3.1 - Physical properties of Type I portland cement used

\begin{tabular}{|c|c|c|c|}
\hline \multirow{2}{*}{ Specific Gravity } & \multirow{2}{*}{$\begin{array}{c}\text { Fineness } \\
\text { (Blaine) }\end{array}$} & \multicolumn{2}{|c|}{ Setting Time } \\
\cline { 3 - 4 } & & Initial(min.) & Final(min.) \\
\hline 3.15 & $320 \mathrm{~m}^{2} / \mathrm{kg}$ & 90 & 260 \\
\hline
\end{tabular}

Table 3.2 - Compound compositions of portland cement

\begin{tabular}{|c|c|}
\hline Compounds & Percentage by mass \\
\hline $\mathrm{C}_{3} \mathrm{~S}$ & 49 \\
\hline $\mathrm{C}_{2} \mathrm{~S}$ & 25 \\
\hline $\mathrm{C}_{3} \mathrm{~A}$ & 12 \\
\hline $\mathrm{C}_{4} \mathrm{AF}$ & 8 \\
\hline $\mathrm{C}^{-} \mathrm{S}_{2}$ & 2.8 \\
\hline $\mathrm{CaO}$ & 0.8 \\
\hline $\mathrm{MgO}$ & 2.4 \\
\hline
\end{tabular}

\subsection{Coarse Aggregate}

One type of crushed limestone from Greer, WV was used. Aggregates used conformed to ASTM C 33 (Standard Specifications for Concrete Aggregates). Table 3.3

shows few physical properties and Table 3.4 shows the sieve analysis data. 
Table 3.3 - Properties of coarse aggregates

\begin{tabular}{|c|c|}
\hline Properties & Value \\
\hline Nominal Size & $19 \mathrm{~mm}$ \\
\hline Absorption (\%) & 0.53 \\
\hline SSD Specific Gravity & 2.69 \\
\hline Bulk Specific Gravity & 2.68 \\
\hline Apparent Specific Gravity & 2.719 \\
\hline
\end{tabular}

Table 3.4 - Sieve analysis result

\begin{tabular}{|c|c|c|c|}
\hline \multirow{2}{*}{ Sieve Size } & \multicolumn{2}{|c|}{ Specifications } & Percentage Passing \\
\cline { 2 - 4 } & Low & High & Greer \#57 \\
\hline $25 \mathrm{~mm}$ & 95 & 100 & 100 \\
\hline $19 \mathrm{~mm}$ & - & - & - \\
\hline $16 \mathrm{~mm}$ & - & - & 73 \\
\hline $12.5 \mathrm{~mm}$ & 25 & 60 & 45 \\
\hline $9.5 \mathrm{~mm}$ & - & - & - \\
\hline $4.75 \mathrm{~mm}$ & 0 & 10 & 1 \\
\hline $2.36 \mathrm{~mm}$ & 0 & 5 & 3 \\
\hline
\end{tabular}

\subsection{Fine Aggregate}

Joe Lucas Dredge sand which conformed to ASTM C 33 (Standard Specification for Concrete Aggregates) was used for this study. Table 3.5 and 3.6 shows the properties of sand and sieve analysis data respectively. 
Table 3.5- Properties of fine aggregate

\begin{tabular}{|c|c|}
\hline \multicolumn{2}{|c|}{ Source and Basic Properties } \\
\hline Facility Source & Joe Lucas Dredge \\
\hline Type & Natural silica sand \\
\hline SSD specific gravity & 2.61 \\
\hline Bulk specific gravity & 2.59 \\
\hline Apparent specific gravity & 2.65 \\
\hline Absorption & $1.0 \%$ \\
\hline Fineness modulus & 2.79 \\
\hline
\end{tabular}

Table 3.6 - Sieve analysis of sand

\begin{tabular}{|c|c|c|c|}
\hline \multirow{2}{*}{ Sieve } & \multicolumn{2}{|c|}{ Specifications } & Percentage Passing \\
\cline { 2 - 4 } & Low & High & River Sand \\
\hline $19 \mathrm{~mm}$ & 100 & 100 & 100 \\
\hline $4.75 \mathrm{~mm}$ & 95 & 100 & 97.2 \\
\hline $2.36 \mathrm{~mm}$ & 80 & 100 & 82.3 \\
\hline $1.18 \mathrm{~mm}$ & 50 & 85 & 69 \\
\hline $600 \mu \mathrm{m}$ & 25 & 60 & 54.6 \\
\hline $300 \mu \mathrm{m}$ & 5 & 30 & 16.1 \\
\hline $150 \mu \mathrm{m}$ & 0 & 10 & 2 \\
\hline $75 \mu \mathrm{m}$ & - & - & 0.7 \\
\hline
\end{tabular}

\subsection{Supplementary Cementing Material}

\subsubsection{Silica fume}

The silica fume used in this study was commercially available and supplied by Master Builders, Inc. It conformed to ASTM C 1240 (Standard Specification for Silica 
Fume for Use in Hydraulic-Cement Concrete and Mortar). The specific gravity of the silica fume was 2.2 .

\subsubsection{Slag}

Commercially available ground granulated blast furnace slag from local source Weirton, WV conforming to ASTM C 989 (Standard Specification for Ground Granulated Blast-Furnace Slag for use in Concrete and Mortar) was used for the study. Table 3.7 shows typical properties of slag.

Table 3.7- Properties of slag

\begin{tabular}{|c|c|}
\hline Items & Values/ Description \\
\hline Grade & White Powder \\
\hline Appearance & No distinct odor \\
\hline Odor & Solid ( powder) \\
\hline Physical State & 10.5 to 12.7 \\
\hline pH Value (in water) & Slightly ( 0.1 to 1.0$)$ \\
\hline Solubility in water $(\%)$ & $1300-1350$ \\
\hline Melting point $\left({ }^{\circ} \mathrm{C}\right)$ & 2.8 \\
\hline Specific Gravity & \\
\hline
\end{tabular}

\subsubsection{Fly ash}

The Class F fly ash used in this study conforming to ASTM C 618 (Standard Specification for Coal Fly Ash and Raw Calcined Natural Pozzolan for Use as a Mineral Admixture in Portland cement concrete) was from Hatfield power station, Pennsylvania. The specific gravity of the fly ash was 2.4.

\subsection{Chemical Admixtures}

\subsubsection{High-range water reducing admixture (HRWRA)}

The commercially available high-range water reducing admixture used in this study was a naphthalene-based superplasticizer conforming to ASTM C 494 Type F. 


\subsubsection{Water reducing admixture (WRA)}

Water reducing admixture used in the study conform to ASTM C 494Type A.

\subsubsection{Air Entraining Agent (AEA)}

The air entraining agent used in the study conforming to ASTM C 260 was based on neutralized vinsol resin.

\subsection{Mixing Water}

Mixing water used in this study was tap water from the Morgantown city water supply and was assumed to have a density of $1000 \mathrm{~kg}$ per cubic meter.

\subsection{Mixture Proportioning}

A total of 24 mixtures were prepared for the study. A water to cementitious material ratio of $0.4(\mathrm{w} / \mathrm{cm})$ was selected as it is very common for HPC mixtures. Binary mixtures with slag or silica fume or fly ash were proportioned with different replacement

levels of cement. Ternary mixtures with and the following combinations were also proportioned with different replacement levels of cement. Both binary and ternary mixture ingredients are shown with proportions by mass of cement. A concrete was made without any supplementary cementing materials.

The following replacement levels are proportioned for Binary mixtures:

Slag + cement $-25 \%, 35 \%, 45 \%$ replacement of cement by mass

Fly ash + cement $-15 \%, 25 \%, 45 \%$ replacement of cement by mass

Silica Fume + cement $-5 \%, 10 \%, 15 \%$ replacement of cement by mass

Ternary mixtures:

Slag + silica fume $-25+5(25 \%$ slag $+5 \%$ silica fume $), 25+10,35+5,35+10,35+15,45+5$

Fly ash + silica fume $-15+5(15 \%$ slag $+5 \%$ silica fume $), 25+5,25+10,35+5,35+10$, $35+15$

Slag + Fly Ash - 25+15(25\% slag +15\% fly ash), 35+15 
All of the above combination and replacement levels have been selected keeping in mind the replacements used frequently in the preparations of HPC for different purposes. In all the cases, the aggregate to cement paste ratio was kept constant to 2.3.In all the mixtures the total cementitious material content was also kept almost same as 387 to $392 \mathrm{Kg} / \mathrm{m}^{3}$. HRWRA and WRA were proportioned to achieve a slump of 150-200 mm and AEA to achieve an air-content of 5.5 to $6 \%$ for all the mixtures. Table 3.8 shows the mixture proportioning of all HPC including normal mixture.

Table 3.8- Mixture proportioning

\begin{tabular}{|c|c|c|c|c|c|c|c|c|c|c|c|}
\hline Mixture & Cement & Slag & $\begin{array}{l}\text { Fly } \\
\text { Ash }\end{array}$ & $\begin{array}{l}\text { Silica } \\
\text { Fume }\end{array}$ & $\begin{array}{c}\text { Coarse } \\
\text { Aggregate }\end{array}$ & $\begin{array}{c}\text { Fine } \\
\text { Aggregate }\end{array}$ & HRWRA & WRA & AEA & Slump & $\begin{array}{c}\text { Air } \\
\text { content }\end{array}$ \\
\hline & $\mathrm{Kg} / \mathrm{m}^{3}$ & $\mathrm{Kg} / \mathrm{m}^{3}$ & $\mathrm{Kg} / \mathrm{m}^{3}$ & $\mathrm{Kg} / \mathrm{m}^{3}$ & $\mathrm{Kg} / \mathrm{m}^{3}$ & $\mathrm{Kg} / \mathrm{m}^{3}$ & $\mathrm{ml} / \mathrm{m}^{3}$ & $\mathrm{ml} / \mathrm{m}^{3}$ & $\mathrm{ml} / \mathrm{m}^{3}$ & $\mathrm{~mm}$ & $\%$ \\
\hline SL 25 & 293 & 98 & & & 1038 & 699 & 2500 & 750 & 1350 & 200 & 6 \\
\hline SL 35 & 253 & 136 & & & 1038 & 699 & 2500 & 750 & 1350 & 190 & 6 \\
\hline SL 45 & 213 & 174 & & & 1038 & 699 & 2500 & 750 & 1350 & 190 & 5.5 \\
\hline $\mathrm{Fl} 15$ & 330 & & 58 & & 1038 & 699 & 2730 & 620 & 870 & 210 & 6 \\
\hline $\mathrm{FL} 25$ & 293 & & 98 & & 1038 & 699 & 2730 & 620 & 870 & 200 & 6 \\
\hline $\mathrm{Fl} 35$ & 253 & & 136 & & 1038 & 699 & 2730 & 620 & 870 & 200 & 6 \\
\hline SF5 & 373 & & & 20 & 1038 & 699 & 2730 & 620 & 870 & 190 & 6 \\
\hline SF 10 & 350 & & & 39 & 1038 & 699 & 2730 & 620 & 870 & 190 & 6 \\
\hline SF 15 & 327 & & & 58 & 1038 & 699 & 2730 & 620 & 870 & 180 & 5.5 \\
\hline SS $25+5$ & 272 & 97 & & 19 & 1038 & 699 & 3410 & 620 & 870 & 190 & 5 \\
\hline SS $25+10$ & 249 & 96 & & 38 & 1038 & 699 & 3910 & 610 & 870 & 200 & 6 \\
\hline SS $35+5$ & 231 & 135 & & 19 & 1038 & 699 & 3478 & 610 & 870 & 185 & 6 \\
\hline SS $35+10$ & 209 & 133 & & 38 & 1038 & 699 & 4348 & 610 & 870 & 190 & 6 \\
\hline SS $35+15$ & 189 & 132 & & 57 & 1038 & 699 & 4783 & 610 & 870 & 200 & 5 \\
\hline SS $45+5$ & 191 & 172 & & 19 & 1038 & 699 & 3768 & 610 & 870 & 185 & 5.5 \\
\hline FS $15+5$ & 307 & & 58 & 19 & 1038 & 699 & 2754 & 600 & 870 & 200 & 6 \\
\hline FS 25+5 & 266 & & 95 & 19 & 1038 & 699 & 3333 & 600 & 870 & 210 & 6 \\
\hline FS $25+10$ & 245 & & 94 & 38 & 1038 & 699 & 4058 & 600 & 870 & 200 & 6 \\
\hline FS $35+5$ & 225 & & 131 & 19 & 1038 & 699 & 3188 & 600 & 870 & 200 & 5.5 \\
\hline FS $35+10$ & 204 & & 130 & 37 & 1038 & 699 & 4203 & 600 & 870 & 190 & 6 \\
\hline FS $35+15$ & 184 & & 129 & 55 & 1038 & 699 & 3980 & 600 & 870 & 185 & 6 \\
\hline $\mathrm{CC}$ & 396 & & & & 1038 & 699 & 2730 & 620 & 870 & 200 & 6 \\
\hline$S L+F A \quad 25+15$ & 230 & 96 & 57 & & 1038 & 699 & 3188 & 650 & 870 & 200 & 6 \\
\hline$S L+F A 35+15$ & 190 & 133 & 57 & & 1038 & 699 & 2610 & 650 & 870 & 200 & 6 \\
\hline
\end{tabular}

$\mathrm{SL}=\mathrm{Slag}, \mathrm{FL}=$ Fly ash, $\mathrm{SF}=$ Silica fume, $\mathrm{SS}=\mathrm{Slag}+$ Silica fume, $\mathrm{FS}=$ Fly ash + Silica fume, $\mathrm{SL}+\mathrm{FA}=$ Slag + Fly ash, SL 25 is slag with $25 \%$ slag replacement, SS $25+$ S is $25 \%$ silica replacement and $5 \%$. Silica fume replacement and $\mathrm{CC}=\mathrm{Control}$ concrete with $0 \%$ replacement. For all other mixtures similar abbreviations have been used. 


\subsection{Mixing Procedure}

The following protocol was used for all the concrete mixtures:

1. Batched the materials by weight.

2. Added the AEA to sand and WRA to water and stirred thoroughly.

3. Added about $3 / 4$ th of mixing water (including WRA already mixed) to mixer machine

4. Added the coarse aggregate and silica fume followed by the rotation of the drum for 1 minute.

5. Added the sand (includes AEA already mixed) and mixed for another 1 minute.

6. Added the cementitous materials and remaining amount of mixing water.

7. Mixed for 3 minutes followed by 3 minutes of rest and again mixed for 2 minutes.

8. Added the HRWRA till the required slump was achieved.

\subsection{Curing}

After curing in the molds under wet burlap all the specimens for shrinkage and strength were demoulded and the shrinkage specimens were placed in the environmental chamber with a $\mathrm{RH}$ of $50 \%$ and temperature of $23 \pm 2^{\circ} \mathrm{C}$ and the compressive strength cylinders were cured under water. 


\section{Chapter 4}

\section{Estimation of C-S-H gel}

\subsection{Introduction}

As mentioned in chapter 2, C-S-H is the principal component of Hcp and it has maximum binding capacity. Moreover it has a large surface area compared to other products of hydration resulting into considerable influence on shrinkage and strength of cementing materials. A high amount of $\mathrm{C}-\mathrm{S}-\mathrm{H}$ gel formation can produce a denser microstructure with reduced porosity. Addition of silica fume, fly ash and slag with a lower w/cm produce a dense microstructure due to additional C-S-H gel and different microstructure. So, estimating the amount of C-S-H gel formed in a cement paste can give indication to how much reactive products have formed. A correlation between C-S$\mathrm{H}$ gel formation and drying shrinkage and compressive strength can be also deduced from large number of experimental data. Estimating C-S-H gel also will also give an idea about the reactivity of different supplementary cementing materials with cement. Generally it can be expected that with an increase in C-S-H gel a higher amount of strength and shrinkage can be expected (Jennings 2001). Water adsorption and nitrogen adsorption has been used for surface area measurements of C-S-H but they cannot be used directly for volume measurement. A novel method based on water adsorption test performed by Olson and Jennings (2000) is used in this research for C-S-H gel measurement.

\subsection{Method of Estimation}

Following section describes the methods of estimation of C-S-H gel

\subsubsection{Protocol}

1. The cement or cementitous paste samples were made using OPC, slag, fly ash and silica fume with $\mathrm{w} / \mathrm{cm}$ of 0.4 .

2. The Samples were cured under water at $23^{\circ} \mathrm{C}$. 
3. The hardened pastes were crushed into powdered sample using a mortar pestle.

4. The crushed particles are then sieved using nos. 30 and nos. 50 sieves to obtain particles with an approximate size range of 600 to $300 \mu \mathrm{m}$.

5. 2 to 3 gms. of these powdered samples are kept under $100 \mathrm{ml}$ of $70 \%$ Isopropyl alcohol for 5-6 days to stop hydration.

6. The powdered samples are then extracted from alcohol by filtering using filter paper and D-dried for 14 days at a constant pressure of .07Pa.

7. Next the samples are placed in the oven at $105^{\circ} \mathrm{C}$ for $48 \mathrm{hrs}$. to confirm D-drying.

8. Around 2 gms. of each of D-dried samples are kept in vials and then were left in a relative humidity chamber at $20 \% \mathrm{RH}$ chamber.

9. Weight of the samples were recorded regularly till the increase in weight stabilized for each of the samples.

10. In total, 24 mixtures were tested - for each mixture; six hydration days (1-d, 3-d, 7-d, 14-d, 28-d and 90-d) were considered. For each mixture and age two replicate samples were tested. Thus a total of 288 samples were estimated for C-S-H gel.

\subsubsection{Technique of D-drying}

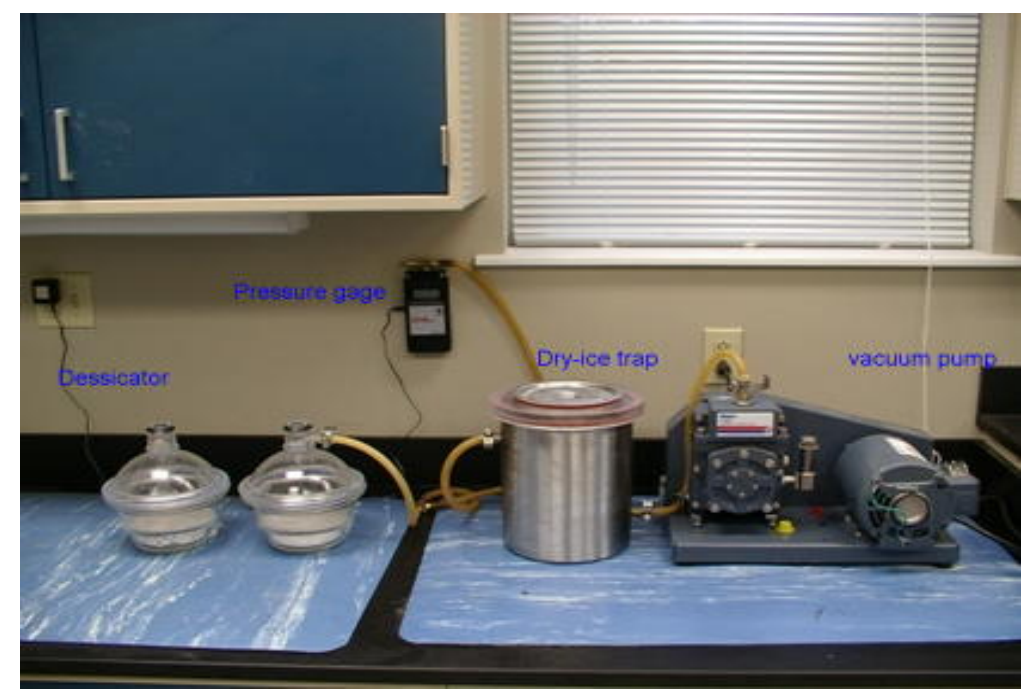

Fig. 4.1 - D-drying in progress 
D-dried state of cement paste is the state at which all the evaporable is lost and the only water contained by the paste is the non-evaporable water. D-drying can be performed either by vacuuming for 2 weeks under a pressure $0.07 \mathrm{~Pa}$ or by heating at $105^{\circ} \mathrm{C}$. In the laboratory the samples were vacuumed under a pressure of $.07 \mathrm{~Pa}$ for two weeks with intermittent pumping using a D-dry apparatus. A dry ice trap with a 1:1 mixture of dry-ice and acetone was used to attain a temperature of $-79^{\circ} \mathrm{C}$ and correspondingly a pressure of $0.07 \mathrm{~Pa}$ (Fig. 4.1)

\subsubsection{Relative humidity chamber}

Olson and Jennings (2001) used a glove box and maintained humidity by using lithium chloride with the box. However in the current study the method used by them was slightly modified by using a glove box (Fig. 4.2) with an automated humidity controller. A sensor and a dehumidifying pump were used to maintain a constant RH (Fig. 4.3) of $20 \%$ with an accuracy of $\pm 1.0 \%$. Fig. 4.6 shows how the samples were stored within glove box. A fan was used (Fig. 4.4) to keep the air (moisture level) uniform throughout the chamber.

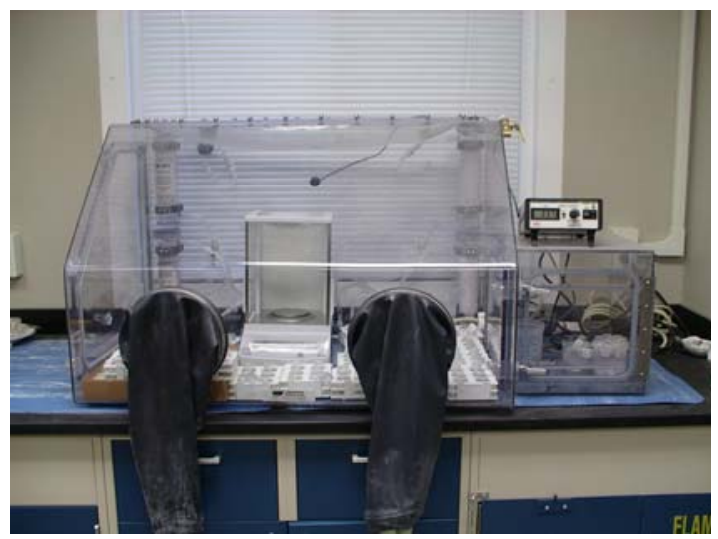

Fig. 4.2 - Constant relative humidity chamber

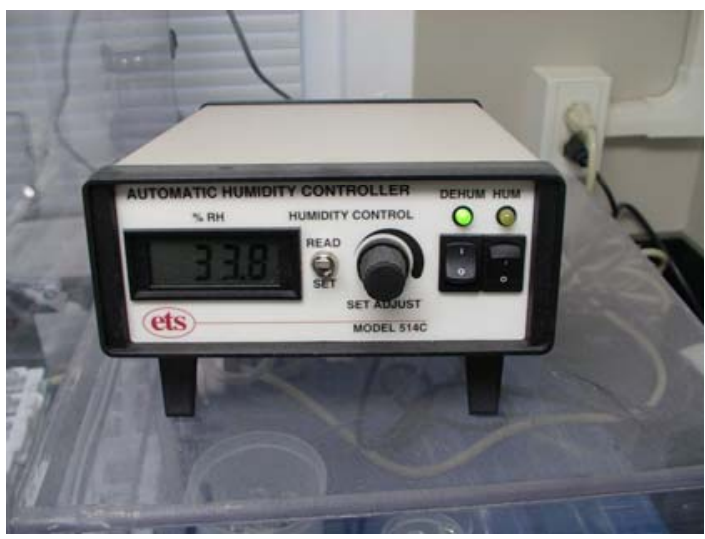

Fig 4.3 - Humidity controller

\subsubsection{Techniques of weighing}

Weighing of the samples was performed using a high precision digital electronic scale which can measure the mass with an accuracy of .0001 gram. The scale was placed within the glove box, in order to facilitate the measurement of change of weight of each 
sample within the control humidity chamber as shown in Fig. 4.4. Weighing was done in the following sequences:

1. Weights of the vials were measured

2. Weights of the vials and the samples were measured to obtain the weight of the samples

3. Weights of the samples were taken regularly for 14-18 days until there is no change in weight

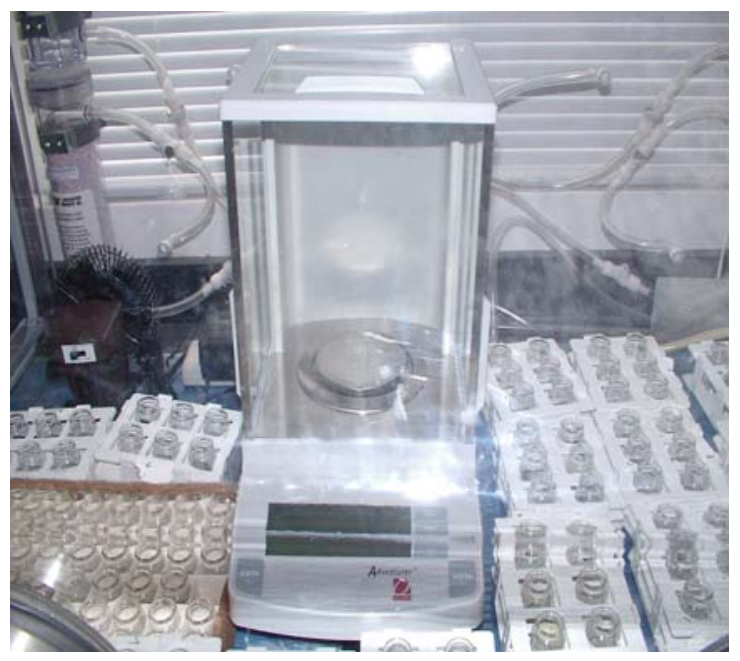

Fig 4.4 - A four place of decimal balance used for weight measurement placed within the $\mathrm{RH}$ chamber

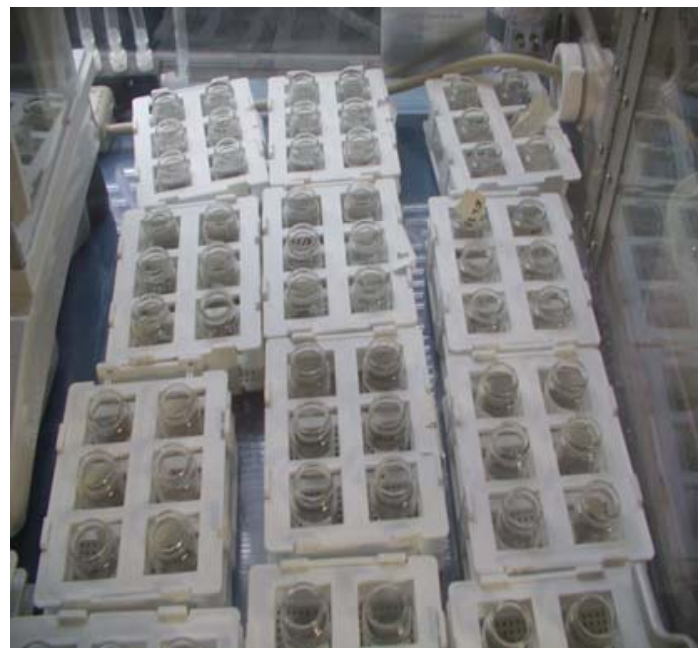

Fig 4.5 - D-dried samples kept within the RH chamber for water adsorption

\subsection{Theory for C-S-H estimation}

D-dried state is the state of cementitous material paste where there is no evaporable water is present (Fig. 4.6(b)). If D-dried cementitous paste is exposed to increasing RH it starts adsorbing water. The relationship between the amount of water absorbed and RH is non-linear below a RH of $11 \%$. At $11 \%$ RH water starts entering the interlayer spaces between the C-S-H layers. Below the RH of $11 \%$ adsorbed water is not proportional to amount of C-S-H gel apart of the water enters into the interlayer space.

The amount of water adsorbed by $11 \% \mathrm{RH}$ is enough to form a monolayer if it were distributed evenly (Fig. 4.6(c)). However from 11\%RH to 50\% RH multilayer water adsorption continues (Fig. 4.6(d)), water adsorption above 11\% RH can be assumed to be 
proportional to the amount of C-S-H gel formed but multilayer water adsorption by C-S$\mathrm{H}$ gel starts before monolayer is complete.

Between the ranges of $11 \% \mathrm{RH}$ to $50 \% \mathrm{RH}$ there exists a linear relationship between the amount of water adsorbed and the partial pressure. Above $50 \% \mathrm{RH}$, the water condenses in the pores and as a result the linear relationship does not exist. At any particular RH value above $11 \% \mathrm{RH}$, amount of water adsorbed will be proportional to the C-S-H gel formed. The $20 \% \mathrm{RH}$ was chosen so that it is within the range of $11-50 \% \mathrm{RH}$ and at this value there will be higher amount of water adsorption, which will increase the sensitivity of the test through higher amount of weight gain and reduce the chances of capillary condensation.

From pure $\mathrm{C}_{3} \mathrm{~S}$ paste, it is possible to determine the amount of C-S-H gel formed per gram of D-dried paste at different days. Therefore a water adsorption test at $20 \% \mathrm{RH}$ will give the amount of water adsorbed by C-S-H gel per gram of D-dried paste. Olson and Jennings (2001) found that at any degree of hydration amount of water adsorbed per gm of C-S-H gel is fairly constant at a particular $\mathrm{RH}$ value. From the pure paste performing stoichometric calculation they both found the amount of C-S-H gel per gm of D-dried paste and the amount of water adsorbed per gm of D-dried paste. Dividing the above mentioned quantities it is possible to obtain the amount of water adsorbed per gm of C-S-H gel. For example -

$\frac{\text { gm. of C - S - H gel formed }}{\text { gm. of D - dried paste }}=\frac{\text { water adsorbed by } 1 \mathrm{gm} \text {. of D }- \text { dried paste }}{\text { Water adsorbed by } 1 \text { gm. of C }-\mathrm{S}-\mathrm{H} \text { gel }}$

Olson and Jennnings (2001) performing the water adsorption technique on hydrated pure $\mathrm{C}_{3} \mathrm{~S}$ samples found a relatively constant value of $100 \mathrm{mg}$ water adsorbed / gm of C-S-H gel. This value is constant for C-S-H gel formed from any kind of cementitous material at $20 \% \mathrm{RH}$.

For our purpose we assume that 100mg of water will be adsorbed by $1 \mathrm{gm}$. of C$\mathrm{S}-\mathrm{H}$ gel. Assuming a density of $2.6 \mathrm{gm} / \mathrm{cm}^{3}$ for C-S-H gel equation can be re-written in the form-

$$
\mathrm{cm}^{3} \text { wateradsorbed } / \text { gm.of D }- \text { dried paste }=\frac{\text { wateradsorbedby } 1 \text { gm.of D }- \text { dried paste }}{100 \times 2.6}
$$



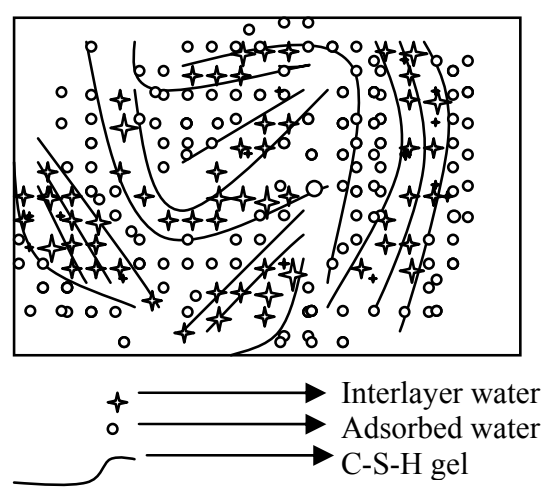

(a)

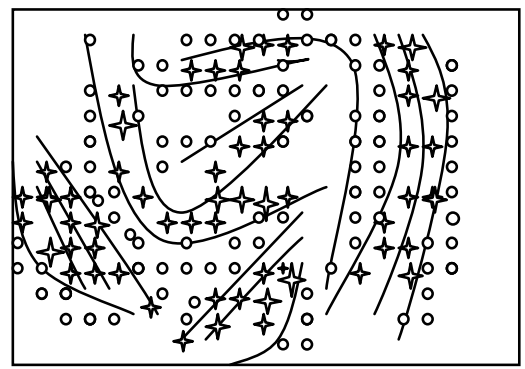

(b)

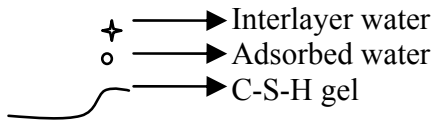

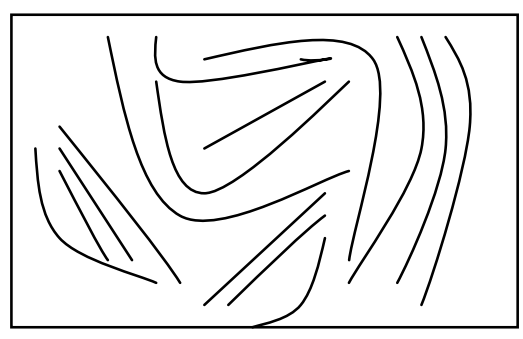

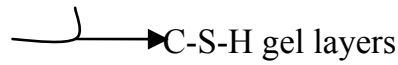

(b)
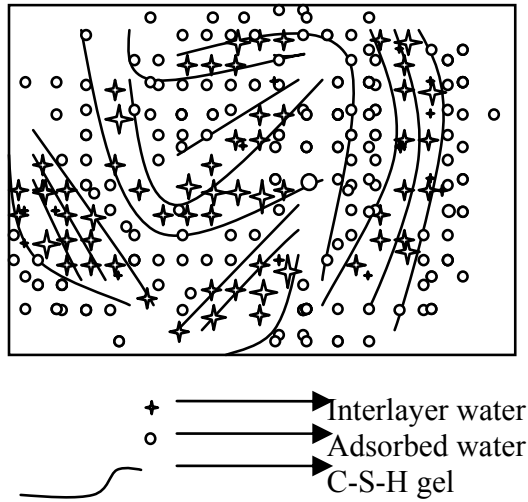

(d)

Fig 4.6 - (a) Before D-drying microstructure of C-S-H gel (b) after D-drying microstructure of C-S-H gel (c) microstructure of C-S-H gel at 11\%RH with water entering interlayer spaces and monolayer water adsorbed (d) microstructure of C-S-H gel at a RH $>11 \% \mathrm{RH}$ (with multilayer adsorption) and amount of water adsorbed is proportional to $\mathrm{RH}$ in the range $11 \%-50 \% \mathrm{RH}$ 
Table 4.1 -Typical calculation for C-S-H gel estimation

\begin{tabular}{|c|c|c|c|c|c|c|c|c|c|c|}
\hline 1 & 2 & \multicolumn{2}{|c|}{3} & \multicolumn{2}{|c|}{4} & \multicolumn{2}{|c|}{5} & \multicolumn{2}{|c|}{6} & 7 \\
\hline \multirow{2}{*}{ Mixture } & $\begin{array}{l}\text { Age of } \\
\text { Sample }\end{array}$ & \multicolumn{2}{|c|}{$\begin{array}{l}\text { Wt. of D-dried } \\
\text { sample in gm. }\end{array}$} & \multicolumn{2}{|c|}{$\begin{array}{c}\text { Amount of } \\
\text { adsorbed water } \\
\text { in gm. }\end{array}$} & \multicolumn{2}{|c|}{$\begin{array}{l}\text { gm of adsorbed } \\
\text { water/gm of D- } \\
\text { dried paste }\end{array}$} & \multicolumn{2}{|c|}{$\begin{array}{c}\mathrm{cm}^{3} \text { of C-S-H /gm. } \\
\text { of } \\
\text { D-dried paste }\end{array}$} & \multirow{2}{*}{$\begin{array}{c}\mathrm{cm}^{3} \text { of } \\
\mathrm{C}-\mathrm{S}-\mathrm{H} / \\
\mathrm{gm} \text {. of } \\
\begin{array}{c}\text { D-dried } \\
\text { paste }\end{array} \\
\begin{array}{c}\text { avg. of } \\
\text { two } \\
\text { samples }\end{array}\end{array}$} \\
\hline & Days & $\underset{\text { I }}{\text { Sample }}$ & $\underset{\text { II }}{\text { Sample }}$ & $\underset{\text { I }}{\text { Sample }}$ & $\underset{\text { II }}{\text { Sample }}$ & $\underset{I}{\text { Sample }}$ & $\begin{array}{l}\text { Sample } \\
\text { II }\end{array}$ & $\underset{\text { I }}{\text { Sample }}$ & $\underset{\text { II }}{\text { Sample }}$ & \\
\hline FL 15 & 3 & 1.977 & 1.347 & 0.0555 & .0341 & 0.0281 & 0.0253 & 0.0937 & 0.0947 & .0942 \\
\hline FL15 & 60 & 1.2629 & 1.5924 & 0.0417 & 0.0572 & 0.0330 & 0.0359 & 0.1268 & 0.1380 & .1324 \\
\hline SL 25 & 3 & 1.7908 & 1.7645 & 0.0425 & 0.0360 & 0.0237 & 0.0204 & 0.0912 & 0.0786 & .0849 \\
\hline SL 25 & 60 & 1.3622 & 1.7422 & 0.0506 & 0.0671 & 0.0372 & 0.0385 & 0.1429 & 0.1481 & .1455 \\
\hline $\mathrm{CC}$ & 1 & 1.4488 & 1.1554 & 0.0353 & 0.0271 & 0.0243 & 0.0235 & 0.0937 & 0.0903 & .0920 \\
\hline $\mathrm{CC}$ & 60 & 1.589 & 2.3612 & 0.0579 & 0.0850 & 0.0365 & 0.0360 & 0.1402 & 0.1384 & .1393 \\
\hline SS $25+5$ & 7 & 2.2965 & 2.2381 & 0.076 & 0.0744 & 0.0331 & 0.0332 & 0.1273 & 0.1279 & .1276 \\
\hline SS $25+5$ & 60 & 1.4478 & 1.73 & 0.0573 & 0.0668 & 0.0396 & 0.0386 & 0.1523 & 0.1485 & .1504 \\
\hline
\end{tabular}

Column $5=$ Column $4 /$ Column 3; Column $6=$ Column 5/ (.1*2.6); Column $7=$ avg. of two samples in Column 6

FL - fly ash, SL - slag, CC - $0 \%$ replacement / cement, SS - slag + silica fume

\subsection{Test Results and Discussions}

Figs. 4.9 through Fig. 4.17 furnish the relationship between estimated volumes of C-S-H gel per gm. of D-dried paste for all mixtures. Each figure has been plotted for volume of C-S-H gel vs. number of days of maturity of samples or hydration age. Each figure also displays the comparisons among four mixtures out of which one is always kept as only cement. 


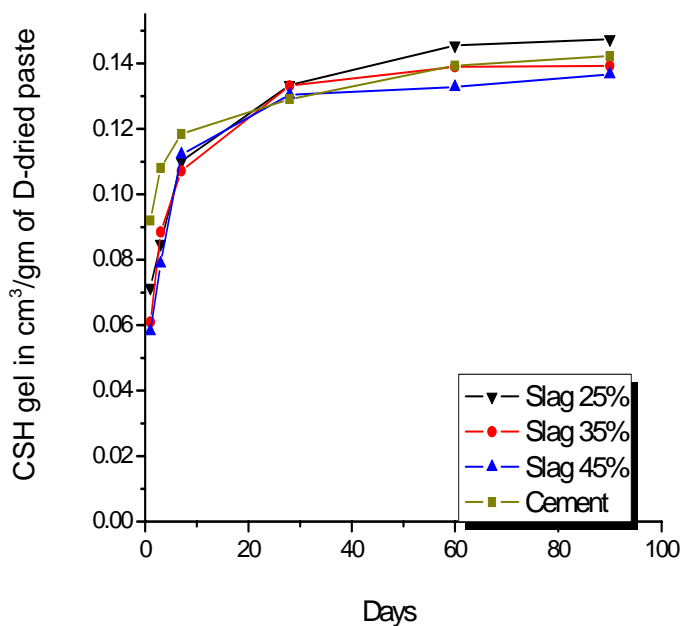

(a)

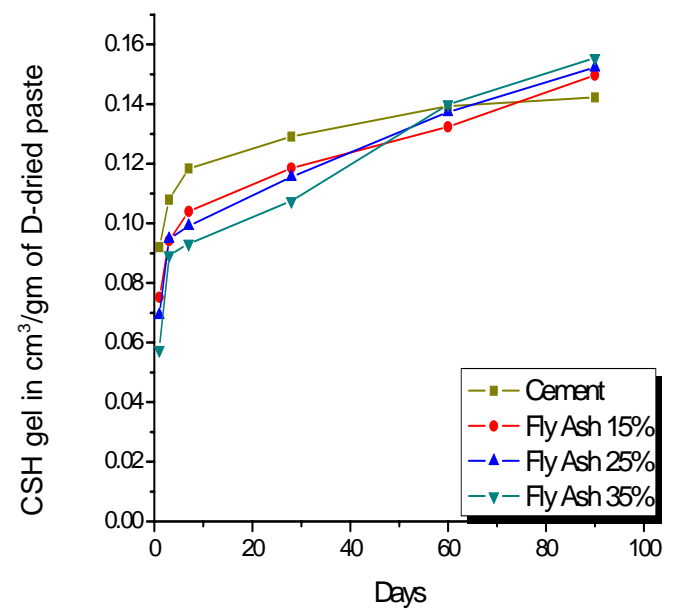

(b)

Fig. 4.7 - (a) Formation of C-S-H gel up to 90 days for different amount of replacement by slag (b) formation of C-S-H gel up to 90 days for different amount of replacement by fly ash

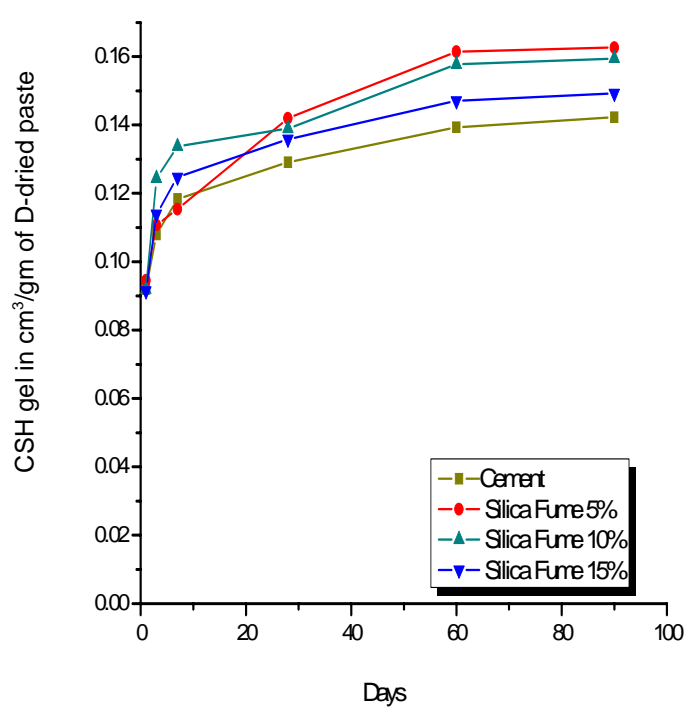

(a)

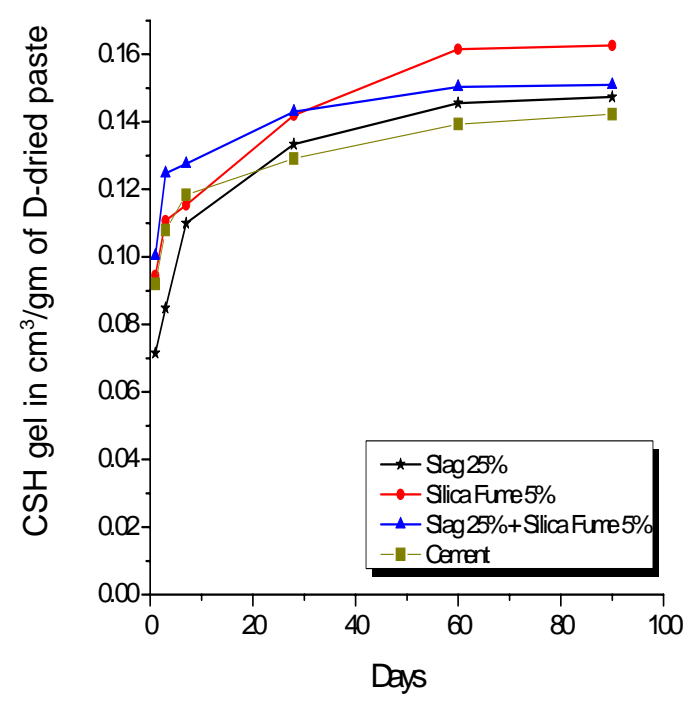

(b)

Fig. 4.8 - (a) Formation of C-S-H gel up to 90 days for different amount of replacement by silica fume (b) formation of C-S-H gel up to 90 days for different amount of replacement by slag $25 \%+$ silica fume $5 \%$ 


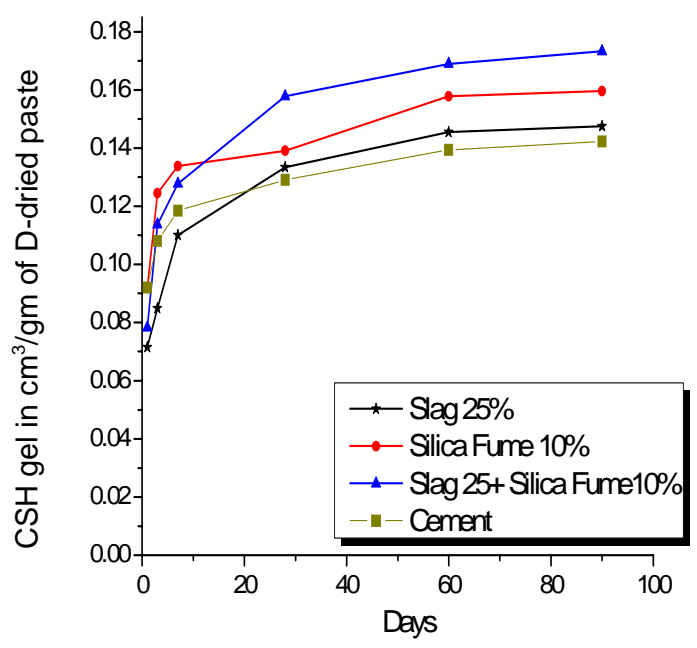

(a)

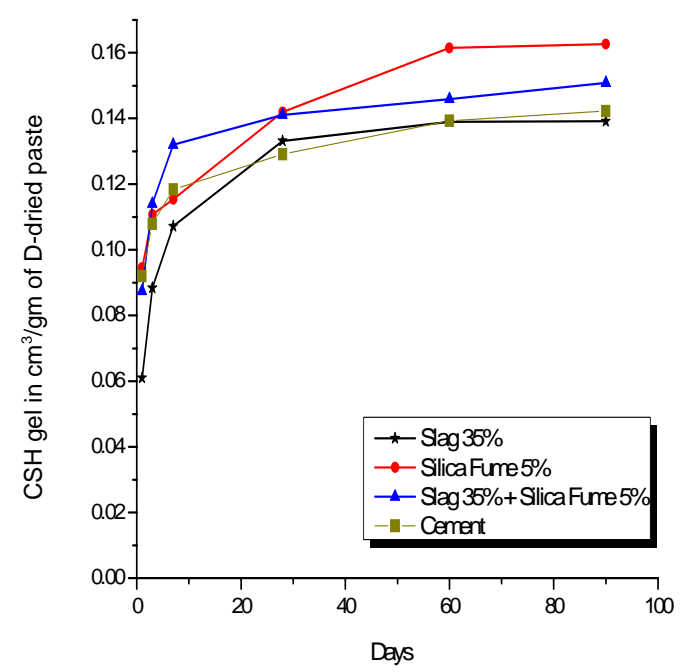

(b)

Fig. 4.9 - (a) Formation of C-S-H gel up to 90 days for different amount of replacement by slag $25 \%+$ silica fume $10 \%$ (b) formation of C-S-H gel up to 90 days for different amount of replacement by slag $35 \%+$ silica fume $5 \%$

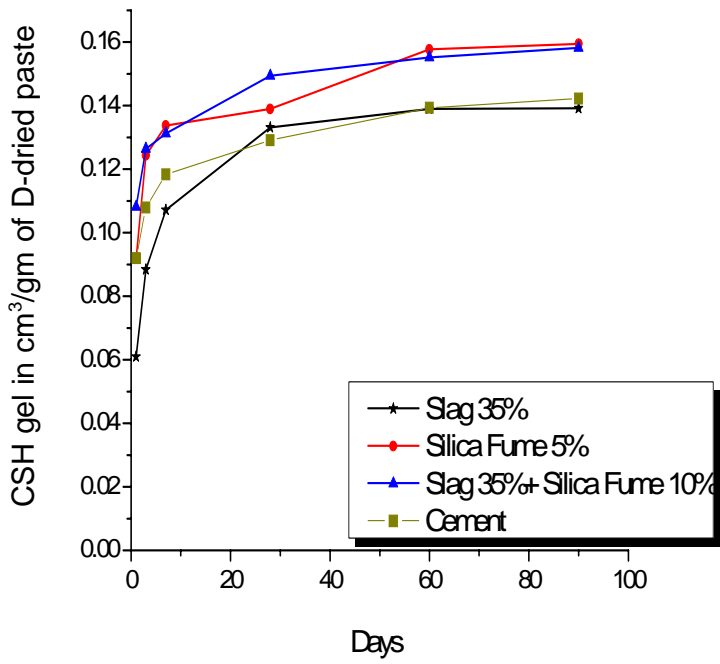

(a)

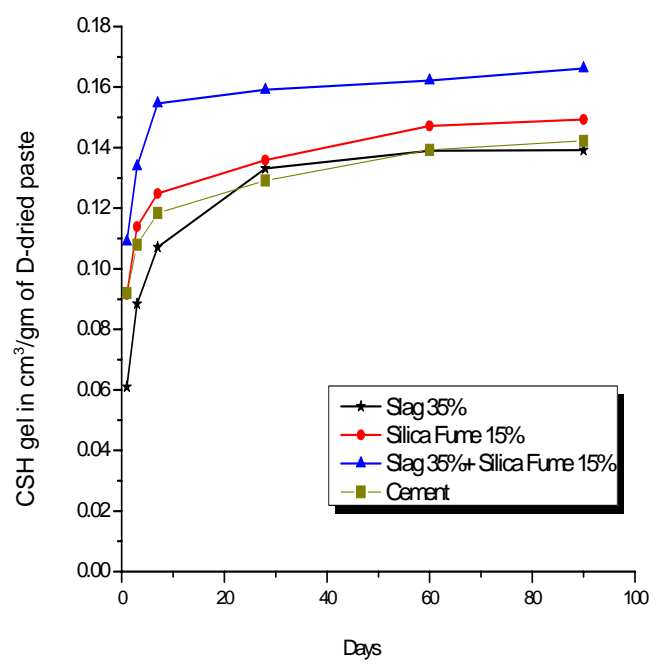

(b)

Fig. 4.10 - (a) Formation of C-S-H gel up to 90 days for different amount of replacement by slag $35 \%+$ silica fume $10 \%$ (b) Fformation of C-S-H gel up to 90 days for different amount of replacement by slag $35 \%+$ silica fume $15 \%$ 


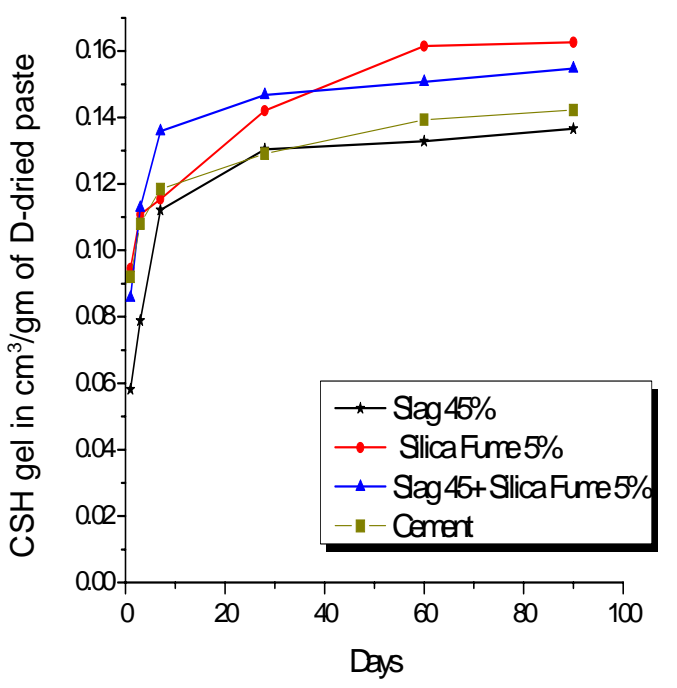

(a)

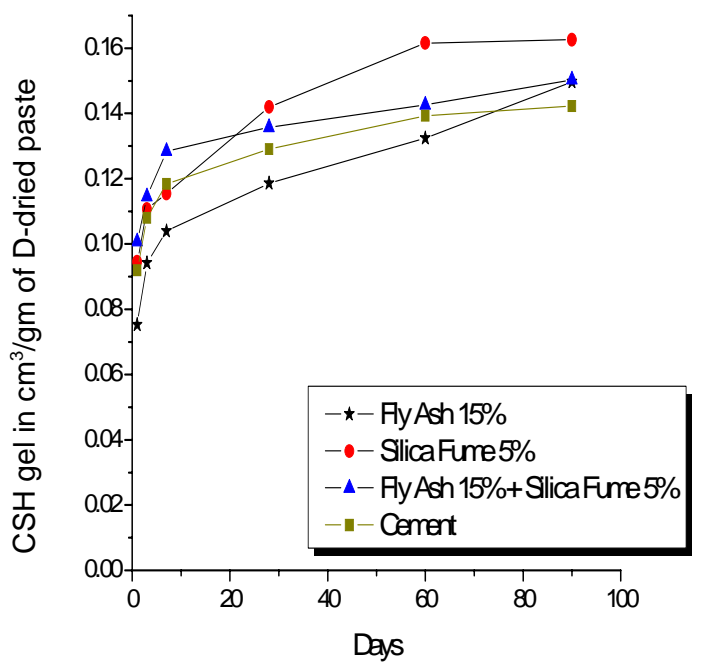

(b)

Fig. 4.11 - (a) Formation of C-S-H gel up to 90 days for different amount of replacement by slag $45 \%+$ silica fume $10 \%$ (b) formation of C-S-H gel up to 90 days for different amount of replacement by fly ash $15 \%+$ silica fume $15 \%$

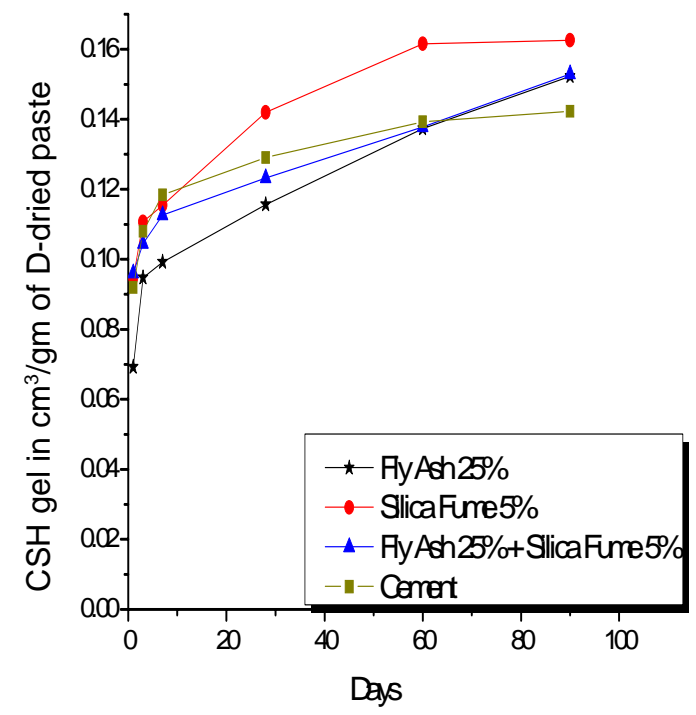

(a)

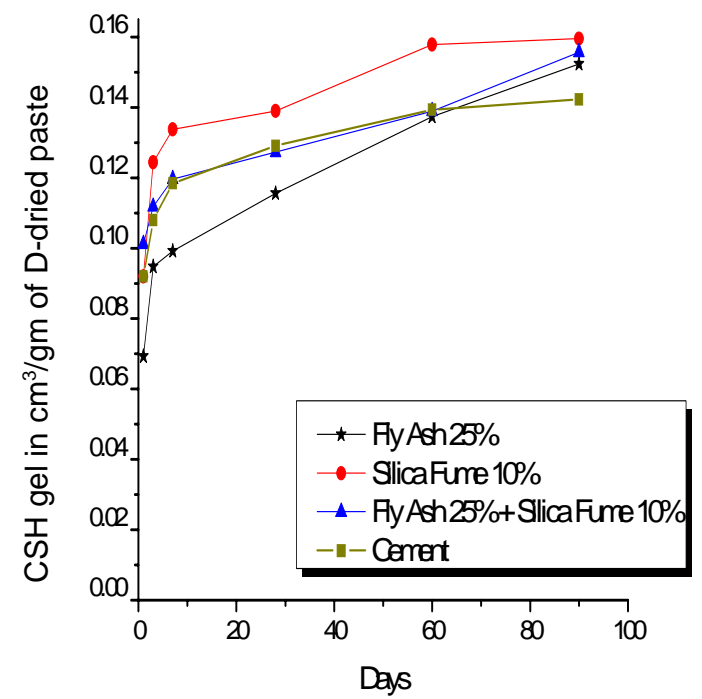

(b) 
Fig. 4.12 - (a) Formation of C-S-H gel up to 90 days for different amount of replacement by fly ash $25 \%+$ silica fume $5 \%$ (b) formation of C-S-H gel up to 90 days for different amount of replacement by fly ash $25 \%+$ silica fume $10 \%$

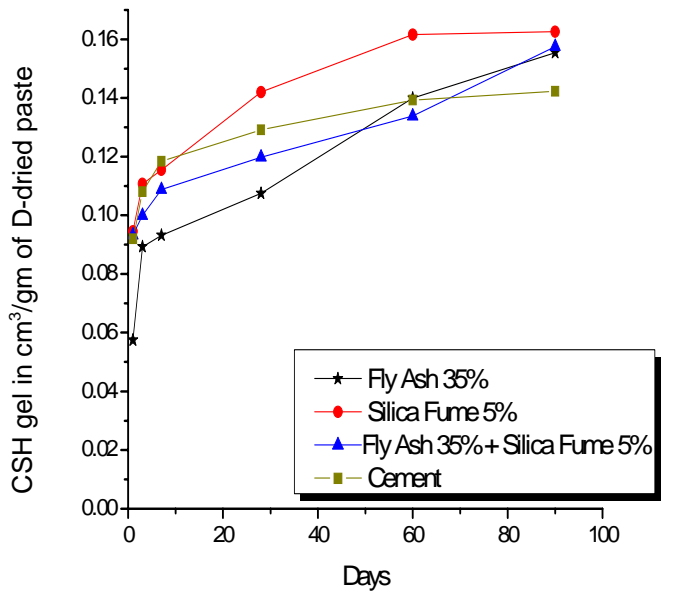

(a)

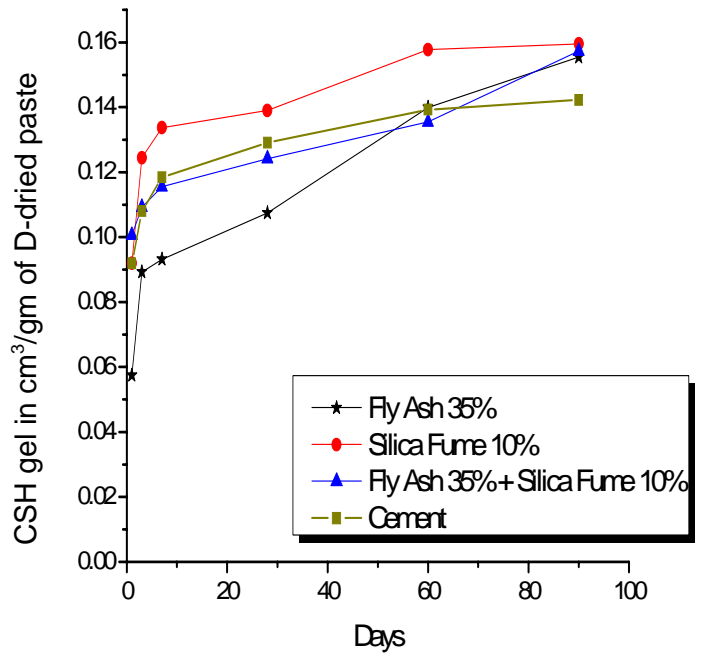

(b)

Fig. 4.13 - (a) Formation of C-S-H gel up to 90 days for different amount of replacement by fly ash $35 \%+$ silica fume $5 \%$ (b) formation of C-S-H gel up to 90 days for different amount of replacement by fly ash $35 \%+$ silica fume $10 \%$

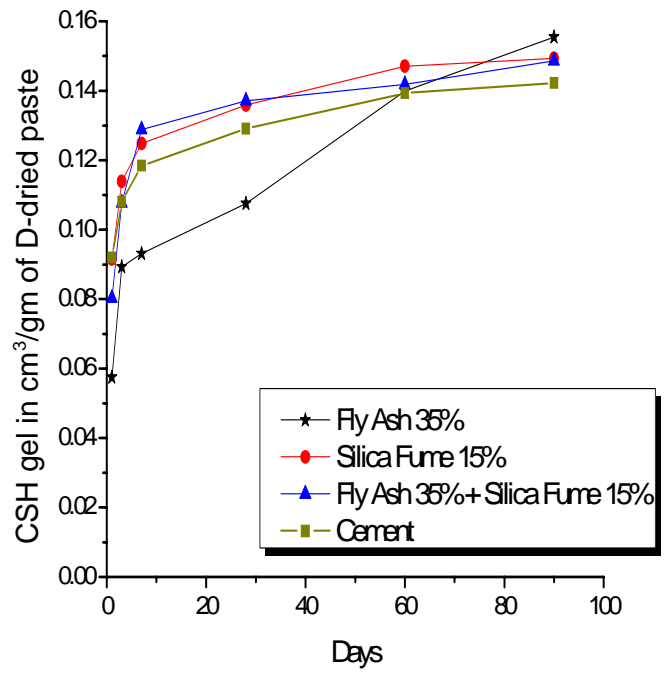

(a)

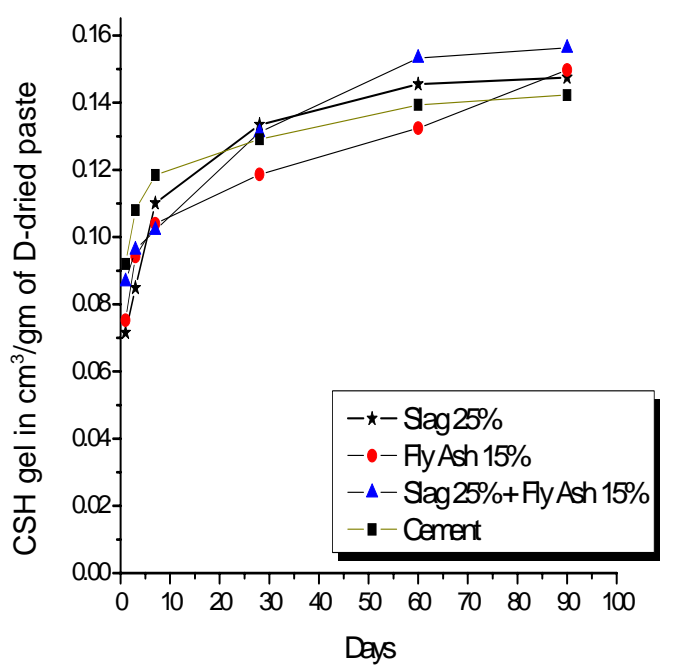

(b)

Fig. 4.14 - (a) Formation of C-S-H gel up to 90 days for different amount of replacement by fly ash $35 \%+$ silica fume $15 \%$ (b) formation of C-S-H gel up to 90 days for different amount of replacement by slag $25 \%+$ fly ash $15 \%$ 


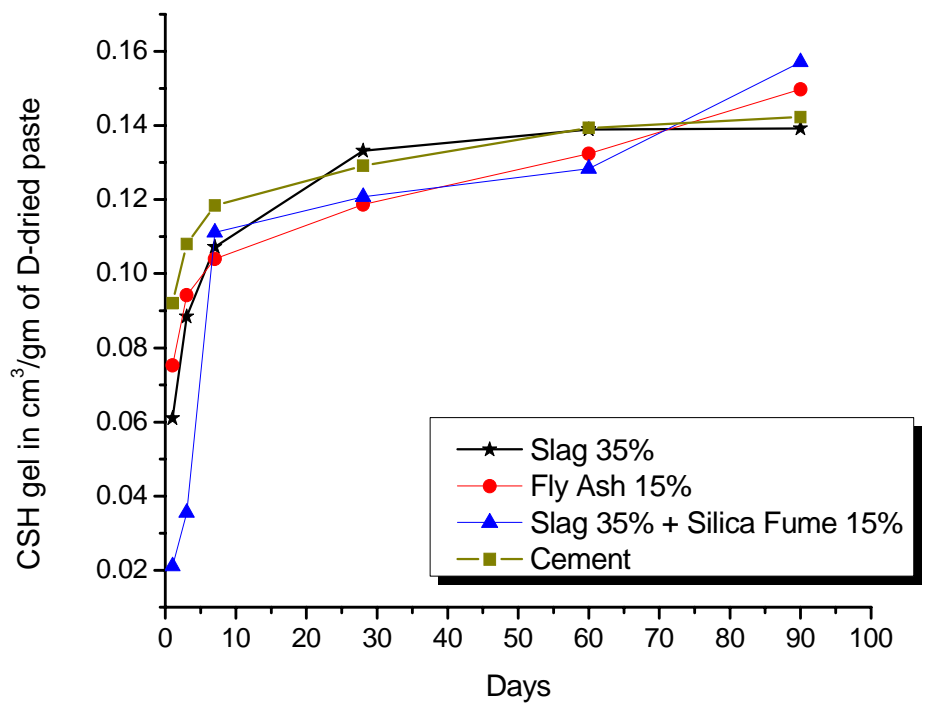

Fig 4.15 - Formation of C-S-H gel up to 90 days for different amount of replacement by slag $35 \%+$ fly ash $15 \%$

The amounts of C-S-H gel formed have been shown as $\mathrm{cm}^{3}$ per gm. of D-dried paste. Since due to variations in supplementary cementing materials, the unhydrated pastes have different specific volumes, the D-dried pastes for all the mixtures are not exactly same. However the values are close to each other. Further in this study the comparison of rate of gel formation among pastes will always be made on the basis of unit mass of D-dried paste.

From Fig. 4.7 (a) and (b) it is evident that the formation of C-S-H gel is low up to 7 days for pastes containing slag and fly ash compared to cement paste. But in the later ages the amount of C-S-H gel formed is more for the mixtures with replacement by either slag or fly ash. Though for $25 \%$ slag replacement the C-S-H gel formation is less. He relatively lower quantity of C-S-H gel formation for slag and fly ashes indicates the binary mixtures reacted slowly, however at later ages the reactivity of binary mixture increased as indicated by more C-S-H gel formation. This increase in C-S-H formation and reactivity are is due to the pozzolanic reaction that takes place at the later ages. As already discussed in chapter 2 , due to the pozzolanic reaction the $\mathrm{CH}$ formed due to hydration of cement reacts with the amorphous silica present in the supplementary cementing materials to form C-S-H gel. This C-S-H gel is in excess of the amount of C- 
$\mathrm{S}-\mathrm{H}$ gel that is already formed due to direct reaction of cement with water. In case of slag, it can be seen that the amount of C-S-H gel formed for higher replacements in the later ages is less that of the case mixtures containing $100 \%$ cement. At the same replacement level fly ash produces more C-S-H gel. In case of slag, the amount of C-S-H gel formed at 90 days decreases with the increase in amount of replacement whereas in case of fly ash this value increases in the range of 15 to $35 \%$. All these test results are in accordance with results of Olson and Jennings (2001) who have conducted the tests for a $\mathrm{w} / \mathrm{cm}$ 0.5. The trends of the results are same though they have obtained higher values due to the higher $\mathrm{w} / \mathrm{cm}$ ratio where degree of hydration is more due to availability of more water. For fly ash the replacements the C-S-H gel formation is more from 60-90 days, whereas for slag and cement pates there are little differences in the corresponding values.

Figure 4.8(a) shows the C-S-H gel formation for cement pastes containing silica fume at the replacement level of 5-15\%. At all the replacement levels the amount of C-S$\mathrm{H}$ gel formed in $\mathrm{cm}^{3}$ per gm. of D-dried paste is considerably higher than the cement paste both at early ages and as well as in the later ages. But as time progresses, the reaction rate decreases and there is not much difference in $\mathrm{C}-\mathrm{S}-\mathrm{H}$ gel formation between 28 days and 90 days. At higher replacement levels the C-S-H gel formation is lower.

In the case of ternary mixtures the amount of C-S-H gel formed both in the early age as well as in the later age is more than that for $0 \%$ replacement. As shown in Fig. 4.8(b) through 4.11(a) for slag and silica fume mixtures, there is a considerable increase in C-S-H gel formation both at early ages between 0-28 days and also afterwards. Even in case of ternary mixes like the silica fume containing binary mixtures the rate of formation are high at the early age but they slow down at later ages. In case of ternary mixtures as the replacement level increases, more C-S-H gel forms in with respect to cement.

Fig. 4.11(b) through 4.14(a) show that the C-S-H gel formation for fly ash and silica fume containing ternary mixtures. For the cases where these two supplementary cementing materials has been used the $\mathrm{C}-\mathrm{S}-\mathrm{H}$ gel formation is close to that of cement until 60 days with a little lesser quantity. But there is strong indication that considerable reaction occurs between 60 to 90 days to form more C-S-H gel as observed from the steep portion of the graphs. At higher replacement the C-S-H gel formed is more than 
cement paste at all ages. So fly ash has a unique character of being reacted towards the later part of hydration reaction through pozzolanic activity between 60 to 90 days.

In case of ternary mixture with $25 \%$ slag and $15 \%$ fly ash (Fig $4.14(\mathrm{~b})$ ) the C-S-H gel formation is considerably low between 0-28 days and there is a considerable pozzolanic reaction between 28-60 days and 60-90 days. Fig. 4.15 shows the gel formation for mixture containing slag and fly ash in the proportion $35 \%$ and $15 \%$ respectively the C-S-H gel formation is excessively between 0-3 days, from 3 to 7 days there is considerable increase in the reaction rate and then again an increased reactivity is observed between 60 to 90 days.

As reported by Taylor (1997) the progress of hydration increases gel pores but reduces, total porosity therefore it can be expected that the concrete containing ternary admixtures having more C-S-H gel will have lower total porosity in the pastes compared to cement pastes. More amount of C-S-H gel formation can be expected to provide a higher compressive strength which will be discussed subsequently in chapter 6 . the higher quantity of C-S-H gel in cases of all mixtures (binary and ternary) containing silica fume, therefore may produce a denser matrix, which will improve the compressive strength significantly, which is discussed subsequently in Chapter 6.

\subsection{Summary of Discussions}

This section describes the summarized information on the effects of supplementary cementing materials on rate of C-S-H gel formation. These are as follows: 1. Specific volume of D-dried paste was not same for different mixtures so a volumetric comparison is not possible between different mixtures with respect to $\mathrm{C}-\mathrm{S}-\mathrm{H}$ formation but gravimetric comparison is possible. In most of the cases for concrete volumetric calculation is considered, so it is not possible to compare quantitatively the C-S-H gel formation for a particular mixture containing supplementary cementing material with respect to cement. But certainly with the results it is possible to compare the values qualitatively and rate of reactions can be used to predict the shrinkage and strength of concrete. 
2. Pozzolanic reactivity was obvious from considerably more amount of $\mathrm{C}-\mathrm{S}-\mathrm{H}$ gel formed for some binary as well as ternary mixtures.

3. Both slag and fly ash reacted very slowly between 0-3 days. The rate of reaction increases between 3-60 days for both slag and fly ash. Between 60 to 90 days pastes containing slag underwent small amount of reaction compared to fly ash, whereas fly as paste exhibited much higher rate of C-S-H gel formation between these two ages.

4. Silica fume reacted very quickly at the early age (0-7 days) as a result considerably more C-S-H gel was formed but the rate of reaction does not vary much between 7-28 days.

5. In case of binary mixtures with higher replacement level C-S-H gel formation increases possibly due to more amount of pozzolanic reaction that took place. But the trend was reverse in case of silica fume.

6. In ternary mixtures slag and silica fume produces considerably more C-S-H gel compared to cement paste at all replacement levels. At lower replacement levels fly ash and silica fume produces C-S-H gel in the same range that of cement paste but at higher replacement levels the C-S-H gel formation increased. There was also a considerable amount of C-S-H gel formation between 60 to 90 days as observed in the case of binary mixtures containing fly ash.

7. For slag and fly ash concrete C-S-H gel formation was extremely low between 0-3 days. Then the hydration reaction and the pozzolanic reaction progressed at a rapid rate and eventually produce more C-S-H gel compared to cement paste.

The relationship of C-S-H gel with time can be used in predicting the shrinkage and strength of concrete containing various supplementary cementing materials. The relative quantity of the gel formations and their rate control the rate of shrinkage and strength directly, it will be significant to incorporate these factors into the present equations of shrinkage and strength to modify them for concretes containing supplementary cementing materials. 


\section{Chapter 5}

\section{Shrinkage and Prediction Equations}

\subsection{Introduction}

In this chapter the effect of different supplementary cementing materials on drying shrinkage of concrete have been investigated. It has been observed from the previous work Khatri, Sirivivatnanon and Gross (1995), Symons and Fleming (1980) addition of supplementary cementing materials the shrinkage properties of concrete significantly. Models have been proposed to take into the variations of supplementary cementing materials on drying shrinkage and the proposed models have been compared with few existing models.

\subsection{Test Procedure}

$76 \mathrm{~mm} \times 76 \mathrm{~mm} \times 254 \mathrm{~mm}$ prisms were cast for the mixes mentioned in Chapter 4 for length change measurement due to drying shrinkage. Length change measurements were done according to ASTM C 150 (Standard Test method for Length Change of Hardened Hydraulic-Cement Mortar and Concrete). All the specimens were cured for 24 hrs. under wet burlap and were placed in an environmental chamber maintained at $23 \pm 1^{\circ}$ $\mathrm{C}$ and $50 \pm 2 \%$ RH (Fig. 5.2 and 5.3) immediately after demolding. Length change of three replicate specimens were measured for each mixture by a standard comparator (Fig. 5.1) on every third day after drying until 9 day, every fourth day until 33 days and finally every sixth day until 93 days. From the values of length change the free shrinkage strains were calculated in microstrain. The individual strains of all the mixtures are shown in the Appendix A. 


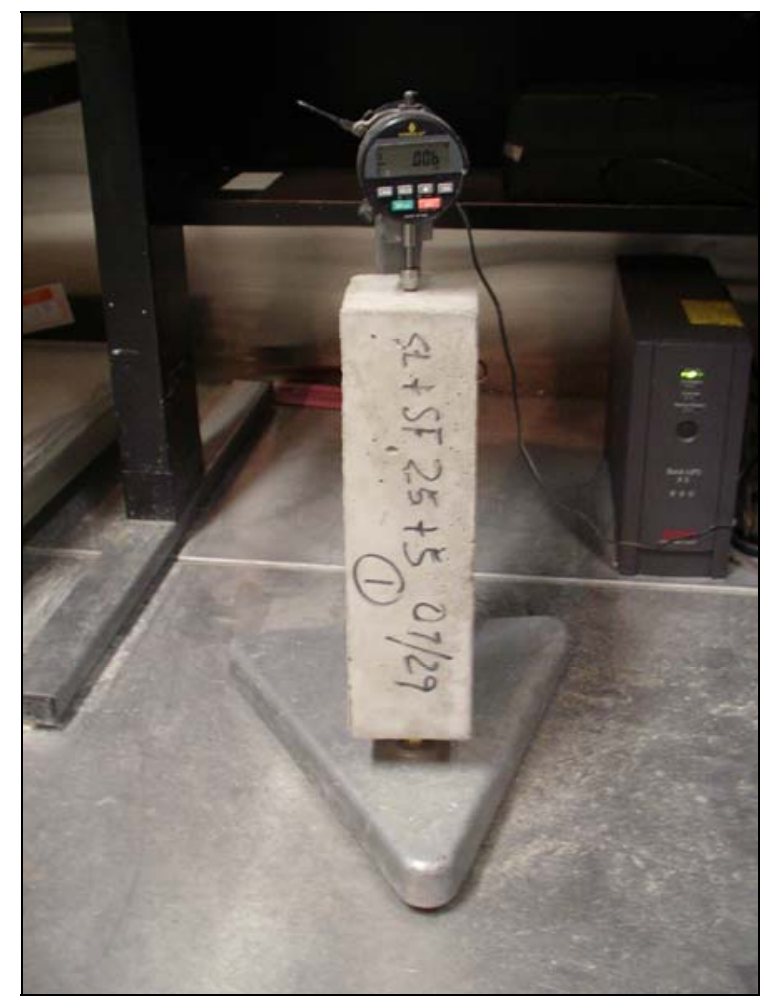

Fig 5.1 - Free Shrinkage Test in Progress

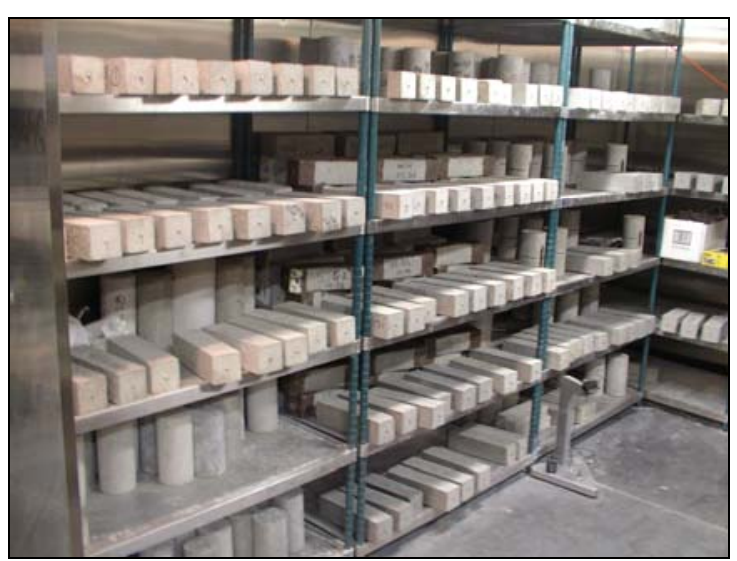

Fig 5.2 - Storage of shrinkage specimens

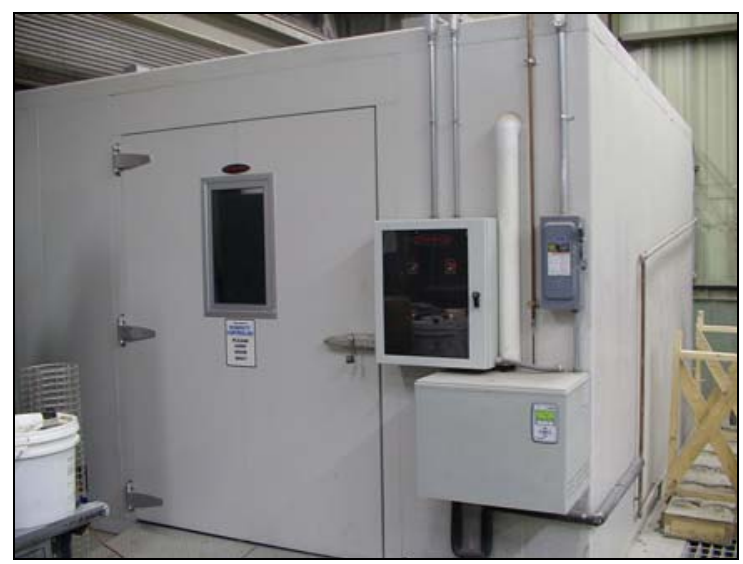

Fig 5.3 - Environmental chamber

\subsection{Comparisons of Models with the Shrinkage Data}

Typically two HPC (with or without supplementary cementing materials are compared with the existing models. 


\subsubsection{Control concrete with $0 \%$ replacement}

Few models have been compared with the obtained data of drying shrinkage for control concrete $(0 \%$ replacement). The coefficient of variation $(\mathrm{COV})$ of the proposed models are shown in table 5.1

Table 5.1 - Coefficient of Variation of different models with respect to drying shrinkage data control concrete

\begin{tabular}{|c|c|}
\hline Model & COV \\
\hline ACI & $20.0 \%$ \\
\hline GL & $20.3 \%$ \\
\hline CEB & $24.8 \%$ \\
\hline Huo et al. & $34.8 \%$ \\
\hline
\end{tabular}

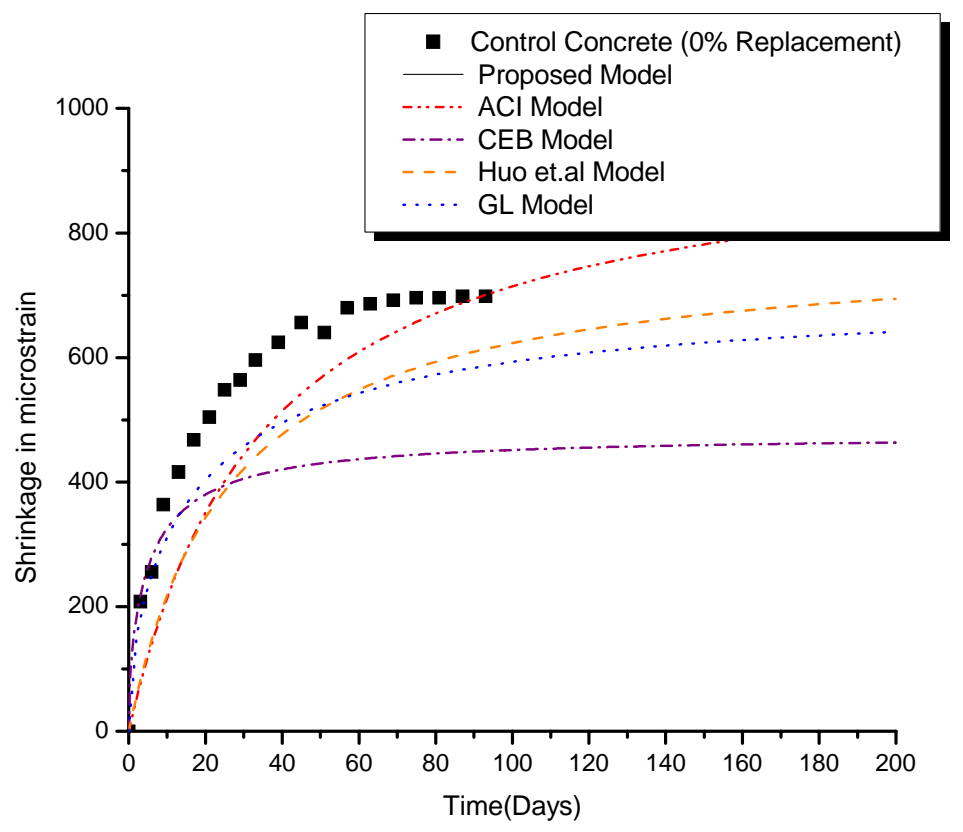

Fig. 5.4 - Comparison of few models with obtained test results for drying shrinkage for control concrete with $\mathrm{w} / \mathrm{cm}=0.4$ and $0 \%$ replacement 


\subsubsection{Fly ash replaced concrete (15\% fly ash replacement)}

Table 5.2 - Coefficient of Variation of different models with respect to drying shrinkage data for $15 \%$ fly ash concrete

\begin{tabular}{|c|c|}
\hline Model & COV \\
\hline ACI & $25 \%$ \\
\hline GL & $21 \%$ \\
\hline CEB & $30 \%$ \\
\hline Huo et al. & $30 \%$ \\
\hline
\end{tabular}

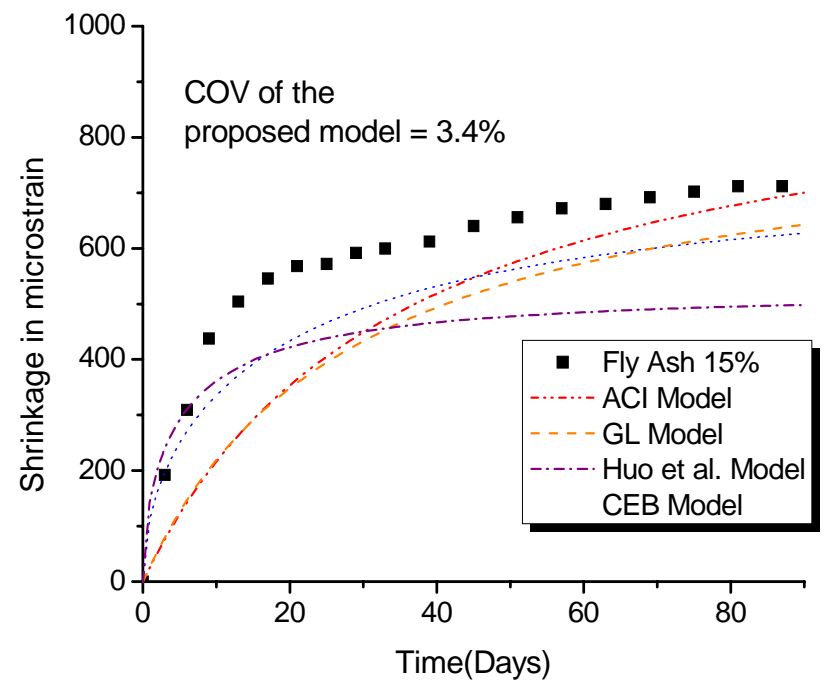

Fig. 5.5 - Comparison of few models with obtained test results for drying shrinkage for control concrete with $\mathrm{w} / \mathrm{cm}=0.4$ and $15 \%$ fly ash replacement

Gardner and Lockman (2001) mentioned that - a model which can predict the shrinkage within $15 \%$ may be regarded as excellent. Excellent and a prediction within $20 \%$ would be adequate. Therefore a better prediction model, the COV of $15 \%$ is accepted as threshold value in this study. As shown in table 5.1 and table 5.2 that COV for all the models are more than $15 \%$ for 90 days of shrinkage data. Fig. 5.4 and 5.5 also show all the models give non-conservative estimates. 


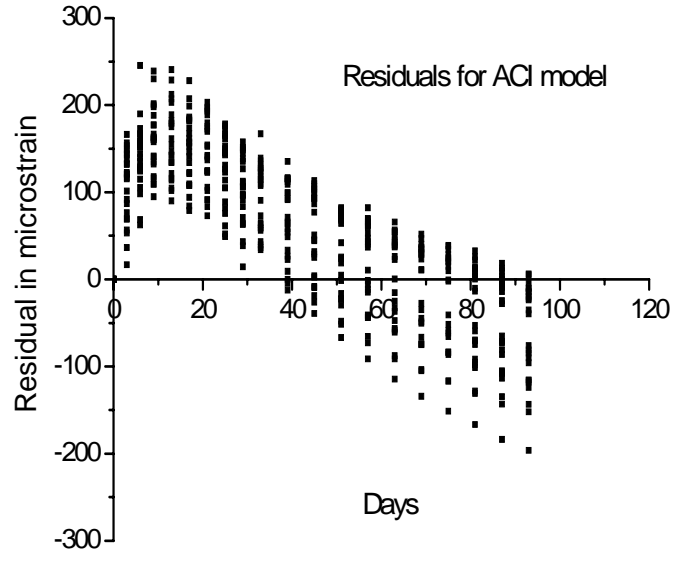

(a)

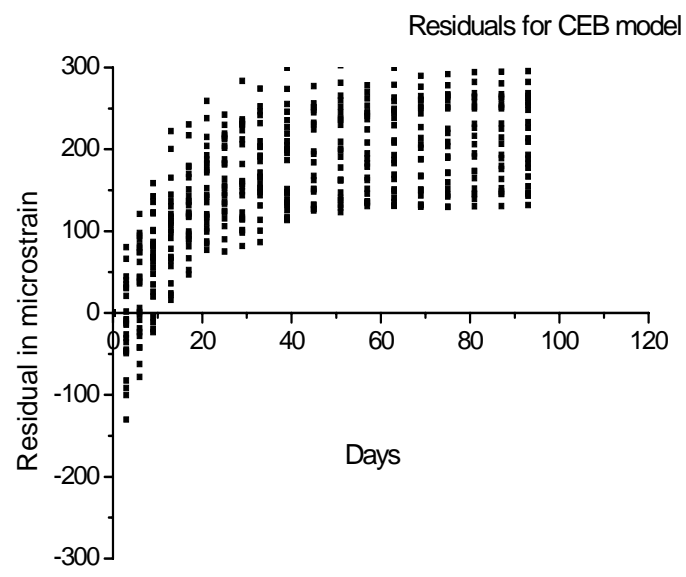

(b)

Fig. 5.6 - (a) Residual plot of the ACI model, (b) Residual plot of the CEB model

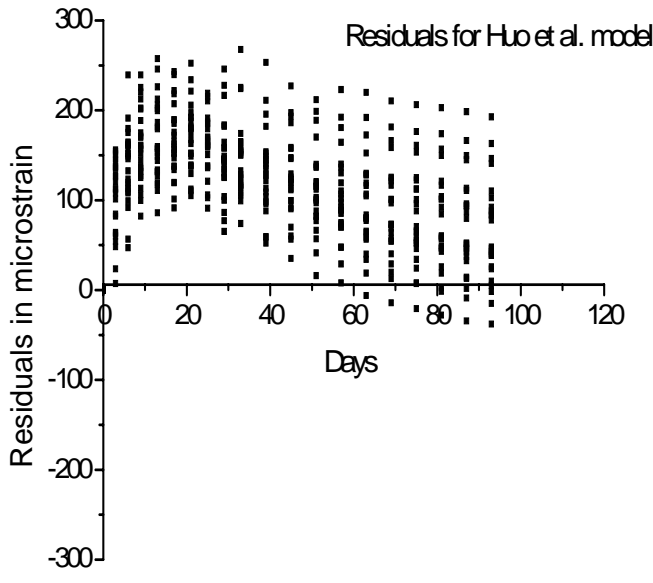

(a)

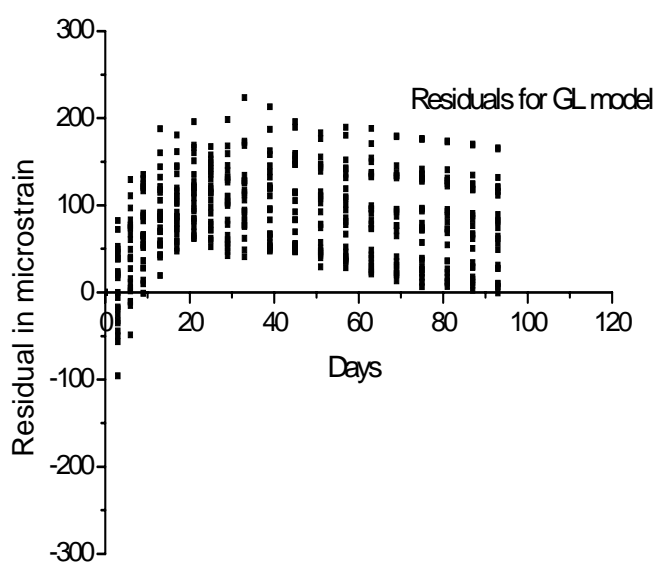

(b)

Fig. 5.7 - (a) Residual plot of the Huo et al. model (b) Residual plot of the GL model

As mentioned by McDonald and Roper, 1993 that a residual plot can give a good idea about the accuracy of a prediction model. Figure 5.6(a) shows a definite hump within 0-40 days for the ACI 209R equation and the values are non-conservative. But with progress of time the ACI 209R equation furnishes conservative prediction. Whereas the GL model, Huo et al. model have humps between 0- 40 days (Fig. 5.7(a) and Fig.5.7(b)) but the values are non-conservative all along. Figure 5.6(b) shows that the CEB model shows a non-conservative value all along 90 days and the residuals are as big as 300 microstrains, greater than any other models. The large non-conservative values for 
CEB and the GL and Huo et al. models are probably due to the inclusion compressive strength in the ultimate shrinkage value. The strength factor is reducing the ultimate shrinkage to a considerable extent producing too much non-conservative results. The w/cm 0.4 and inclusion of supplementary cementing materials increases the strength considerably as a result the ultimate shrinkage is being lowered too much for these three models. Generally a hump in the residual plot indicates a modification in the time function and shift from the horizontal axis indicates a calibration. So the residual plot indicates a need for a better model.

\subsection{Proposed Model}

On the basis of the above discussion there is a need for a better shrinkage prediction model for concretes with supplementary cementing materials and HPC. Here the ACI -209 R time function has been taken as a basis and has been calibrated for control concrete $(0 \%$ replacement and $0.4 \mathrm{w} / \mathrm{cm})$. Afterwards the model has been modified to include the effects of supplementary cementing materials.

\subsubsection{Theory}

In chapter 2 it has been discussed that the gels undergo the maximum amount of volume reduction during shrinkage and all the other phases present produces a restraining effect (Juegner and Jennings 2002). From chapter 5 we get an idea that the C-S-H gel formation is affected significantly by the addition of supplementary cementing materials. So estimation of C-S-H gel provides insight in to the variation in shrinkage strains due to addition of supplementary cementing materials. The results of chapter 4 have been used extensively to propose the new model.

The model has been developed on HPC with water-cementitous material ratio $(\mathrm{w} / \mathrm{cm})$ of 0.4 . After studying all the models the ACI model has been chosen as a baseline and modifications have been done to incorporate the effects of supplementary cementing material on drying shrinkage. For all the mixtures the aggregate cement paste ratio have been kept constant (2.3) and the amount of cementitous material, used is fairly constant with the value $375 \mathrm{~kg} / \mathrm{m}^{3}$ to $395 \mathrm{~kg} / \mathrm{m}^{3}$. The slump and air content values were also kept constant $180-200 \mathrm{~mm}$ and $6 \pm 1 \%$ respectively. 
Two major modifications have been done in the ACI model to incorporate the effects of supplementary cementing materials. Both the time function and the ultimate shrinkage strain parameters have been modified by using two parameters $\mathrm{K}_{1}$ and $\gamma_{\mathrm{scm}}$, respectively. All the other correction factors of the ACI equation those are applicable to the ultimate shrinkage also need to be applied to this model.

As discussed in Chapter 2 the ACI model is -

$$
\varepsilon_{\text {sh }}=\frac{t}{f+t}\left(\gamma_{\text {sh. }} \varepsilon_{\text {shu }}\right)
$$

where $\mathrm{f}=$ time taken to reach half of the ultimate shrinkage value

ACI 209R recommends $\mathrm{f}=35$ for moist cured concrete and $\mathrm{f}=55$ for steam cured concrete. Since this study is limited to moist cured concrete, according to ACI for normal moist cured concrete -

$$
\varepsilon_{s h}=\frac{t}{35+t}\left(\gamma_{s h .} \varepsilon_{s h u}\right)
$$

where -

$\mathrm{t}=$ time in days

$\gamma_{s h}=$ ACI correction factors for ultimate shrinkage

$\varepsilon_{\text {sh }}=$ shrinkage strain in microstrain

$\gamma_{s h}=\gamma_{\lambda} \cdot \gamma_{\mathrm{cp}} . \gamma_{\mathrm{vs}} . \gamma_{\mathrm{s} .} \gamma_{\psi} \cdot \gamma_{\mathrm{c}} . \gamma_{\alpha}$

$\gamma_{\lambda}=$ correction factor for relative humidity

$\gamma_{\mathrm{cp}}=$ correction factor for age of drying

$\gamma_{\mathrm{vs}}=$ correction factor for volume/surface ratio

$\gamma_{\mathrm{s}}=$ correction factor for slump

$\gamma_{\psi}=$ correction for fine aggregate content

$\gamma_{\mathrm{c}}=$ correction factor for cement content

$\gamma_{\alpha .}=$ correction factor for air content

In the above equation (5.2) it is observed that there is no scopes for incorporating the effects of supplementary cementing materials and concretes with different rate of strength developments as encountered in HPC. The comparison in section 5.3.1 and 5.3.2 
show that the effects of these supplementary cementing materials and different rate of strength developments are significant. Unless the existing models are modified the predicted values will be too erroneous to be accepted.

Considering the above facts, the existing ACI equations are modified and the proposed equation will be in the following from:

$$
\begin{aligned}
& \varepsilon_{s h}=\frac{t}{K_{1} * 35+t}\left(\gamma_{s h 1 .} \varepsilon_{s h u}\right) \\
& \mathrm{K}_{1}=\text { parameter modifying the time function } \\
& \gamma_{s h l .}=\gamma_{s h} \cdot \gamma_{s c m} . \\
& \gamma_{s c m}=\text { Correction factor for inclusion of supplementary cementing materials }
\end{aligned}
$$

$\mathrm{K}_{1}$ has been taken as a time function in the form-

$\mathrm{K}_{1}=\mathrm{P} *(1.14-2 * \mathrm{~A}) *(\mathrm{~A}+\mathrm{B} * \ln (\mathrm{t}))$

$\mathrm{P}$ is a constant for all types of concrete and $\mathrm{A} \& \mathrm{~B}$ will change from mixture to mixture to include the effects of supplementary cementing materials. A\&B can be obtained from fitting the C-S-H gel data in the $\ln \left(\log _{e}\right)$ scale for all the mixtures

\subsubsection{Calibration for control concrete (with no replacement)}

Also curve fitting and non-linear regression using Origin 7.5 suggested a $\varepsilon_{\text {shu }}=$ $650 \times 10^{-6}$ instead of $780 \times 10^{-6}$ used in ACI 209R equation. This variation in the ultimate shrinkage value is mostly due to the variation in aggregate modulus of elasticity, aggregate size and $\mathrm{w} / \mathrm{cm}$ ratio for which ACI do not have any modification factors.

- The model has been first calibrated on the experimental results of normal concrete to find the value of P. $\gamma_{\mathrm{scm}}$ was assigned 1 for the control concrete which contains cement only as the cementing material.

As mentioned in chapter 2 in the mechanisms of shrinkage, the early age shrinkage occurs mainly due to withdrawal of water from capillary pore spaces and autogenous shrinkage. Later age shrinkage is mainly due to withdrawal of adsorbed water from the C-S-H gel - through disjoining pressure effect and surface energy reduction. In the early age, C-S-H gel formation can be perceived way to influence shrinkage in the following - 
1. Less C-S-H gel formation allows more water filled capillary space causing more shrinkage

2. More C-S-H gel formation causes more autogenous shrinkage

However there is no existing relationship on the role of amount of C-S-H gel on the mechanisms of shrinkage. Probably both acts together and in cases of silica fume containing concretes autogenous shrinkage prevails in case of slag and fly ash containing concrete capillary water loss causes higher shrinkage. To incorporate both these effects the both term $(1.14-2 * \mathrm{~A})$ and $(\mathrm{A}+\mathrm{B} * \ln (\mathrm{t}))$ have been included in multiplication form. Since A is a relative measure of early age C-S- $\mathrm{H}$ gel formation for different mixtures, the term $(1.14-2 * \mathrm{~A})$ is included for the autogenous shrinkage in the early age, the term, ( $\mathrm{A}+$ $\left.\mathrm{B}^{*} \ln (\mathrm{t})\right)$ provides indication of C-S-H gel formation, it is to consider the capillary water loss.

Though in case of C-S-H estimation experiment hydration of the paste was at $100 \% \mathrm{RH}$ but hydration of cementing materials rarely takes place at $100 \% \mathrm{RH}$ during drying shrinkage. The inclusion of the terms A \& B of C-S-H gel formation is not for quantitative study rather to compare the rate of formation for C-S-H gel formation. So estimate of C-S-H gel formation will give a reasonably well correlated result. Moreover estimation of C-S-H gel formation at less than $100 \%$ RH would have hindered C-S-H gel formation and estimation would have been tough.

The value for $\mathrm{P}=2.285$ was obtained through curve fitting using Origin 7.5 for normal concrete and performing the necessary correction factors mentioned in $\mathrm{ACI}$ equation for shrinkage. The value of-

$\mathrm{P}=2.285$ was found to give a coefficient of variation of $4.2 \%$ for the control concrete. Therefore equation (5.4) can be rewritten as-

$\mathrm{K}_{1=2.285 *}(\mathrm{~A}+\mathrm{B} * \ln (\mathrm{t})) *(1.14-2 * \mathrm{~A})$

The values of A \& B for different mixtures are supplied in the table 5.1 and the associated graphs are shown in the Appendix B 
Table 5.3 Table for A \& B

\begin{tabular}{|c|c|c|}
\hline Mix & A & B \\
\hline SL 25 & .0707 & .01793 \\
\hline SL 35 & .06728 & .01765 \\
\hline SL 45 & .06406 & .01768 \\
\hline FI 15 & .07518 & .0149 \\
\hline FL 25 & .06989 & .01664 \\
\hline FI 35 & .05864 & .01943 \\
\hline SF5 & .09166 & .01582 \\
\hline SF 10 & .10085 & .01344 \\
\hline SF 15 & .09663 & .01221 \\
\hline SS 25+5 & .10622 & .01067 \\
\hline SS 25+10 & .08508 & .02064 \\
\hline SS 35+5 & .09632 & .01293 \\
\hline SS 35+10 & .1143 & .0104 \\
\hline SS 35+15 & .11869 & .01155 \\
\hline SS 45+5 & .09498 & .01447 \\
\hline FS 15+5 & .10323 & .01023 \\
\hline FS 25+5 & .092 & .0116 \\
\hline FS 25+10 & .09934 & .01957 \\
\hline FS 35+5 & .0875 & .01256 \\
\hline FS 35+10 & .097 & .01073 \\
\hline FS 35+15 & .08949 & .01385 \\
\hline CC & .0945 & .01083 \\
\hline SL+ FA 25+15 & .0795 & .0166 \\
\hline SL+ FA 35+15 & .02313 & .02906 \\
\hline & & \\
\hline
\end{tabular}

Typical calculation for control concrete -

$\mathrm{A}=.0945$ and $\mathrm{B}=.01083$ from table 5.1

The values of A\& B have been obtained by plotting C-S-H gel formation with time semi-

$\log$ scale and performing best fit in the form from $\mathrm{Y}=\mathrm{A}+\mathrm{B} * \ln (\mathrm{t})$.

Where,

$\mathrm{Y}=\mathrm{C}-\mathrm{S}-\mathrm{H}$ gel formation in $\mathrm{cm}^{3} / \mathrm{gm}$ of D-dried paste

$\mathrm{t}=$ time in days 


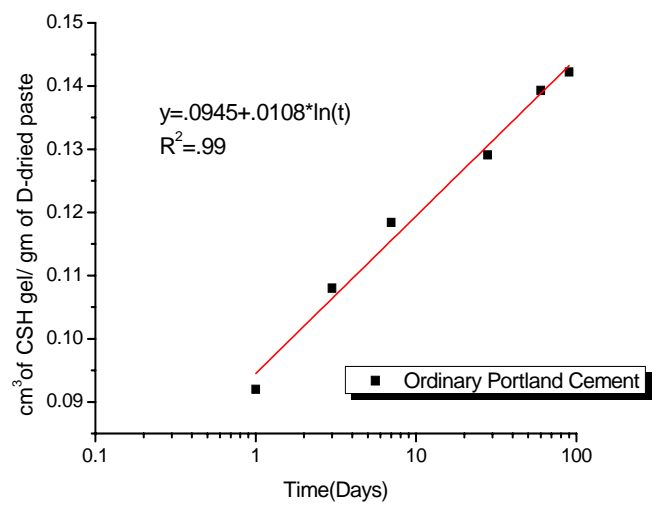

Fig. 5.8 - Typical C-S-H formation for cement paste with $0 \%$ replacement plotted in log scale (best fit) equation Calibration of the model with control concrete -

Information on the concrete -

Cement content $=396 \mathrm{Kg} / \mathrm{m}^{3}$

Air content $=6 \%$

Slump $=200 \mathrm{~mm}$

$\mathrm{RH}=50 \%$

Moist cured for 1 day

Volume/ Surface $=16.34 \mathrm{~mm}$

Fine aggr. / Total aggr. Content $=40 \%$

$$
\begin{aligned}
& \mathrm{K}_{1}=2.285 *(.0945+.01083 \ln (\mathrm{t})) \\
& \gamma_{\lambda}=1.4-.01 \lambda \quad \lambda=50 \% \\
& =0.9 \\
& \gamma_{\mathrm{cp}}=1.2 \\
& \text { for } 1 \text { day moist cured concrete } \\
& \gamma_{\mathrm{vs}}=1.2 \exp (-.00472 \mathrm{v} / \mathrm{s})=1.11 \\
& \gamma_{\mathrm{s}}=0.89+.00161 \mathrm{~s}=1.212 \\
& \mathrm{~s}=200 \mathrm{~mm} \\
& \gamma_{\psi}=0.3+.014^{*} \psi=.86 \\
& \psi=40 \% \\
& \gamma_{\mathrm{c}}=.75+.00061 \mathrm{c}=.99 \\
& \mathrm{c}=396 \\
& \gamma_{\alpha}=.95+.008 \alpha=.998 \\
& \alpha=6 \% \\
& \gamma_{\mathrm{sh}}=\gamma_{\lambda} \cdot \gamma_{\mathrm{cp}} . \gamma_{\mathrm{vs}} . \gamma_{\mathrm{s} .} \gamma_{\psi} . \gamma_{\mathrm{c}} . \gamma_{\alpha .}=1.237
\end{aligned}
$$

For control concrete $\gamma_{\mathrm{scm}}=1$, hence $\gamma_{\mathrm{sh}}=1.237$

Corresponding graph has been shown in Fig. 5.8 


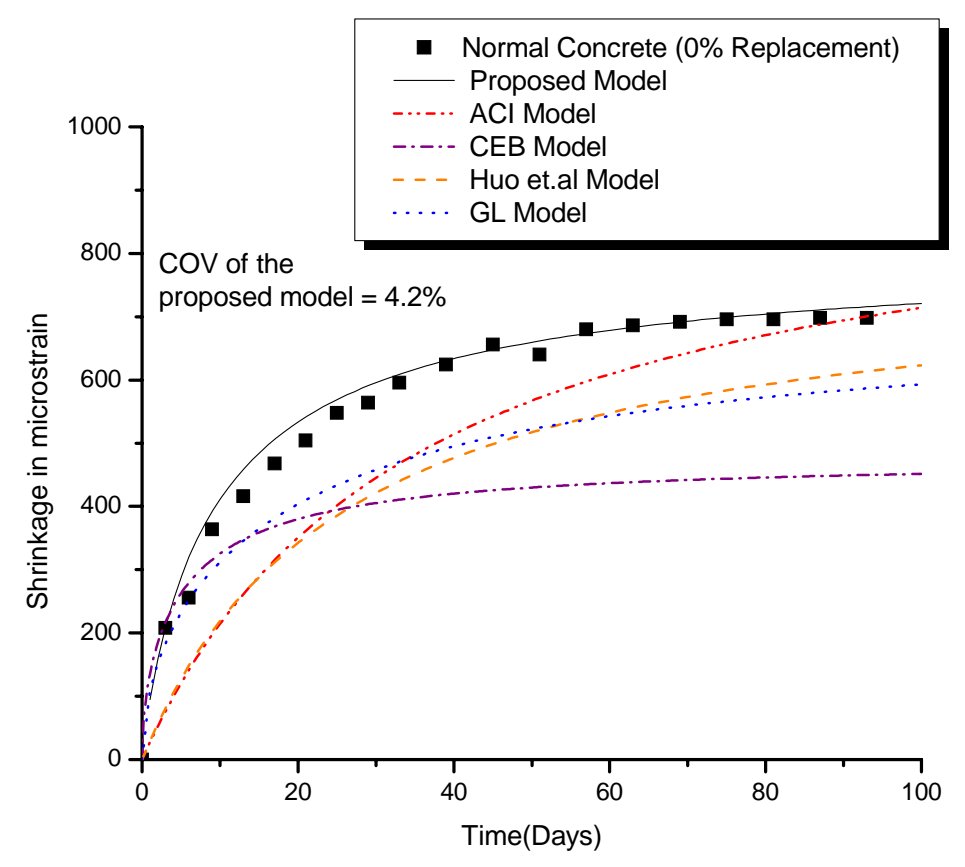

Fig. 5.9 - Comparison of the proposed model and few common prediction models with shrinkage data for normal concrete $(0 \%$ replacement $)$

\subsubsection{Modification of the model for supplementary cementing materials}

While analyzing the results and fitting curves it was found that the inclusion of the C-S-H gel formation equation $\left(1.14-2^{*} \mathrm{~A}\right)^{*}\left(\mathrm{~A}+\mathrm{B}^{*} \ln (\mathrm{t})\right)$ in the time function takes good care of the increase in early age shrinkage values for supplementary cementing materials concrete compared to the control concrete. For supplementary cementing materials the ultimate shrinkage is considerably lower than the control concrete (Khatri, Sirivivatnanon and Gross 1995; Dunstan, 1984; Wee and Wong, 2002). But the reduction in later age shrinkage value or consequently the ultimate shrinkage value bears no well correlated relationship with $\mathrm{C}-\mathrm{S}-\mathrm{H}$ gel formation. The relatively smaller later age shrinkage for concretes containing supplementary cementing materials is probably due to

1. Moisture loss and shrinkage and shrinkage have non-linear relationship with time. Higher the early age shrinkage lesser the later age shrinkage and vice-versa. 
2. The later age shrinkage is mainly due to the disjoining pressure and surface energy variation of C-S-H gel is small comparative to early age shrinkage. As the C-S-H gel formation or hydration reaction slows down with time, the later age shrinkage(since aggregate/ paste ratio has been kept constant) is more influenced by the different amount of restraining effects of different kind of unhydrated supplementary cementing materials .So an empirical relationship was developed through non-linear regression and curve fitting in Origin 7.5. $\gamma_{s c m}$ to account the effect of supplementary cementing materials on later age shrinkage or ultimate shrinkage. The relationship has been proposed directly in terms of $\%$ replacement of supplementary cementing materials either in a binary mixture or ternary mixture.

$$
\begin{aligned}
& \gamma_{\text {scm }}=(1-.0014 * \mathrm{~m}) \quad \mathrm{m}=\% \text { replacement of slag in the range } 25-45 \% \\
& =\left(1-.0006^{*} \mathrm{n}\right) \quad \mathrm{n}=\% \text { replacement of fly ash in the range } 15-35 \% \\
& =\left(1-.0016^{*} \mathrm{r}\right) \quad \mathrm{r}=\% \text { replacement of silica fume in the range } 5-15 \% \text {. } \\
& =\left((1-.0014 * \mathrm{~m}) *\left(1-.0016^{*} \mathrm{r}\right)\right) \quad \text { where } 30 \leq \mathrm{m}+\mathrm{r} \leq 50 \\
& =((1-.0006 * \mathrm{n}) *(1-.0016 * \mathrm{r})-0.05) \quad \text { where } 20 \leq \mathrm{n}+\mathrm{r}<50 \\
& =((1-.0014 * \mathrm{~m}) *(1-.0006 * \mathrm{n})-.15) \quad \text { where } 40 \leq \mathrm{m}+\mathrm{n}<50
\end{aligned}
$$

The proposed equation is valid in the following range for different supplementary cementing materials with $\mathrm{w} / \mathrm{cm}=0.4$

For $0 \%$ replacement or normal concrete

For slag replacement level from $25-45 \%$

For fly ash replacement level from $15-35 \%$

For silica fume replacement level from $25-45 \%$

For slag + silica fume replacement level with the combinations $25+5,25+10,35+5$, $35+10,35+15,45+5$ (replacement levels in \%)

For fly ash + silica fume replacement level with the combinations $15+5,25+5,25+10$, $35+5,35+10,35+15$ (replacement levels in \%)

Any combination between the above mentioned ranges can be interpolated. These combinations have been selected keeping in mind the range of replacement commonly used in the preparation of HPC for practical application. 
Sample calculation for supplementary cementing materials containing slag $\mathrm{A}=.0707$ and $\mathrm{B}=.01793$ (from table 5.1)

Typical calculation for slag concrete -

Information on the concrete -

Cement content $=391 \mathrm{Kg} / \mathrm{m}^{3}$

Air content $=6 \%$

Slump $=290 \mathrm{~mm}$

$\mathrm{RH}=50 \%$

Moist cured for 1 day

Volume/ Surface $=16.34 \mathrm{~mm}$

Fine aggr. $/$ Total aggr. Content $=40 \%$

$$
\begin{aligned}
& \mathrm{K}_{1}=2.285 *(.0945+.01083) \\
& \gamma_{\lambda}=1.4-.01 \lambda \quad \lambda=50 \% \\
& =0.9 \\
& \gamma_{\mathrm{cp}}=1.2 \\
& \text { for } 1 \text { day moist cured concrete } \\
& \gamma_{\mathrm{vs}}=1.2 \exp (-.00472 \mathrm{v} / \mathrm{s})=1.11 \\
& \gamma_{\mathrm{s}}=0.89+.00161 \mathrm{~s}=1.212 \\
& \mathrm{~s}=200 \mathrm{~mm} \\
& \gamma_{\psi}=0.3+.014^{*} \psi=.86 \\
& \psi=40 \% \\
& \gamma_{\mathrm{c}}=.75+.00061 \mathrm{c}=.989 \\
& \mathrm{c}=396 \\
& \gamma_{\alpha}=.95+.09 \alpha=.998 \\
& \alpha=6 \% \\
& \gamma_{\mathrm{scm}}=(1-.0014 * 25)=.965 \\
& m=25 \% \\
& \gamma_{\mathrm{sh} 1}=\gamma_{\lambda} \cdot \gamma_{\mathrm{cp}} . \gamma_{\mathrm{vs}} . \gamma_{\mathrm{s}}, \gamma_{\psi}, \gamma_{\mathrm{c}}, \gamma_{\alpha} \cdot \gamma_{\mathrm{scm}}=1.19 \\
& \mathrm{~K}_{1}=2.285(1.14-2 * .0707) *(.0707+.01793 \ln (\mathrm{t})) \\
& \varepsilon_{\text {sh }}=\frac{t}{K_{1} * 35+t}(1.19 * 650) \text { microstrain }
\end{aligned}
$$




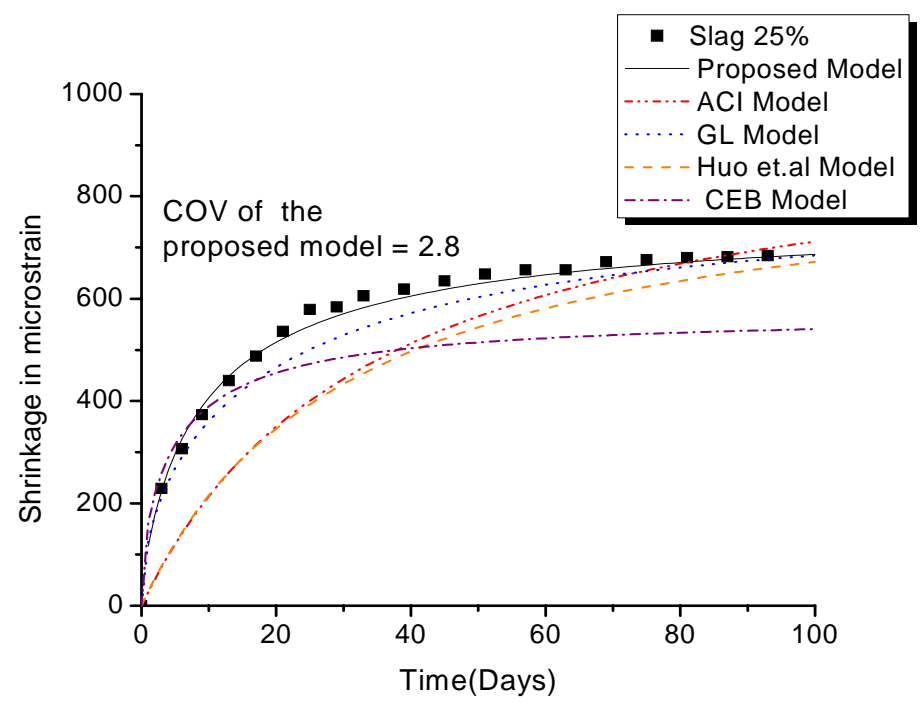

Fig. 5.10 - Comparison of the proposed model and few prediction models with shrinkage data for concrete containing $25 \%$ slag by mass

The fit for rest of the models have been shown in Fig 5.11 through 5.19.

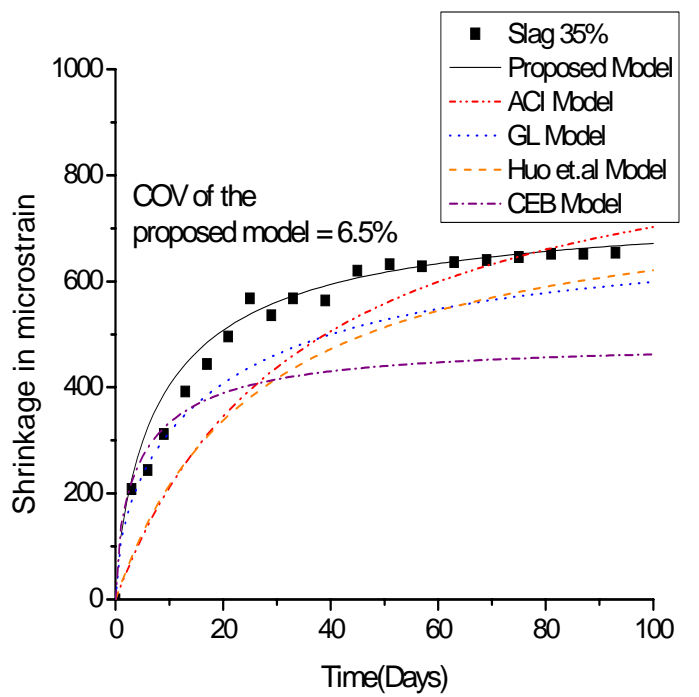

(a)

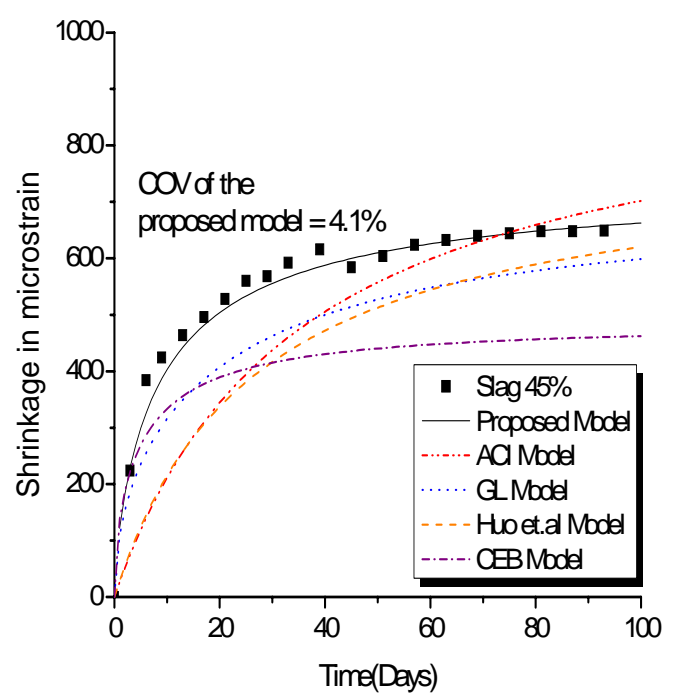

(b)

Fig. 5.11 - Comparison of the proposed model and common prediction models with shrinkage data for concrete containing (a) $35 \%$ slag by mass (b) $45 \%$ slag by mass 


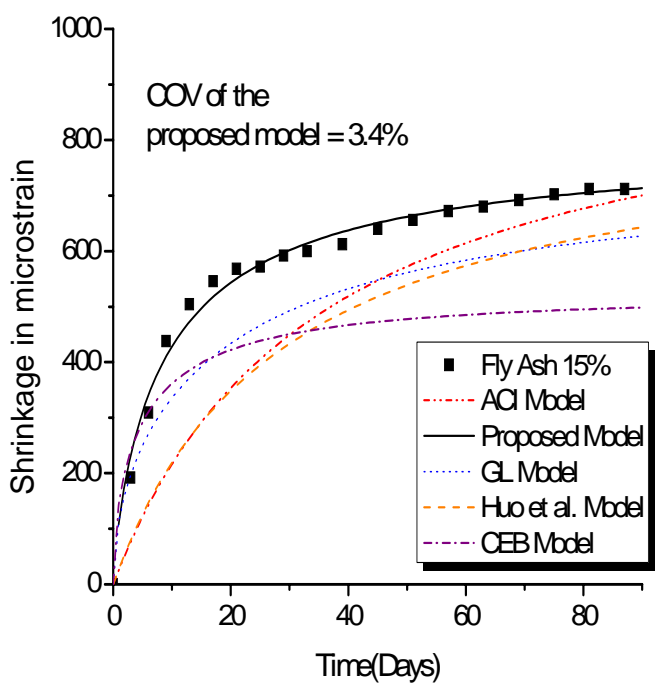

(a)

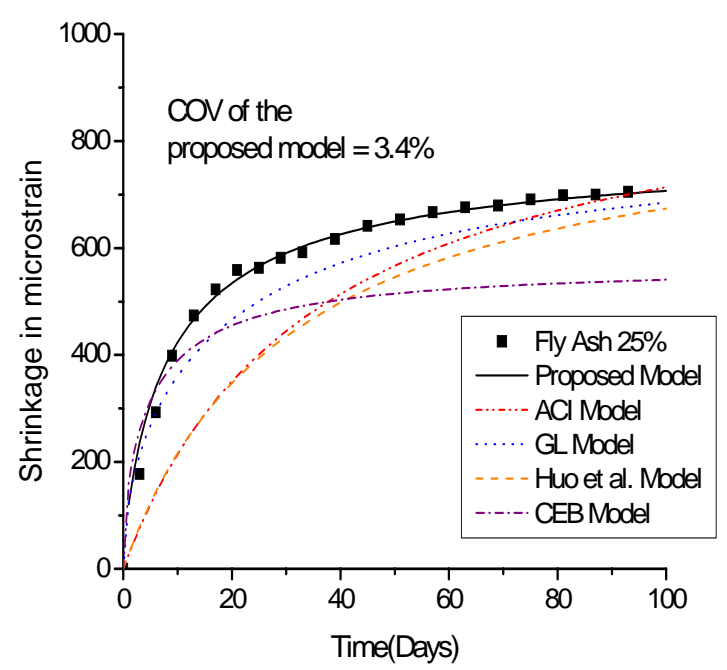

(b)

Fig. 5.12 - Comparison of the proposed model and common prediction models with shrinkage data for concrete containing (a) $15 \%$ fly ash by mass (b) $25 \%$ fly ash by mass

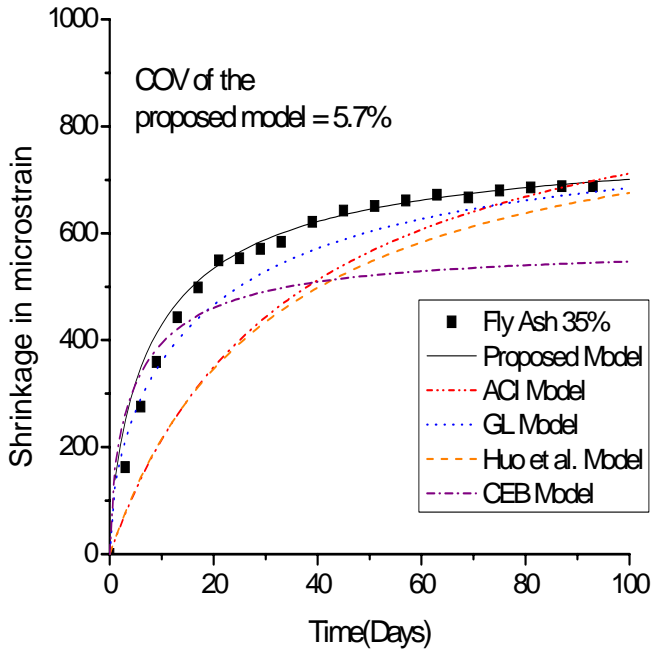

(a)

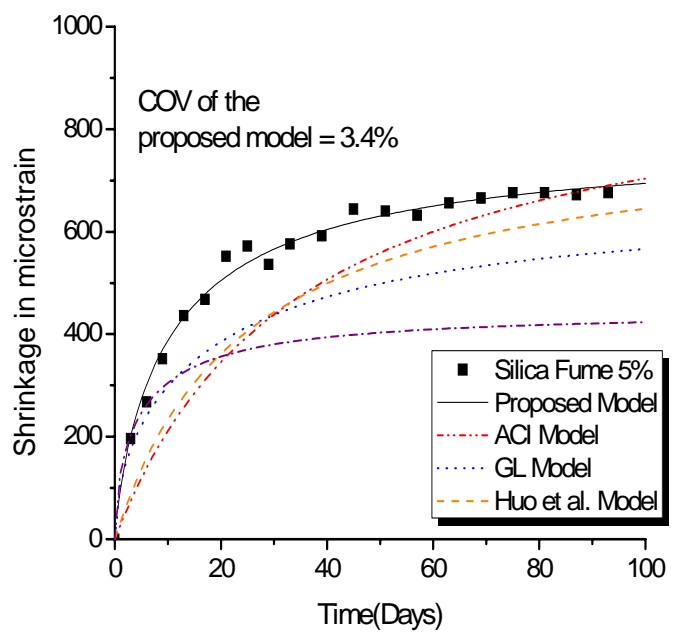

(b)

Fig. 5.13 - Comparison of the proposed model and common prediction models with shrinkage data for concrete containing (a) $35 \%$ fly ash by mass (b) $5 \%$ silica fume by mass 


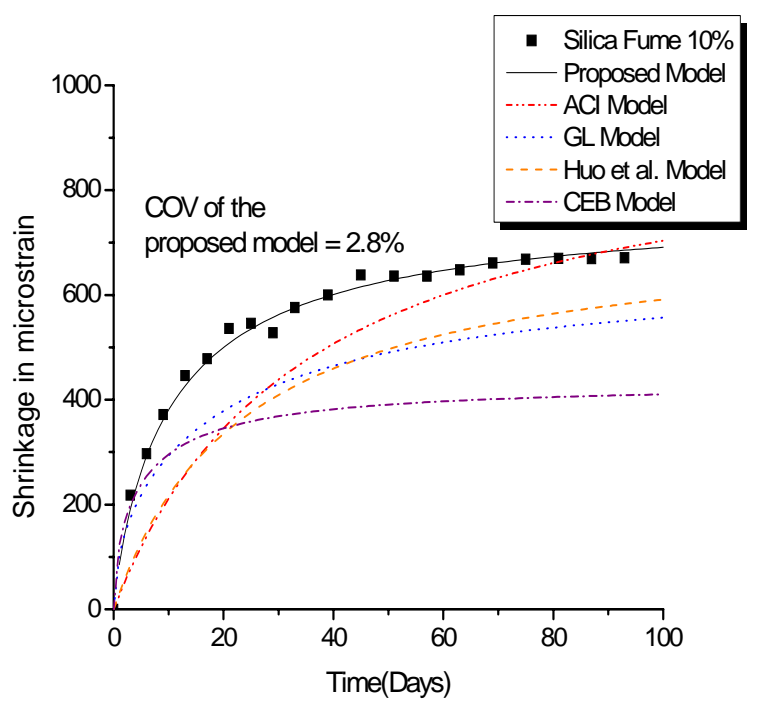

(a)

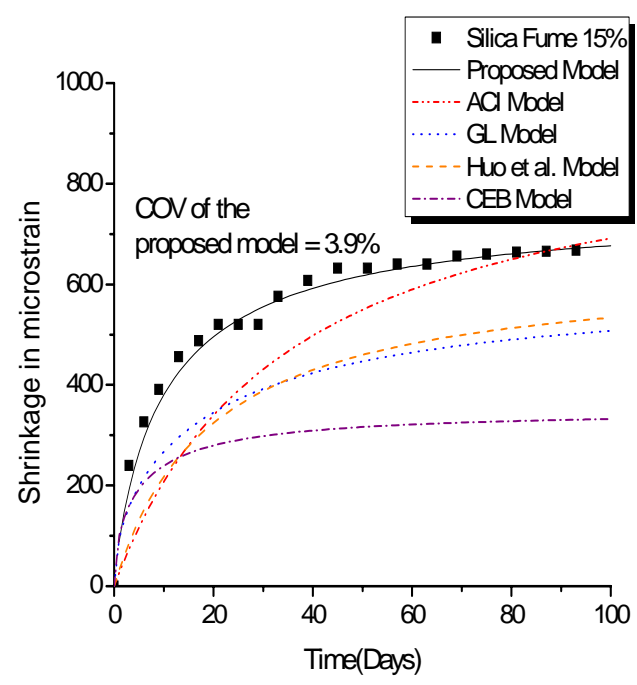

(b)

Fig. 5.14- Comparison of the proposed model and common prediction models with shrinkage data for concrete containing (a) $10 \%$ silica fume by mass (b) $15 \%$ silica fume by mass

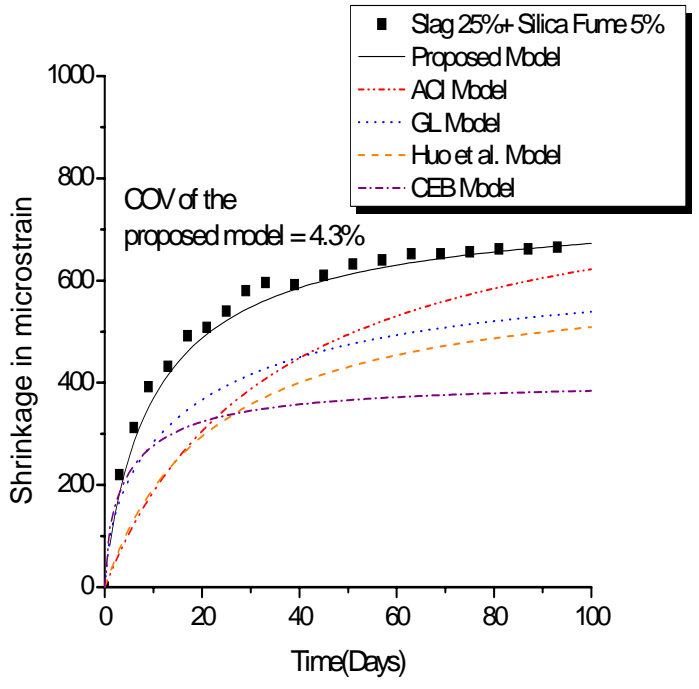

(a)

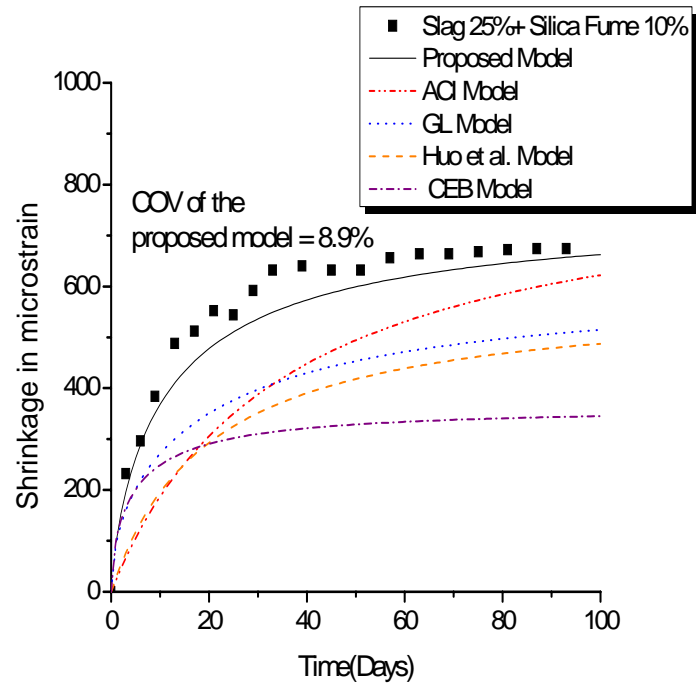

(b)

Fig. 5.15- Comparison of the proposed model and common prediction models with shrinkage data for concrete containing (a) $25 \%$ slag $+5 \%$ silica fume by mass (b) $25 \%$ slag $+10 \%$ silica fume by mass 


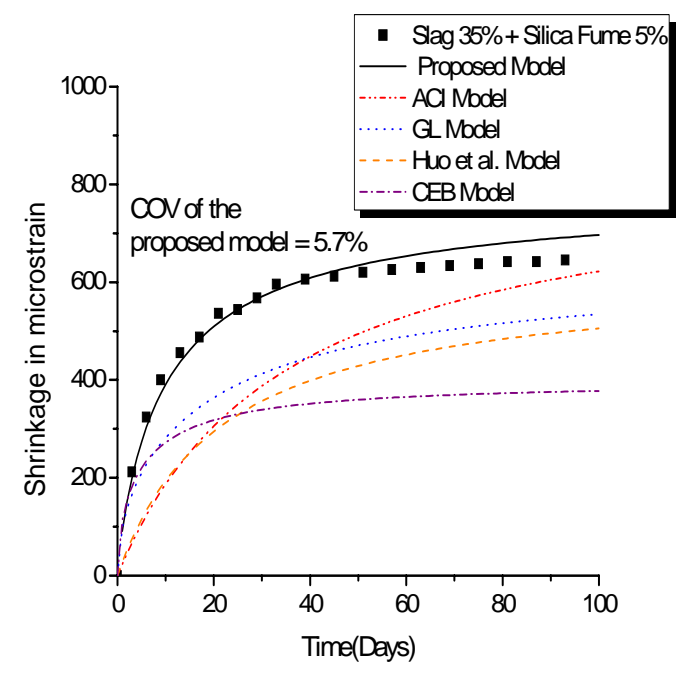

(a)

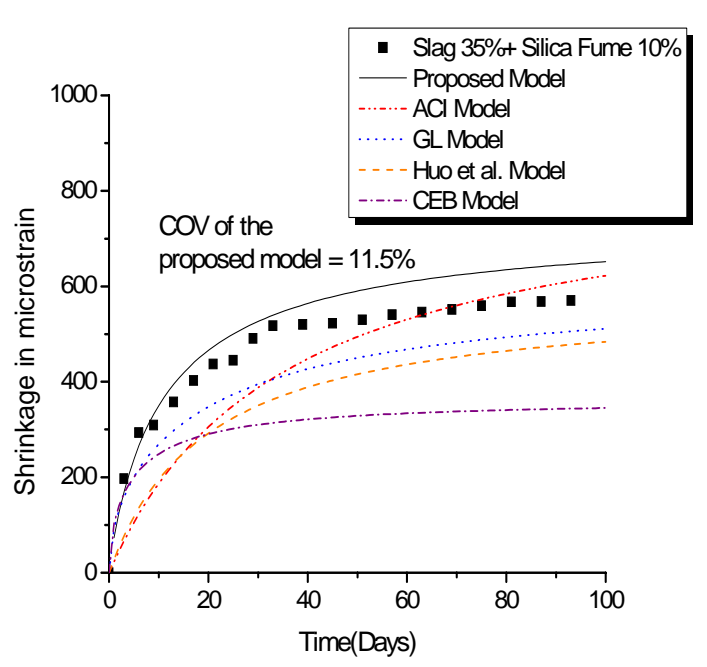

(b)

Fig. 5.16- Comparison of the proposed model and6 common prediction models with shrinkage data for concrete containing (a) $35 \%$ slag $+5 \%$ silica fume by mass (b) $35 \%$ slag $+10 \%$ silica fume by mass

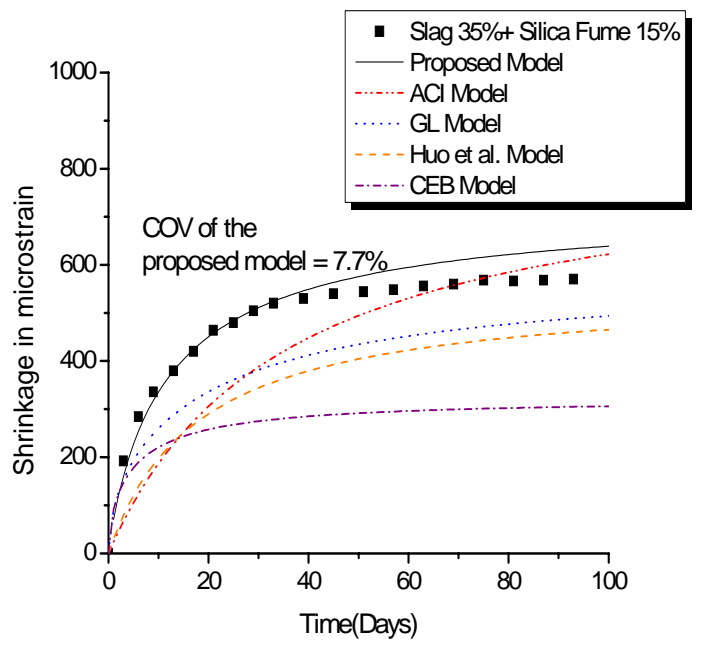

(a)

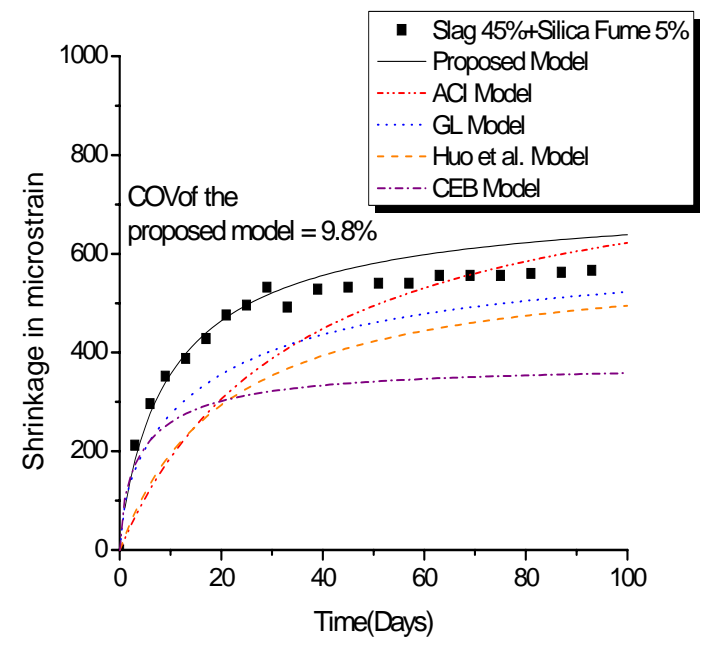

(b)

Fig. 5.17- Comparison of the proposed model and common prediction models with shrinkage data for concrete containing (a) $35 \%$ slag $+15 \%$ silica fume by mass (b) $45 \%$ slag $+5 \%$ silica fume by mass 


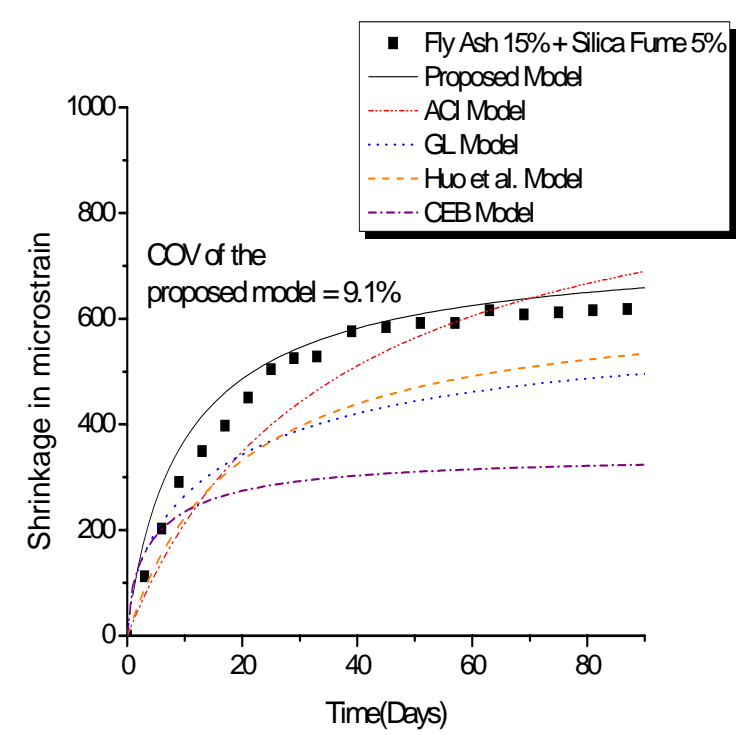

(a)

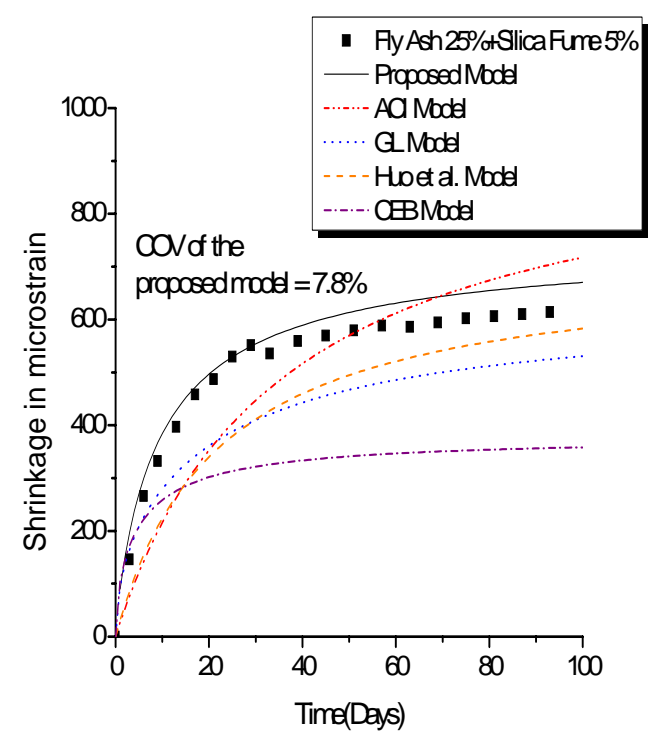

(b)

Fig. 5.18-Comparison of the proposed model and common prediction models with shrinkage data for concrete containing (a) $15 \%$ fly ash $+5 \%$ silica fume by mass (b) $25 \%$ fly ash $+5 \%$ silica fume by mass

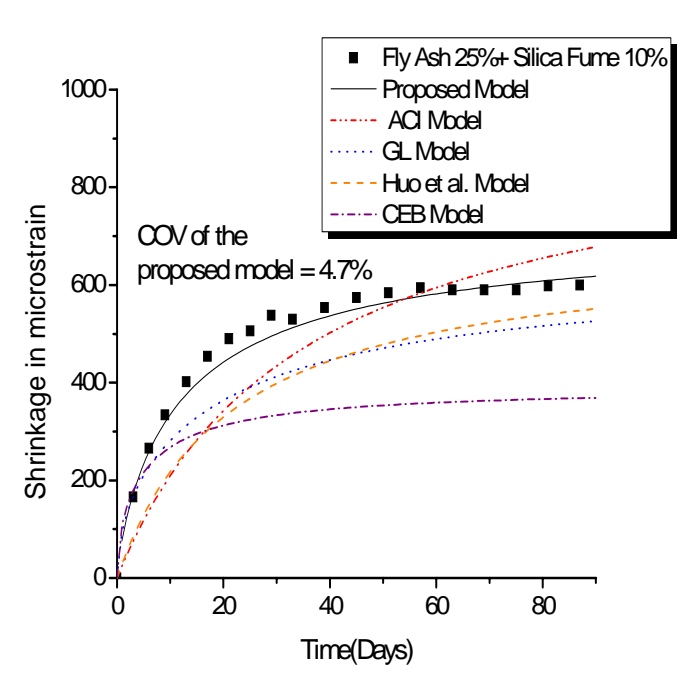

(a)

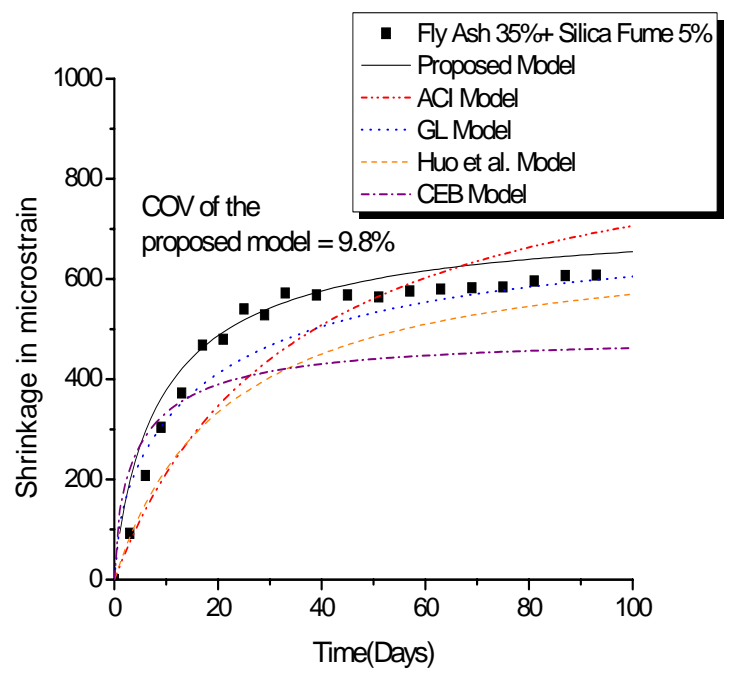

(b)

Fig. 5.19- Comparison of the proposed model and few common prediction models with shrinkage data for concrete containing (a) $25 \%$ fly ash $+10 \%$ silica fume by mass (b) $35 \%$ fly ash $+5 \%$ silica fume by mass 


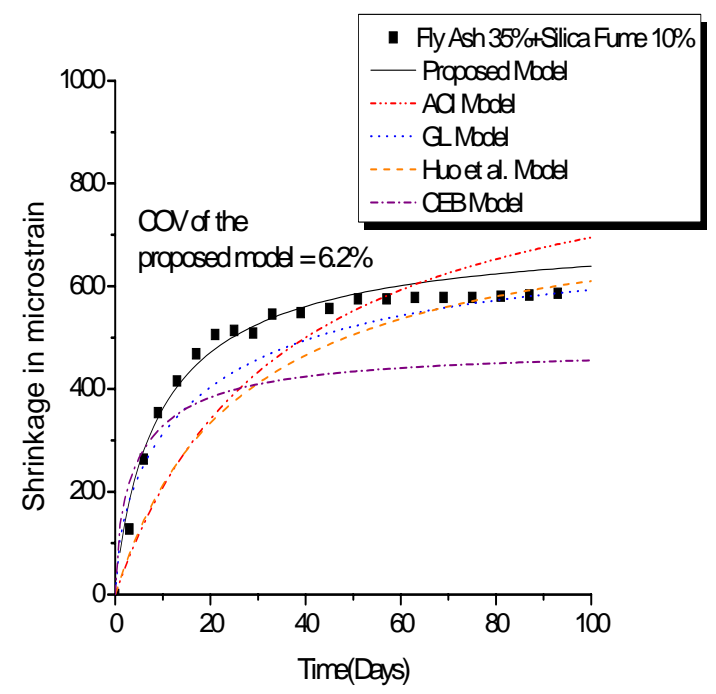

(a)

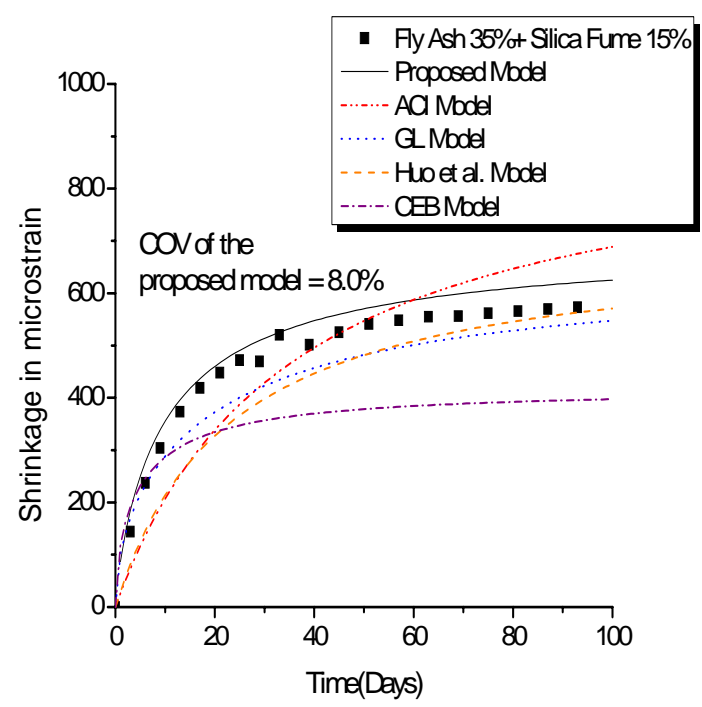

(b)

Fig. 5.20- Comparison of the proposed model and common prediction models with shrinkage data for concrete containing (a) $35 \%$ fly ash $+10 \%$ silica fume by mass (b) $35 \%$ fly ash $+5 \%$ silica fume by mass

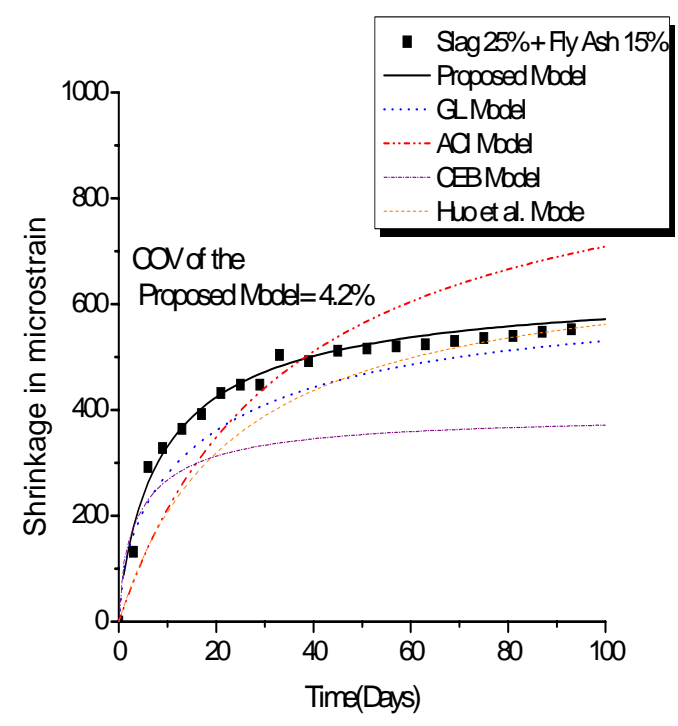

(a)

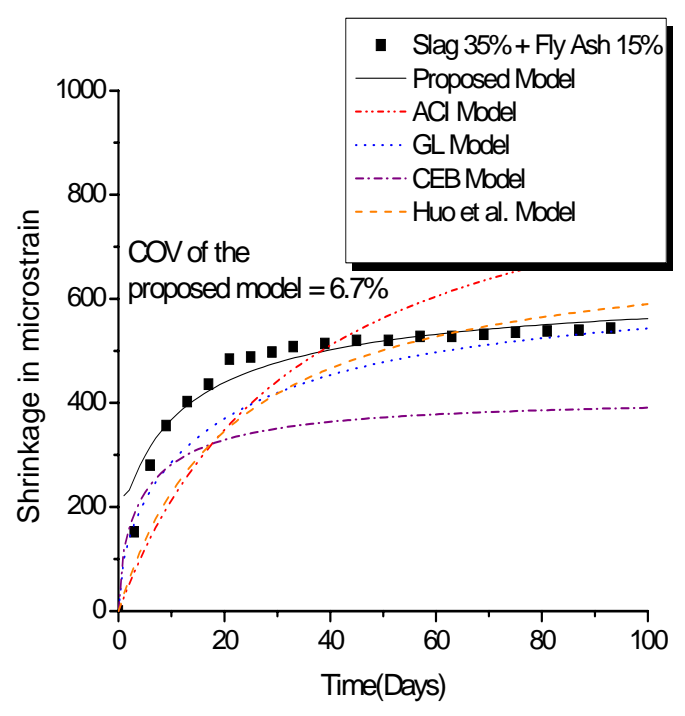

(b)

Fig. 5.21- Comparison of the proposed model and common prediction models with shrinkage data for concrete containing (a) $25 \%$ slag $+15 \%$ fly ash by mass (b) $35 \%$ slag $+15 \%$ fly ash by mass 


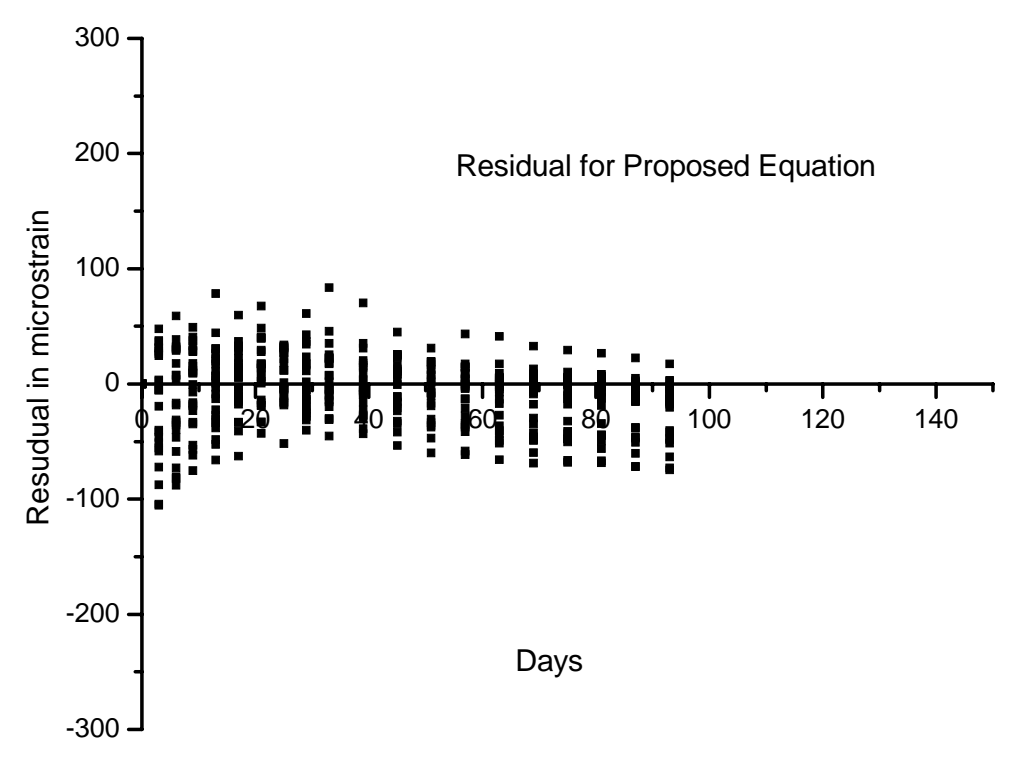

Fig. 5.22- Residual plot of the proposed model

From the figures 5.8-5.29 it is clear that the proposed model gives reasonably good estimate of drying shrinkage of concretes made with a w/cm 0.4 and containing supplementary cementing materials. The largest coefficient of variation (COV) obtained for all the mixtures cast in the laboratory is $11.5 \%$. This is well within the range of $15 \%$ for range coefficient of variations for accuracy as mentioned earlier. Also figure 5.20 shows a well dispersed residual along the horizontal axis and maximum residual strain is around 100 microstrain only. So the proposed equation is reasonably good fit for the mixtures cast in the laboratory during the project.

\subsection{Testing the Model with Data from Other Sources}

Drying shrinkage data obtained from researches done by different authors using similar kind of $\mathrm{w} / \mathrm{cm}=0.4$, aggregate content, cementitous material and environmental conditions were tested for validation of the model. The values of A\&B are found either directly or through interpolating from table 5.1. 


\subsubsection{Results obtained by Gong et al. (2004)}

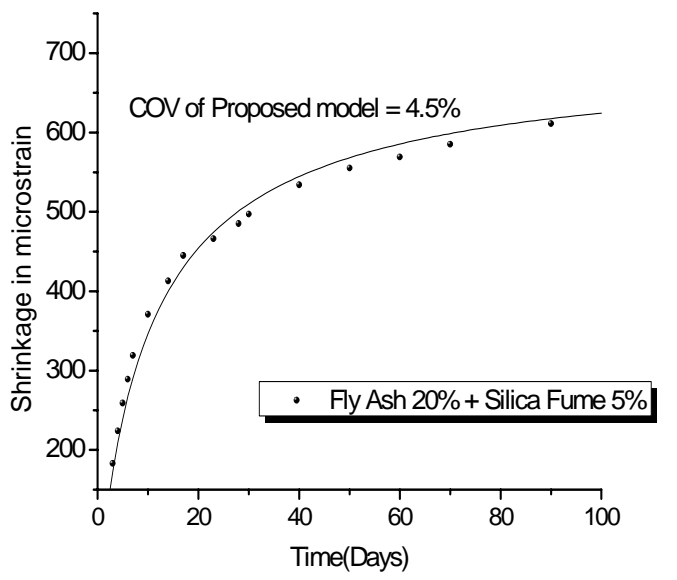

(a)

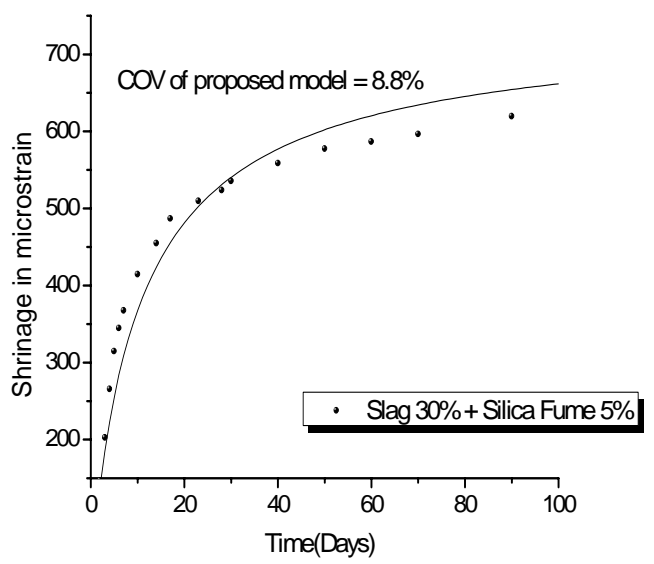

(b)

Fig. 5.23 - Comparison of the model with data obtained for mixtures in a separate research for WVDOH by

Gong et al. 2004 (a) fly Ash 20\% + silica Fume 5\% concrete (b) slag 30\% + silica fume 5\% concrete

$\mathrm{A}=.0976$ and $\mathrm{B}=.09109$ interpolating between the values of mixtures for FS $15+5$ and FS $25+5$ in Table 5.1

$\mathrm{A}=.1013$ and $\mathrm{B}=.0118$ interpolating between the values of mixtures for SS $25+5$ and SS $35+5$ in Table 5.1

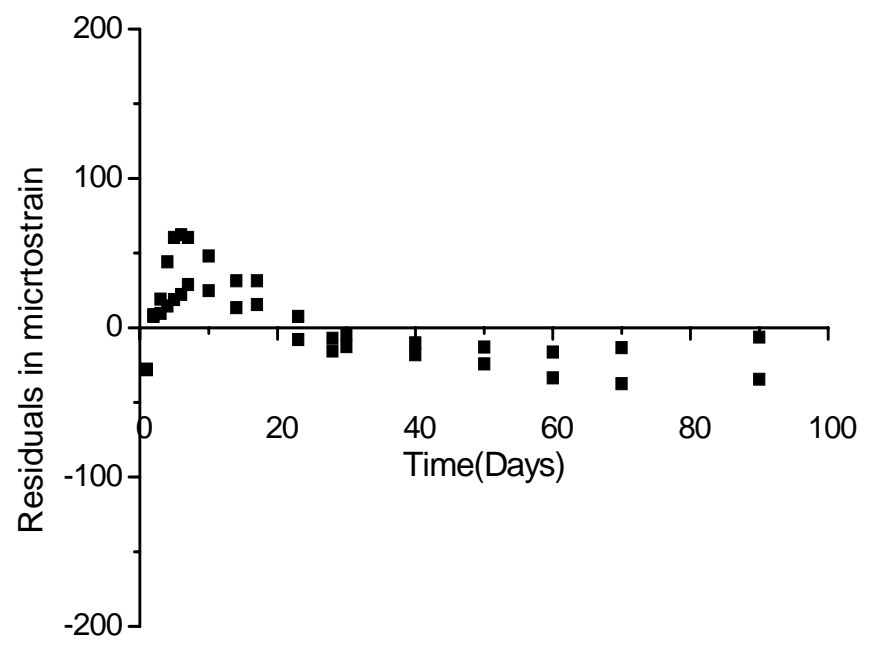

Fig. 5.24 - Residuals of the proposed model for the data obtained by Gong et al. 2004 


\subsubsection{Results obtained by Zhang (2001)}

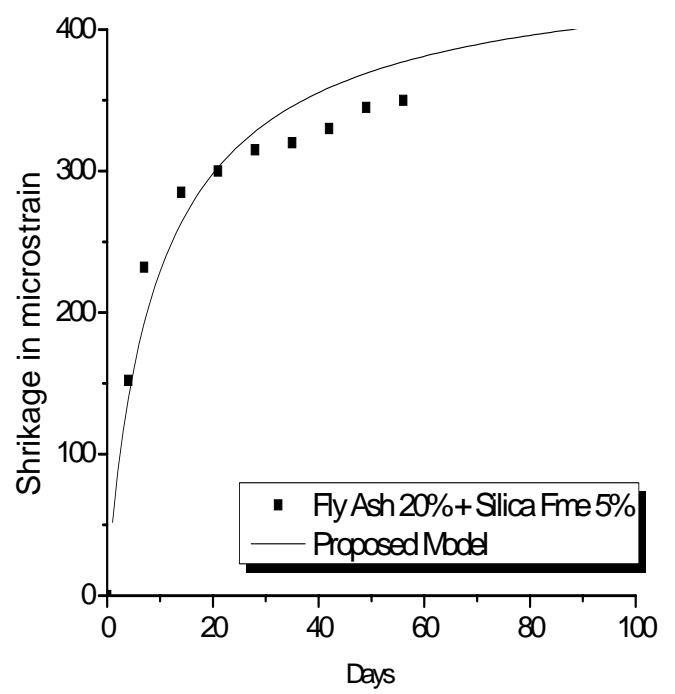

(a)

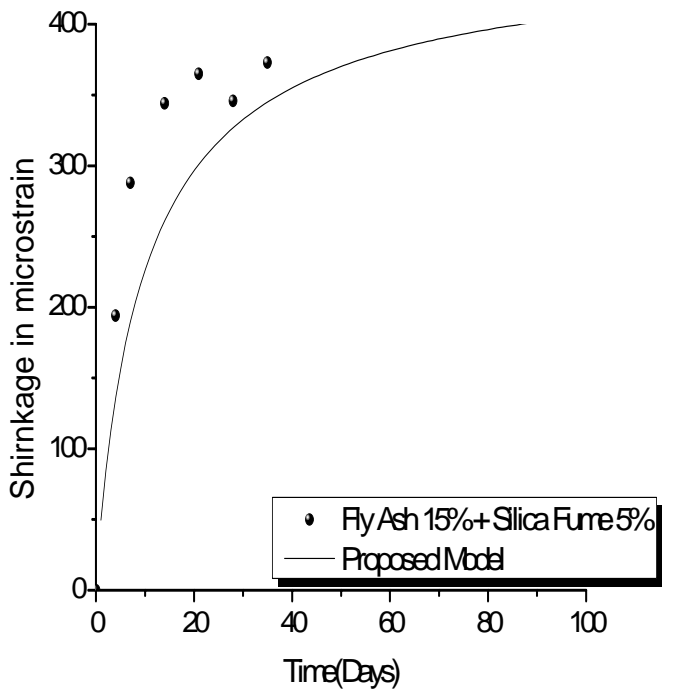

(b)

Fig. 5.25 - Comparison of the model with data obtained for mixtures in research for WVDOH by Zhang, 2001 (a) fly ash $20 \%+$ silica fume $5 \%$ concrete (b) fly ash $15 \%+$ silica fume $5 \%$ concrete

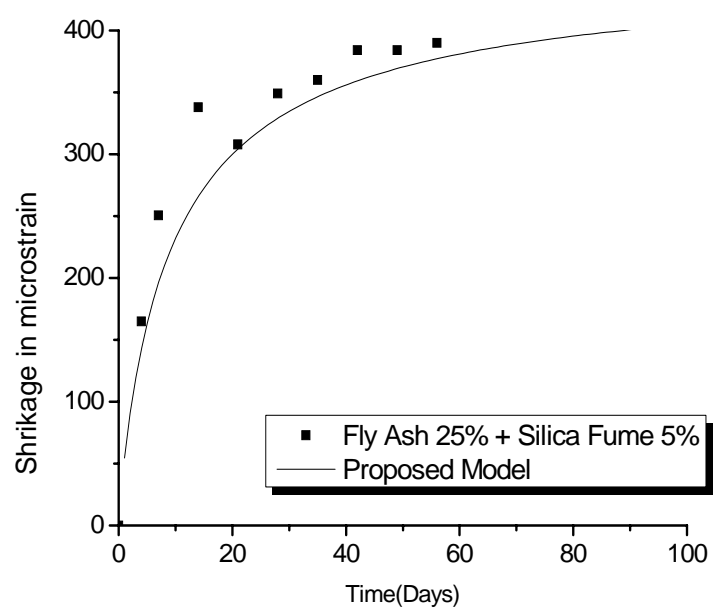

(a)

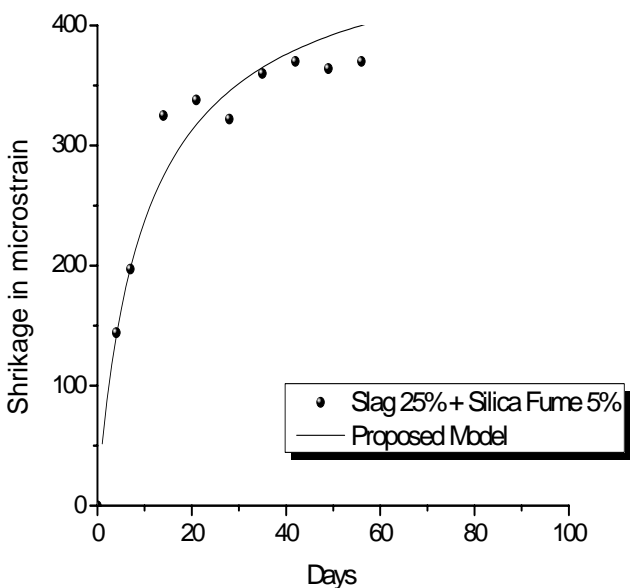

(b)

Fig. 5.26 - Comparison of the model with data obtained for mixtures in research for WVDOH by Zhang, 2001 (a) fFly ash 25\% + silica fume 5\% concrete (b) slag 25\% + silica Fume 5\% concrete 


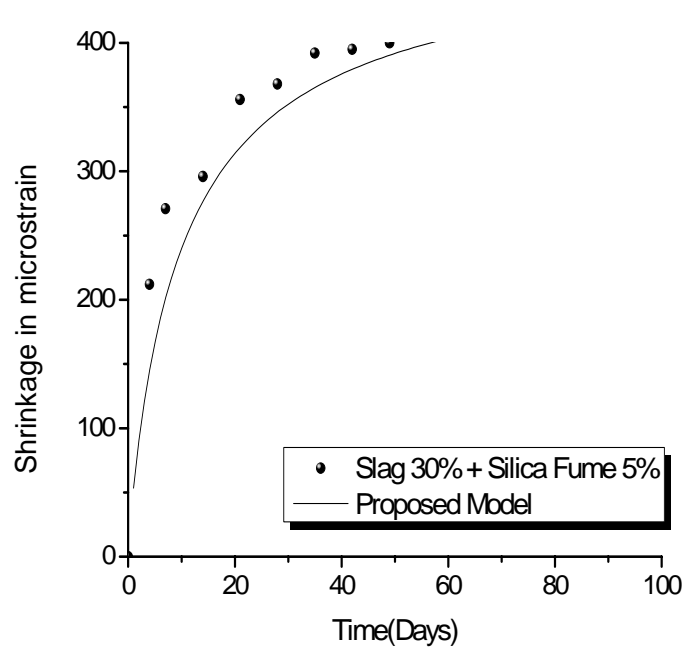

(a)

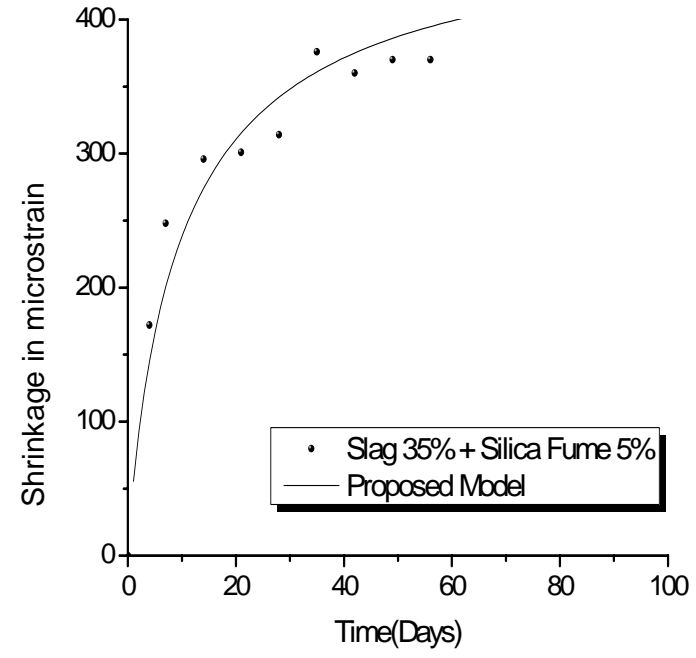

(b)

Fig. 5.27 - Comparison of the model with data obtained for mixtures in research for WVDOH by Zhang, 2001 (a) slag 30\% + silica fume 5\% concrete (b) slag 35\% + silica fume 5\% concrete

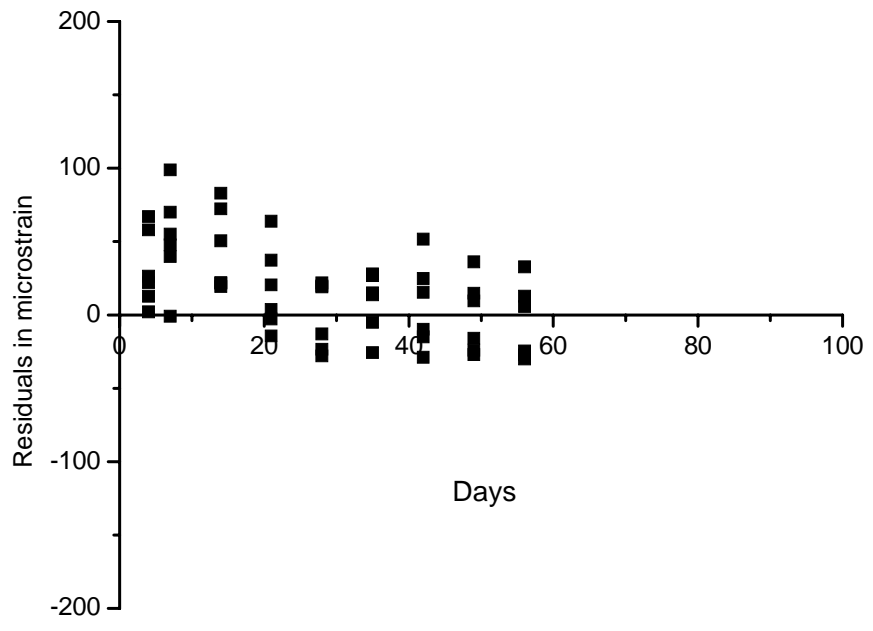

Fig. 5.28 - Residuals of the proposed model for the data obtained by Zhang, 2001 


\subsubsection{Results obtained by Morris (2002)}

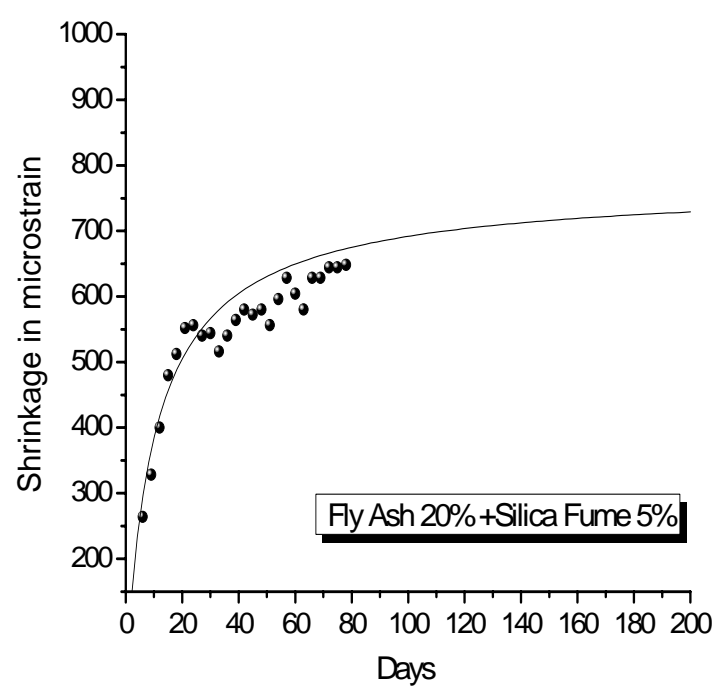

(a)

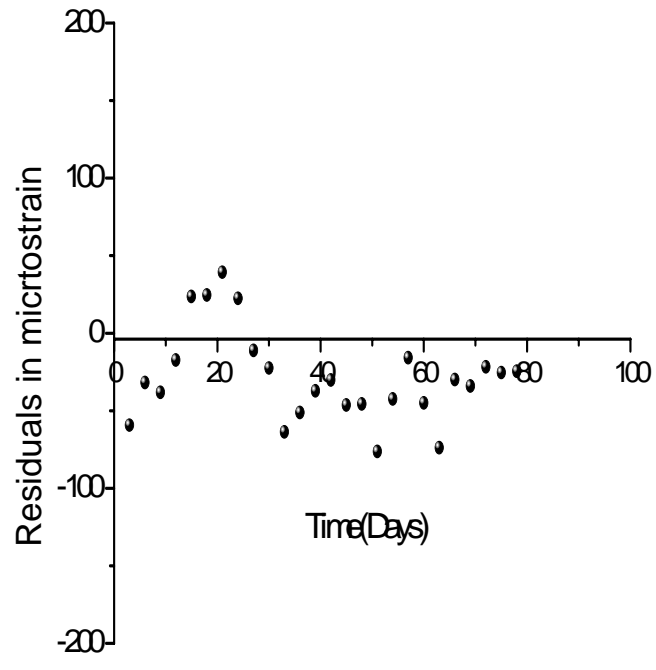

(b)

Fig. 5.29 - Comparison of the model with data obtained in research for WVDOH by Morris, 2002 (a) fly ash $20 \%+$ silica fume $5 \%$ concrete (b) corresponding residuals

\subsubsection{Results obtained by Mokarem (2002)}

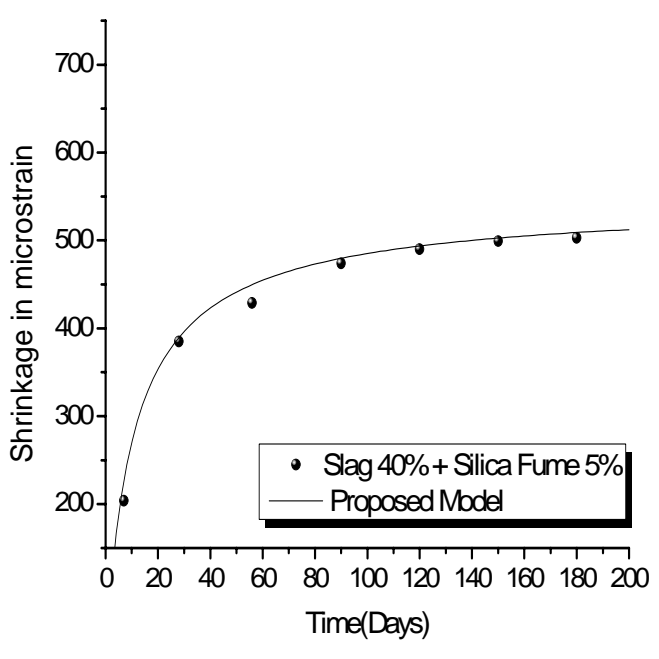

(a)

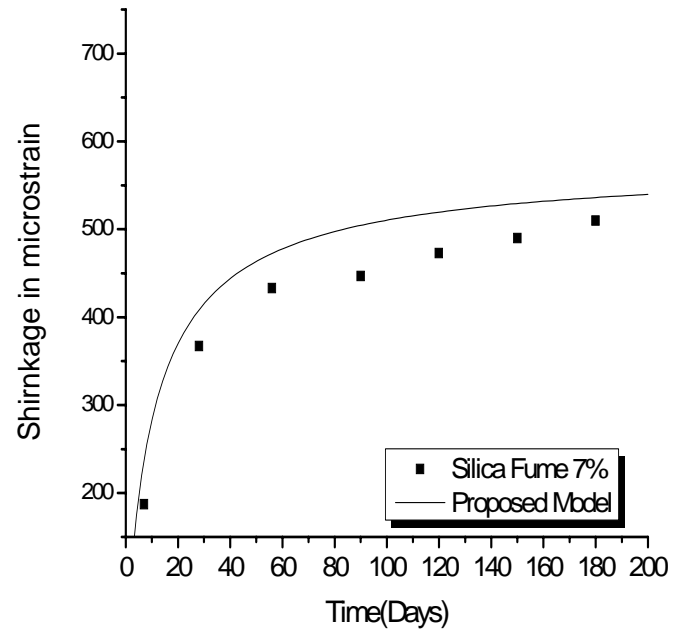

(b)

Fig. 5.30 - Comparison of the model with data obtained for mixtures in research for VDOT by Mokarem, 2002 at Virginia Tech. (a) slag 40\% + silica fume 5\% concrete (b) silica fume 7\% concrete 


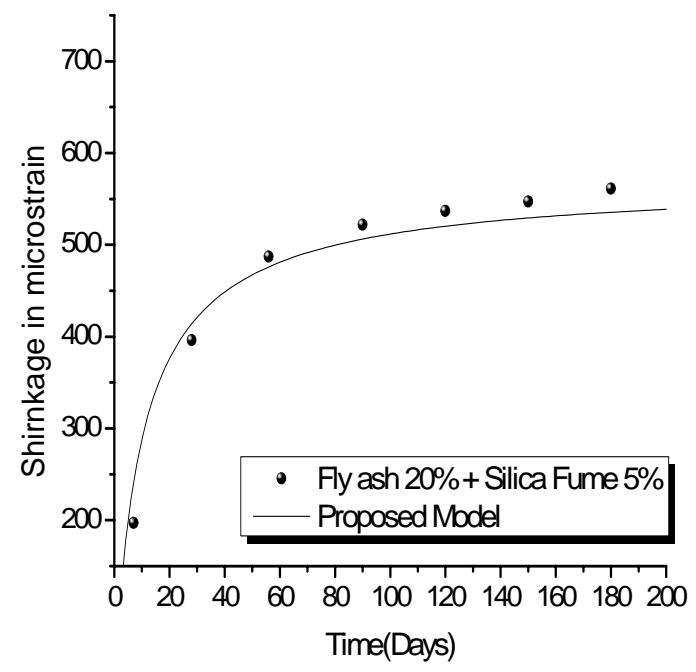

Fig. 5.31 - Comparison of the model with data obtained for mixtures in research for VDOT by Mokarem, 2002 at Virginia Tech. (a) fly ash $20 \%+$ silica fume $5 \%$ concrete

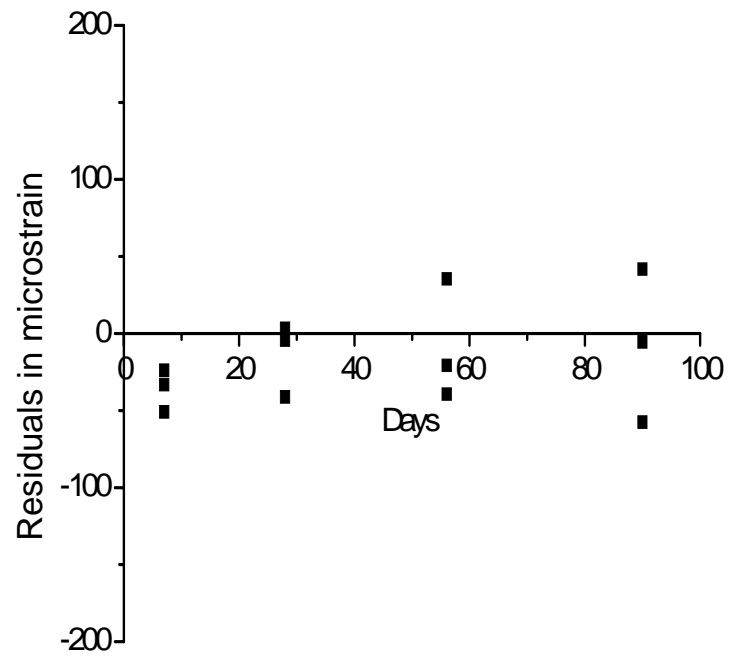

Fig. 5.32- Residuals of the proposed model for the data obtained by Mokarem, 2002 
Table 5.4 - Coefficient of variation of the test data with the proposed model

\begin{tabular}{|c|c|c|c|}
\hline \multirow{2}{*}{ Investigator } & Mix & Values of A\&B & $\begin{array}{c}\text { COV of the proposed } \\
\text { model (\%) }\end{array}$ \\
\hline \multirow{3}{*}{ Gong (2004) } & Slag 30\% + Silica Fume 5\% & $\mathrm{A}=.10127, \mathrm{~B}=.0118$ & 8.82 \\
\cline { 2 - 4 } & Fly Ash 20\% + Silica Fume 5\% & $\mathrm{A}=.0976, \mathrm{~B}=.01092$ & 4.5 \\
\hline \multirow{3}{*}{ Zhang ( 2001) } & Fly Ash 20\% + Silica Fume 5\% & $\mathrm{A}=.0976, \mathrm{~B}=.01092$ & 8.72 \\
\cline { 2 - 4 } & Fly Ash 25\% + Silica Fume 5\% & $\mathrm{A}=.092, \mathrm{~B}=.0116$ & 11.0 \\
\cline { 2 - 4 } & Fly Ash 15\% + Silica Fume 5\% & $\mathrm{A}=.10323, \mathrm{~B}=.01023$ & 20.3 \\
\cline { 2 - 4 } & Slag 30\% + Silica Fume 5\% & $\mathrm{A}=.10127, \mathrm{~B}=.0118$ & 11.8 \\
\cline { 2 - 4 } & Slag 35\% + Silica Fume 5\% & $\mathrm{A}=.09632, \mathrm{~B}=.01293$ & 8.6 \\
\cline { 2 - 4 } & Slag 25\% + Silica Fume 5\% & $\mathrm{A}=.092, \mathrm{~B}=.0116$ & 8.3 \\
\hline Morris (2002) & Fly Ash 20\% + Silica Fume 5\% & $\mathrm{A}=.0976, \mathrm{~B}=.01092$ & 7.8 \\
\hline \multirow{3}{*}{ Mokarem (2002) } & Fly Ash 20\% + Silica Fume 5\% & $\mathrm{A}=.0976, \mathrm{~B}=.01092$ & 9.1 \\
\cline { 2 - 4 } & Slag 30\% + Silica Fume 5\% & $\mathrm{A}=.10127, \mathrm{~B}=.0118$ & 11.4 \\
\cline { 2 - 4 } & Silica Fume 7\% & $\mathrm{A}=.0963, \mathrm{~B}=01463$ & 3.2 \\
\hline
\end{tabular}

(Note: A\&B values for Fly Ash 25\%+ Silica Fume 5\% concrete have been found by interpolating between Fly Ash 15\%+ Silica Fume 5\% and Fly Ash 25\%+ Silica Fume 5\%)

From table 5.4 the it is evident that COV for all the test data is well within the range of $15 \%$ except the case of concrete containing $15 \%$ fly ash \& $5 \%$ silica fume done by Zhang, 2001. It had a COV of $20 \%$, but the shrinkage values have a large scatter (figures 5.26, 5.27) and the author has also mentioned inaccuracy in maintaining the relative humidity during shrinkage test. This might have caused the large scatter and the COV. Figures 5.25, 5.29, 5.30(b) and 5.33 which show the residual plots for all the data the figures display that the plots are evenly distributed on both sides of the horizontal axis and maximum residual strain observed is 100 microstrain. This indicates that the proposed model estimates drying shrinkage reasonably well for concretes containing supplementary cementing materials with a w/cm of 0.4 . 


\section{Chapter 6}

\section{Compressive Strength and Prediction Equations}

\subsection{Introduction}

In this chapter the compressive strength of different mixtures has been compared. The ACI prediction equation for compressive strength has been investigated and a new prediction equation for compressive strength has been proposed and tested with available data.

\subsection{Compressive Strength Measurement}

Compressive strengths of 101.6 diameter x $203.2 \mathrm{~mm}$ long cylinder specimens were measured in accordance with ASTM C 39 (Standard Test Method for Compressive Strength of Cylindrical Concrete Specimens). Each specimen was cured under water at $23 \pm 2^{0} \mathrm{C}$ till the day of testing. Tests were conducted at 1, 3, 7, 28, 60, and 90 days after casting. Average values of compressive strength of 24 mixtures are reported in Appendix D.

\subsection{ACI Prediction Equation for Compressive Strength}

ACI $209 \mathrm{R}$ provides the equation for prediction of compressive strength at any time ' $\mathrm{t}$ ' with respect to 28 days compressive strength, $\mathrm{f}_{\mathrm{c}}$. Following is the equation:

$\left(f_{c}^{\prime}\right)_{t}=\frac{t}{\alpha+\beta t}\left(f_{c}^{\prime}\right)$

Where for Type I concrete with moist curing

$\alpha=4.0$, and $\beta=.85$ 


\subsection{Test Results and Discussions}

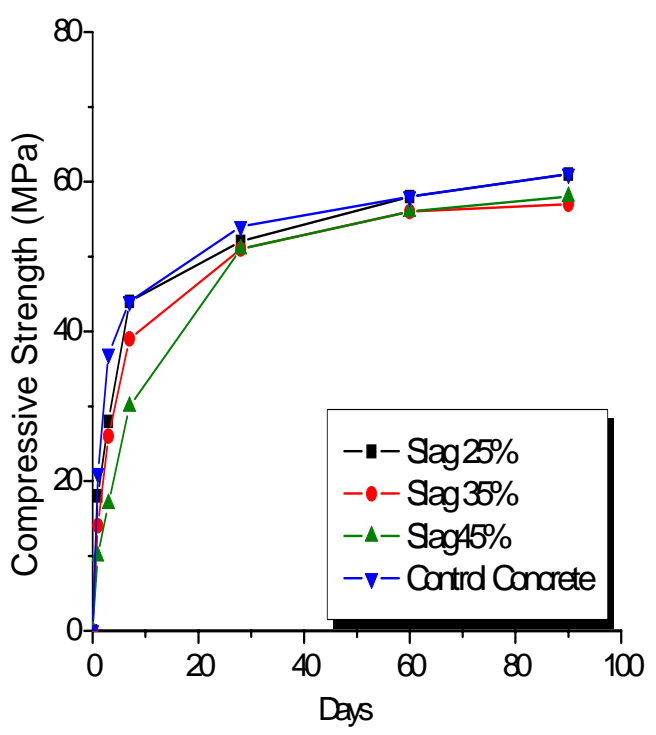

(a)

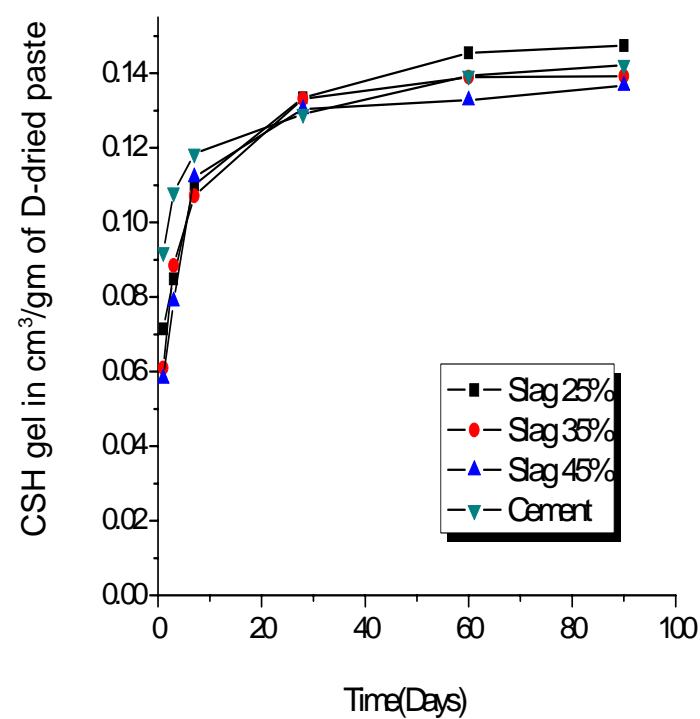

(b)

Fig 6.1 - (a) Compressive strength of concretes with different slag replacements (b) C-S-H gel formation in slag replaced cement pastes

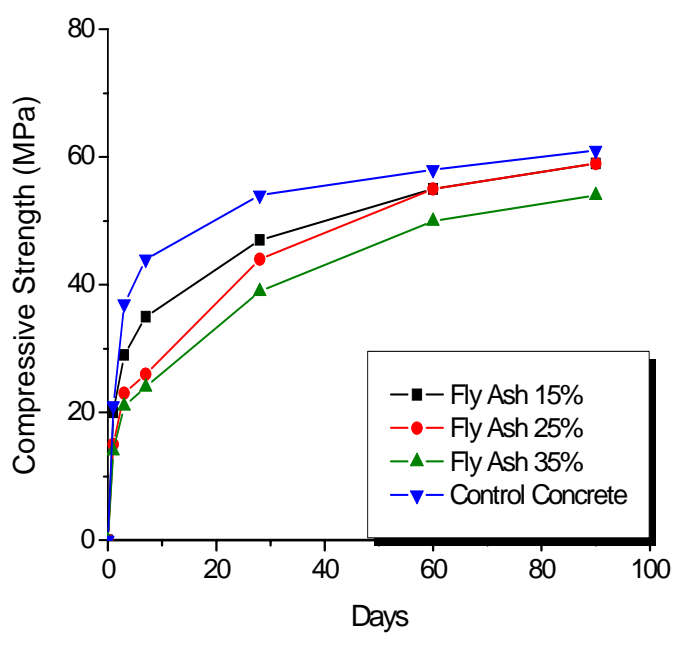

(a)

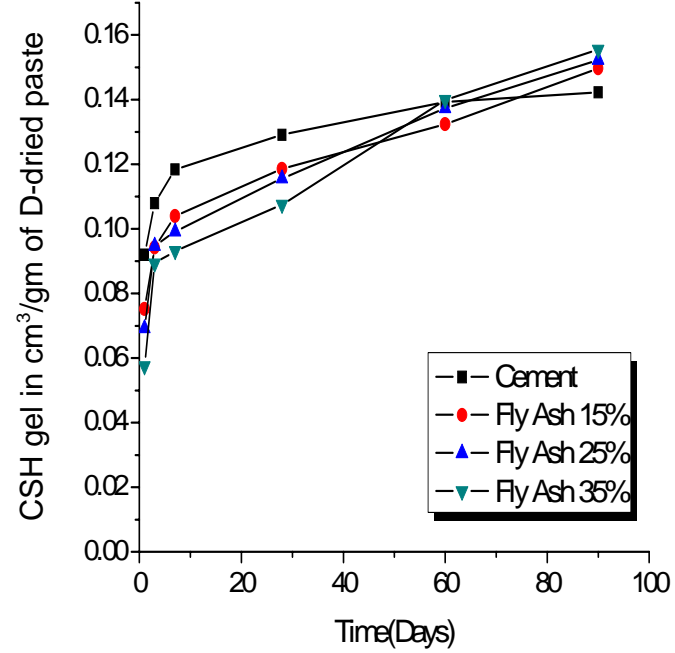

(b)

Fig 6.2 - (a) Compressive strength of concretes with different fly ash replacements (b) C-S-H gel formation for fly ash replaced cement pastes 


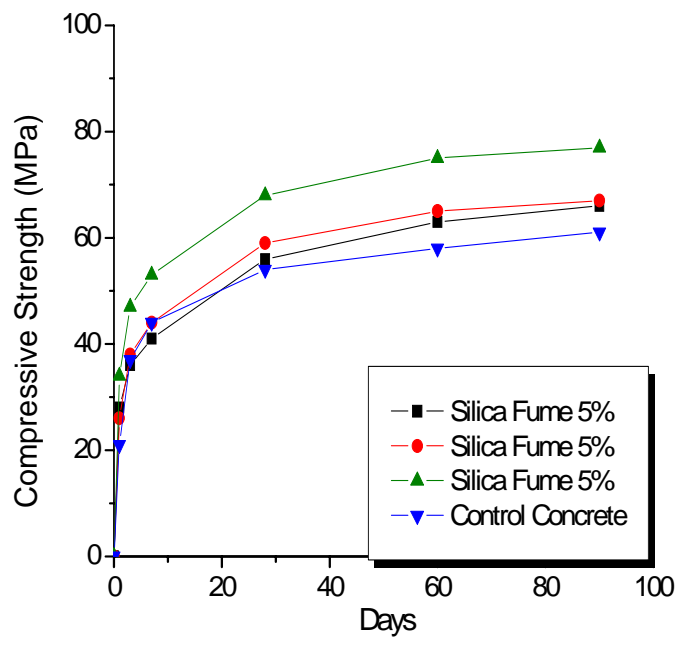

(a)

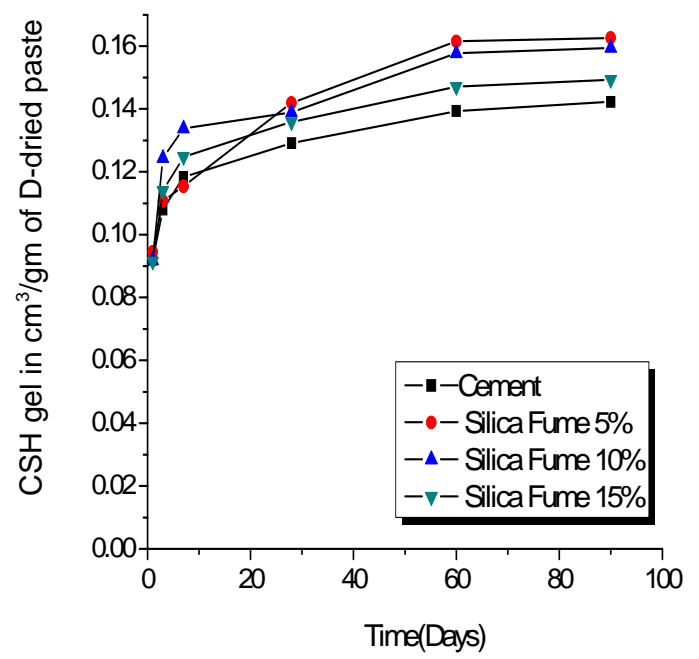

(b)

Fig 6.3 - (a) Compressive strength of concretes with different silica fume replacements (b) C-S-H gel formation for silica fume replaced cement pastes

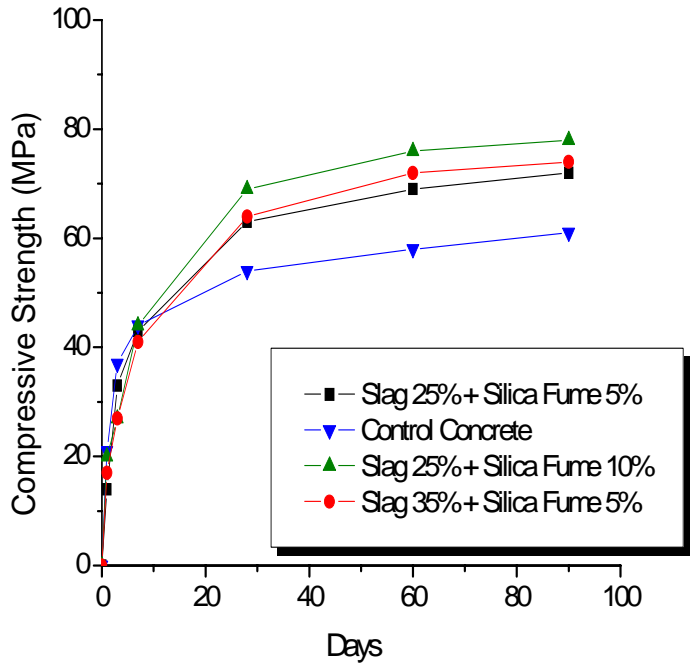

(a)

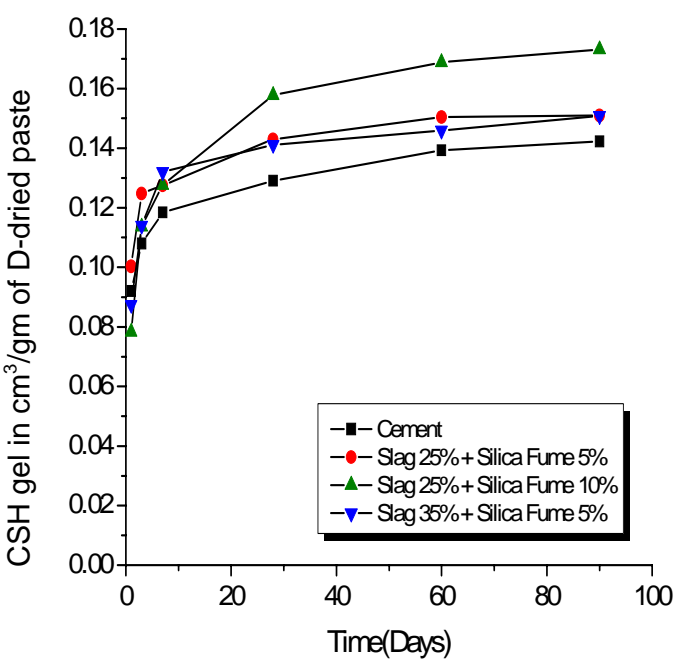

(b)

Fig 6.4 - (a) Compressive strength of concretes with different slag and silica fume replacements (b) C-S-H gel formation for slag and silica fume replaced cement pastes 


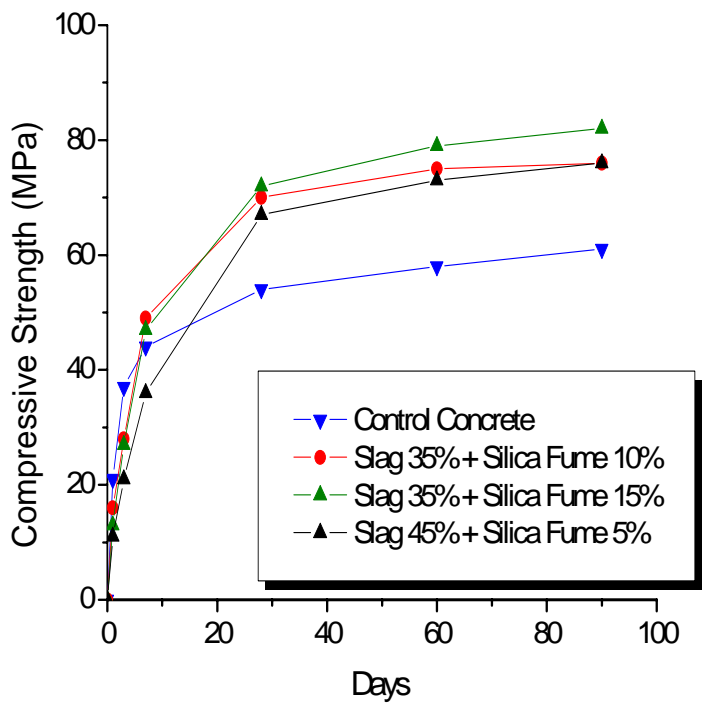

(a)

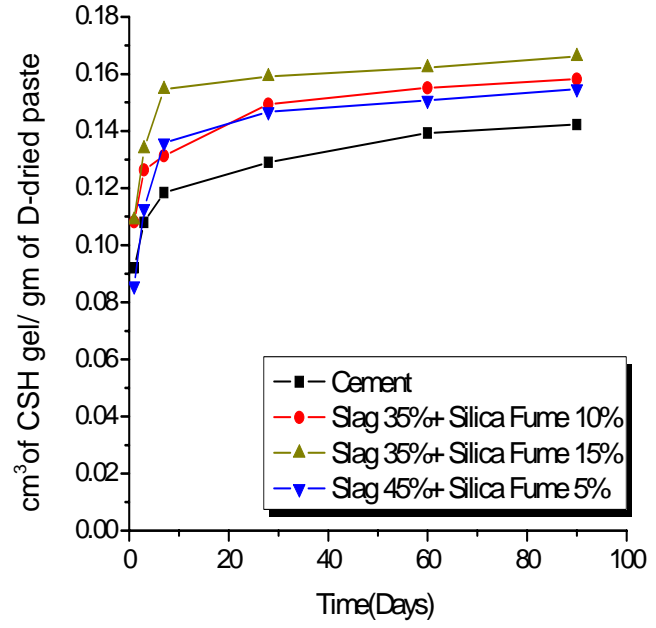

(b)

Fig 6.5 - (a) Compressive strength of concretes with different slag and silica fume replacements (b) C-S-H gel formation for slag and silica fume replaced cement pastes

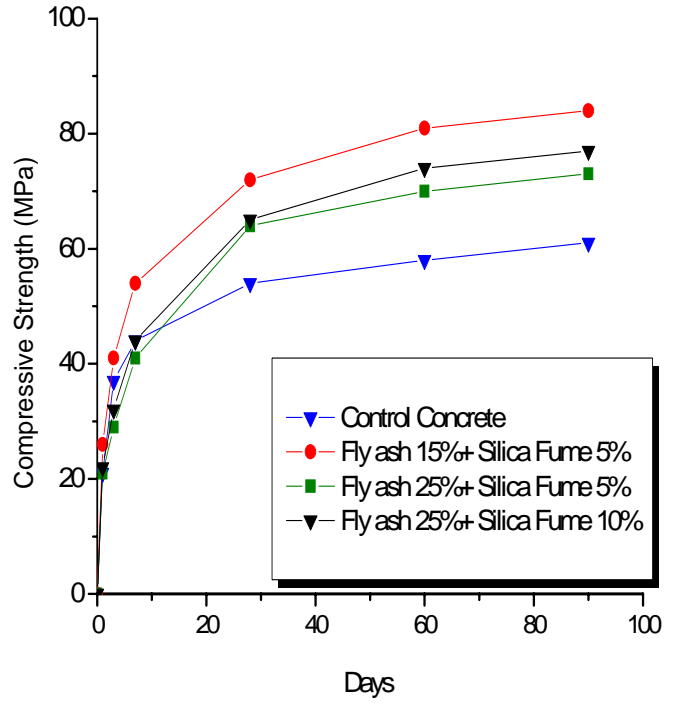

(a)

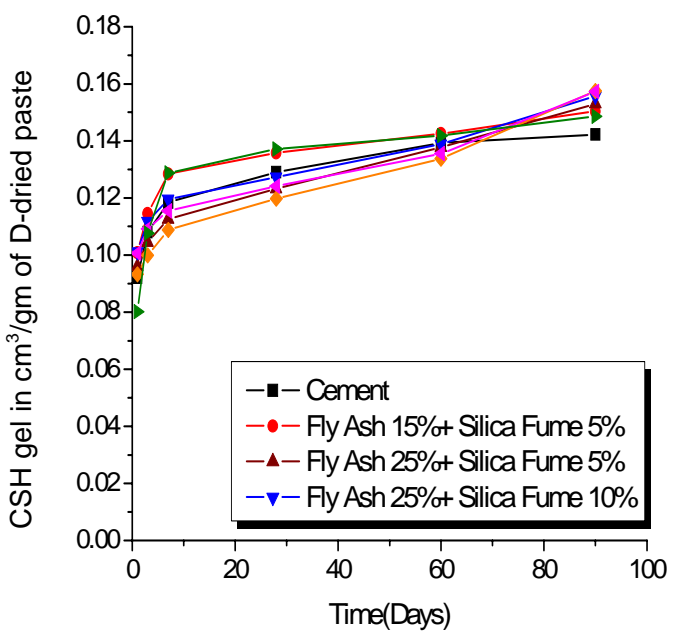

(b)

Fig 6.6 - (a) Compressive strength of concretes with different fly ash and silica fume replacements (b) C-S$\mathrm{H}$ gel formation for fly ash and silica fume replaced cement pastes 


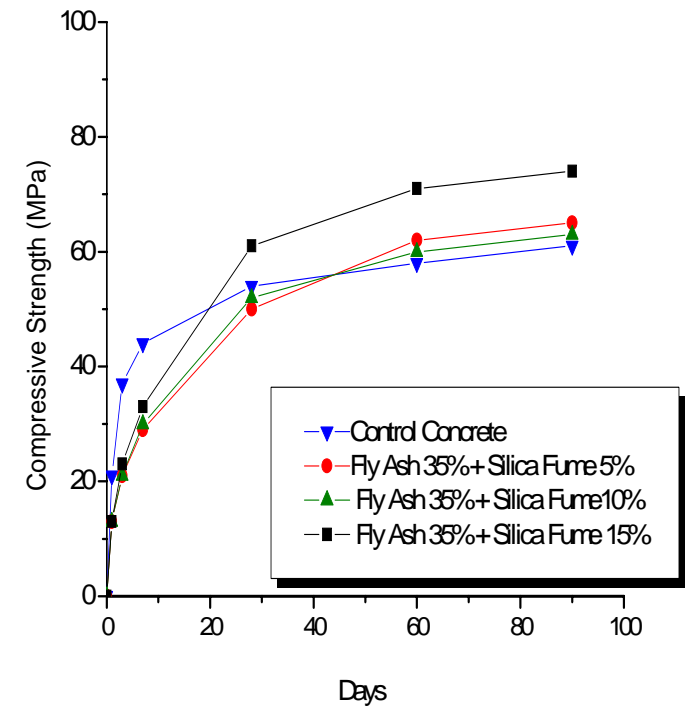

(a)

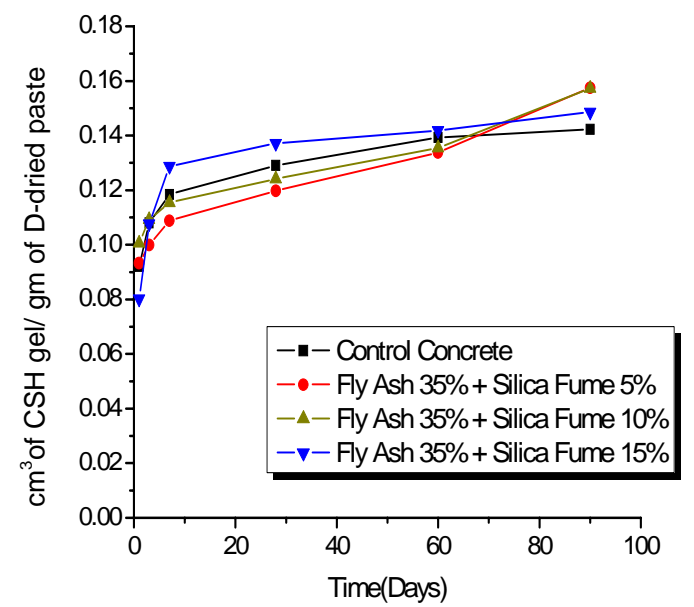

(b)

Fig 6.7 - (a) Compressive strength of concretes with different fly ash and silica fume replacements (b) C-S$\mathrm{H}$ gel formation for fly ash and silica fume replaced cement pastes

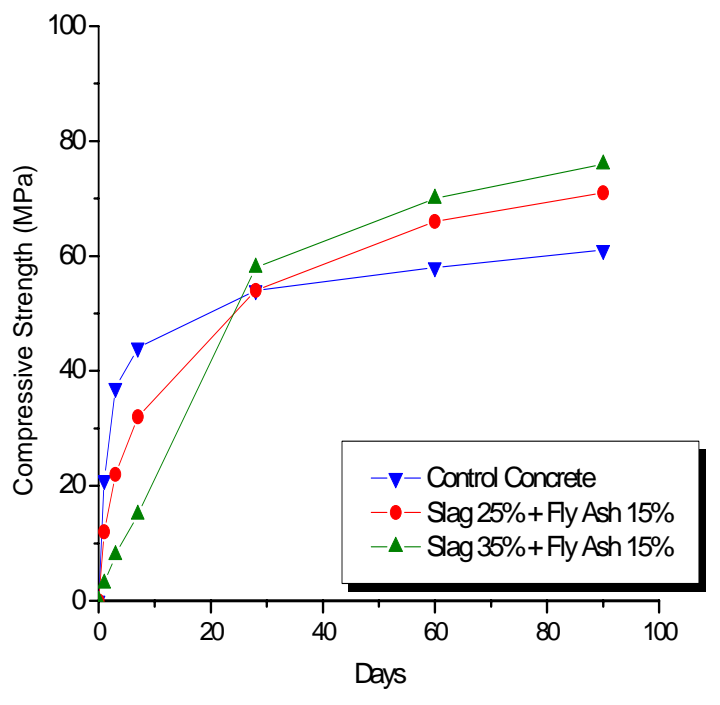

(a)

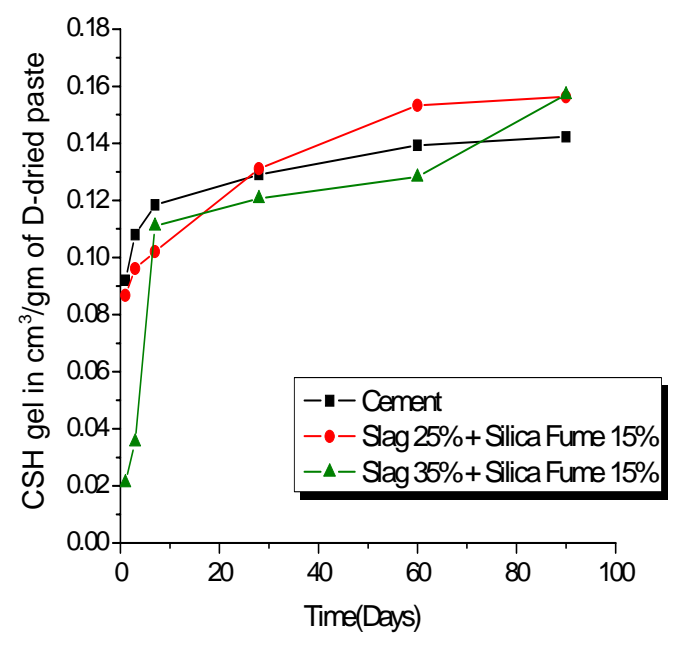

(b)

Fig 6.8 (a) Compressive strength of concretes with different slag and fly ash replacements (b) C-S-H gel formation for slag and fly ash replaced cement pastes 
Figure 6.1 (a) and (b) show the compressive strength development of slag replaced concretes and the C-S-H gel formation for slag replaced pastes, respectively. It is observed that due to replacements by slag, both the compressive strength of concretes and the gel formation in pastes become lower compared to those values of the control concrete (without replacement) and normal cement paste (without replacement), respectively. As the replacement level of slag increases, both gel formation and compressive strength decrease compared to control concrete. Fly ash containing concretes have lesser compressive strength at all ages, though at $15 \%$ and $25 \%$ replacement levels the compressive strength values are close to the control concrete at 90 days. But there is a considerable gain in compressive strength between 60 days and 90 days for fly ash containing concretes, which was absent both in cases of slag concretes and the control concrete. It can be also observed that (Fig. 6.2 (b)) C-S-H gel formation for fly ash containing pastes increases significantly between 60 and 90 days. This indicates a good correlation between gel formation and compressive strength development.

In case of silica fume containing mixtures, the C-S-H gel formation in the pastes and the compressive strengths of the concretes are found to be greater than the control concrete (Fig. 6.3) at all ages. Both the compressive strength and the gel formation at al ages are more than control concrete showing an indication of high reactivity of silica fume containing mixtures at early ages. Whereas the later age strength development and gel formation are unlike that of fly ash.

Fig. 6.6 shows compressive strength gain and C-S-H gel formation of slag and silica fume containing ternary mixtures. In case of slag and silica fume replacements, both the C-S-H gel formation and compressive strength development are greater than the control concrete after 3 to 7 days indicating significant reactivity between 7 to 28 days. It is observed that more the gel formation, higher the strength developed.

Fly ash and silica fume concretes have higher strength than the control concrete at lower replacement levels at all ages (Fig. 6.6). On the other hand at higher replacement levels for ternary mixtures containing fly ash and silica fume, strength increases considerably between 60 and 90 days (Fig. 6.7). Also a significant increase in gel 
formation is evident from Fig. $6.8 \mathrm{~b}$ and Fig. $6.9 \mathrm{~b}$ for fly ash and silica fume containing pastes.

For two mixtures with slag and fly ash (Fig. 6.8), compressive strengths of concretes and gel formation in the pastes are excessively lower than that of the values of control concrete between 0 to 7 days respectively. A rapid gain in strength and gel formation occurs after 7 days for slag and fly ash containing mixtures.

In all the cases at higher replacement levels, higher compressive strength is observed after 28 days. Generally between 0 to 7 days, the compressive strength for mixtures containing slag or fly ash (or in combinations) is close or lower than the control concrete. Only for silica fume concretes the compressive strength is considerably higher at all ages.

Slag concrete gains most of its strength between 0 to 60 days though the values between 0 to 7 days are close to that of control concrete. Fly ash on the other hand gains most of its strength between 7 to 60 days and there is a considerable jump in compressive strength between 60 and 90 days. Silica Fume produces very high early age strength and there is very small difference in the observed compressive strength values between 60 and 90 days. In case of ternary mixtures containing silica fume, slag and silica fume combination produces greater compressive strength at all ages than the control concrete at all replacement levels, whereas fly ash and silica fume have lesser strength than control concrete at higher replacement level before 60 days. At lower replacements the observed compressive strengths are higher than the control concrete at all ages. Also there is a considerable gain in compressive strength between 60 to 90 days for any mixtures containing fly ash. For slag and fly ash concretes, the compressive strength is excessively low between 0 to 7 days compared to control concrete, but eventually it gains strength and shows higher values at later ages. It is worth mentioning that concrete containing slag of $35 \%$ and fly ash of $15 \%$ had such a low strength at early age that few specimens were broken during demolding.

From the above discussion it can be concluded that there exists a very good correlation between C-S-H gel formation and compressive strength development (Fig. 6.9) which justifies that $\mathrm{C}-\mathrm{S}-\mathrm{H}$ gel is the principal contributor to compressive strength. Also there are other factors that influence the strength to a smaller extent. 


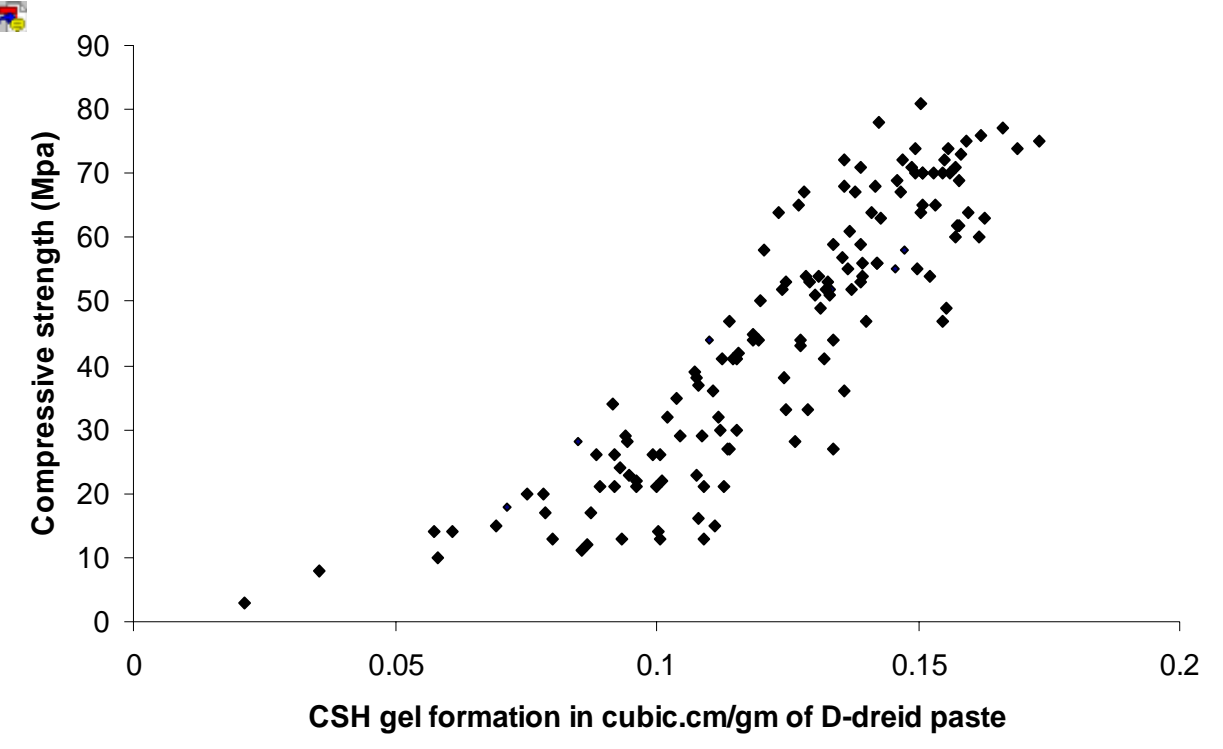

Fig. 6.9- Gel-Strength relationship

\subsection{Proposed Model}

As mentioned above in equation 6.1, ACI 209R provides an equation to calculate the compressive strength of a concrete at all ages with respect to the 28 days compressive strength. By substituting the constants we get the following equation:

$f_{c, t}^{\prime}=\frac{t}{(4+.85 t)} * f_{c, 28}^{\prime}$

$f_{c, 28}^{\prime}=28$ - days compressive strength

$f_{c, t}^{\prime}=$ compressive strength at any-time $\mathrm{t}$ (days)

Based on the ACI format in this study a model has been proposed on the basis of gel formation and calibrating on the 24 mixtures cast in the laboratory. This is as follows:

$$
f_{c, t}^{\prime}=\frac{t}{\alpha+\beta t} *(K)_{t} *\left(\frac{f_{c, 28}^{\prime}}{K_{28}}\right)
$$

$f_{c, 28}^{\prime}=28$ - days compressive strength

$f_{c, t}^{\prime}=$ compressive strength at any-time $\mathrm{t}$ (days)

$K=\frac{(A+B \ln (t))}{(\gamma+\delta \ln (t))}$ 
Where $\mathrm{A}$ and $\mathrm{B}$ can be obtained for any mixture from table 5.1 and values of $\alpha, \beta, \gamma$ and $\delta$ can be obtained from the following table 6.1 for different mixtures.

Table 6.1 Co-efficient for the proposed model

\begin{tabular}{|c|c|c|c|c|}
\hline Mixtures & $\alpha$ & $\beta$ & $\gamma$ & $\delta$ \\
\hline Fly Ash + Cement & 2 & 0.92 & 1.2 & 0.005 \\
\hline Slag + Cement & 2 & 0.92 & 1.0 & 0.15 \\
\hline Silica Fume + Cement & 1 & 0.96 & 1.0 & 0.01 \\
\hline Slag + Silica Fume+ Cement & 3 & 0.89 & 0.7 & 0.04 \\
\hline Fly Ash + Silica Fume+ Cement & 2 & 0.92 & 0.95 & 0.01 \\
\hline Slag + Fly Ash + Cement & 3 & 0.89 & 1.05 & 0.04 \\
\hline Cement & 2 & 0.92 & 1.2 & 0.02 \\
\hline
\end{tabular}

Typical sample calculation for control concrete is shown below:

From table 6.1, we get $\alpha=2, \beta=0.92, \gamma=1.2$ and $\delta=0.02$

And from table 5.3, $\mathrm{A}=0.0945$ and $\mathrm{B}=0.1083$

and substituting the values of $\alpha, \beta, \gamma, \delta, \mathrm{A}$ and $\mathrm{B}$ in equation. 6.3, we get,

$$
\begin{aligned}
& f_{c, t}^{\prime}=\frac{t}{\alpha+\beta t} *(K)_{t} *\left(\frac{f_{c, 28}^{\prime}}{K_{28}}\right) \\
& K=\frac{(.0945+.1083 \ln (t))}{(1.2+.02 \ln (t))} \\
& K_{28}=\frac{(.0945+.1083 \ln (28))}{(1.2+.02 \ln (28))}=.3595 \text { and } f_{c, 28}^{\prime}=54 \mathrm{MPa} \quad \text { from Appendix D } \\
& f_{c, t}^{\prime}=\frac{t}{2+.92 t} \cdot \frac{(.0945+.1083 \ln (t))}{(1.2+.02 \ln (t))} \cdot\left(\frac{54}{.3595}\right)
\end{aligned}
$$




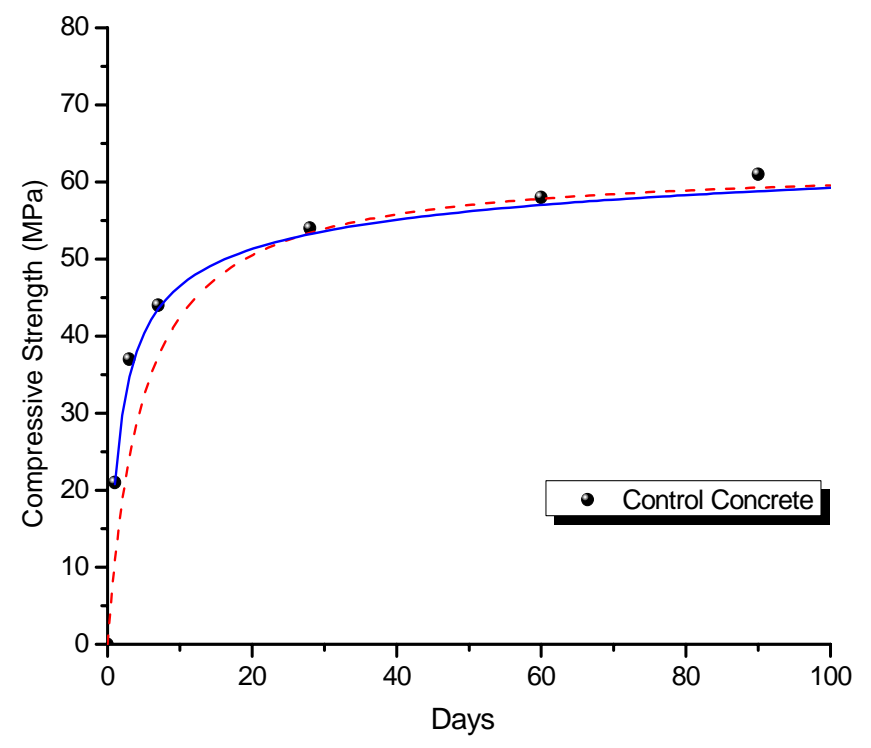

Fig. 6.10 - Comparison of ACI model and proposed model for compressive strength for control concrete

Calibration for all the models have been shown in the following figures -

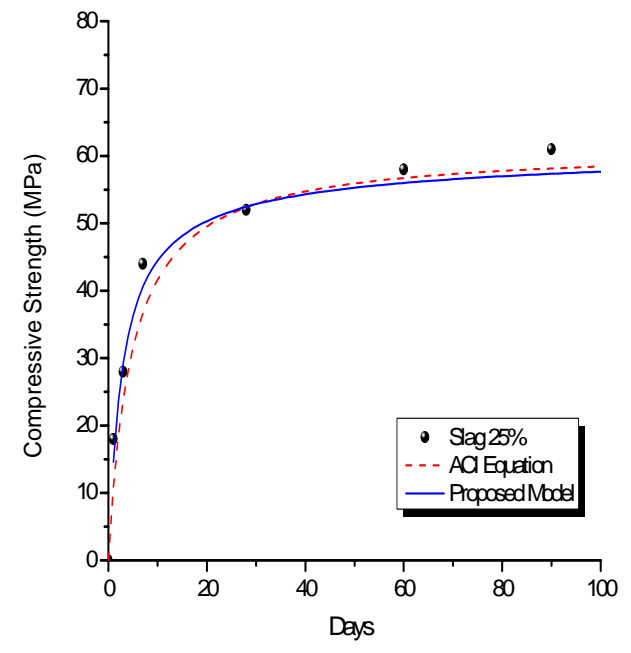

(a)

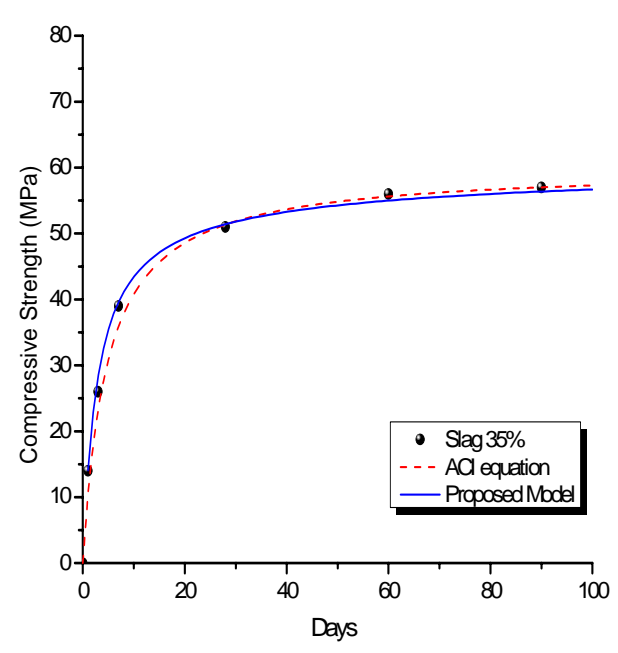

(b)

Fig. 6.11 - Comparison of ACI model and proposed model for compressive strength (a) slag $25 \%$ by mass (b) slag $35 \%$ by mass 


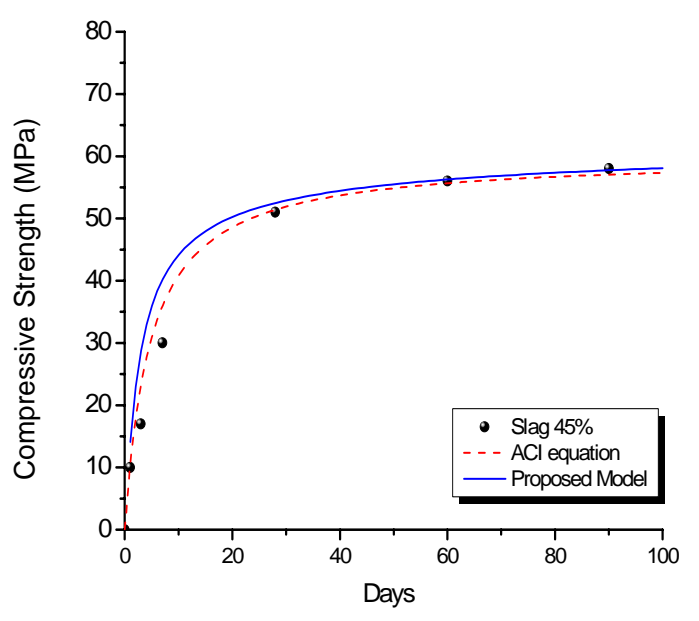

(a)

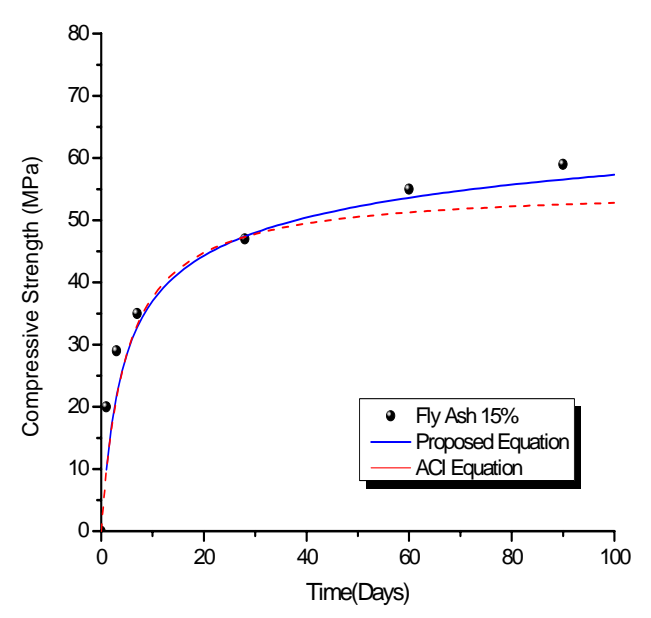

(b)

Fig. 6.12 - Comparison of ACI model and proposed model for compressive strength (a) slag $45 \%$ by mass (b) fly ash $15 \%$ by mass

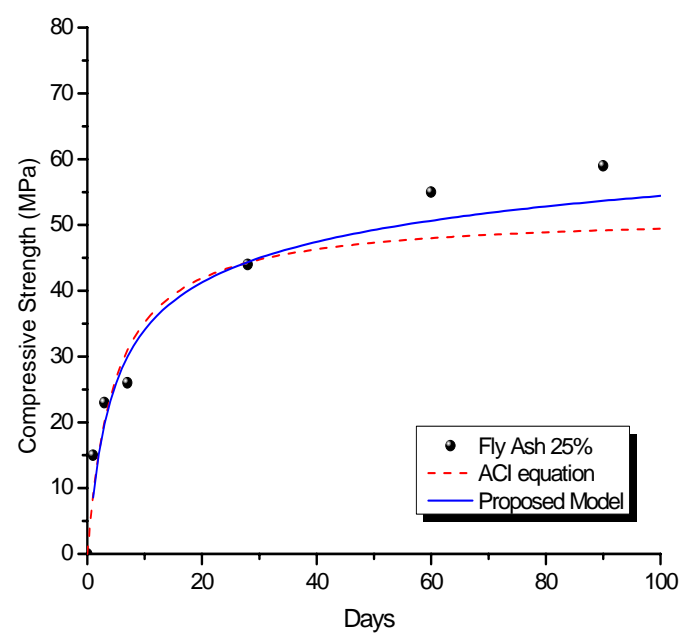

(a)

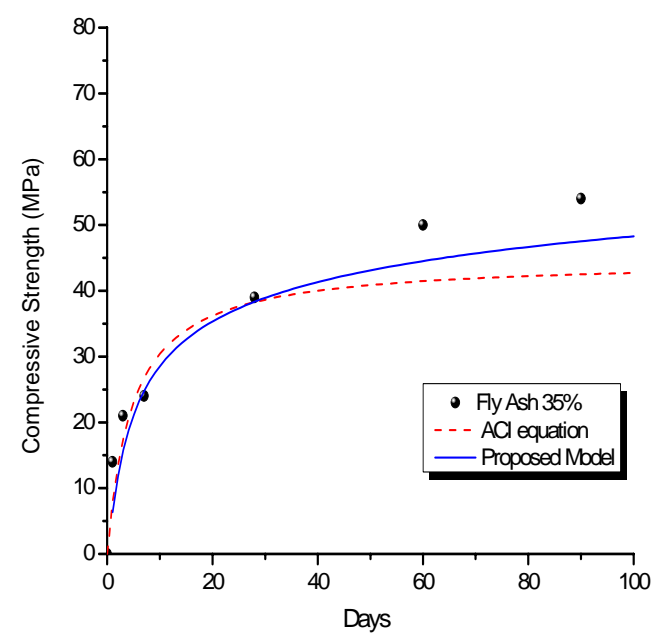

(b)

Fig. 6.13 - Comparison of ACI model and proposed model for compressive strength (a) fly ash $25 \%$ by mass (b) fly ash $35 \%$ by mass 


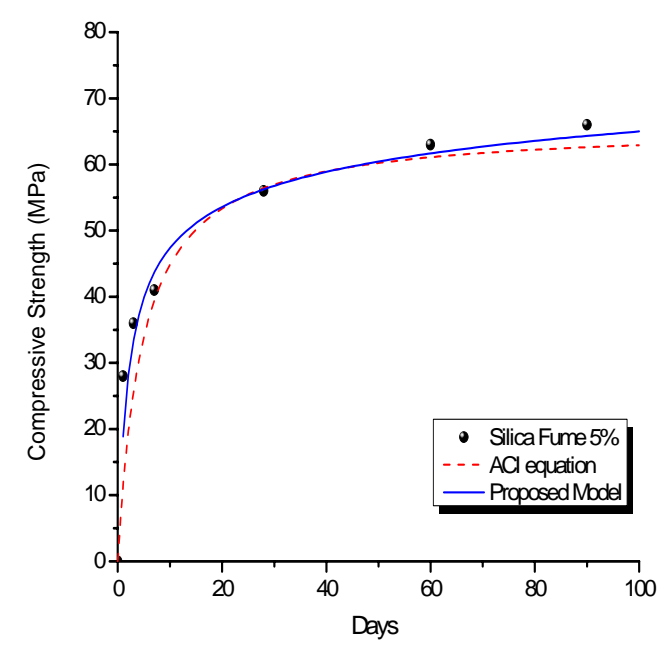

(a)

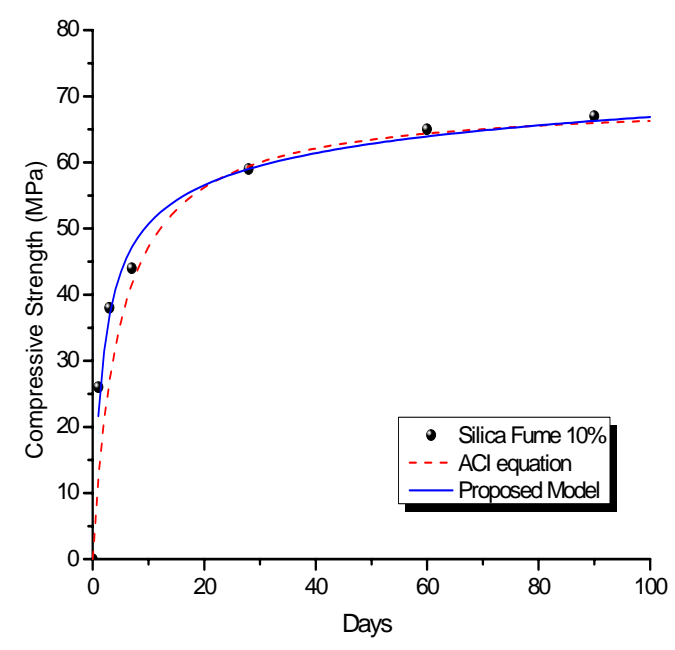

(b)

Fig. 6.14 - Comparison of ACI model and proposed model for compressive strength (a) silica fume $5 \%$ by mass (b) silica fume $10 \%$ by mass

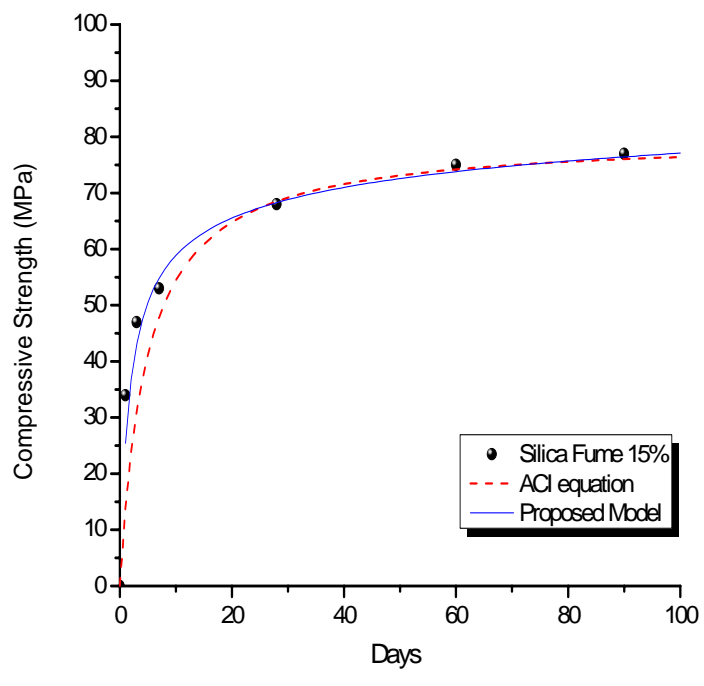

(a)

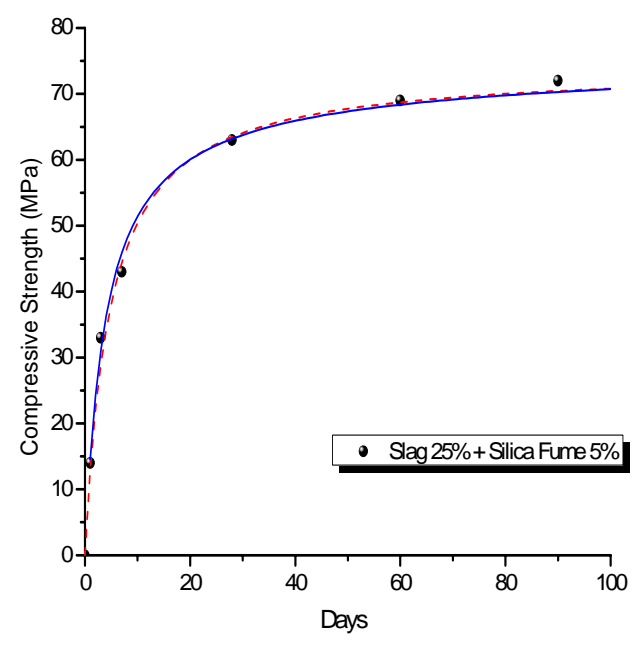

(b)

Fig. 6.15 - Comparison of ACI model and proposed model for compressive strength (a) silica fume $10 \%$ by mass (b) ) slag $25 \%+$ silica fume $5 \%$ by mass 


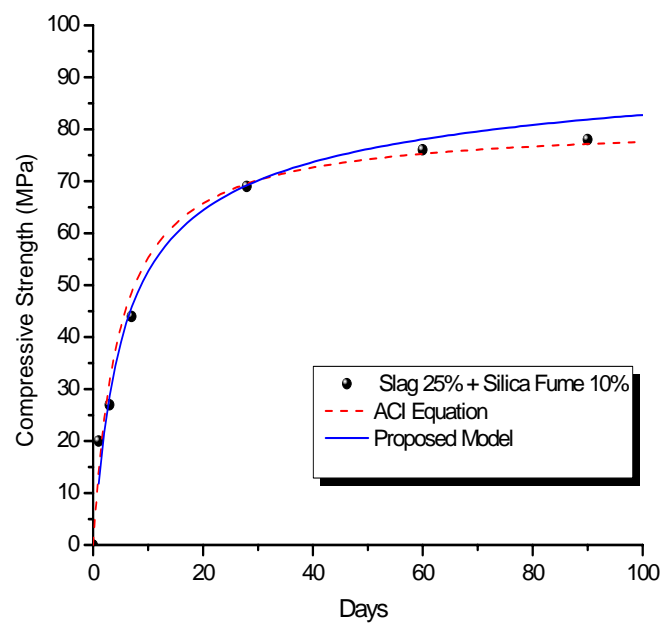

(a)

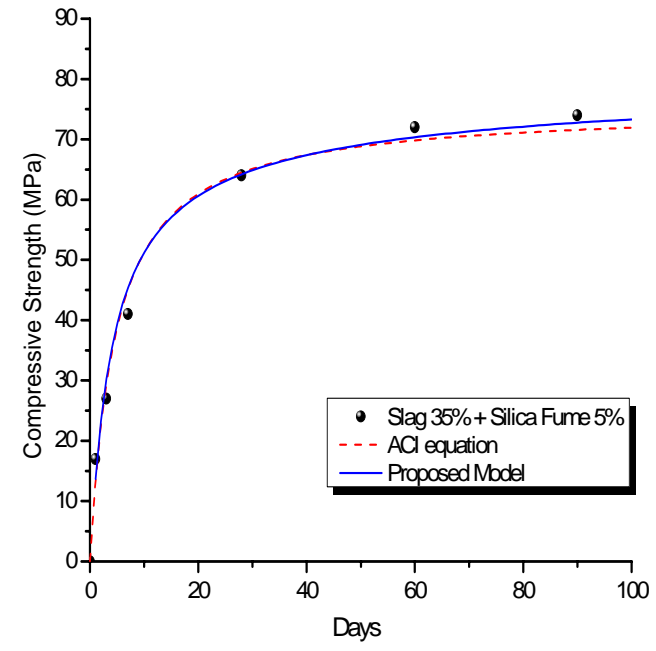

(b)

Fig. 6.16 - Comparison of ACI model and proposed model for compressive strength (a) slag $25 \%+$ silica fume $10 \%$ by mass (b) slag $35 \%+$ silica fume $5 \%$ by mass

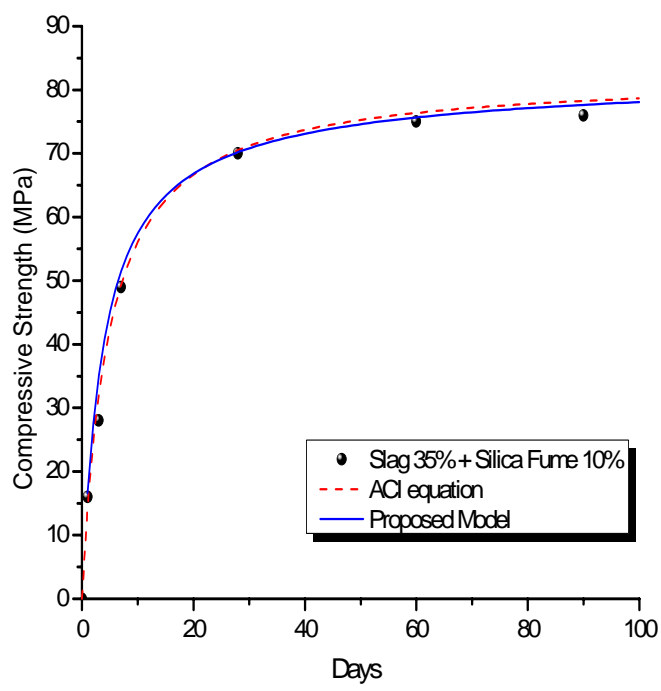

(a)

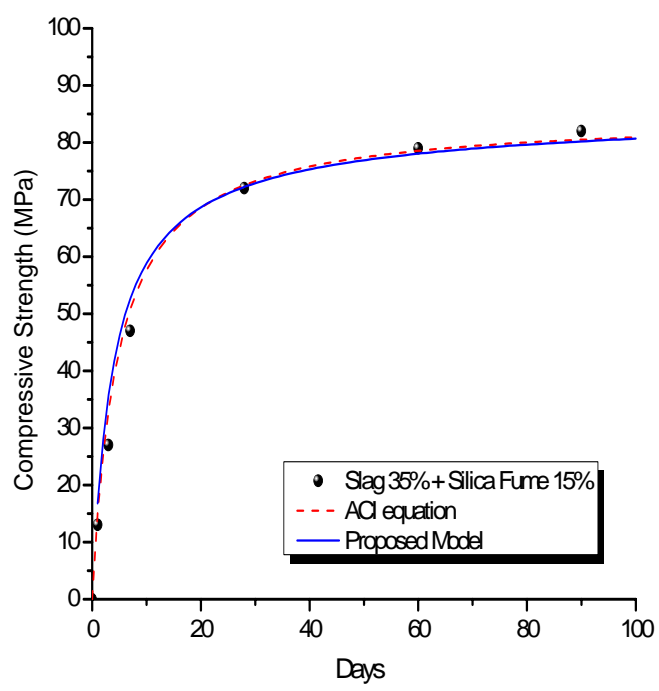

(b)

Fig. 6.17 - Comparison of ACI model and proposed model for compressive strength (a) slag $35 \%+$ silica fume $10 \%$ by mass (b) slag $35 \%+$ silica fume $15 \%$ by mass 


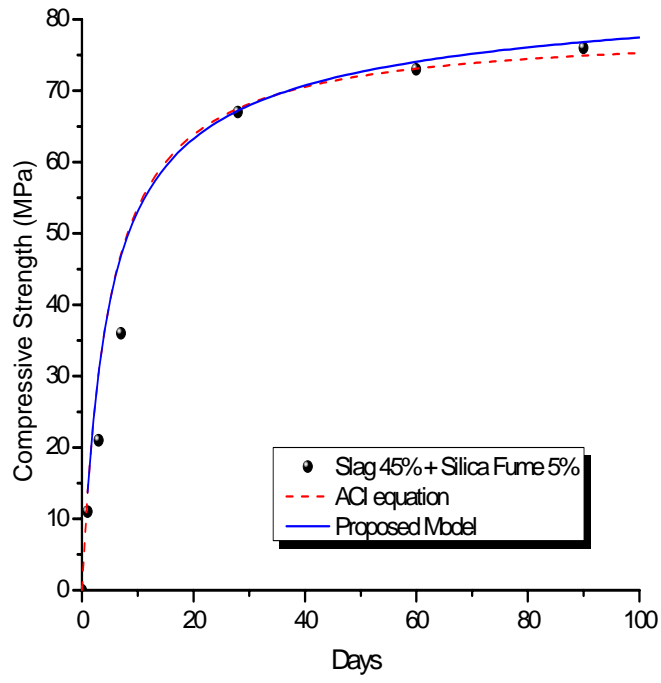

(a)

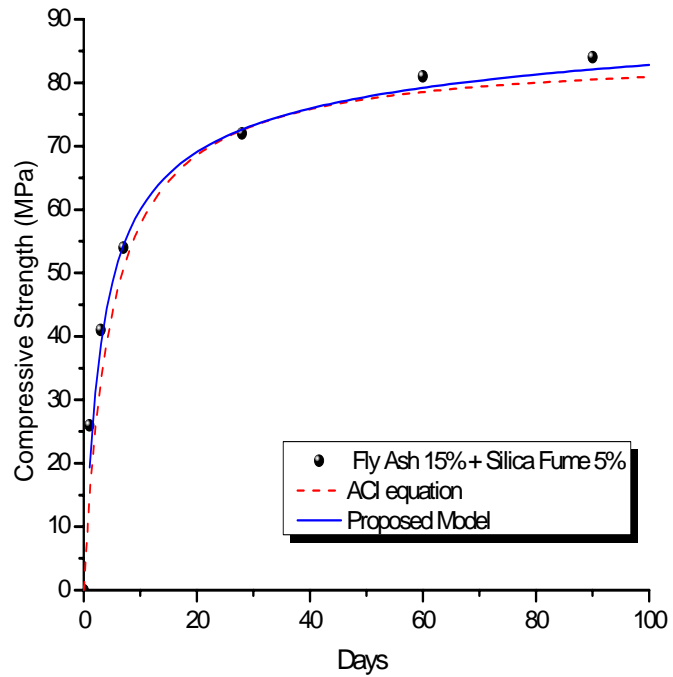

(b)

Fig. 6.18 - Comparison of ACI model and proposed model for compressive strength (a) slag $45 \%+$ silica fume $5 \%$ by mass (b) fly ash $15 \%+$ silica fume $5 \%$

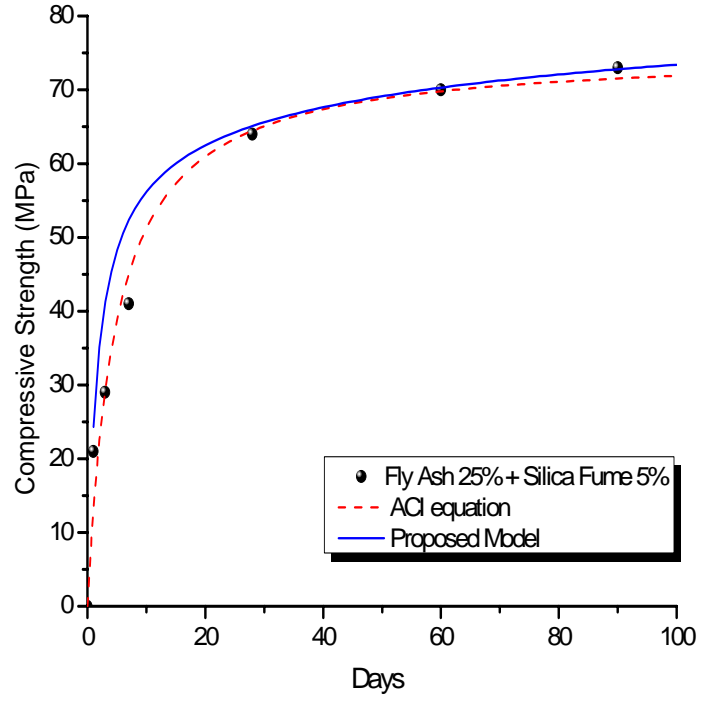

(a)

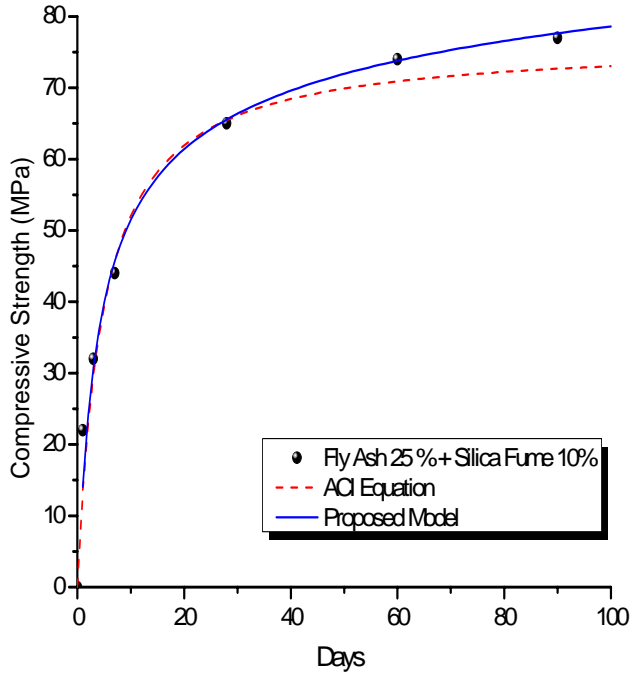

(b)

Fig. 6.19 - Comparison of ACI model and proposed model for compressive strength (a) fly ash $15 \%+$ silica fume 5\% (b) fly ash $15 \%+$ silica fume $5 \%$ 


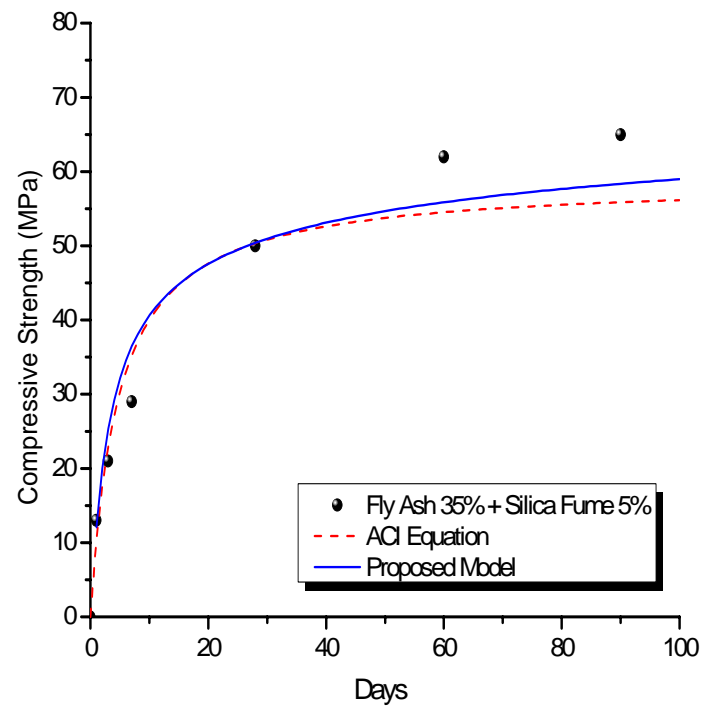

(a)

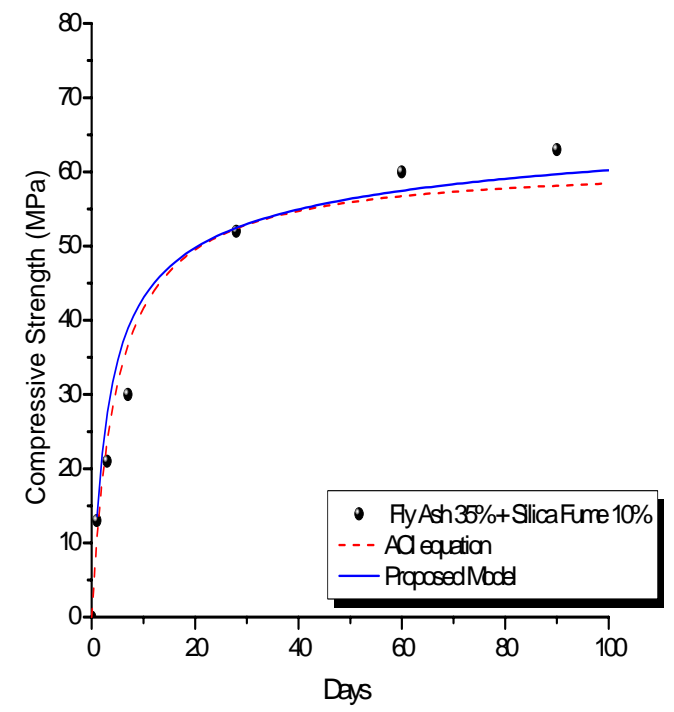

(b)

Fig. 6.20 - Comparison of ACI model and proposed model for compressive strength (a) fly ash $15 \%+$ silica fume $5 \%$ (b) fly ash $15 \%+$ silica fume $5 \%$

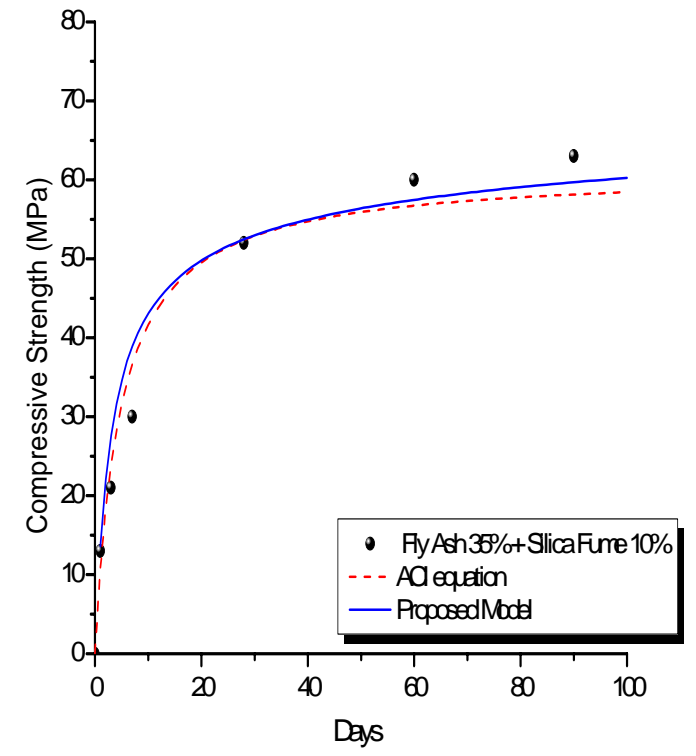

(a)

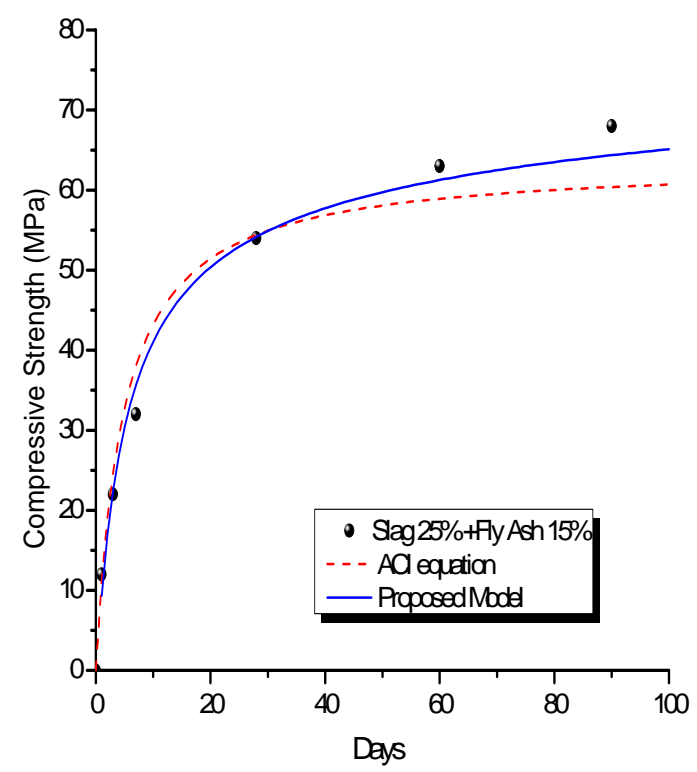

(b)

Fig. 6.21 - Comparison of ACI model and proposed model for compressive strength (a) fly ash $15 \%+$ silica fume $5 \%$ (b) slag $25 \%+$ fly ash $15 \%$ 


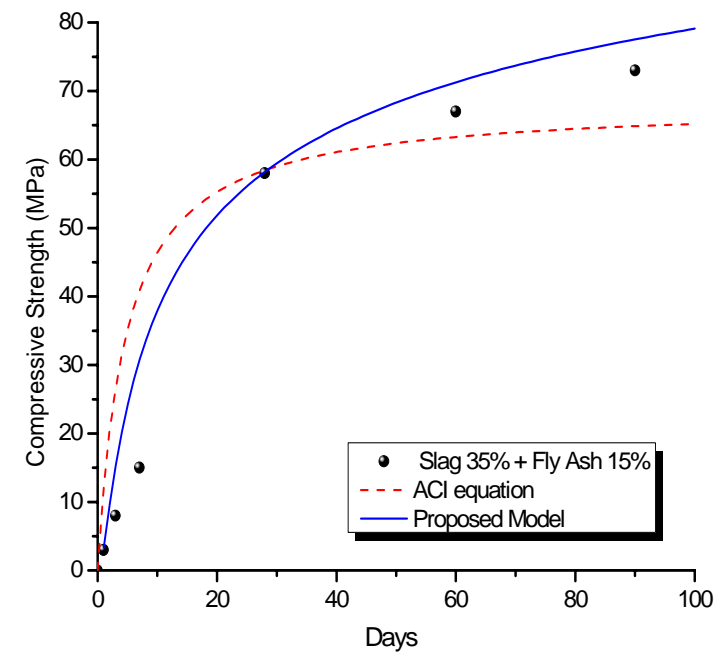

Fig. 6.22 - Comparison of ACI model and proposed model for compressive strength (a) slag $35 \%+$ fly ash $15 \%$

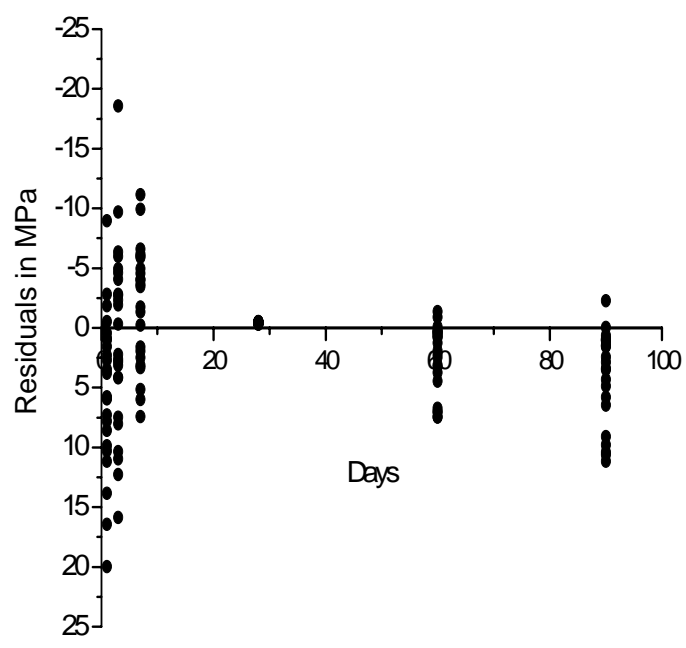

(a)

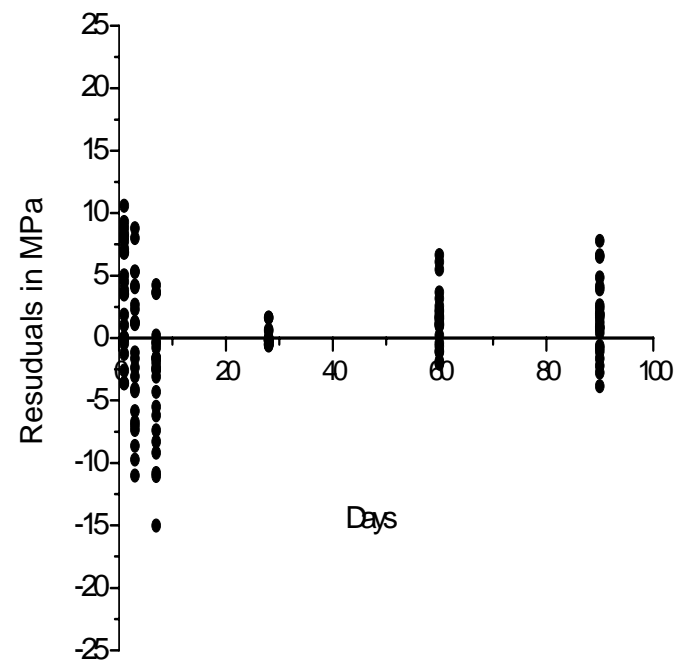

(b)

Fig. 6.23 - (a) Residual plot for ACI equation for compressive strength with data obtained from laboratory (b) residual plot for proposed model for compressive strength with data obtained from laboratory 
From Fig. 6.23 (a) and (b) it is evident that the residuals are evenly distributed along the horizontal axis. For the ACI equation residuals are in the range of +20 MPa to $-20 \mathrm{MPa}$, whereas for proposed model at early ages, the values are in the range of +10 MPa to -15 $\mathrm{MPa}$. At later age (60 and 90 days) the proposed model gives residuals concentrated in the range $+7 \mathrm{MPa}$ to $-3 \mathrm{MPa}$ with some scattered values near $-10 \mathrm{MPa}$. But the residual values for the ACI model is evenly distributed in the range of +2.5 $\mathrm{MPa}$ to $-12.5 \mathrm{MPa}$. Table 6.2 shows the coefficient of variation (COV) calculated for all the mixtures for the ACI model and the proposed model. For most of the mixtures, the proposed model gives a lower COV than the ACI model. The maximum COV for the ACI model is $41 \%$ compared to $20 \%$ for the proposed model. However for few ternary mixtures containing slag and silica fume, the ACI model was reasonably good.

Table 6.2 Comparison of the ACI model and the proposed model for compressive strength

\begin{tabular}{|c|c|c|c|}
\hline & Mix & $\begin{array}{c}\text { COV for ACI } \\
\text { model (\%) }\end{array}$ & $\begin{array}{c}\text { COV for Proposed } \\
\text { model }\end{array}$ \\
\hline $0 \%$ replacement & $\mathrm{CC}$ & 16.5 & 4.2 \\
\hline \multirow{3}{*}{ Slag replacement } & SL 25 & 11.9 & 7 \\
\hline & SL 35 & 6.0 & 3.1 \\
\hline & SL 45 & 10.6 & 18.0 \\
\hline \multirow{3}{*}{ Fly ash replacement } & Fl 15 & 16.5 & 16.5 \\
\hline & FL 25 & 17.6 & 16.1 \\
\hline & Fl 35 & 19.7 & 11.7 \\
\hline \multirow{3}{*}{ Silica Fume replacement } & SF5 & 18.4 & 9.5 \\
\hline & SF 10 & 16.0 & 5.1 \\
\hline & SF 15 & 19.8 & 7.6 \\
\hline \multirow{6}{*}{ Slag+ Silica Fume replacement } & SS $25+5$ & 4.4 & 5.8 \\
\hline & SS $25+10$ & 7.5 & 6.6 \\
\hline & SS $35+5$ & 6.2 & 6.1 \\
\hline & SS $35+10$ & 4.4 & 6.5 \\
\hline & SS $35+15$ & 6.2 & 9.3 \\
\hline & SS $45+5$ & 14.2 & 14 \\
\hline \multirow{6}{*}{$\begin{array}{c}\text { Fly Ash + Silica Fume } \\
\text { replacement }\end{array}$} & FS $15+5$ & 11.1 & 5.7 \\
\hline & FS $25+5$ & 8.0 & 8.2 \\
\hline & FS $25+10$ & 9.0 & 7.2 \\
\hline & FS $35+5$ & 15.3 & 13.9 \\
\hline & FS $35+10$ & 10.7 & 12.0 \\
\hline & FS $35+15$ & 13.2 & 13.5 \\
\hline \multirow{2}{*}{ Slag + Fly Ash replacement } & SL+FA $25+15$ & 15 & 7.2 \\
\hline & SL+FA $35+15$ & 41.4 & 19.6 \\
\hline
\end{tabular}




\subsection{Validation of the Proposed Model}

The proposed models have been tested with data obtained from two different sources.

The model have been tested with compressive strength development data for high strength concretes containing supplementary cementing materials as indicated by Neville (1996) and that obtained from current project of WVDOH at WVU.

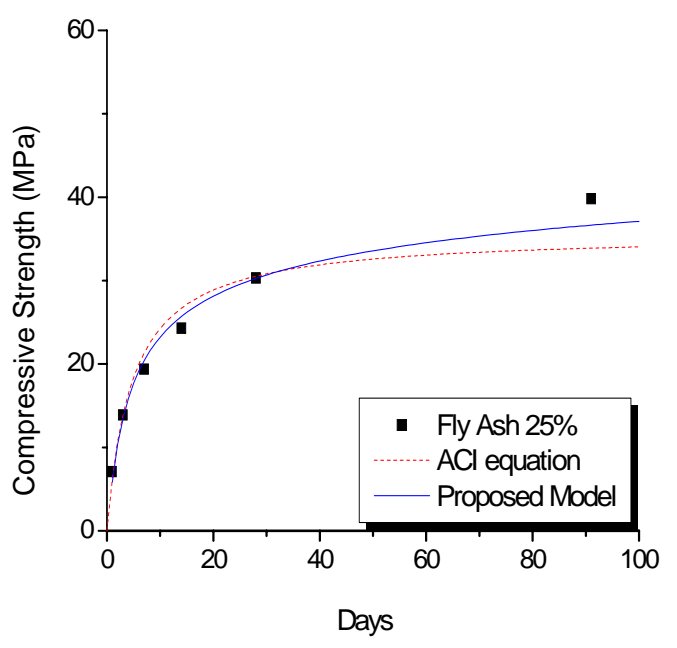

(a)

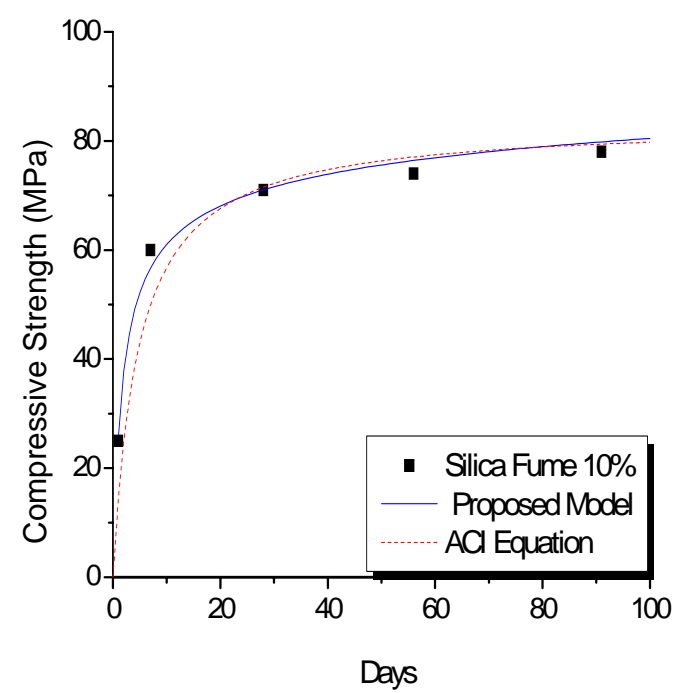

(b)

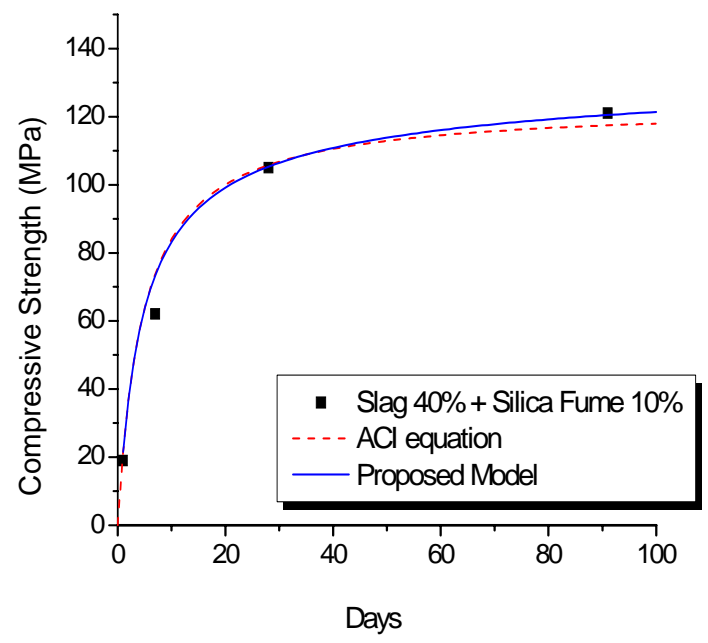

(c)

Fig. 6.24 - Comparison of the ACI and the proposed model with data obtained from Neville (1996) for fly ash $25 \%$ concrete (b) for silica fume $10 \%$ concrete (c) for slag $40 \%+$ silica fume $10 \%$ concrete 


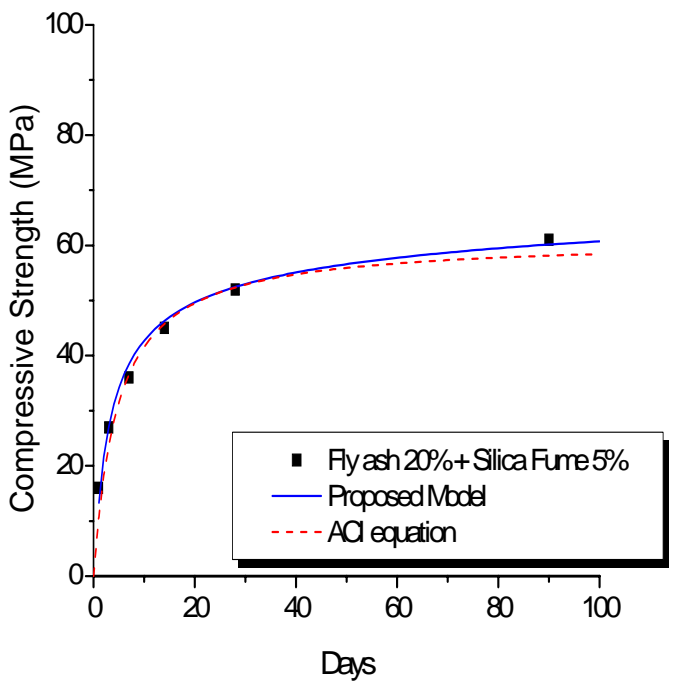

(a)

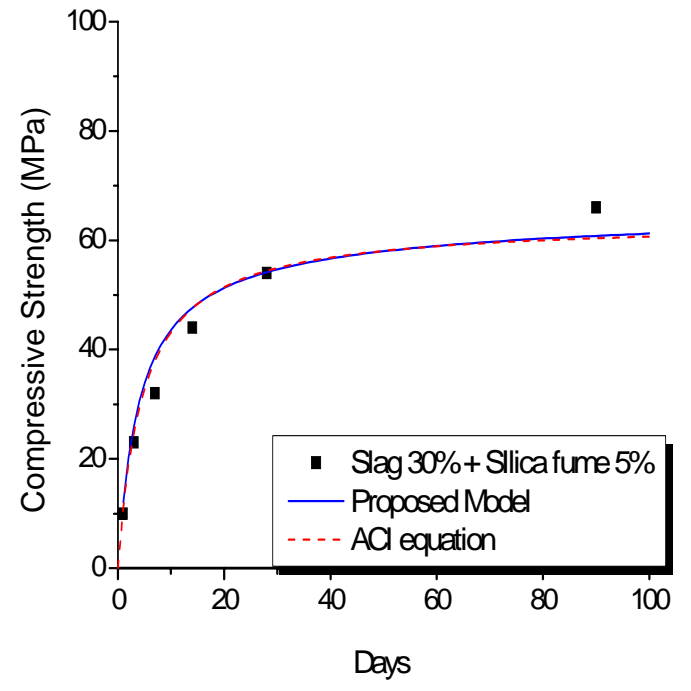

(b)

Fig. 6.25 - Comparison of the ACI and the proposed model with data obtained in a current project of WVDOH at WVU (a) for fly ash $25 \%$ + silica fume $10 \%$ concrete (b) for slag $30 \%+$ silica fume $10 \%$ concrete

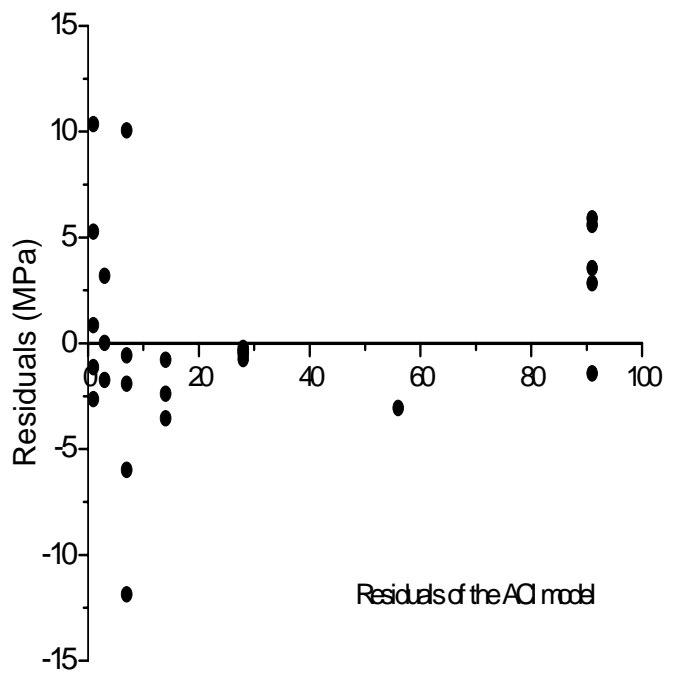

(a)

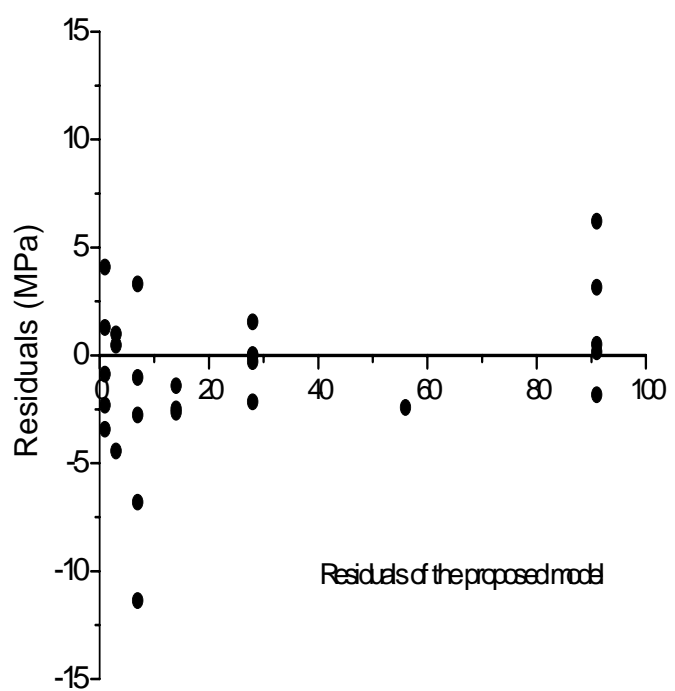

(b)

Fig. 6.26 - Residuals of the ACI model and the proposed models with respect to the data obtained from Neville (1996) and Gong et al. (2004) 
Table 6.3 Comparison of ACI and Proposed model on data obtained from other sources

\begin{tabular}{|c|c|c|c|}
\hline \multirow{2}{*}{ Source } & Mixture & \multicolumn{2}{|c|}{ COV } \\
\cline { 3 - 4 } & & ACI model & Proposed model \\
\hline \multirow{2}{*}{ Neville (1996) } & Fly Ash 25\% & $21.7 \%$ & $9.0 \%$ \\
\cline { 2 - 4 } & Silica Fume 10\% & $13.8 \%$ & $10.9 \%$ \\
\cline { 2 - 4 } & Slag 40\% + Silica Fume 10\% & $7.7 \%$ & $7.3 \%$ \\
\hline \multirow{2}{*}{ Gong et al. (2004) } & Fly Ash 20\% + Silica Fume 10\% & $7.8 \%$ & $6.9 \%$ \\
\cline { 2 - 4 } & Slag 30\% + Silica Fume 10\% & $10.8 \%$ & $13.1 \%$ \\
\hline
\end{tabular}

As can be seen from Fig. 6.26, the maximum residual strength is in the range of $+12 \mathrm{MPa}$ to $-14 \mathrm{MPa}$ for the ACI model, while it is in the range of $+7 \mathrm{MPa}$ to $-12 \mathrm{MPa}$ for the proposed model. Table 6.3 also indicates that except slag $30 \%$ and silica fume $10 \%$ combination the COV for the proposed model was lower than ACI. Hence it can be concluded that the proposed model gives a better estimate for concretes containing supplementary cementing material. 


\section{Chapter 7}

\section{Conclusions}

This chapter draws the conclusions on the test results and accuracy of the proposed models. Also the scopes for future works have been suggested. The following sections discuss the results on C-S-H gel estimation, shrinkage and compressive strength models; and suggests the scopes for future works.

\subsection{C-S-H gel Estimation}

From chapter 4 it is evident that the water adsorption test can give accurate information on C-S-H gel formation for different supplementary cementing materials. C$\mathrm{S}-\mathrm{H}$ gel formation provides good indication of the reactivity of supplementary cementing materials. Following conclusions can be made from the results of C-S-H gel vs. time relationship mentioned in chapter 4 .

1. Replacement of cement by slag and fly ash slowed down the C-S-H gel formation or the reactivity between 0 to 7 days.

2. At 60-90 days slag and fly ash produced more C-S-H gel compared to cement due to formation of additional C-S-H gel through pozzolanic reactions.

3. In case of slag and fly ash as replacement percentage increased, the reactivity between 0 to 7 days reduced proportionally whereas the amount of C-S-H gel formation between 28 and 90 days increased.

4. Inclusion of silica fume expedited the reactivity at early age. Little change in gel formation was observed between 60 and 90 days for silica fume containing pastes. It was also observed that as replacement level increased from 5 to $15 \%$, the C-S-H gel formation decreased with time. 
5. For the ternary mixtures, slag and silica fume produced considerably more C-S-H gel at all ages. Fly ash and silica fume on the other hand reacted like only cement between 0 to 7 days, and thereafter the reactivity increased considerably. When slag and fly ash were used as combination, they hindered the hydration reaction significantly between 0 to 3 days. The C-S-H gel formation at 1 day was only $20 \%$ of the corresponding values of cement pastes and $30 \%$ of pastes containing slag or fly ash.

\subsection{Shrinkage Model}

The inclusion of the gel time relationship in the shrinkage equation made the prediction more accurate. All the commonly used models do not have any provision to include the effects of supplementary cementing material on drying shrinkage. The proposed model is more versatile as it included the rate of C-S-H gel formation in the equation. Using the proposed equation a significant level of accuracy can be achieved while predicting the shrinkage with time. The ACI 209R, CEB, GL and Huo et al. model yielded COV values significantly greater than $15 \%$ (assumed as threshold for acceptance) as shown in table 5.1 and 5.2. However, the proposed models had COV values in the range of 4 to $15 \%$ during calibration and testing. Also from the residual plots (Figs. 5.6 and 5.7) the above mentioned models show residuals in the range of 300 microstrain compared to 100 microstrain observed by the proposed model. From the residual plots it can also be observed that the ACI equation is less accurate at early ages whereas the CEB model is less accurate at later stages. Residual plot for all the models had either a hump or they had become parallel to the horizontal axis indicating a need for modifications. The proposed model was distributed evenly along the axis in the residual plot. Also the proposed model showed very good results when compared to the shrinkage data obtained by Mokarem (2001) in Virginia Tech. and other sources of data indicating a validity of the model. 


\subsection{Compressive Strength Model}

Compressive strength showed a good correlation with the gel formation (Fig. 6.9). Similar to shrinkage model, the C-S-H gel formation was also included in the proposed model for compressive strength. As shown in the residual plots (Fig. 6.23), the residual strain magnitude of ACI model was in the range of $20 \mathrm{MPa}$ between 0 to 7 days and 10 $\mathrm{MPa}$ at 90 days, whereas the corresponding values for the proposed model was $10 \mathrm{MPa}$ (between 0 to 7 days) and $5 \mathrm{MPa}$ (90days), respectively. Also table 6.2 shows large $\mathrm{COV}$ values for ACI, while COV values of the proposed models were within the acceptable range.

\subsection{Suggestions for Future Work}

1. A comprehensive data base can be formed for constants A and B (table 5.3) using different types of supplementary cementing materials and for different $\mathrm{w} / \mathrm{cm}$. This will modify the proposed model to enable to use for a wider range of supplementary cementing materials combination and water-to-cementitious material ratios.

2. X-ray diffraction (XRD) and Differential scanning calorimetry (DSC) techniques can be used to estimate the reduction in calcium hydroxides during hydration in presence of supplementary cementing materials. The information may be used to indirectly check the estimated C-S-H gel formation with time by the current method.

2. The scanning electron microscopy (SEM), mercury intrusion porosimetry or any other suitable techniques can be used to estimate the porosity and pore size distributions. This information can be included in the proposed shrinkage and strength equations to incorporate the effects of porosity and pore size distribution.

4. Proposed models for shrinkage and compressive strength should be tested with more data collected from different sources. Also the models should be validated with longterm data and other $\mathrm{w} / \mathrm{cm}$. 


\section{Bibliography}

1. ACI Committee 209, 1997, "Prediction of Creep, Shrinkage, and Temperature Effects In Concrete Structures(ACI 209R-92)", American Concrete Institute, Farmington Hills, MI

2. ACI Committee 234, 1997, "Guide for the Use of Silica Fume in Concrete (ACI 234R-96)", American Concrete Institute, Farmington Hills, MI

3. ACI Committee 232, 1997, "Use of Fly Ash in Concrete (ACI 232.2R- 96)", American Concrete Institute, Farmington Hills, MI

4. ACI Committee 233, 1997,"Ground Granulated Blast-Furnace Slag as a Cementitious Constituent in Concrete (ACI 233R-95)", American Concrete Institute, Farmington Hills, MI

5. ACI Committee 363, 1997, " State-of-the Art Report on High Strength Concrete (ACI 363R-92)", American Concrete Institute, Farmington Hills, MI,

6. Aitcin, P.C., 1998, High-Performance Concrete, E \& FN Spon.,

7. Almudaiheem, Jamal A. and Hansen, Will, 1987," Effect of Specimen Size and Shape on Drying Shrinkage of Concrete", ACI Materials Journal, Vol.84, No. 3, pp. $130-135$

8. Almudaiheem, Jamal A. and Hansen, Will, 1987," Ultimate Drying Shrinkage of Concrete-Influence of Major Parametrs", ACI Materials Journal, V.84, No.3, pp. $217-223$

9. American Society for Testing and Materials, 2004, Annual Book of ASTM Standards, vol. 04.02, Concrete and Aggregates

10. ASTM C 39M-03, "Standard Test Method for Compressive Strength of Cylindrical Concrete Specimens", 2004 Annual Book of ASTM Standards, Vol. 04. 02, Concrete and Aggregates, American Society for Testing and Materials, pp. 21-27 11. ASTM C 138M-01a," Standard Test Method for Unit Weight, Yield and Air Content (Gravimetric) of Concrete", 2004 Annual Book of ASTM Standards, Vol. 04.02 , Concrete and Aggregates, American Society for Testing and Materials, pp. 89-92 
12. ASTM C 143M-03," Standard Test Method for Slump of Hydraulic Cement Concrete”, 2004 Annual Book of ASTM Standards, Vol. 04.02, Concrete and Aggregates, American Society for Testing and Materials, pp. 95-98

13. ASTM C 157M-04," Standard Test Method for Length change of Hardened Hydraulic-Cement Mortar and Concrete", 2004 Annual Book of ASTM Standards, Vol. 04.02, Concrete and Aggregates, American Society for Testing and Materials, pp. $104-110$

14. ASTM C 192M-02," Standard Test Method for Making and Curing Test specimens in the Laboratory", 2004 Annual Book of ASTM Standards, Vol. 04.02 , Concrete and Aggregates, American Society for Testing and Materials, pp.126-133

15. ASTM C 231-03," Standard Test Method for Air Content of Freshly Mixed Concrete by the Pressure Method ", 2004 Annual Book of ASTM Standards, Vol. 04.02, Concrete and Aggregates, American Society for Testing and Materials, pp. $146-153$

16. ASTM C 260-04,"Specification for Air-Entraining Admixtures for Concrete", 2004 Annual Book of ASTM Standards, vol. 04.02, Concrete and Aggregates, American Society for Testing and Materials, pp. 165-67

17. ASTM C 490-04," Standard Practice for Use of Apparatus for the Determination of Length Change of Hardened Cement, Paste, Mortar, and Concrete ", 2004 Annual Book of ASTM Standards, Vol. 04.02, Concrete and Aggregates, American Society for Testing and Materials, pp. 266-270

18. ASTM C 494M-04," Specification for Chemical Admixtures for Concrete", 2004 Annual Book of ASTM Standards, Vol. 04.02 , Concrete and Aggregates, American Society for Testing and Materials, pp. 271-279

19. ASTM C 618-03," Standard Test Method for Coal Fly Ash and Raw or Calcined Natural Pozzolan for use as a Mineral Admixture in Concrete", 2004 Annual Book of ASTM Standards, Vol.04.02, Concrete and Aggregates, American Society for Testing and Materials, pp. 319-325

20. ASTM C 494M-04," Standard specification for Ground Granulated Blast Furnace Slag for Use in Concrete and Mortar", 2004 Annual Book of ASTM Standards, Vol. 
04.02 , Concrete and Aggregates, American Society for Testing and Materials, pp. $528-532$

21. ASTM C 1240-04," Standard Test Method for Use of Silica Fume as Mineral Admixture in Hydraulic-Cement Concrete, Mortar and Grout", 2004 Annual Book of ASTM Standards, Vol. 04.02, Concrete and Aggregates, American Society for Testing and Materials, pp. 662-668

22. Basma, Adnan A. and Abel-Jawad, Yahia, 1995," Probability Model for the Drying Shrinkage of Concrete", ACI Materials Journal, Vol. 92, No. 3, pp. 246-251

23. Bazant, Z.P., 1995," Creep and shrinkage prediction model for analysis and design of concrete structures-model B3", Materials and Structures, Vol. 28, pp. 357365

24. Bazant, Z.P.; Wittman, F.H., Kim J.K. and Alou F., 1987, "Statistical Extrapolation of Shrinkage Data- Part I: Regression”, ACI Materials Journal, Vol. 84 , pp. $20-34$

25. Bazant, Z.P.; Wittman, F.H., Kim J.K. and Alou F., 1987,"Statistical Extrapolation of Shrinkage Data- Part II: Bayesian Updating”, ACI Materials Journal, Vol. 84, pp. 83-91

26. Bentz, Dale P.; Quenard, Daniel A.; Baroghel-Bouny, Veronique, Garboczi, Edward J.; Jennings, H.M., 1995,"Modeling drying shrinkage of cement paste and mortar Part 1. Structural models from nanometers to millimeters", Materials and Structures, Vol. 28, pp. 450-458

27. Bissonnette, B.; Marchand J.; Charron J. P.; Delagrave, A. and Barcelo, L, 2001," Early Age Bahavior of Cement-Based Materials", Material Science of Concrete VI, Edited by Mindess, S. and Skalny, J., The American Ceramic Society

28. Brooks, J.J., 1989, “ Influence of mix proportions, plasticizers and superplasticizers on creep and drying shrinkage of concrete", Magazine of Concrete Research, Vol. 41, No. 148, pp. 145-154

29. Brooks, J.J. and Neville, A.M., 1992, "Creep and shrinkage of concrete as affected by admixtures and cement replacement materials", Creep and Shrinkage of Concrete: Effect of Materials and Environment, ACI SP-135, pp.19-36

30. CEB-FIP Model Code, 1990 
31. Copeland, L.E. and Hayes, J.C., 1953," Determination of Non-Evaporable Water in Hardened Portland-Cement Paste", ASTM Bulletin, December 1953, pp.70-74

32. Diamond, Sidney, 2004, "The microstructure of cement paste and concrete- a visual primer", Cement and Concrete Composites, Vol. 26, pp. 919-933

33. Daimon, M.; Abo-el-enein, S.A.; Hosaka, G.; Goto, S. and Kondo, R., 1977, "Pore Structure of Calcium Silicate Hydrate in Hydrated Tricalcium Silicate", Journal of the American Ceramic Society, Vol. 60, No.3-4, pp. 110-114

34. Derjaguin, B.V. and Chuarev N.V., 1974, "Structural Component of Disjoining Pressure", Journal of Colloid and Interface Science, Vol. 49, No.2, pp.249-255

35. Dunstan, E., 1984, "Fly Ash and Fly Ash Concrete", Bureau of Reclamation, Report REC-ERC-82-1, pp. 42

36. Feldman, R.F. and Sereda, 1968," A model for Hydrated Portland Cement Paste as Deduced from Sorption-Length Change and Mechanical Properties", Materials and Structures, Vol.1, No.6, pp. 509-519

37. Ferraris, C.F. and Wittman, F.H., 1987, "Shrinkage mechanisms of hardened cement paste", Cement and Concrete Research, Vol. 17, pp.453-464

38. Gardner, N.J. and Lockman M.J., 2001, "Design Provision for Dying Shrinkage and Creep of Normal-Strength Concrete", ACI Materials Journal, Vol. 98, No. 3, pp. 236-246

39. Gardner, N.J. and Zhao, J.W., 1994, "Creep and Shrinkage Revisited", ACI Materials Journal, Vol. 90, No. 1, pp. 3-10

40. Gong et al., 2004, WVDOH Report, WVU

41. Hogan, F.J. and Meusel, J.W., 1981, "Evaluation for Durability and Strength Development of Ground Granulated Blast-Furnace Slag", Cement, Concrete and Aggergates, Vol. 3, No. 1, pp. 40-52

42. Huo, X.S.; Al-Omaishi, Nabil and Tadros M.K., 2001, "Creep, Shrinkage and Modulus of High Performance Concrete", ACI Materials Journal, Vol. 98, No. 6, pp. 440-449

43. Hua, C.; Acker, P. and Ehrlacher, A., 1995, "Analysis and model of autogenous shrinkage of hardening cement paste - Part I: Modeling at macroscopic scale", Cement and Concrete Research, Vol. 25, Nos. 10, pp. 1457-1468 
44. Jennings, H.M., " A model for microstructure of calcium silicate hydrate in cement paste", Cement and Concrete Research, Vol. 30, 2000, pp. 101-116

45. Jennings, H.M. and Johnson, S.K, 1986," Simulation of Microstructure Development during the Hydration of a Cement Compound", Journal of American Ceramic Society, Vol. 69, No.11, pp. 790-795

46. Jianyong, Li and Yan, Yao, 2001, “ A Study on creep and drying shrinkage of high performance concrete", Cement and Concrete Research, Vol. 31, pp. 1203-1206 47. Juenger, Maria C.G and Jennings, H.M, 2002," Examining the relationship between the microstructure of calcium silicate hydrate and drying shrinkage of cement paste", Cement and Concrete Research, Vol.32, pp. 289-296

48. Khatri, R.P. and Sirivivatnanon, V. and Gross, W. 1995, "Effect of Different Supplementary Cementitous materials on mechanical properties of high performance concrete”, Cement and Concrete Research, Vol. 25, No. 1, pp. 209-220

49. Li, H., Wee T.H. and Wong S.F., 2002, "Early-Age Creep and Shrinkage of Blended Cement Concrete”, ACI Materials Journal, Vol. 99, No. 1, pp. 3-10

50. Lea, F.M, 1971, The Chemistry of Cement and Concrete, First Edition, Chemical Publishing Company, NY

51. Luo, Shiwei, 2002, Evaluations of Concrete Overlays for Bridge Deck Applications, Master's Thesis, West Virginia University

52. Mehta, P. K., 1986, Concrete Structure, Properties and Materials, Prentice Hall, New Jersey

53. Mindess, S. and Young, J. F., 1981, Concrete, Prentice Hall, Inc., New Jersey

54. McDonald, David B. and Roper Harold, 1993, “Accuracy of Prediction Models for Shrinkage of Concrete”, ACI Materials Journal, Vol. 90, No. 3, pp. 265-272

55. Mokarem, David, 2002, Development of Concrete Shrinkage Performance Specifications, $\mathrm{PhD}$ Dissertation, Virginia Tech

56. Morris, Jennifer, 2002, A Comparative Study of Shrinkage and Cracking of High Performance Concrete mixtures for Bridge Decks, Master's Thesis, West Virginia University

57. Neville, A.M, 1996, Properties of Concrete, Addison Wesley Longman Limited, Harlow, England, $4^{\text {th }}$ Edition 
58. Ojdrovic, Rasko P. and Zarghamee, Mehdi S., 1996 "Concrete Creep and Shirkage Prediction from Short-Term Tests”, ACI Materials Journal, Vol. 93, No. 2, pp. 169-177

59. Olson, R.A. and Jennings, H.M., 2001,“ Estimation of C-S-H content in a blended cement paste using water adsorption”, Cement and Concrete Research, Vol. 31, pp. $351-356$

60. Parrot, Leslie, 1987,'Measurement and Modeling of Porosity in Drying Cement Paste", Materials Research Society Symposium Proceedings, Vol. 85, pp.91-104

61. Popovics, S., "Concrete Materials, Properties, Specification and Testing”, $2^{\text {nd }}$ Edition, Noyes Publication, New Jersey, USA

62. Powers, T.C., 1949 ,“ The Nonevaporable Water Content of Hardened PortlandCement Paste-Its Significance for concrete Research and Its method of Determination”, ASTM Bulletin, May 1949, pp. 68-76

63. Powers, T.C., 1986, The properties of Fresh Concrete, John Wiley and Sons, Inc., 64. Pratt, P. L., 1987,'”Relationship between microstructure and engineering properties”, Materials Research Society Symposium Proceedings, Vol. 85, pp.145155

65. Pickett, G., 1956, "Effect of aggregate on shrinkage of concrete and hypothesis concerning shrinkage", Journal of American Concrete Institute, Vol. 52, pp. 581-590

66. Ramachandran, V.S. and Beaudoin, J.J., 2001, Handbook of Analytical Techniques in Concrete Science and Technology, William Andrews Publishing

67. Rilem TC 107-CSP, 1998, "Measurement of time-dependent strains of concrete", Materials and Structures, Vol. 31, October 1998, pp. 507-512

68. Richardson, I.G., 1999, "The nature of C-S-H in hardened cements", Cement and Concrete Research, Vol. 29, pp.1131-1147

69. Russsell. H.G., 1999,"ACI Defines High-Performance Concrete", Concrete International, Vol. 21, No.2, pp-56-57

70. Scherer, G. W., "Structure and properties of gels", Cement and Concrete Research, Vol. 29, pp 1149-1157 
71. Smadi, Mohammad M.; Slate Floyd O. and. Nilson, Arthur H, 1987,"Shrinkage and Creep of High-, Medium-, and Low-Strength Concretes, Including Overloads", ACI Materials Journal, Vol. 96, pp. 224-234

72. Symons, M.G. and Fleming K.H., 1980, "Effect of Post Augusta Fly Ash on Concrete Shrinkage", Civil Engineering Transactions, Vol. 22, No. 3, pp. 181-185

73. Taylor, H.F.W, 1986," Proposed Structure for Calcium Silicate Hydrate Gel", Journal of the American Ceramic Society, Vol. 69, Issue 6, pp.464-467

74. Taylor, H.F.W., 1997, Cement Chemistry, $2^{\text {nd }}$ Edition, Thomas Telford 75. Tennis, Paul D. and Jennings, H.M., 2000, "Model for two types of calcium silicate hydrate in the microstructure of Portland cement pastes", Cement and Concrete Research, Vol. 30, pp. 855-863

76. Videla, Carlos; Covarrubias, Juan Pablo and Masana, Cristian, , 2004, "Updating Concrete Drying-Shrinkage Prediction Models for Local Materials", ACI Materials Journal, Vol. 101, No. 3, pp. 187-198

77. Wittman, F.H, 1973," Interaction of Hardened Cement Paste and Water", Journal of the American Ceramic Society, Vol. 56, Issue 8, pp.409-415

78. Xi, Yunping and Jennings,H.M., 2001,"Relationship Between Microstructure and Creep and Shrinkage of Cement Paste", Materials Science of Concrete Part III, Edited by Skalny, J. , The American Ceramic Society

79. Zhang, Wenbo, 2001, Exploratory Study on High Performance Concrete for Bridge Decks in West Virginia, Master's Thesis, West Virginia University 
Appendix A: Shrinkage data for different mixtures (microstrain)

Table 1

\begin{tabular}{|c|c|c|c|c|c|c|c|c|c|c|c|c|c|}
\hline Day & SL 25 & SL 35 & SL 45 & NC & FI 15 & $\mathrm{Fl} 25$ & $\mathrm{Fl} 35$ & SF 5 & SF 10 & SF 15 & SS $25+5$ & SS $25+10$ & ss $35+5$ \\
\hline 3 & 229 & 208 & 224 & 208 & 192 & 177 & 163 & 196 & 218 & 240 & 220 & 232 & 212 \\
\hline 6 & 307 & 244 & 384 & 256 & 309 & 293 & 276 & 268 & 297 & 326 & 312 & 296 & 324 \\
\hline 9 & 373 & 312 & 424 & 364 & 438 & 399 & 359 & 352 & 372 & 391 & 392 & 384 & 400 \\
\hline 21 & 536 & 496 & 528 & 504 & 568 & 559 & 549 & 552 & 536 & 520 & 508 & 552 & 536 \\
\hline 25 & 579 & 568 & 560 & 548 & 572 & 563 & 553 & 572 & 546 & 520 & 540 & 544 & 544 \\
\hline 29 & 584 & 536 & 568 & 564 & 592 & 581 & 571 & 536 & 528 & 520 & 580 & 592 & 568 \\
\hline 51 & 648 & 632 & 604 & 640 & 656 & 653 & 651 & 640 & 636 & 632 & 632 & 632 & 620 \\
\hline 57 & 656 & 628 & 624 & 680 & 672 & 667 & 661 & 632 & 636 & 640 & 640 & 656 & 626 \\
\hline 63 & 656 & 636 & 632 & 686 & 680 & 676 & 672 & 656 & 648 & 640 & 652 & 664 & 630 \\
\hline 69 & 672 & 640 & 640 & 692 & 692 & 679 & 667 & 666 & 661 & 656 & 652 & 664 & 634 \\
\hline 75 & 676 & 646 & 644 & 696 & 702 & 691 & 680 & 676 & 668 & 660 & 656 & 668 & 638 \\
\hline 81 & 680 & 652 & 648 & 696 & 712 & 699 & 685 & 676 & 670 & 664 & 662 & 672 & 642 \\
\hline 87 & 682 & 652 & 648 & 698 & 712 & 700 & 688 & 672 & 669 & 666 & 662 & 674 & 642 \\
\hline 93 & 684 & 654 & 649 & 698 & 713 & 705 & 688 & 676 & 671 & 668 & 665 & 674 & 645 \\
\hline
\end{tabular}

Table 2

\begin{tabular}{|c|c|c|c|c|c|c|c|c|c|c|c|}
\hline Day & SS $35+10$ & SS $35+15$ & SS $45+5$ & FS $15+5$ & FS 25+5 & Fs $25+10$ & FS $35+5$ & FS $35+10$ & FS $35+15$ & SF $25+15$ & SF35+15 \\
\hline 0 & 0 & 0 & 0 & 0 & 0 & 0 & 0 & 0 & 0 & 0 & 0 \\
\hline 3 & 197 & 192 & 212 & 112 & 146 & 166 & 92 & 127 & 144 & 132 & 152 \\
\hline 6 & 293 & 284 & 296 & 203 & 266 & 266 & 208 & 263 & 237 & 292 & 280 \\
\hline 9 & 309 & 336 & 352 & 291 & 333 & 334 & 304 & 354 & 304 & 328 & 356 \\
\hline 13 & 357 & 380 & 388 & 349 & 397 & 402 & 372 & 415 & 373 & 364 & 402 \\
\hline 17 & 403 & 420 & 428 & 397 & 458 & 454 & 468 & 469 & 419 & 392 & 436 \\
\hline 21 & 437 & 464 & 476 & 451 & 487 & 490 & 480 & 506 & 448 & 432 & 484 \\
\hline 25 & 445 & 480 & 496 & 504 & 530 & 506 & 540 & 514 & 472 & 448 & 488 \\
\hline 29 & 491 & 504 & 532 & 525 & 551 & 538 & 528 & 509 & 469 & 448 & 498 \\
\hline 33 & 517 & 520 & 492 & 528 & 535 & 530 & 572 & 546 & 520 & 504 & 508 \\
\hline 39 & 520 & 530 & 528 & 576 & 559 & 554 & 568 & 549 & 501 & 492 & 514 \\
\hline 45 & 523 & 540 & 532 & 584 & 570 & 574 & 568 & 557 & 525 & 512 & 520 \\
\hline 51 & 530 & 544 & 540 & 592 & 579 & 584 & 564 & 575 & 541 & 516 & 520 \\
\hline 57 & 541 & 548 & 540 & 592 & 589 & 594 & 576 & 575 & 548 & 520 & 528 \\
\hline 63 & 546 & 556 & 556 & 616 & 586 & 590 & 580 & 578 & 555 & 524 & 528 \\
\hline 69 & 551 & 560 & 556 & 608 & 594 & 590 & 582 & 578 & 556 & 530 & 532 \\
\hline 75 & 559 & 568 & 556 & 612 & 602 & 590 & 584 & 578 & 562 & 536 & 536 \\
\hline 81 & 567 & 566 & 560 & 616 & 606 & 598 & 596 & 581 & 566 & 540 & 538 \\
\hline 87 & 568 & 568 & 562 & 618 & 610 & 600 & 607 & 583 & 570 & 548 & 540 \\
\hline 93 & 570 & 570 & 566 & 620 & 614 & 603 & 608 & 586 & 573 & 552 & 544 \\
\hline
\end{tabular}




\section{Appendix B: C-S-H gel formation (semi-log plot)}
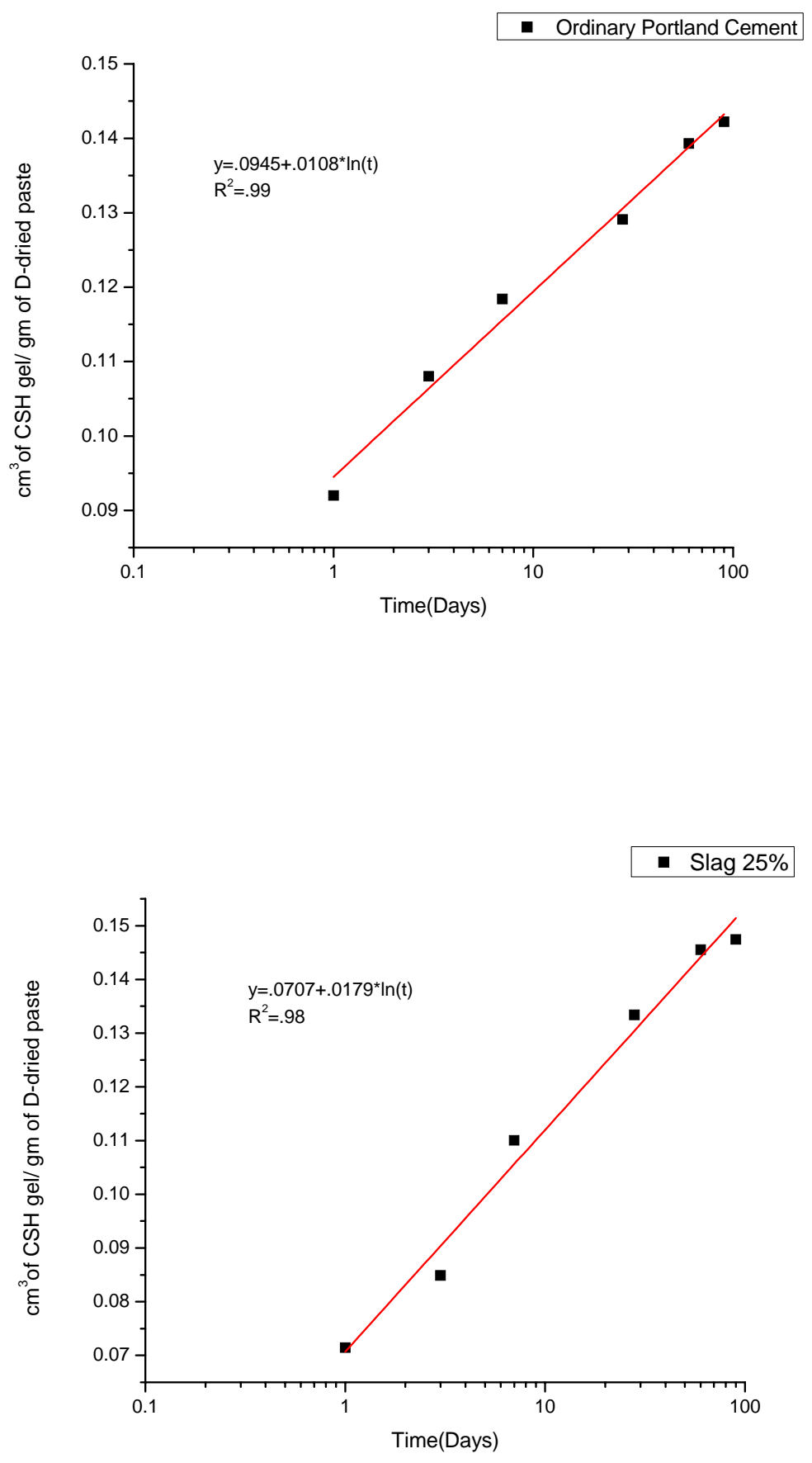

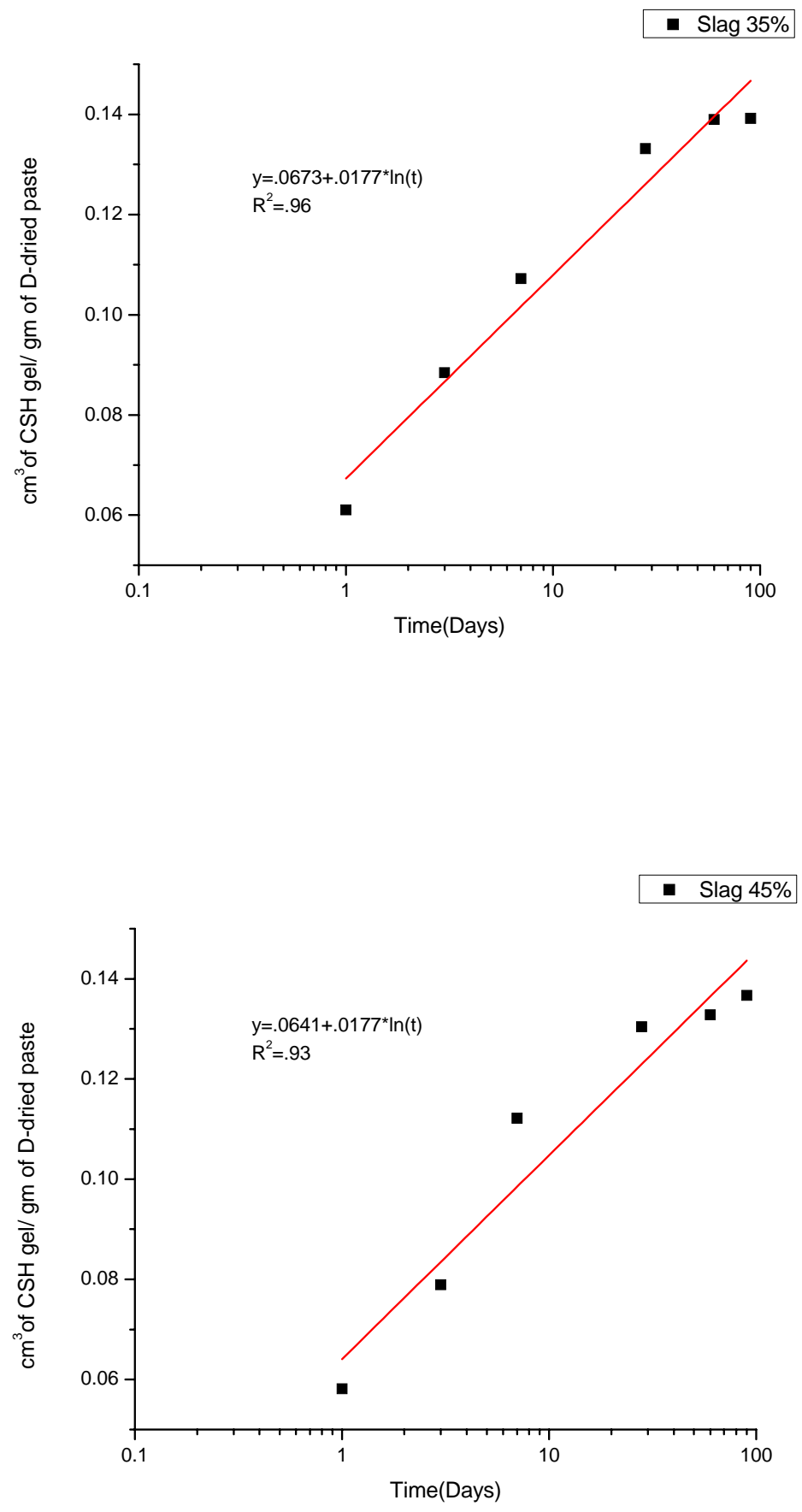

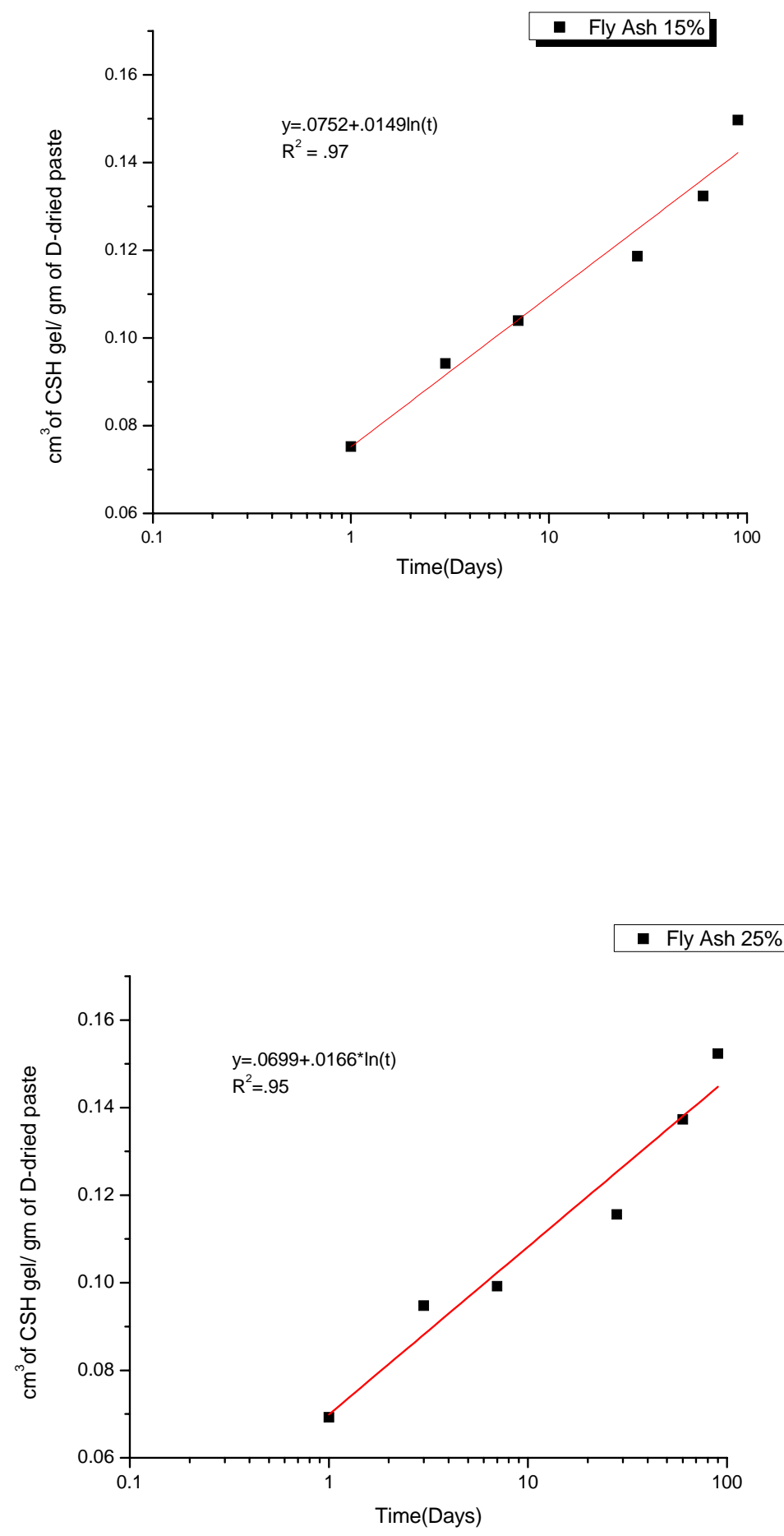
- Fly Ash $35 \%$
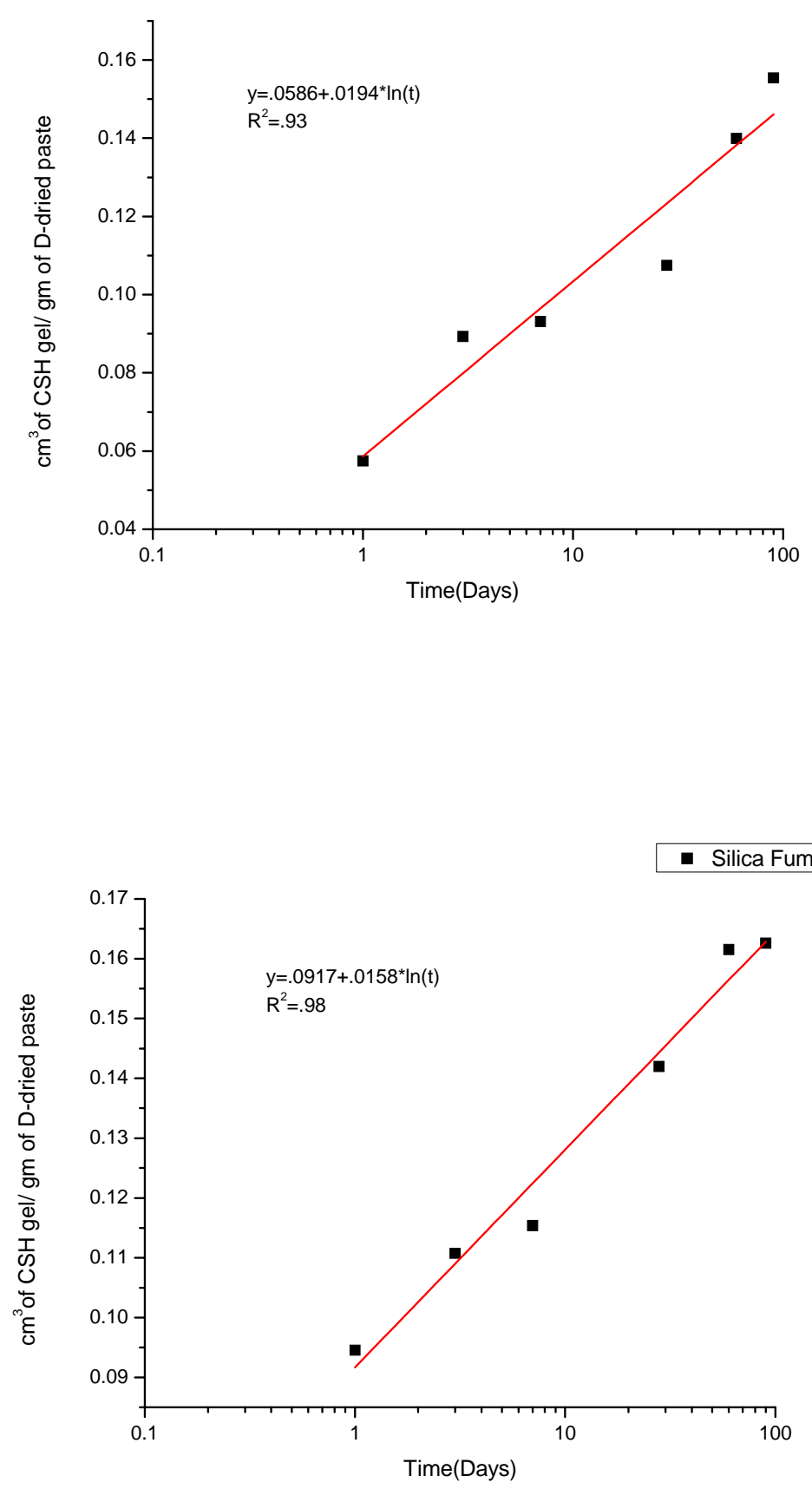

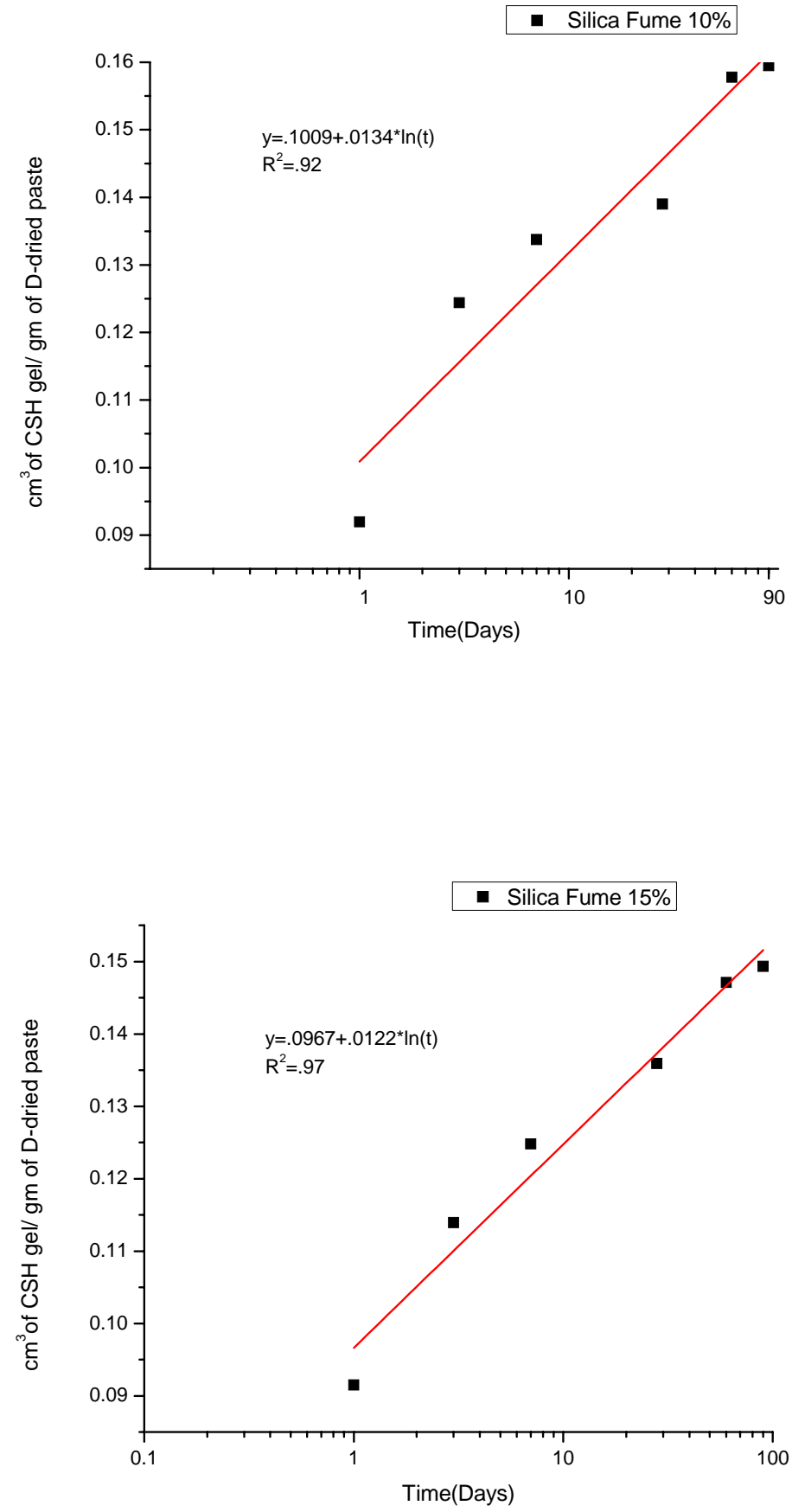
- Slag $25 \%+$ Silica Fume $5 \%$
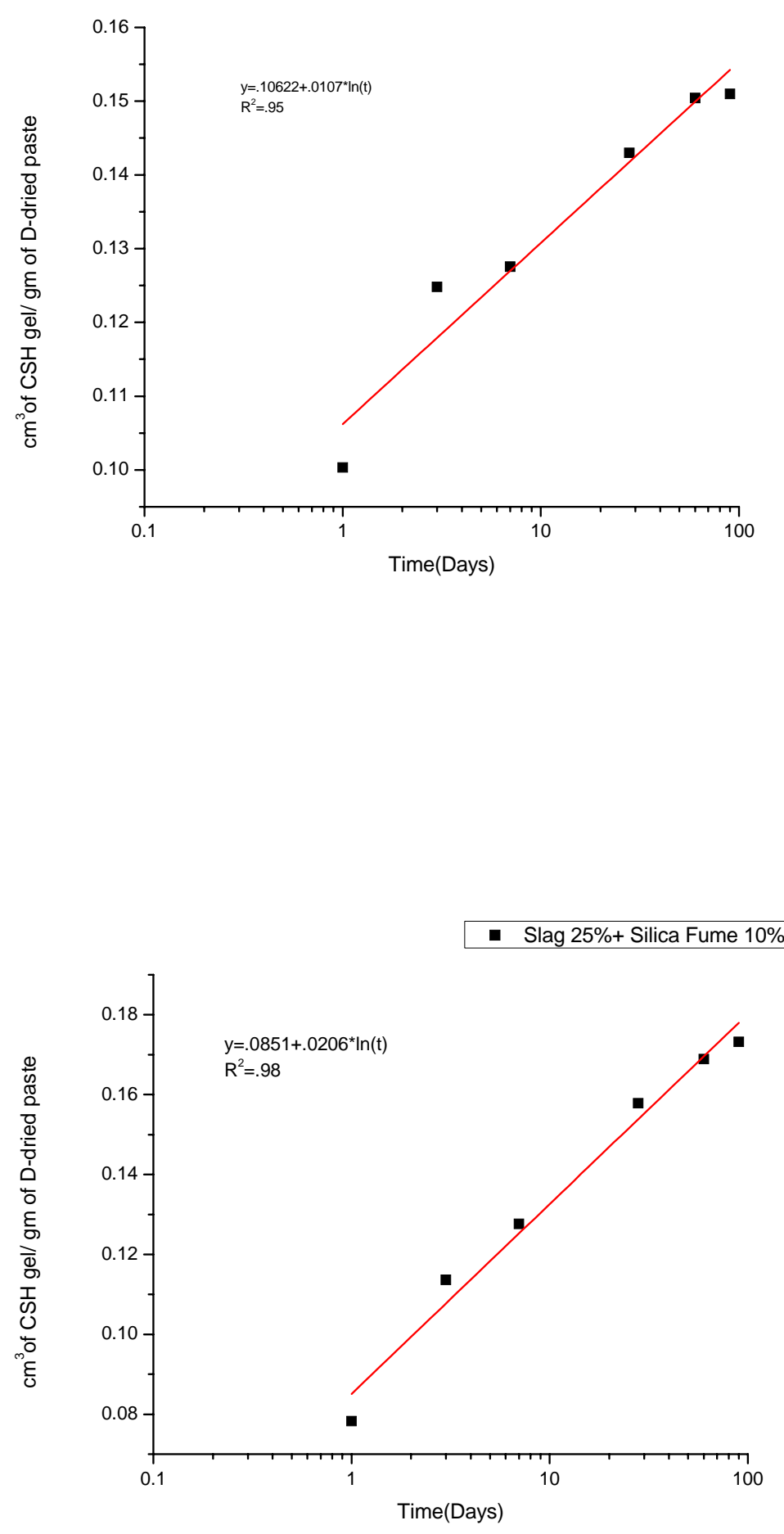

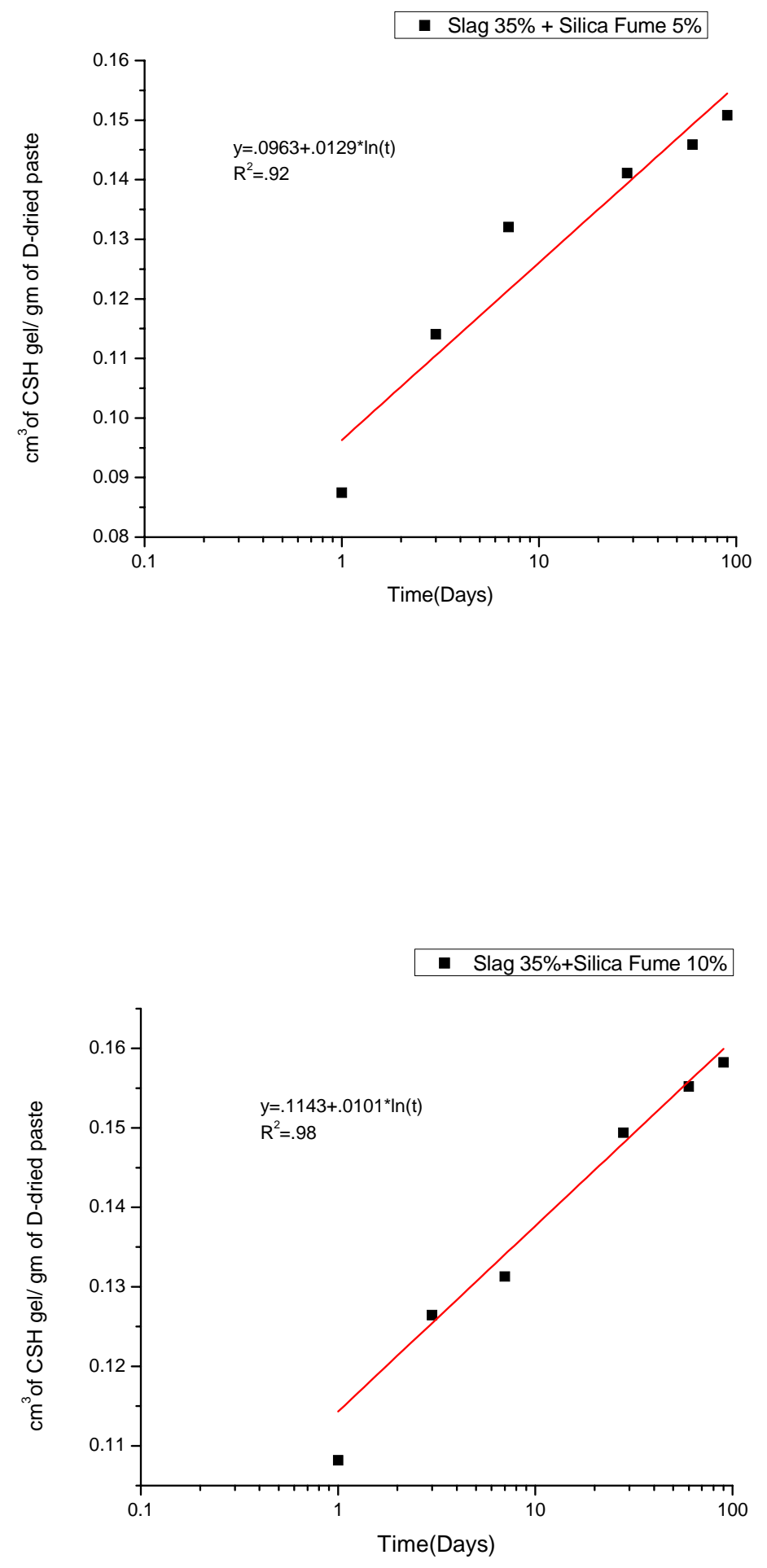
- Slag 35\% + Silica Fume 15\%

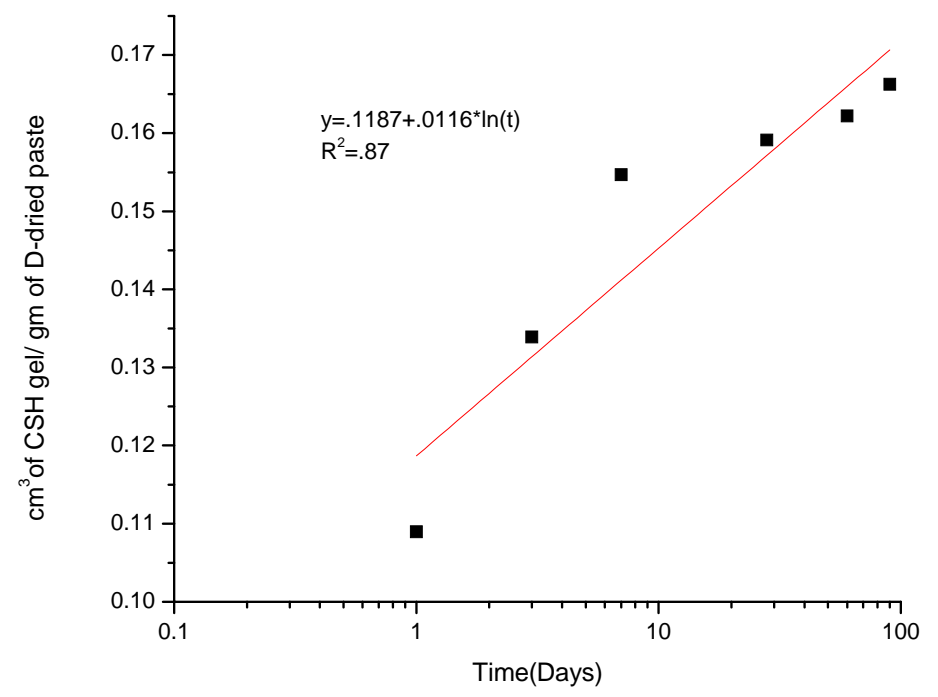

- Slag $45 \%+$ Silica Fume $5 \%$

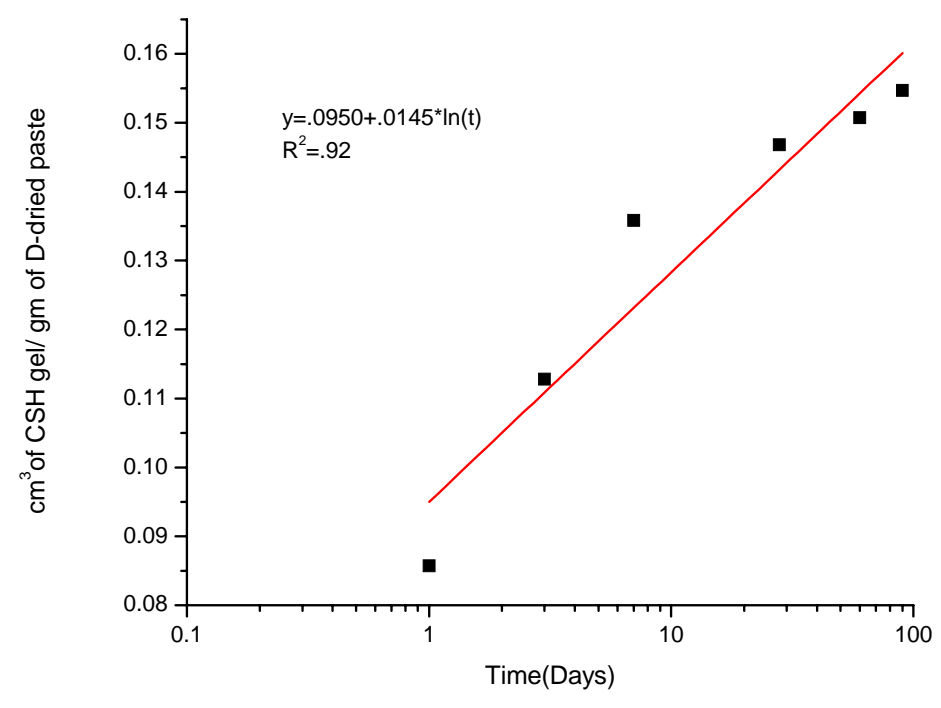



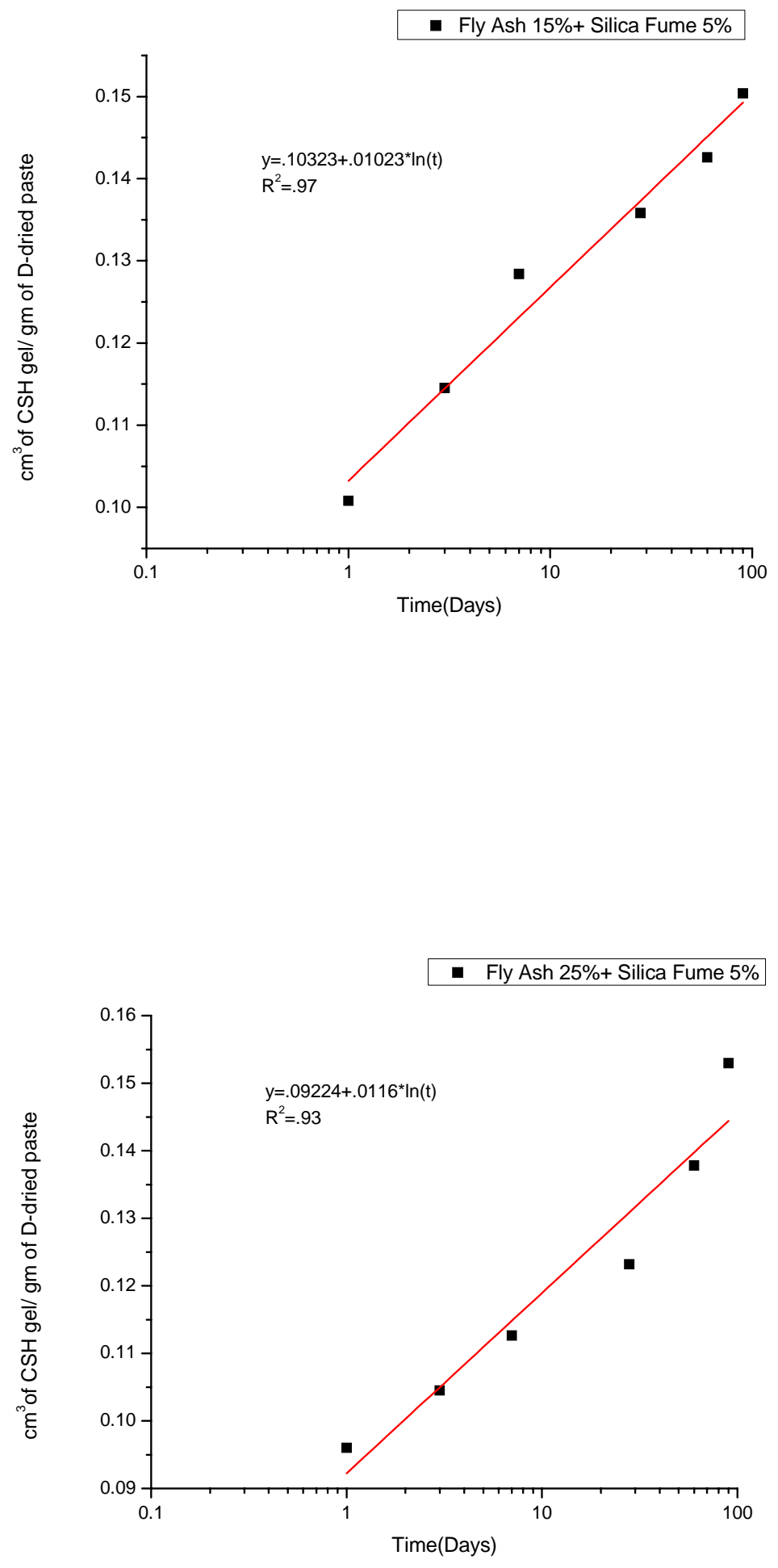
- Fly Ash $35 \%+$ Silica Fume $5 \%$
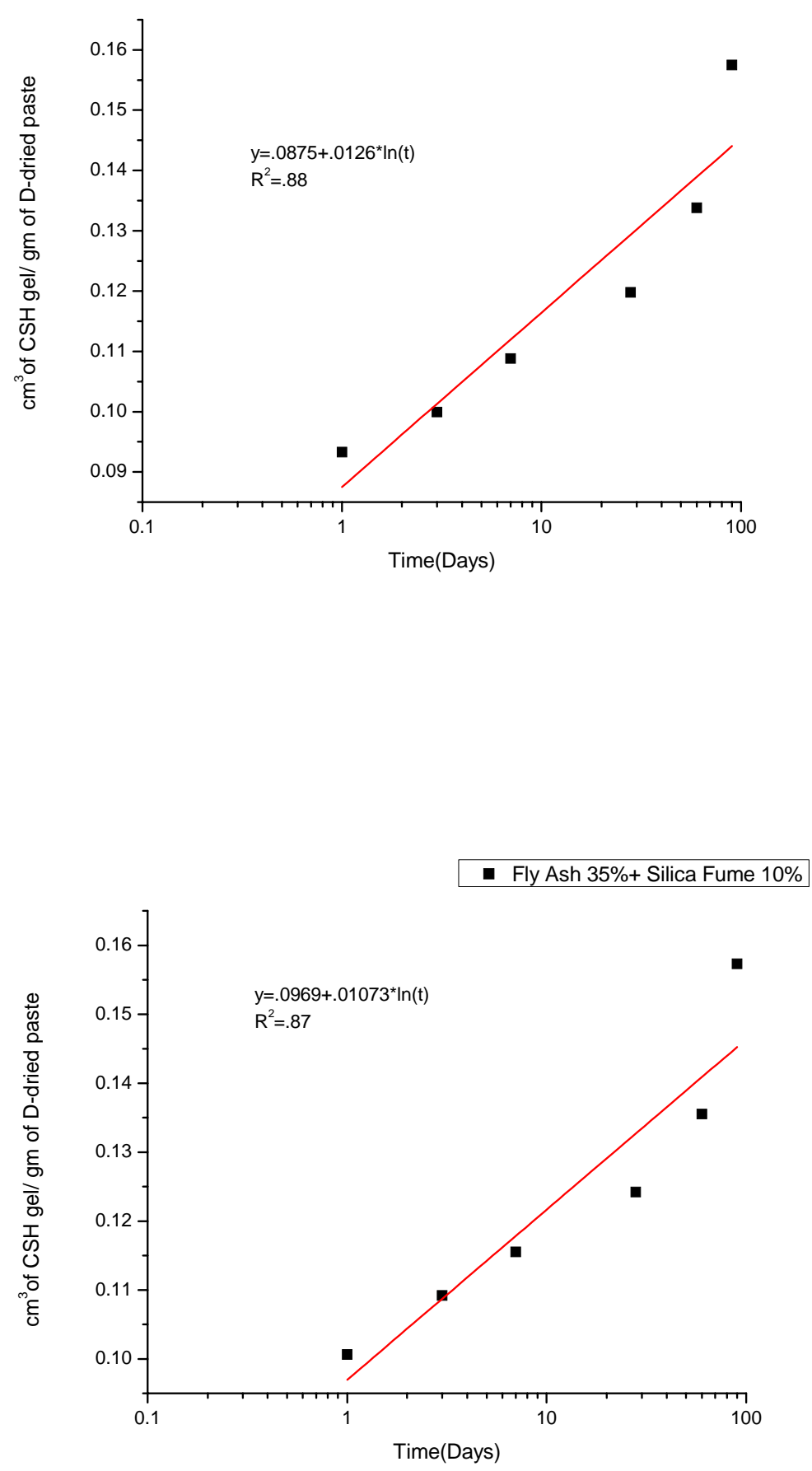
- Fly Ash $35 \%+$ Silica Fume $15 \%$

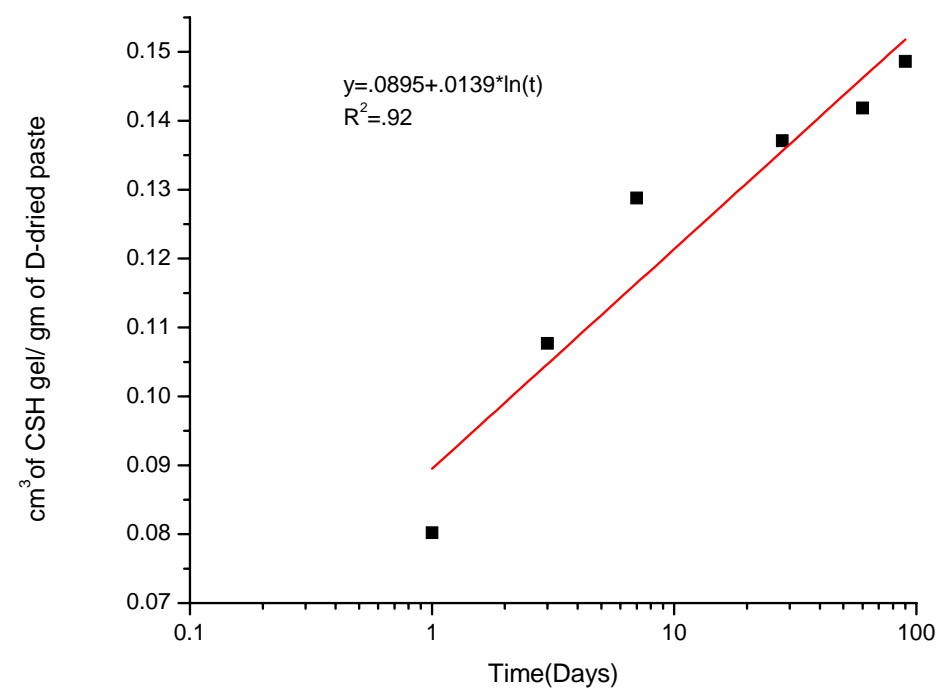

- Slag $25 \%+$ Fly Ash $15 \%$

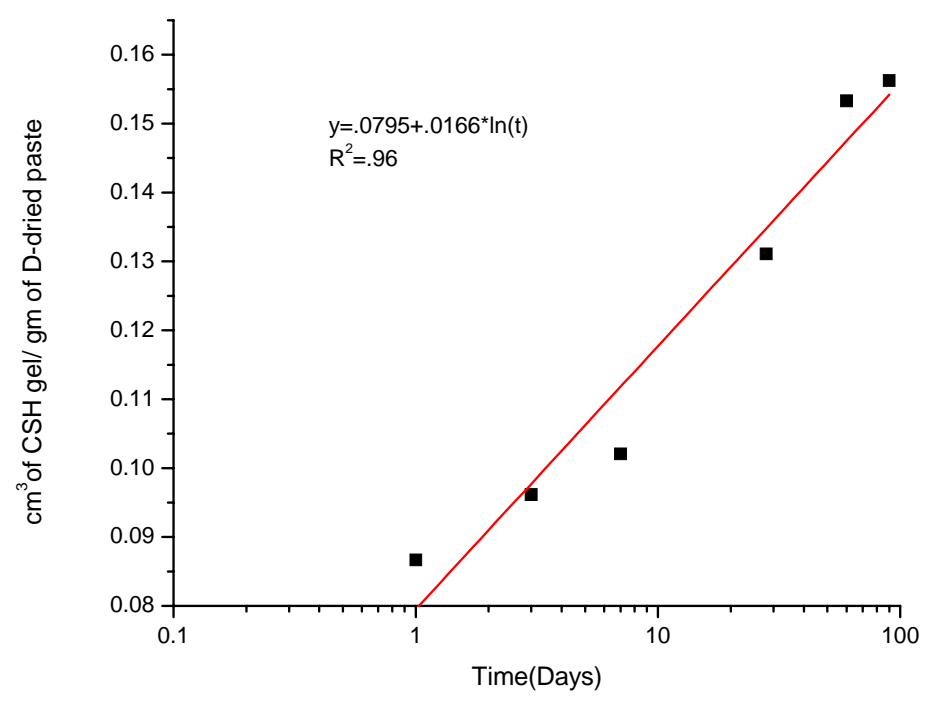


- Slag $35 \%+$ Fly Ash $15 \%$

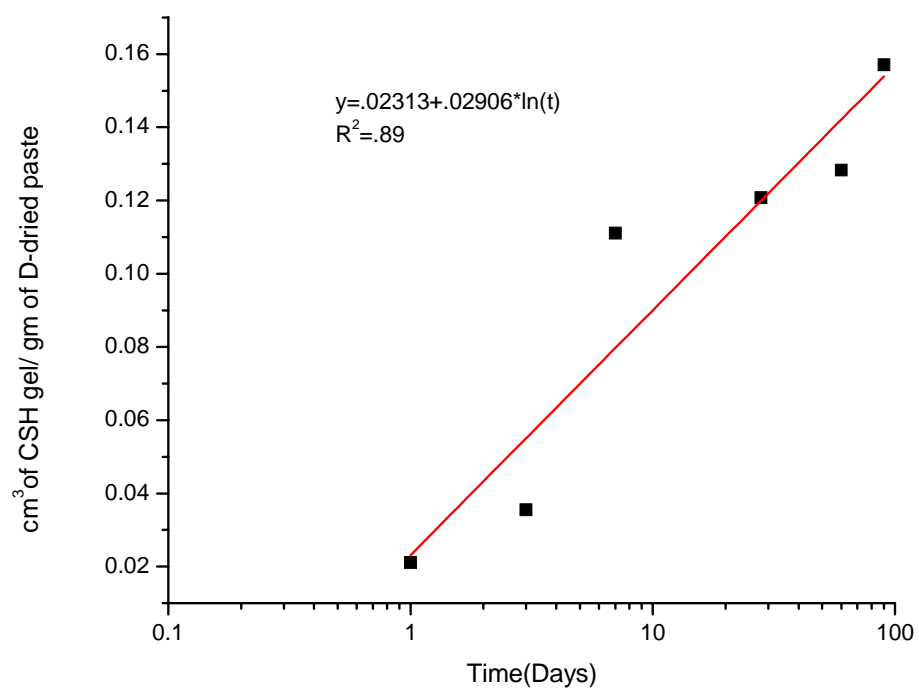




\section{Appendix C: Results of C-S-H gel Estimation (C-S-H gel in $\mathrm{cm}^{3} / \mathrm{gm}$ of D-dried paste)}

Table 1:

\begin{tabular}{|c|c|c|c|c|c|c|c|c|c|c|}
\hline Day & SL 25 & SL 35 & SL 45 & Cement & FL 15 & FL 25 & FL 35 & SF 5 & SF 10 & SF 15 \\
\hline $\mathbf{1}$ & 0.0715 & 0.0610 & 0.0582 & 0.0920 & 0.0752 & 0.0692 & 0.0575 & 0.0945 & 0.0920 & 0.0915 \\
$\mathbf{3}$ & 0.0849 & 0.0884 & 0.0789 & 0.1080 & 0.0942 & 0.0948 & 0.0893 & 0.1107 & 0.1244 & 0.1139 \\
$\mathbf{7}$ & 0.1100 & 0.1072 & 0.1122 & 0.1184 & 0.1040 & 0.0992 & 0.0931 & 0.1154 & 0.1338 & 0.1248 \\
$\mathbf{2 8}$ & 0.1334 & 0.1332 & 0.1304 & 0.1291 & 0.1186 & 0.1156 & 0.1075 & 0.1420 & 0.1390 & 0.1359 \\
$\mathbf{6 0}$ & 0.1455 & 0.1390 & 0.1328 & 0.1393 & 0.1324 & 0.1373 & 0.1400 & 0.1615 & 0.1578 & 0.1471 \\
$\mathbf{9 0}$ & 0.1474 & 0.1392 & 0.1367 & 0.1422 & 0.1497 & 0.1523 & 0.1555 & 0.1626 & 0.1595 & 0.1493 \\
\hline
\end{tabular}

Table 2:

\begin{tabular}{|c|c|c|c|c|c|c|c|c|c|c|c|c|c|c|}
\hline Day & SS $25+5$ & SS $25+10$ & SS $35+5$ & SS $35+10$ & SS $35+15$ & SS $45+5$ & FS $15+5$ & FS $25+5$ & FS $25+10$ & FS $35+5$ & Fs $35+10$ & FS $35+15$ & SL+FA $25+15$ & SL+FA $35+15$ \\
\hline 1 & 0.1003 & 0.0783 & 0.0875 & 0.1082 & 0.1090 & 0.0857 & 0.1008 & 0.0960 & 0.1011 & 0.0933 & 0.1006 & 0.0802 & 0.0867 & 0.0211 \\
\hline 3 & 0.1248 & 0.1137 & 0.1141 & 0.1264 & 0.1339 & 0.1128 & 0.1145 & 0.1045 & 0.1118 & 0.0999 & 0.1092 & 0.1077 & 0.0962 & 0.0355 \\
\hline 7 & 0.1276 & 0.1276 & 0.1321 & 0.1313 & 0.1547 & 0.1358 & 0.1284 & 0.1126 & 0.1196 & 0.1088 & 0.1155 & 0.1288 & 0.1020 & 0.1111 \\
\hline 28 & 0.1430 & 0.1578 & 0.1411 & 0.1494 & 0.1591 & 0.1468 & 0.1358 & 0.1232 & 0.1273 & 0.1198 & 0.1242 & 0.1371 & 0.1311 & 0.1207 \\
\hline 60 & 0.1504 & 0.1689 & 0.1459 & 0.1552 & 0.1622 & 0.1507 & 0.1426 & 0.1378 & 0.1389 & 0.1338 & 0.1355 & 0.1418 & 0.1533 & 0.1283 \\
\hline 90 & 0.1510 & 0.1732 & 0.1508 & 0.1582 & 0.1662 & 0.1547 & 0.1504 & 0.1530 & 0.1557 & 0.1575 & 0.1573 & 0.1486 & 0.1562 & 0.1571 \\
\hline
\end{tabular}


Appendix D: Compressive strength of various mixtures for 90 days in MPa

Table 1:

\begin{tabular}{|c|c|c|c|c|c|c|}
\hline Day & $\mathbf{1}$ & $\mathbf{3}$ & $\mathbf{7}$ & $\mathbf{2 8}$ & $\mathbf{6 0}$ & $\mathbf{9 0}$ \\
\hline SI-25 & 18 & $\mathbf{2 8}$ & 44 & 52 & 58 & 61 \\
\hline SI-35 & 14 & 26 & 39 & 51 & 56 & 57 \\
\hline SI-45 & 10 & 17 & 30 & 51 & 56 & 58 \\
\hline FI-15 & 20 & 29 & 35 & 47 & 55 & 59 \\
\hline FI-25 & 15 & 23 & 26 & 44 & 55 & 59 \\
\hline FI-35 & 14 & 21 & 24 & 39 & 50 & 54 \\
\hline SF-5 & 28 & 36 & 41 & 56 & 63 & 66 \\
\hline SF-10 & 26 & 38 & 44 & 59 & 65 & 67 \\
\hline SF-15 & 34 & 47 & 53 & 68 & 75 & 77 \\
\hline Control Concrete & 21 & 37 & 44 & 54 & 58 & 61 \\
\hline SS 25+5 & 14 & 33 & 43 & 63 & 69 & 72 \\
\hline SS 25+10 & 20 & 27 & 44 & 69 & 76 & 78 \\
\hline SS 35+5 & 17 & 27 & 41 & 64 & 72 & 74 \\
\hline SS 35+10 & 16 & 28 & 49 & 70 & 75 & 76 \\
\hline SS 35+15 & 13 & 27 & 47 & 72 & 79 & 82 \\
\hline SS 45+5 & 11 & 21 & 36 & 67 & 73 & 76 \\
\hline FS 15+5 & 26 & 41 & 54 & 72 & 81 & 84 \\
\hline FS 25+5 & 21 & 29 & 41 & 64 & 70 & 73 \\
\hline FS 25+10 & 22 & 32 & 44 & 65 & 74 & 77 \\
\hline FS 35+5 & 13 & 21 & 29 & 50 & 62 & 65 \\
\hline FS 35+10 & 13 & 21 & 30 & 52 & 60 & 63 \\
\hline FS 35+15 & 13 & 23 & 33 & 61 & 71 & 74 \\
\hline SL+FA-25+15 & 12 & 22 & 32 & 54 & 66 & 71 \\
\hline SL+FA-35+15 & 3 & 8 & 15 & 58 & 70 & 76 \\
\hline
\end{tabular}

